\title{
STUDY OF THE VARIABILITY OF AIR LEAKAGE RATE BETWEEN IN-SITU TESTED AND LABORTATORY TESTED FENESTRATION
}

\author{
by \\ Negar Pakzadianmoghaddam \\ Master of Architectural Science, University of Qazvin, Iran, 2008
}

A MRP
presented to Ryerson University

in partial fulfillment of the

requirements for the degree of

Master of Building Science

in the program of

Building Science

Toronto, Ontario, Canada, 2017

CNegar Pakzadianmoghadam 2017 


\section{AUTHOR'S DECLARATION FOR ELECTRONIC SUBMISSION OF A THESIS}

I hereby declare that I am the sole author of this thesis. This is a true copy of the thesis, including any required final revisions, as accepted by my examiners.

I authorize Ryerson University to lend this thesis to other institutions or individuals for the purpose of scholarly research.

I further authorize Ryerson University to reproduce this thesis by photocopying or by other means, in total or in part, at the request of other institutions or individuals for the purpose of scholarly research.

I understand that my thesis may be made electronically available to the public. 


\title{
STUDY OF THE VARIABILITY OF AIR LEAKAGE RATE BETWEEN IN-SITU TESTED AND LABORTATORY TESTED FENESTRATION
}

\author{
By \\ Negar Pakzadianmoghaddam \\ Master of Building Science in Building Science, 2017 \\ Ryerson University, Toronto
}

\begin{abstract}
The air leakage measured using the laboratory test of fenestration is important to gauge its initial performance and for certification. Field testing based on a statistical approach was carried out in this study on newly installed fenestration product to study the nature of distribution of air leakage measurements. The measured values from these tests were also compared to the laboratory tested value of the same product and to the values as suggested in field testing guidelines as provided in AAMA 502. Results indicate that field measured values at standard pressure difference follow a normal distribution with a mean and a variance. The results also show that while number of test results fall within a certain range of the laboratory value and the AAMA 502 stipulated value, there are number of values that are higher than them.
\end{abstract}


Acknowledgements

I would like to thank Professor Hitesh Doshi at Ryerson University for his guidance and insights that have expanded my understanding of building science research.

I wish to thank my family for their unconditional support throughout this endeavor. 


\section{Contents}

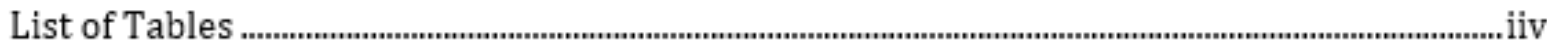

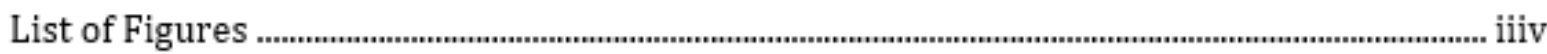

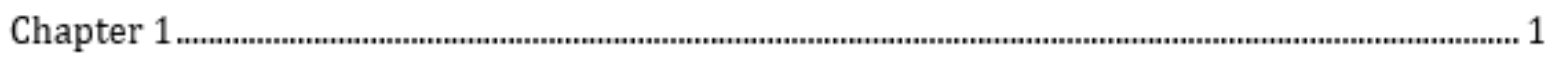

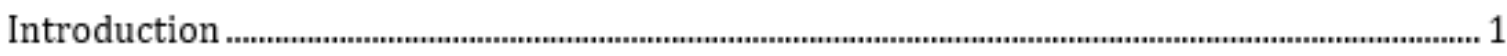

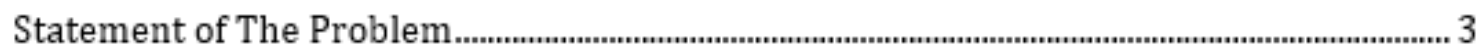

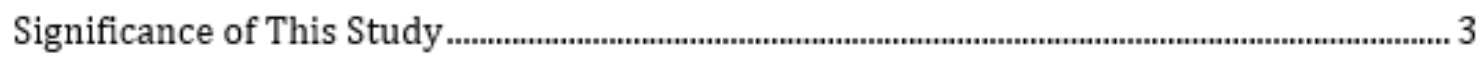

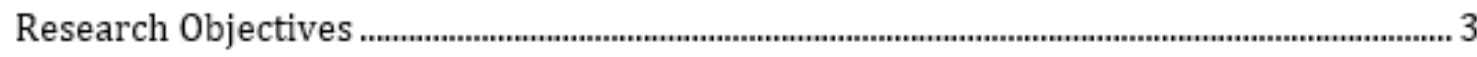

Chapter 2

Review of Related Literature and Studies............................................................................. 5

Air Leakage, Importance, and Impacts on Buildings ............................................................... 5

Air Leakage, Impact on Energy Consumption.................................................................................. 5

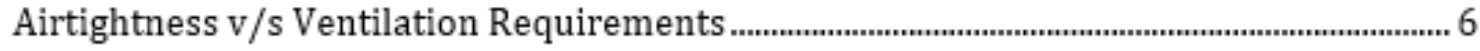

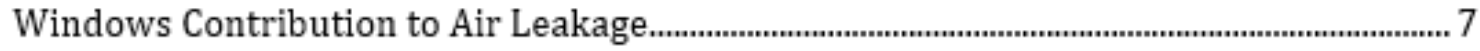

Measuring Window's Air Tightness Performance in Laboratory v/s Field .......................... 9

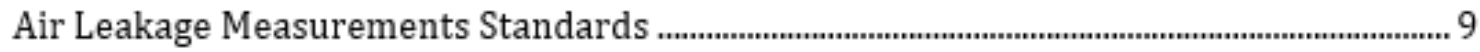

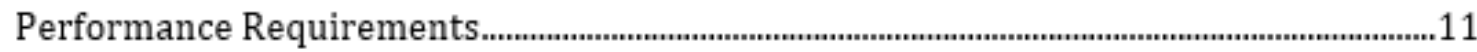

Uncertainty and Lack of Sufficient Data on Field Performance ................................................12

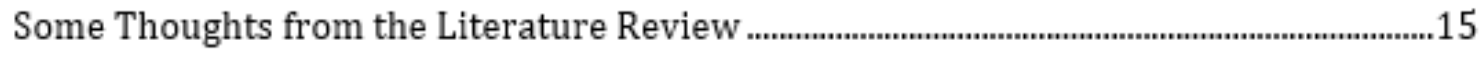

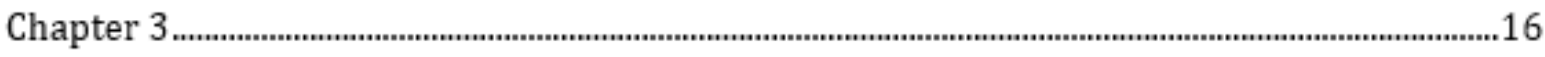

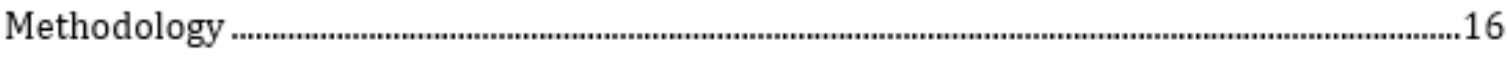

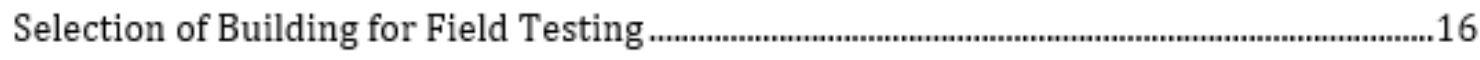

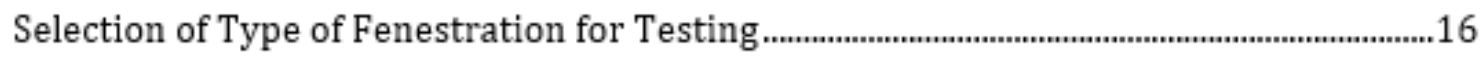

Description of the Tested Fenestration Product ….................................................................17

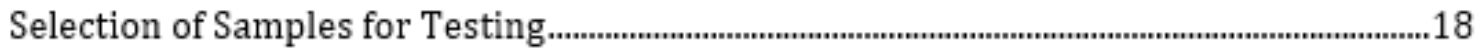

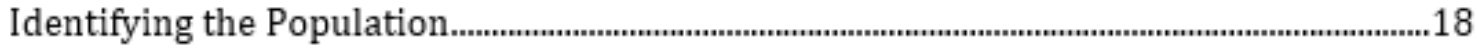

Correction of the Temperature and Pressure .................................................................................22

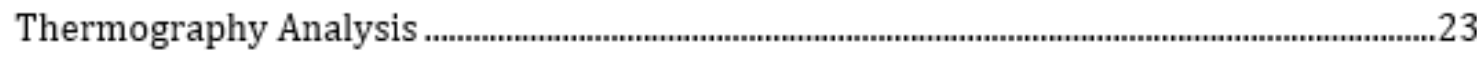

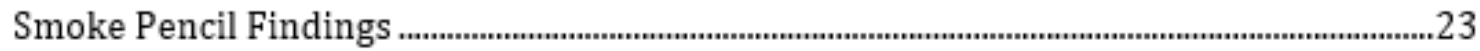




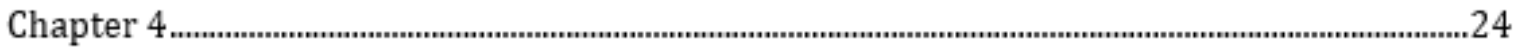

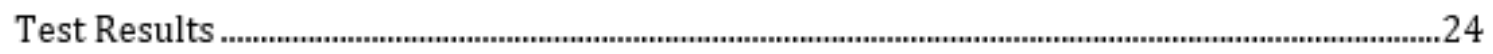

Review of the Test Results at Different Pressure Differences ...............................................26

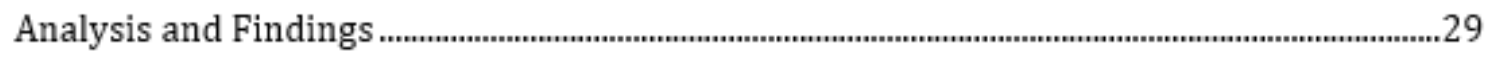

The Standard Field Test Pressure (75 Pascal): ...................................................................................29

Test Variables ..............................................................................................................................34

Extrapolate Data From Laboratory Test Results ..............................................................................36

Analysis of Extrapolated Air Leakage Results at Different Pressure Differences

calculating from Laboratory Test Result at 75 Pascal................................................................37

Chapter 6

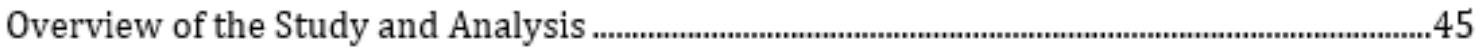

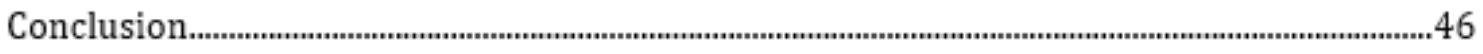

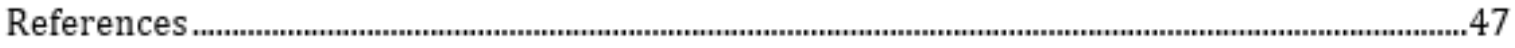

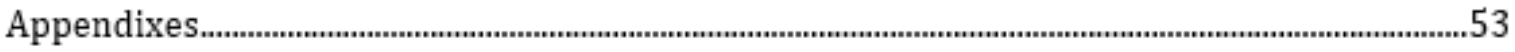

Appendix A (Laboratory Sample Description).

Appendix B (Population Identification Tables)

Appendix C (Raw Data Collection) 


\section{List of Tables}

Table 1- Distribution of Type I Patio Doors by Floors - Total and Tested

Table 2 - Temperature and Wind Conditions during Testing

Table 3 - Excluded test results from the study (Outliers)

Table 4 - Air Leakage rates - Nov. 19, 2016

Table 5 - Air Leakage rates - Dec. 1, 2016

Table 6 - Air Leakage at 75 Pa - Dec. 3, 2016

Table 7- Air Leakage at 75 Pa - Dec. 16, 2016

Table 8 - Air Leakage at 75 Pa - Dec. 28, 2016

Table 9 - Frequency distribution pivot table at $75 \mathrm{~Pa}$

Table 10 - Air Leakage Rates for Comparative Analysis

Table 11 - The average results in different temperatures

Table 12 - Test results in different floor levels

Table 13 - Test results in different elevations

Table 14 - Frequency distribution pivot table at $25 \mathrm{~Pa}$

Table 15 - Frequency distribution pivot table at $50 \mathrm{~Pa}$

Table 16 - Frequency distribution pivot table at $100 \mathrm{~Pa}$ 


\section{List of Figures}

Figure 1 - Cross-section at the sill of the door assembly-Page 16

Figure 2 - Elevation view of the door assembly-Page 17

Figure 3 - Typical test assembly-Page 20

Figure 4 - Wind Maker test equipment-Page 20

Figure 5 - Air flow and Pressure measuring devices-Page 20

Figure 6 - Test results at 25 Pascal pressure difference-Page 26

Figure 7 - Test results at 50 Pascal pressure difference-Page 26

Figure 8 - Test results at 75 Pascal pressure difference-Page 27

Figure 9 - Test results at 100 Pascal pressure difference-Page 27

Figure 10 - Air leakage results at 75 Pascal-Page 28

Figure 11 - Box plot of Sample Air Leakage Rate at 75 Pa-Page 29

Figure 12 - Frequency Distribution of Air Leakage Measurements-Page 30

Figure 13 - Box plot of Sample Air Leakage Rate at 25 Pa- Page 36

Figure 14 - Frequency Distribution of Air Leakage Measurements at 25 Pa- Page 37

Figure 15 - Extrapolated air leakage VS field test results at 25 Pa- Page 37

Figure 16 - Box plot of Sample Air Leakage Rate at 50 Pa- Page 39

Figure 17 - Frequency Distribution of Air Leakage Measurements at 50 Pa- Page 39

Figure 18 - Extrapolated air leakage VS field test results at 50 Pa- Page 40

Figure 19 - Box plot of Sample Air Leakage Rate at 100 Pa- Page 41

Figure 20 - Frequency Distribution of Air Leakage Measurements at 100 Pa- Page 42

Figure 21 - Extrapolated air leakage VS field test results at 100 Pa- Page 36 


\section{Chapter 1}

\section{Introduction}

The widely used Fenestration Standard, NAFS and AAMA (AAMA, 2012), clearly stipulates in section 0.1.1- Applicability that provisions in the standard apply to laboratory testing only. For field testing in the US the NAFS refers to AAMA 502 (AAMA, 2012). The AAMA 502 provides guidance in terms of the way the field testing might be carried out and guidance in terms of the interpretation of results with respect to performance values that are stipulated in the AAMA. For Canada, the NAFS makes no reference in terms of using AAMA 502. Some reference to the similar guidance in Canada can be found in CSA A440.4. In the Annex D (informative) to A440.4 it provides information on the field testing of window and door installations.

AAMA 502 (AAMA, 2012) addresses the need to carry out field testing that is often necessary to verify the performance against the values that are used for certification. It stipulates the parameters for the time-frame in which testing can be done after installation. The standard is limited to the field testing of newly installed fenestration products. It is intended for testing prior to issuance of the occupancy permit and for a period not to exceed 6 months after installation of the fenestration product. The CSA A440.4 stipulates that the standard "does not require routine field testing". There are no time limit stipulations in CSA A440.4.

For air leakage testing AAMA 502 allows for the testing to be carried out at the same pressure differences as required for NAFS but allows the air leakage to be 1.5 times the value that is used for certifying the product as per the NAFS. The CSA A440.4 indicates the air leakage testing to be carried out at a pressure of $75 \mathrm{~Pa}$. With respect to the air leakage testing the annex recognizes the difficulty in doing the test for air exfiltration and suggest that air infiltration alone may be acceptable way of determining the air leakage characteristics. It provides a detailed list of allowable rates of air leakage for field testing based on the original rating and the size of windows. CSA A440.4, also has a separate section for doors in which it stipulates the maximum air leakage rates for doors based on the original rating. The maximum values stipulated for sliding doors are as follows: 
Rating A1 - $2.79 \mathrm{~m} 3 / \mathrm{h}$, Rating A2 - $1.65 \mathrm{~m} 3 / \mathrm{h}$, rating A3 - $1.00 \mathrm{~m} 3 / \mathrm{h}$.

Other than the two standards indicated above there is some mention in Woods et al. in 1995 about determining the rationale for field testing. They suggest that field air leakage testing on existing buildings, for values of greater than $15 \%$ of the design values for windows and doors would call for intervention to reduce air leakage.

Both the AAMA 502 and the CSA A440.4 indicate that the field testing for air leakage is to be done in accordance with ASTM E783-02. However, it is evident that the acceptable values for field testing are not similar. AAMA 502 appears to be more widely used compared to similar requirements in CSA A440.4.

There has been discussion in popular media about the field testing with respect to water leakage in accordance with AAMA 502. An example of it is a BSC Experts Session in 2014, Baker in 2014 talks in much detail about windows and water leakage testing in relationship to field performance. In it the question of "how much testing?" has been raised. Baker suggests that for punched windows and door a total of $1 \%$ to $2 \%$ of the total number of units installed to be tested. AAMA 502 suggests a minimum of three units to be tested in the field. Neither the suggestion made by Baker (Baker, 2014) nor suggestion made in AAMA 502 are indicative of any statistical basis for determining the sample sizes for testing in the field. It would seem they are more reflective of the practicality and the cost of field testing which in itself may be rationale reason to determine the extent of field testing to be done. On the other hand, ASTM E783-02 in section 9 provides some guidance in terms of sampling based on statistical considerations.

Practical considerations related to field testing are well addressed by Goncalves et al in 2007. They provide some guidelines to decide on the choice of sample selection for testing. They recommend at least three tests, one each at the beginning, the middle and end of the installation. 


\section{Statement of the Problem}

ASTM E783-02 raises caution in terms of comparing field results to laboratory results. In section 5.3 it indicates that correlation between actual performance of in-service products and the response to these tests has not been established because of insufficient data.

It has been determined through a literature review (shown later) that little is known about the air leakage performance of newly installed fenestration products in comparison to its laboratory tested performance. Little data exists on relating laboratory performance and field performance of fenestration products after installation.

\section{Significance of This Study}

There exists a significant body of work related to air leakage characteristics of whole buildings. In particular the energy loss through infiltration has shown to be excessive. Most studies that focus on the benefits of improving the air tightness of buildings examine it from a whole building perspective. In high rise apartment buildings where operable fenestration is a norm, the air leakage characteristics of the fenestration can form a substantial portion of the whole building air leakage. It is therefore important that designers particularly in such buildings are aware about the differences between the specified air leakage values and the field-tested air leakage values.

\section{Research Objectives}

The main objective of this project is to examine the nature of differences between the air leakage determined in a laboratory condition to that measured in the field for the same product that is newly installed. 


\section{Chapter 2}

\section{Review of Related Literature and Studies}

As stated in ASTM E-283, laboratory standard for measuring air leakage in fenestration products, section 5, part 3," The correlation between the laboratory and field test results, and the correlation between the actual performance of in service products and the response to these tests have not been yet established because of insufficient data" (ASTM Standard, 2012).

As part of this study various aspects of air leakage through buildings were examined as they relate to the research objective. The work involved a review of literature and studies that were found through searches and from discussion with a few experts in the field. The findings are categorized under appropriate headings

\section{Air Leakage, Importance, and Impacts on Buildings}

Air leakage as the uncontrolled and usually unintentional movement of the air across the building envelope is a critical factor affecting building's long-term durability and energy performance. It has a major influence on noise transmission, smoke propagation, overall indoor space quality and comfort health (Proskiw \& Phillips, 2008; Kalamees et al., 2008; Becker, 2009; Domhagen, 2016).

Moisture convection through the building envelope may cause severe moisture load imposed on the structure. Indoor air exfiltration in cold climates can cause condensation or moisture accumulation which leads to the microbial growth on materials, the change in their properties or even to structural deterioration. Air leakage through a building envelope could introduce outdoor airborne pollutants as well as, radon gas into the indoor air. (Kalamees et al., 2008; Domhagen, 2016)

\section{Air Leakage, Impact on Energy Consumption}

According to the North American insulation manufacturers association's (NAIMA) study of seven buildings in 1990 and 1997, airtightness plays a significant role in energy saving in buildings (Fennell \& Haehnel, 2005). Thirty six percent of annual energy consumption in the U.S. belongs to the building sector. The largest single energy end user in buildings is space 
heating and cooling, which counts for over $50 \%$ of their energy use. In the residential building sector, $50 \%$ of the energy is consumed for space heating and $6 \%$ for space cooling (Sherman, 1980).

Different studies have shown air infiltration affects the heating load in commercial and residential buildings by $24 \%$ to $50 \%$ (Younes et al., 2012; Canada mortgage and housing corporation (CMHC), 2007). The energy use in buildings is affected by variation in air tightness to the variation in total air exchange rates. In less air tight buildings, a higher imbalance between supply and exhaust air flow is required to create negative or positive indoor pressure (Domhagen, 2016).

In 1982, Persily attributed one third of heating and cooling loads in buildings to air infiltration (Younes et al., 2012). In a 2001 study, by Orme on the effects of air infiltration and ventilation on energy consumption in buildings, It was estimated that one third of energy (delivered for heating and cooling in buildings) is attributed to air change and space conditioning energy losses (Orme, 2001). In a study conducted in a cooling dominated weather condition in California, Probst in 2004 showed that infiltration may cause a $50 \%$ increase in cooling energy consumption (Probst, 2004). The Washington, D.C. -based U.S. Department of Energy office of the building technologies department at 2005, estimated that infiltration is responsible for 33 percent of total heating energy use which only could save 3.3 percent of total cooling energy. A further study in 2005, on investigation of the impact of commercial building envelope airtightness on HVAC energy use done by the U.S Department of Energy found that 3 to $36 \%$ of energy cost could be saved through air tightness (Goedken, 2007). Dale et al in 1985, reported that after a 53\% decrease in air infiltration in two test rooms, energy consumption decreased approximately up to 20\% (Becker, 2009). The National Institute of Standards and Technology estimated that $15 \%$ of the heating loads in commercial buildings is caused by air infiltration (Younes et al., 2012).

\section{Airtightness v/s Ventilation Requirements}

The requirements in air tightness standard should be compatible with natural ventilation requirements. The extent of air infiltration with respect to ventilation on the one hand and energy conservation on the other hand, are the main factors to be assessed by the designers. 
Energy conservation may be achieved by restricting air infiltration, but extensive air tightness may lead to condensation and dampness problems (Provan \& Younger, 1986). Extreme airtightness affects the indoor air quality and can be hazardous to one's health, where pollutant levels inside a building may be much higher than outside levels (Sherman, 1980). In an extreme airtight design, energy consumption will not necessarily decrease due to expansion of ventilation requirements to maintain an acceptable indoor air quality (Alfano et al., 2016). The related extreme airtightness problems could be avoided by supplying heating and ventilation at the expense of energy conservation. Balance is required between energy conservation needs and natural ventilation requirements for the complete building and its component parts such as, windows (Provan et al., 1986).

\section{Windows Contribution to Air Leakage}

Nowadays windows and glass curtain walls represent a higher portion of the large building's exterior cladding. Window air tightness is a determining element in the performance evaluation of this type of building envelopes. This is essential in pre-construction and construction phase of buildings to avoid undesirable problems occurring in duration of building service life. Obviously, resistance to air and water penetration are not the only performance criteria for fenestration products to consider, but in fact they contribute to the majority of in service performance failures of building envelopes (Gonçalves \& Jutras, 2007).

The contribution of windows and doors to the whole building, air tightness varies from $15 \%$ to $31 \%$ as shown by the American society of heating and cooling (ASHRAE) in 1997 and Kalamees in 2008 respectively. Windows count for $40 \%$ of the total energy demand of buildings. Correct assessment of window air leakage rates can help proper ventilation system design and could avoid energy waste (Alfano et al., 2016; Fennell \& Haehnel, 2005). Implementing air tightness improvement measures to window and walls can save energy in buildings of up to $12 \%$ (Woods, 1995).

Prime locations of air leakage in windows could be cracks and joints between various parts of windows such as sash, frame, or weather stripping. The physical defects in windows could contribute to excessive air leakage rates. In 1979, Weidt et al, concluded in their windows air leakage assessment report that the majority of window defects were related to 
manufacturing and fabrication process and few were related to the abuse of windows during construction. Weather stripping discontinuity, sash fit and hardware seal failures were shown as main factors contributing to high air leakage rates. In Daoud's report in 1992, windows with less visible defects produced $46 \%$ lower air leakage rates than the mean value. They concluded that visible defects due to design and fabrication were the most frequent, where $50 \%$ of the windows were suffering from either or both sources. Maintenance problems were responsible for almost $30 \%$ of the defects and installation defects were the least frequent, at almost 25\%. Minor repairs were shown to improve the air tightness performance by 10 to 30\%. (Daoud, 1992). Despite of window retrofit by substitution of existing window to high performance one, and changing the rubber seal on the window frame, Alfano et al, did not notice any improvement due to the existing installation issues.

The operation type was defined as one of the factors influencing window air leakage performance in Weidt et al. report in 1979. Their test results indicated that $70 \%$ of double sliders and $84 \%$ of single slider windows had higher field air leakage rates than manufacture's laboratory reports.

Daoud et al. investigated the effect of window dimensions, to see if there is any optimum dimension at which air infiltration is minimized. Since there are other factors involved (Such as window defect location), no clue was found regardless of the window type except that larger windows, have larger perimeters and a higher volume of air infiltration. However, the amount of leakage is not portion of the crack length as windows leak more at corners, meeting rails and meeting stiles than along the crack length (CSA Group, 2017).

Weidt et al. and Daoud et al. reports, supported the impact of manufacturers on window performance. Window design, fabrication procedure, quality of workmanship procedure highly depends on the manufacturer performance.

Weidt et al. found no clues on window material difference, effecting air leakage performance of the window, however off shored materials could represent lower quality because of the lack of proper quality control (Trudeu, 2016). Imported materials vary widely in quality due to the absence of control and low-grade material use. They performed 13\% below those locally produced and 9\% below the average (Daoud et al., 1991). Addressing cultural, 
economic, technical issues, confirming the compatibility of products with shop drawings and in situ testing of products is important when using offshore products versus inshore ones (Hubbs, 2016).

\section{Measuring Window's Air Tightness Performance in Laboratory v/s Field}

AAMA/NWWDA-101, CAN/CSA-A440, AAMA 501 are principal industry standards determining air leakage resistance laboratory performance criteria and AAMA 502, AAMA 503 , CAN/CSA-A440.4 (appendix D) are the principal industry standards, for determining air leakage resistance field performance criteria of windows and curtain walls in North America (Gonçalves \& Jutras, 2007). NAFS (North American Fenestration Standard/Specification for windows, doors, and skylights), is a harmonized performance standard published jointly by CSA (Canadian Standards Association) in Canada, AAMA (American Architectural Manufacturers Association ) and WDMA (Window and door association manufacturers) in the United states (Jaugelis, 2014).

\section{Air Leakage Measurements Standards}

ASTM E283 Standard, covers laboratory test procedure for determining air leakage rates of exterior windows, curtain walls and doors under specified pressure differences across the specimen. Although, temperature and relative humidity fluctuations can cause shrinkage and affect air leakage rates of window components, but ASTM E208 specifies the air leakage rates under constant relative humidity and temperature of $20^{\circ} \mathrm{C}$ for labeling purposes. The measured rates in this test are associated with the assembly and not the installation. This test consists of sealing a test specimen into or against one face of an air chamber. Then supplying air to or exhausting air from the chamber at the required rate to maintain the specified test pressure difference across the specimen and measuring the resultant air flow. For this test, the specifying authority shall apply information such as specimen test size, test pressure difference (If nothing specified, it will be tested under 75 pa pressure difference), and direction of air flow (exfiltration or infiltration). Air leakage rates, can be reported as total air leakage per unit length of operable crack perimeter (L/(s.m) $\left(\mathrm{ft}^{3} / \mathrm{min} . \mathrm{ft}^{2}\right)$ and per unit area of outside frame dimension(L/(s. $\left.\mathrm{m}^{2}\right)\left(\mathrm{ft}^{3} / \mathrm{min} \cdot \mathrm{ft}^{2}\right)$ (ASTM Standard, 2012). 
The Canadian window performance standard CAN/CSA-A440-M90 provides three categories for the rating of operable windows when tested at a specified temperature of $20{ }^{\circ} \mathrm{C}$ and pressure difference of 75 Pascal. Ratings are named as A1, A2 and A3 when air leakage is less than $2.79,1.65$ and $0.55\left(\mathrm{~m}^{3} / \mathrm{h} . \mathrm{m}\right)$ relatively (Canadian standard association (CSA), 2004).

ASTM E783 (Field Measurement of Air Leakage through Installed Exterior Windows and Doors) and ASTM E1186 (Standard Practice for Air Leakage Site Detection in Building Envelope and Air Barrier Systems), are quantitative test method to qualitatively assess field air leakage through installed windows and doors and exterior building envelope and air barrier systems relatively. Regardless of the test method, the test procedure consists of sealing a chamber to cover the interior and exterior surface of the test specimen, supplying air to or exhausting air from the chamber at a rate required to maintain the specified test pressure and measuring the air flow rate result (lost or gained) across the testing specimen. Air leakage is typically undertaken at a pressure differential of $1.57 \mathrm{psf}$ (75 pa) or $6.24 \mathrm{psf}$ (300 pa).

The air flow through the test chamber will be adjusted to provide the specific test pressure difference across the test specimen. When the test condition and pressure difference is stabilized, test pressure difference and air flow will be recorded through the flow meter. This measured air flow is the total air flow. Extraneous air leakage will be documented to ensure the proper leakage measurement from the specimen. By subtracting the total air flow and the extraneous leakage, in terms of flow at standard conditions, air leakage through the specimen will be defined. The air leakage can be calculated for the test specimen, per both unit length of operable crack perimeter and unit area.

In Accordance to AAMA 502, allowable air leakage rates for field testing shall be 1.5 times the achieved laboratory test rating. In Canada, guidelines for air leakage rate measurements are provided by CSA A440.4. The allowable air leakage rates are indicated in architectural specification and depends on several factors such as building location, energy code and operation types (Gonçalves \& Jutras, 2007.; ASTM, 2012). The building type has a shown a slight effect on window air infiltration performance. Residential buildings have $28 \%$ and 
$17 \%$ less air infiltration rates compared to those of office buildings, possibly due to extra care taken in selecting and maintaining windows (Daoud et al., 1991).

\section{Performance Requirements}

Window air leakage performance is generally available performance according to ASTM E283. To estimate overall building air leakage, often energy simulation software simplify window air leakage calculations by only applying the stack and wind effect. However, temperature and pressure difference are important variables in determining the overall envelope air leakage performance. Temperature gradient could cause distortion and shrinkage of window components and impact the leakage characteristic under more extreme summer and winter condition. Henry et al. showed that air leakage rates increase in higher temperature and pressure differences. Most windows experienced higher or slightly higher leakage rates at colder temperatures however, nearly half remained in the same performance category. Window air leakage rate changes seemed to be more affected by the design rather than material and operation type. Henry et al. pointed out the fact that annual energy ratings do not take the seasonal temperature fluctuation into account for the Energy rating of windows. Even though their study showed air leakage increase has negligible effect on Annual Energy Ratings.

In a 1979 study on newly installed residential windows, the air leakage of installed 192 windows was compared with the standard used by the government and industry. The effect of sash and frame material, differences between production lines of a single manufacturer, differences between multiple manufacturers, installation practice, effects of cold weather on performance and changes in performance during the time were studied. Overall, $40 \%$ of all tested windows showed higher air leakage rates than the required standards and $60 \%$ of the windows exceeded manufacturer's specifications for performance. (Weidt \& Weidt, 1979)

In Daoud et al. report in 1990 on air leakage performance, of 154 windows in Kuwait, only $6 \%$ of the samples consisting of tilt-and turn and fixed satisfied the air leakage performance required ratings. In contrast, with Weidt el al. study found $35 \%$ of the windows were showing less or equal to three times the ANSI/AAMA allowed air infiltration rate limit and the remaining windows, which were $65 \%$ of the test samples were showing higher rates. 
Despite constructing a curtain wall system under laboratory conditions with a selected crew by the manufacture, it was shown in Becker report that it is impossible to achieve anticipated air tightness performance using original details based on a multitude of intermediate sealing at many points and perfect workmanship. Therefore, under in-situ construction conditions that is very much characterized by much poor workmanship and sealing practice, lower levels of air tightness is anticipated (Becker, 2009).

Most of the studies focused on the whole buildings airtightness and its effects on energy consumption but in high rise apartments with high portion of glazed envelope systems, operable fenestration's air tightness could affect the building air tightness significantly. It is important that the designers nowadays be aware about the differences between the specified air leakage values and the field-tested air leakage values.

\section{Uncertainty and Lack of Sufficient Data on Field Performance}

Having well trained test operators, properly calibrated and reliable equipment, clear calculation methods and standards are few prerequisites for accurate air leakage rate measurements. Despite all the mentioned prerequisites, air leakage results always show uncertainty due to different pressure differences around the building envelope. This pressure difference is result of the temperature, wind speed and relative humidity difference which create air leakage rate variations.

Under repeatability circumstances, where the operator and equipment remained the same, Delmotte and Laverge in 2011, reported a standard deviation of $1.4 \%$ and a maximum variation of $4 \%$ in 10 pressurization air leakage tests. This number increased to $2.7 \%$ and $7.9 \%$ under reproducibility conditions, where the test operator and test equipment had changed. In 1982, Persily found a 5.5\% standard deviation and 19.4\% maximum variation in 28 performed pressurization tests on a house during a three-month period. In Calm weather, this statistic decreased to $1.7 \%$ and $4.8 \%$ due to the high impact of the wind speed on repeatability of pressurization test results. (Bracke et al. , 2016). In a study on seasonal variation of air tightness in semi-detached houses over a period of one week, the measurements Kim and Shaw noticed were a standard deviation of $1.7 \%$ and maximal variation of 4.2\% (Kim \& Shaw, 1986). In Bracke et al. study on two passive houses in Belgium, their measurements in the first house which was 
built with traditional methods using masonry walls, through conducting 48 pressurization tests, done in 7 different days in a 5-month period, showed a standard deviation of $1.1 \%$ to $3.5 \%$ within the same day. In the second house which had a wood-frame structure, the variation within the same day was higher and was reported as a standard deviation of $2.7 \%$ and an average maximum variation of $7.7 \%$. The average standard deviation for both tested houses was 3.2 and $3.5 \mathrm{~m} 3 / \mathrm{h}$ relatively. Bracke et al. could find no correlation between wind speed and air leakage in their study but air leakage results showed more variation on windy days. But It can't be concluded that wind effect is negligible as its effect could get masked by usual variations in air tightness measurements (Bracke et al., 2016).

Windows in the Weidt et al. report showed approximately $29 \%$ average decline in performance between the time they were manufactured and the time they were installed. Their results indicated no significant trend for air leakage performance to deteriorate during cold weather(Weidt et al., 1979).

Studies are available on air leakage seasonal variations, but different building methods and climate are important factors impacting the drawing conclusions. Persily, in multiple tests conducted in one house in a period of one-year, reported 30\% higher air leakage rates in the winter compared to lowest measurement results in the summer. He also reported lower air leakage rates in the presence of higher relative humidity, as he claimed that moisture in hot summers results in a swelling of the wood and disappearing of small gaps and cracks (Bracke et al., 2016). Kim and Shaw measured a seasonal variation of $20 \%$ in their test performances on two houses with the highest air leakage rates appearing in the winter(Kim \& Shaw, 1986). Elmroth and Logdberg measured 70\% air leakage increase in five houses during the first year of occupancy in Sweden. Carlsson and Kronvall in 1984 had found no significant change in fifteen timber frame houses, 1 to 4 years after construction. Warren and Webb in 1980 found evidences of a $40 \%$ increase in air leakage in one house during the winter and $83 \%$ increase in air tightness in three other houses, during one year after construction. In 1992, Bassett's study on five houses showed no significant trend in airtightness variation during the first year of their construction(Bassett, 1992). 
Bracke et al. study showed a 13\% increase in air leakage over each single test day over a duration of 7 test days in their first case study. Their second case study which was a similar traditional wood frame house (similar to Persily study in 1982), in contrast, showed no decrease in air leakage during summer. The reason of having different results despite of climate and construction method similarities, could be that all joints between wood panels and around envelope details such as windows were sealed with tape and along with wood swelling it could even make the building tighter. Following a different pattern, Dickinson and Feustel performed a study on 10 houses in three different climates in 1986 that showed a $45 \%$ higher air leakage in the summer. The fact that the winter results were showing less variation can be explained by large quantities of snow on and around the building envelope (Bracke et al., 2016).

Lux in 1987 studied 30 relatively air tight houses, six years after original air tightness tests were conducted (only five houses did not have any interventions performed on them). The maximum air leakage increase was measured at $32 \%$ but one of the houses showed $9 \%$ more air tightness compared to the original amounts. Proskiw is case studies, showed maximum increase in air tightness of $37 \%$ and a 30\% decrease over the period of 5 years (G. Proskiw, 1992). Reiß and Erhorn compared air leakage rates of passive houses after construction in a two-year period, and reported 30\% increase in air leakage rates. In their study, an increase of $216 \%$ in air leakage was reported and a few houses showed decreases up to 39\% (Bracke et al., 2016). Temse and Bredene is a report on air leakage re-measurements, supported air leakage increase by $29 \%$ and $45 \%$ over a two year period due to construction wear and tears (Bracke et al., 2016).

In a recent study by Wahlgren et al in 2015, air tightness of the building was shown varying as much as $10 \%$ throughout the year. The main reason could be variation in relative humidity and temperature fluctuations. Dmhagen is research results, showed a strong correlation between increased indoor relative humidity and increased airtightness, as well as a strong correlation between decreased relative humidity and decreased airtightness. Persily is study showed 25\% of air tightness fluctuation throughout a year (Domhagen, 2016). 
Gids et al. Study supports that a large portion of air leakage can be attributed to design and workmanship in whole building air tightness evaluation. (Bracke et al., 2016).

\section{Some Thoughts from the Literature Review}

The energy implications of air leakage from the point of view of whole building have been of interest. As one of the studies indicated the implications if reducing air leakage can be as significant as improving $\mathrm{R}$ values in roofs or walls or improving SHGC. As we improve the air tightness of buildings and with energy recovery from ventilated air the air leakage characteristics of operable fenestration products will become relatively more important. The values of air leakage specified in the certification process need to reflect in some form the air leakage values achieved after installation. Recent changes to field testing standards such as AAMA 502 appear to deal with this issue. However, we still do not know the level of variation, statistically speaking, in the field installed window. Although the Weidt in 1979 study is decades old it did show that variations can be significant. Some of these variations may be controlled by better quality control during manufacturing and more care during installation. However, without undertaking a study on such variations it may be viewed as mere speculation. 


\section{Chapter 3}

\section{Methodology}

To review the fenestration air leakage performance, choosing an appropriate building, reviewing the architectural and window shop drawings, selecting test samples, conducting visual inspection and field air leakage tests were the main steps.

\section{Selection of Building for Field Testing}

A building under construction was selected for the air leakage field testing of the fenestration product. The building is located in a built-up-area of Toronto, Ontario, Canada. The exterior cladding of the building was completely installed and the interior finishes were complete to a varying degree.

The building HVAC system was not operational. The building is over 60 storeys high and the general construction method and the materials used are typical of condominium buildings being constructed in Toronto at the time of this study - it's exterior envelope uses windowwall type of construction, and the structure is cast-in-place concrete with unenclosed cantilevered balconies.

The choice of the building was predominantly dictated by the need to study fenestration that would not have been subjected to use by the occupants, and the ability to get a sample size adequate for statistical purposes. The chosen building provided that opportunity.

Access to the building for conducting field tests as well as access to building architectural and window shop drawings were other important factors affecting this selection. The manufacturer of fenestration products used in the project, indeed cooperated a lot in sharing laboratory test reports and other required information.

\section{Selection of Type of Fenestration for Testing}

This building provided an opportunity to choose fixed windows, operable windows and sliding patio doors for testing. 
In this study sliding patio doors were chosen for testing predominantly because of the ease of access to the exterior side through the balcony. Such access would be necessary as part of the testing.

The laboratory test results that formed the basis of the certification of the patio door and the details of the patio door were made available by the manufacturer. (Refer to Appendix A)

\section{Description of the Tested Fenestration Product}

As mentioned before the building had many different types of windows and sliding doors that were used as part of the exterior envelope. For the purpose of this study it was decided to use an operational fenestration products available in forms of horizontal sliding windows and horizontal sliding doors.

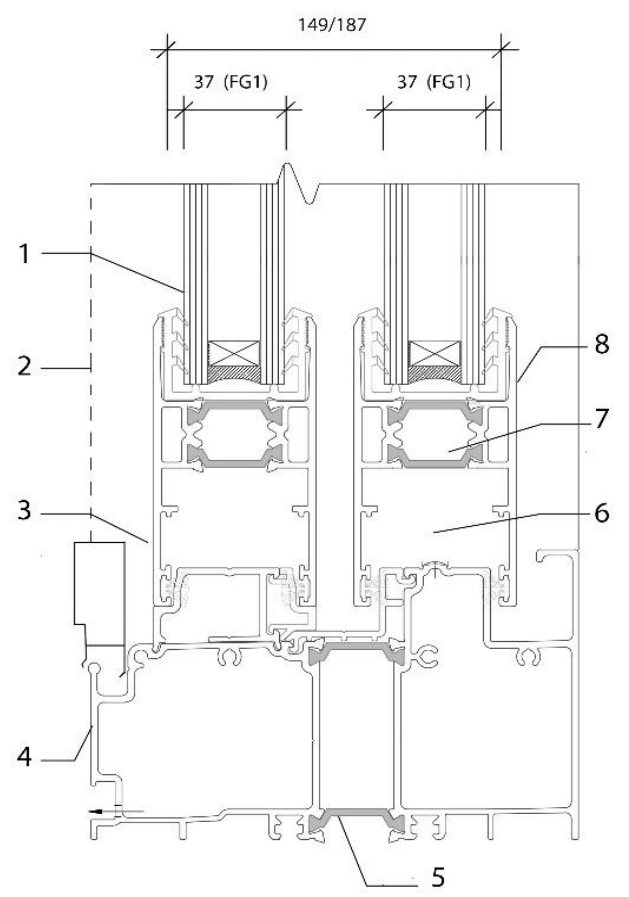

1 - IGU, 2- Fly screen, 3 - Fixed panel, 4Threshold,

5-Thernal break, 6- Roller, 7- Thermal break, 8-Sliding panel

It was decided to test sliding doors primarily because the exterior of these doors would be accessible

Figure 1 - Cross-section at the sill of the door assembly through the balconies across which they were installed. This would allow access to sliding doors throughout the building without the need to access the exterior via suspended stages.

The description of the sliding door as stated in the laboratory test results is stated in this section and more detailed in the Appendix A. The installed door was the same as the laboratory door but with different dimensions. 
The door is described as a thermally broken aluminum exterior sliding door set on a frame with a width from the inside to the outside of $149 \mathrm{~mm}$. It has one fixed panel and one operable panel both with IGUs. It has a fiberglass fly screen in aluminum frame on rollers. The frame finish is anodized aluminum. The handle and locking hardware consists of pull handle on each side of the operable door, single point hook lock and an interior side lock lever. The overall door frame size of the laboratory tested sample was $2260 \mathrm{~mm}$ high $\mathrm{x}$ $1830 \mathrm{~mm}$ wide. The operable and fixed panel were

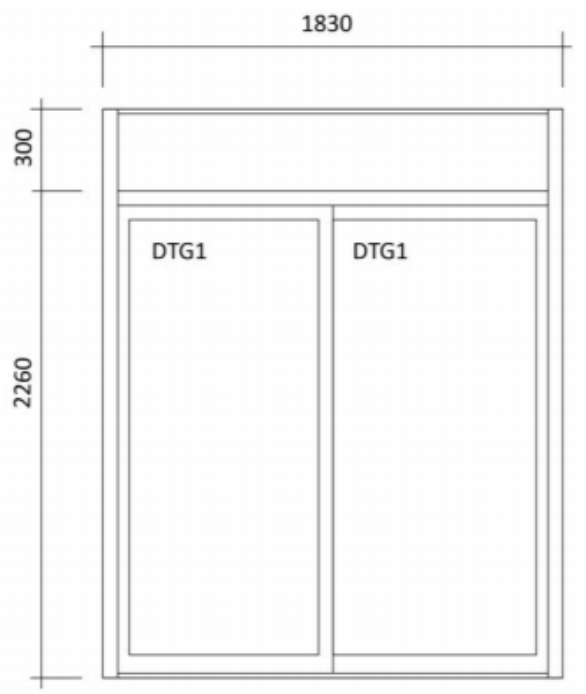

Figure 2 - Elevation view of the door assembly each $890 \mathrm{~mm}$ high $\times 716 \mathrm{~mm}$ wide. The weather stripping of polypile was used at all fixed and operable rails, operable panel lock stile and fixed and operable interlocks. Composite dust plugs were used at the end of interlock stile.

All corners in the frame were square cut and butted aluminum sealed with butyl tape and secured with long pan head screws. All corners in the panels were mitered and sealed with sealant and secured with two aluminum corners and one plastic corner bracket. (Refer to Figure 1 and 2).

The air leakage reported in the laboratory test report was $0.5\left(\mathrm{~L} / \mathrm{s} / \mathrm{m}^{2}\right)$ at 75 Pascal pressure difference in infiltration and exfiltration as tested in accordance with ASTM E283.

\section{Selection of Samples for Testing Identifying the Population}

As indicated in architectural and shop drawings, there are different types of patio doors in the building. Test samples were selected on a randomized basis. However, before making the random selection, it was necessary to identify same type patio door's locations at identical window wall system combinations.

Identical window walls were named based on the lowest floor level; for example, W7, is the window wall system combination on level 7, 8, 14, 16, 19 and 20; or W11 is the window wall system combinations on level 11, 17 and 18. (Refer to table 1 in Appendix B, Part A\&B) 
Window wall combinations, consisting of fixed and operable windows and patio doors, are named as a, b and $\mathrm{c}$ in the window shop drawings. For example, "W11-1b "is the window wall system for 11th, 17th and 18th Floor;1b indicates the location of the system (south east elevation) and its combination of operational types. $1 \mathrm{~b}$ is, for instance, the combination of awning and fixed "TG2" windows at bypass locations; and fixed and sliding doors of type TG2 and DTG2 at balcony location with the dimensions specified in the drawings. (Refer to table 2 and 3 in Appendix B, Parts A\&B)

After determining different window wall combinations and configurations, the ones consisting of sliding doors have been selected at each floor. As indicated in window shop drawings, there are two types of different sliding doors from the same series, which comprise of thermally broken aluminum exterior sliding doors with frames of $149 \mathrm{~mm}$ wide. The frame's finishing is painted Duranar Sunstorm gray; with clear top coat for exterior and Duracron gloss white; on the interior.

The sliding door hardware consists of pull handles on each side, single point hook lock and interior side lock lever. Both types of sliding doors have double glazed sealed units, however, with different thicknesses and sound transmission ratings. Insulated glass units comprise of FG1 and FG2 with thicknesses of $37 \mathrm{~mm}$ and $39 \mathrm{~mm}$, and STC rating of 33 (Typical) and 36 respectively.

One type of patio door DTG1- which will be called Type I in this study - is chosen to be studied. The drawings indicated that there were 460 Type I sliding doors on this project. All these Type I doors were categorized under the same classification in terms of their air leakage characteristics. A further examination revealed that Type I doors that were installed in two different heights. Three Hundred Ten (310) sliding doors with the same height and same air leakage characteristics formed the final population for this study.

Typically, the size of the samples in such a study needs to be determined based on the level of confidence and the confidence interval desired from the expected results. It is assumed that the air leakage of the doors would follow a normal distribution. In this particular 
instance, the variables that impact the air leakage characteristics are the variations in the manufacturing process and the variations in the installation process. Variations related to degradation from use and environmental factors is minimal as the doors are tested before they have been substantially used.

\section{Identifying the Distribution of the Population}

The distribution of the doors by floors is shown below. (Refer to Table 1)

\begin{tabular}{|c|c|c|}
\hline \multirow{2}{*}{ Floor } & \multicolumn{2}{|c|}{ Number of Type I Patio Doors } \\
\hline & Total & Tested \\
\hline Podium & None & 0 \\
\hline To $10^{\text {th }}$ & 24 & 4 \\
\hline $11^{\text {th }}-15^{\text {th }}$ & 11 & 2 \\
\hline $16^{\text {th }}-20^{\text {th }}$ & 18 & 3 \\
\hline $21^{\text {st }}-25^{\text {th }}$ & 26 & 2 \\
\hline $26^{\text {th }}-30^{\text {th }}$ & 33 & 2 \\
\hline $31^{\text {st }}-35^{\text {th }}$ & 27 & 3 \\
\hline $36^{\text {th }}-40^{\text {th }}$ & 41 & 1 \\
\hline $41^{\text {st }}-45^{\text {th }}$ & 22 & 7 \\
\hline $46^{\text {th }}-50^{\text {th }}$ & 54 & 5 \\
\hline $51^{\text {st }}-55^{\text {th }}$ & 33 & 3 \\
\hline $55^{\text {th }}$ and more & 21 & $\mathbf{3 2}$ \\
\hline Total & $\mathbf{3 1 0}$ & \\
\hline
\end{tabular}

Table 1- Distribution of Type 1 Patio Doors by Floors - Total and Tested

As previously mentioned after defining the sample type, window shop drawings and architectural plans were used to identify the distribution of the samples and confirm their being identical, to be field tested. However, after a site visit it was determined that conducting field air leakage test is impossible on some of the selected sliding doors. For instance, in some of the suites on lower floors, interior gypsum boards were installed or were under progress of the installation, therefore, there was not enough room to tape the poly chamber to the window frame or sliding doors were not accessible in some of the suites because, building materials had blocked the access.

\section{Determination of the Test Samples}

In this study, overall 32 sliding doors which counts approximately, for $10 \%$ of the total sliding door population aimed to be field air leakage tested. As it was impossible to check all the suite's sliding doors accessibilities prior to random selection, and to consider all the 
unforeseen situations, 10 more sliding doors were added to the list. Therefore 32 sliding doors targeted to be tested from the 40 randomly selected ones, out of 310. (Refer to table 4 to 6 in Appendix B, Part A\&B)

\section{Field Air Tightness Test Standard and Equipment}

All the sliding doors that were tested for this study were done in accordance with ASTM E783. A calibrated Wind Maker Plus test kit was used to carry out the testing. Figure 3 to 5 shows the test apparatus and a typical test assembly.

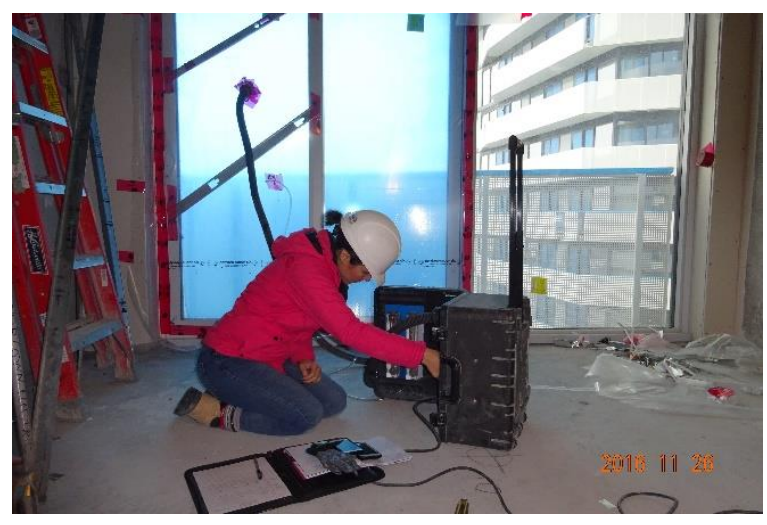

Figure 3 - Typical test assembly

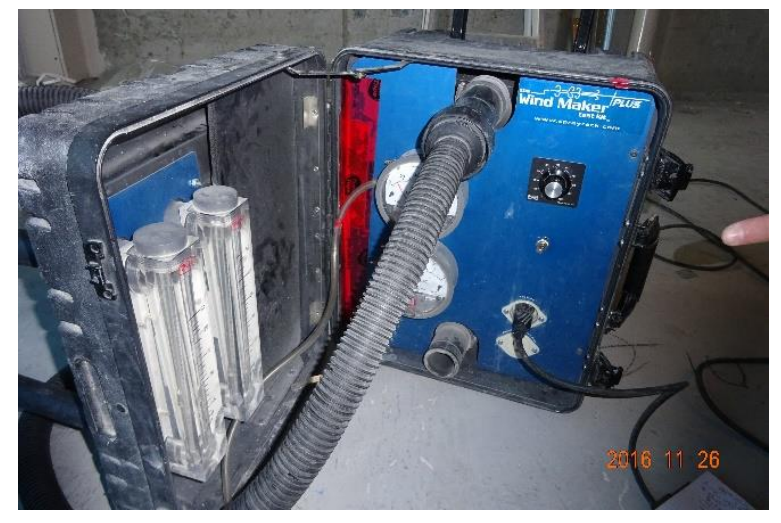

Figure 4 - Wind Maker test equipment

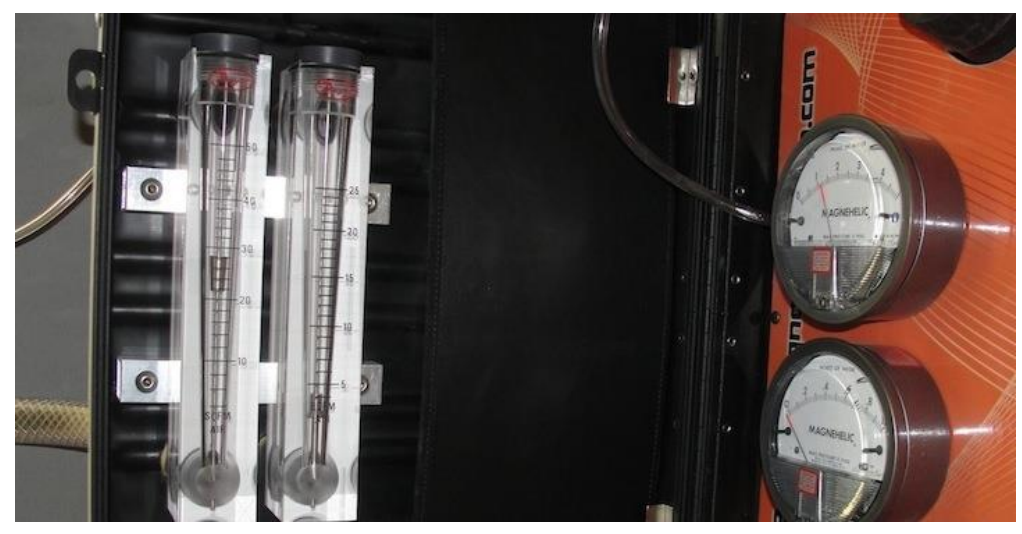

Figure 5 - Air flow and Pressure measuring devices

In general, the test procedure consisted of the following steps:

- The patio door was examined from the inside and the outside for signs of conditions that may impact air leakage measurements. 
- Ambient conditions of temperature and relative humidity were measured. Wind speeds were noted based on local weather reports.

- A chamber was created on the interior using poly sheets. The fan apparatus was connected to the chamber.

- The exterior was isolated with poly sheets taped to the frame.

- The chamber was depressurized and infiltration was measured at 4 different pressure differences: 25, 50, 75 and $100 \mathrm{~Pa}$. Visual observations using smoke pencils and infrared thermographic camera were made to study paths of air leakage.

- The exterior poly sheet was removed and the step 5 was repeated.

The 32 tests were done over a period of 5 days. The weather conditions on these days varied widely. The results obtained from field tests were tabulated and corrections applied to bring the air leakage measurements to $20^{\circ} \mathrm{C}$.

\section{Correction of the Temperature and Pressure}

As stated before, climate condition can affect the air leakage performance of fenestration products in different ways. For example, it can impact the material characteristic, creates shrinkage, and affects the air leakage performance, despite of the fact that according to the Canadian standard association (CSA), stated in part 1.6.2, air leakage test results measured in cold temperature versus the laboratory measured ones have shown an insignificant difference.

To conduct a better statistical review over sliding doors air tightness performance and its correlation with laboratory's performance, it was required to minimize variables. The measurements have been taken in different temperature conditions, therefore, standardization would help investigating the actual impact of temperature difference on final air leakage test results.

Standard temperature and pressure difference in the laboratory performance tests are considered as $20^{\circ} \mathrm{C}$ and 75 Pascals. As per sea level standard atmospheric pressure of 101,325 Pascals, any field pressure difference with the standard one could be neglected.

The laboratory test standard temperature of $20^{\circ} \mathrm{C}$, compared to the field test's various temperatures, could affect the test results, therefore to validate the comparisons, field test 
results must be temporarily corrected. To calculate the effect of temperature difference and correct the results to obtain a standardized air leakage value, the density of the air was calculated on each test date according to temperature. This calculation is based on using Steve Gribble on-line air density calculator and online engineering toolbox. Having the test results in that specific air density and having the standard $20^{\circ} \mathrm{C}$ air density, we could standardize the air leakage results. The standardized conditions are shown at each test results analysis and data collection in Appendix B. (Refer to Appendix B)

\section{Thermography Analysis}

In few windows, infrared thermography was done to investigate possible drafts and leakages. It helped to find colder spots at window frame and joints. Thermography scan was done before beginning of each test, during the test and after finishing the test and scanned pictures were compared to the after test's scanned pictures to find possible leakage and draft paths.

\section{Smoke Pencil Findings}

In windows with higher air leakage rates, smoke pencil was used to determine possible leakage paths. 


\section{Chapter 4}

\section{Test Results}

As previously stated, air tightness performance of randomly selected test samples have been evaluated in accordance to ASTM E-783. Tests were conducted on five different days. Data collected on each day reflects environmental conditions that are similar for those dates. (Refer to table 2)

\begin{tabular}{|c|c|c|c|}
\hline Date & Inside Temp. (oC) & $\begin{array}{c}\text { Average outside Temp. } \\
\text { (oC) }\end{array}$ & 10 \\
\hline Nov. 19, 2016 & 12 to 15 & 5 & W -20 to 26 \\
\hline Dec. 1, 2016 & 7 to 8 & 4.75 & W -24 to 38 \\
\hline Dec. 3, 2016 & 5 to 13 & -6 & NW -11 to 25 \\
\hline Dec. 16, 2016 & 13 & -1 & W -24 to 31 \\
\hline Dec. 28, 2016 & 20 & W -25 \\
\hline
\end{tabular}

Table 2 - Temperature and Wind Conditions during Testing

To evaluate air leakage performance of fenestration products, often they should be tested at 75 Pascal standard pressure difference.

Laboratory airtightness performance test report indicates that test sample (type 1), has 0.5 $\left(\mathrm{L} / \mathrm{s} / \mathrm{m}^{2}\right)$ air leakage rate at 75 Pascal pressure difference. To evaluate airtightness performance of newly installed sliding doors, thirty two (32) sliding doors of the same size and configuration, tested in field at 75 Pascal standard pressure difference. Samples were selected from various heights and elevations. For the purpose of this study test samples were also tested at 25, 50 and 100 Pascal pressure differences.

A preliminary review of the air leakage test results indicated that there are 2 outliers on the higher end and 5 outliers on the lower end of the results. These were further removed from the analysis. (Refer to table 3 ) 
The excluded test results are plotted in table below.

\begin{tabular}{|c|c|c|c|c|c|c|}
\hline $\begin{array}{c}\text { Test } \\
\text { Number }\end{array}$ & Level & Date & $\begin{array}{c}\text { Air leakage at } \\
25 \text { pa } \\
(\mathrm{L} / \mathrm{s}) / \mathrm{m} 2\end{array}$ & $\begin{array}{c}\text { Air leakage at } 50 \\
\text { pa } \\
(\mathrm{L} / \mathrm{s}) / \mathrm{m} 2\end{array}$ & $\begin{array}{c}\text { Air leakage at } 75 \\
\text { pa } \\
(\mathrm{L} / \mathrm{s}) / \mathrm{m} 2\end{array}$ & $\begin{array}{c}\text { Air leakage at } 100 \\
\text { pa } \\
(\mathrm{L} / \mathrm{s}) / \mathrm{m} 2\end{array}$ \\
\hline 13 & 10 & Dec 1,2017 & 1.567 & 1.639 & 2.073 & 2.319 \\
\hline 16 & 53 & Dec 3, 2017 & 0.471 & 0.864 & 1.975 & 1.486 \\
\hline 19 & 38 & Dec 3, 2017 & 0.012 & 0.036 & 0.042 & 0.024 \\
\hline 24 & 36 & Dec 16, 2017 & 0.143 & 0.182 & 0.104 & 0.143 \\
\hline 25 & 36 & Dec 16, 2017 & 0.039 & 0.039 & 0.130 & -0.065 \\
\hline 29 & 49 & Dec 28, 2017 & 0.000 & -0.088 & 0.088 & 0.126 \\
\hline 30 & 49 & Dec 28, 2017 & -0.389 & 0.063 & -0.251 & 0.013 \\
\hline
\end{tabular}

Table 3 - Excluded test results from the study (Outliers)

Air leakage test results of the remaining 25 tests, organized by the dates on which they were done, are shown in tables 4 to 8 . (Refer to tables 4 to 8 )

\begin{tabular}{|c|c|c|c|c|c|}
\hline Test Number & Level & $\begin{array}{c}\text { Air leakage at } 25 \text { pa } \\
(\mathrm{L} / \mathrm{s}) / \mathrm{m}^{2}\end{array}$ & $\begin{array}{l}\text { Air leakage at } 50 \text { pa } \\
(\mathrm{L} / \mathrm{s}) / \mathrm{m}^{2}\end{array}$ & $\begin{array}{c}\text { Air leakage at } 75 \text { pa } \\
(\mathrm{L} / \mathrm{s}) / \mathrm{m}^{2}\end{array}$ & $\begin{array}{c}\text { Air leakage at } 100 \text { pa } \\
(\mathrm{L} / \mathrm{s}) / \mathrm{m}^{2}\end{array}$ \\
\hline 1 & 47 & 0.117 & 0.410 & 0.585 & 0.667 \\
\hline 2 & 46 & 0 & 0.328 & 0.503 & 0.585 \\
\hline 3 & 43 & 0.117 & 0.012 & 0.199 & 0.339 \\
\hline 4 & 20 & 0.257 & 0.456 & 0.714 & 1.358 \\
\hline 5 & 17 & 0.023 & 0.351 & 0.293 & 0.410 \\
\hline 6 & 14 & 0.421 & 0.515 & 0.515 & 0.620 \\
\hline 7 & 14 & 0.339 & 0.573 & 0.749 & 0.913 \\
\hline
\end{tabular}

Table 4- Air Leakage rates - Nov. 19, 2016

\begin{tabular}{|c|c|c|c|c|c|}
\hline Test Number & Level & $\begin{array}{c}\text { Air leakage at 25 pa } \\
(\mathbf{L} / \mathbf{s}) / \mathbf{m} \mathbf{2}\end{array}$ & $\begin{array}{c}\text { Air leakage at 50 pa } \\
\mathbf{( L / s )} / \mathbf{m} 2\end{array}$ & $\begin{array}{c}\text { Air leakage at 75 pa } \\
\text { (L/s)/m2 }\end{array}$ & $\begin{array}{c}\text { Air leakage at 100 pa } \\
(\mathbf{L} / \mathbf{s}) / \mathbf{m} 2\end{array}$ \\
\hline $\mathbf{8}$ & 64 & 0.012 & 0.729 & 0.775 & 0.694 \\
\hline $\mathbf{9}$ & 64 & 0.220 & 0.393 & 0.521 & 0.509 \\
\hline $\mathbf{1 0}$ & 58 & 0.058 & 0.497 & 0.407 & 0.765 \\
\hline $\mathbf{1 1}$ & 54 & 0.086 & 0.620 & 0.604 & 0.827 \\
\hline $\mathbf{1 2}$ & 11 & 0.382 & 0.609 & 0.654 & 0.839 \\
\hline
\end{tabular}

Table 5 - Air Leakage rates - Dec. 1, 2016 


\begin{tabular}{|c|c|c|c|c|c|}
\hline Test Number & Level & $\begin{array}{l}\text { Air leakage at } 25 \text { pa } \\
(\mathrm{L} / \mathrm{s}) / \mathrm{m} 2\end{array}$ & $\begin{array}{l}\text { Air leakage at } 50 \text { pa } \\
(\mathrm{L} / \mathrm{s}) / \mathrm{m} 2\end{array}$ & $\begin{array}{c}\text { Air leakage at } 75 \text { pa } \\
(\mathrm{L} / \mathrm{s}) / \mathrm{m} 2\end{array}$ & $\begin{array}{c}\text { Air leakage at } 100 \text { pa } \\
(\mathrm{L} / \mathrm{s}) / \mathrm{m} 2\end{array}$ \\
\hline 14 & 53 & 0.060 & 0.435 & 0.483 & 0.556 \\
\hline 15 & 53 & 0.423 & 0.930 & 0.894 & 1.317 \\
\hline 17 & 50 & 0.809 & 1.075 & 1.112 & 1.232 \\
\hline 18 & 50 & 0.157 & 0.435 & 0.592 & 0.616 \\
\hline 20 & 35 & 0.012 & 0.036 & 0.423 & 0.024 \\
\hline 21 & 35 & 0 & 0.254 & 0.604 & 0.809 \\
\hline 22 & 26 & 0.423 & 0.640 & 0.785 & 0.749 \\
\hline 23 & 26 & 0.568 & 0.737 & 0.846 & 0.544 \\
\hline
\end{tabular}

Table 6 - Air Leakage at 75 Pa - Dec. 3, 2016

\begin{tabular}{|c|c|c|c|c|c|}
\hline Test Number & Level & $\begin{array}{c}\text { Air leakage at 25 pa } \\
\mathbf{( L / s ) / m 2}\end{array}$ & $\begin{array}{c}\text { Air leakage at 50 pa } \\
\mathbf{( L / s )} / \mathbf{m} 2\end{array}$ & $\begin{array}{c}\text { Air leakage at 75 pa } \\
\mathbf{( L / s ) / m 2}\end{array}$ & $\begin{array}{c}\text { Air leakage at 100 pa } \\
(\mathbf{L} / \mathbf{s}) / \mathbf{m} \mathbf{2}\end{array}$ \\
\hline $\mathbf{2 6}$ & 22 & 0.385 & 0.526 & 0.526 & 0.796 \\
\hline $\mathbf{2 7}$ & 22 & 0.039 & 0.501 & 0.886 & 0.937 \\
\hline $\mathbf{2 8}$ & 22 & 0.436 & 0.976 & 1.155 & 1.053 \\
\hline
\end{tabular}

Table 7- Air Leakage at 75 Pa - Dec. 16, 2016

\begin{tabular}{|c|c|c|c|c|c|}
\hline Test Number & Level & $\begin{array}{c}\text { Air leakage at 25 pa } \\
(\mathbf{L} / \mathbf{s}) / \mathbf{m} \mathbf{2}\end{array}$ & $\begin{array}{c}\text { Air leakage at 50 pa } \\
\mathbf{( L / s )} / \mathbf{m} 2\end{array}$ & $\begin{array}{c}\text { Air leakage at 75 pa } \\
\mathbf{( L / s ) / m 2}\end{array}$ & $\begin{array}{c}\text { Air leakage at 100 pa } \\
(\mathbf{L} / \mathbf{s}) / \mathbf{m} 2\end{array}$ \\
\hline $\mathbf{3 1}$ & 48 & 0.0 & 0.577 & 0.904 & 0.904 \\
\hline $\mathbf{3 2}$ & 54 & 0.452 & 0.565 & 0.628 & 0.967 \\
\hline
\end{tabular}

Table 8 - Air Leakage at 75 Pa - Dec. 28, 2016

\section{Review of the Test Results at Different Pressure Differences}

\section{Review of Test Results at 25 Pascal Pressure Difference:}

The average test result, at 25 Pascal pressure difference is calculated to be $0.28\left(\mathrm{~L} / \mathrm{s} / \mathrm{m}^{2}\right)$. Approximately $40 \%$ of the results are higher than the average rate. Most of the results are below $0.25\left(\mathrm{~L} / \mathrm{s} / \mathrm{m}^{2}\right)$ which the range is shown in grey on the chart. The minimum recorded test result is almost $0\left(\mathrm{~L} / \mathrm{s} / \mathrm{m}^{2}\right)$ and the maximum is $0.81\left(\mathrm{~L} / \mathrm{s} / \mathrm{m}^{2}\right)$. (Refer to figure 6) 


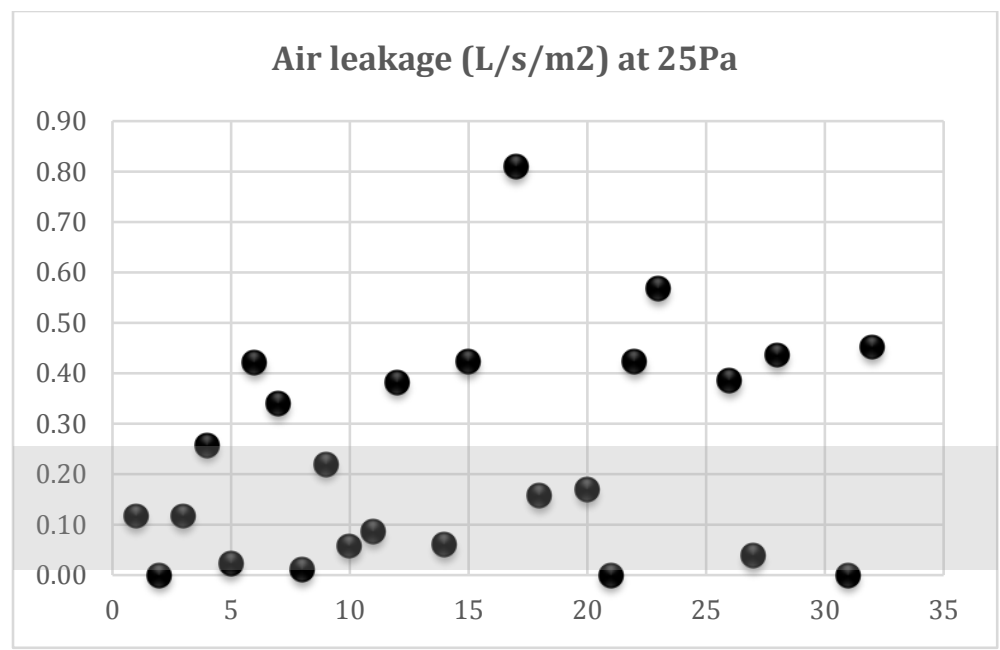

Figure 6 - Test results in 25 Pa pressure difference

\section{Review of Test Results at 50 Pascal Pressure Difference}

As shown in chart below, average test result at 50 Pascal pressure difference is 0.54 $\left(\mathrm{L} / \mathrm{s} / \mathrm{m}^{2}\right)$. Almost $44 \%$ of the results are higher than the average rate. Most of the results are in range of 0.40 to $0.65\left(\mathrm{~L} / \mathrm{s} / \mathrm{m}^{2}\right)$ which is shown in grey in chart below. The minimum reported test result is $0.01\left(\mathrm{~L} / \mathrm{s} / \mathrm{m}^{2}\right)$ and the maximum test result is $1.08\left(\mathrm{~L} / \mathrm{s} / \mathrm{m}^{2}\right)$. (Refer to figure 7)

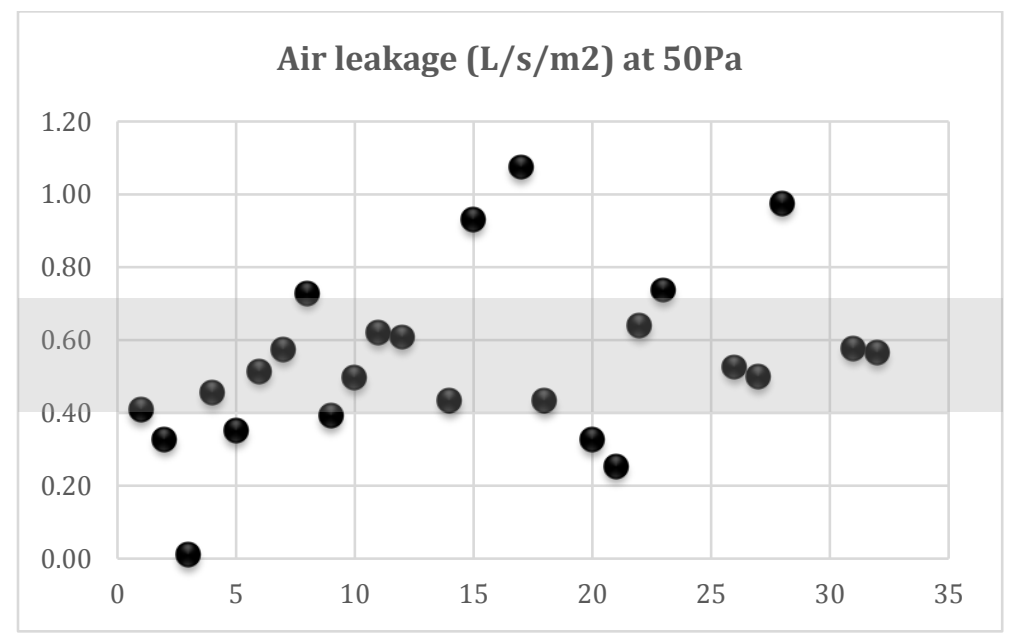

Figure 7- Test results in 50 Pa pressure difference

Average test result at 75 Pascal pressure difference is calculated to be $0.65\left(\mathrm{~L} / \mathrm{s} / \mathrm{m}^{2}\right)$, among the test results at this pressure difference approximately $44 \%$ are higher than the average rate. Most of the results are in range of 0.45 to $0.7\left(\mathrm{~L} / \mathrm{s} / \mathrm{m}^{2}\right)$, which is shown in grey in chart 
below. The minimum measured air leakage rate is $0.2\left(\mathrm{~L} / \mathrm{s} / \mathrm{m}^{2}\right)$ and the maximum rate is $1.16\left(\mathrm{~L} / \mathrm{s} / \mathrm{m}^{2}\right)$. (Refer to figure 8 )

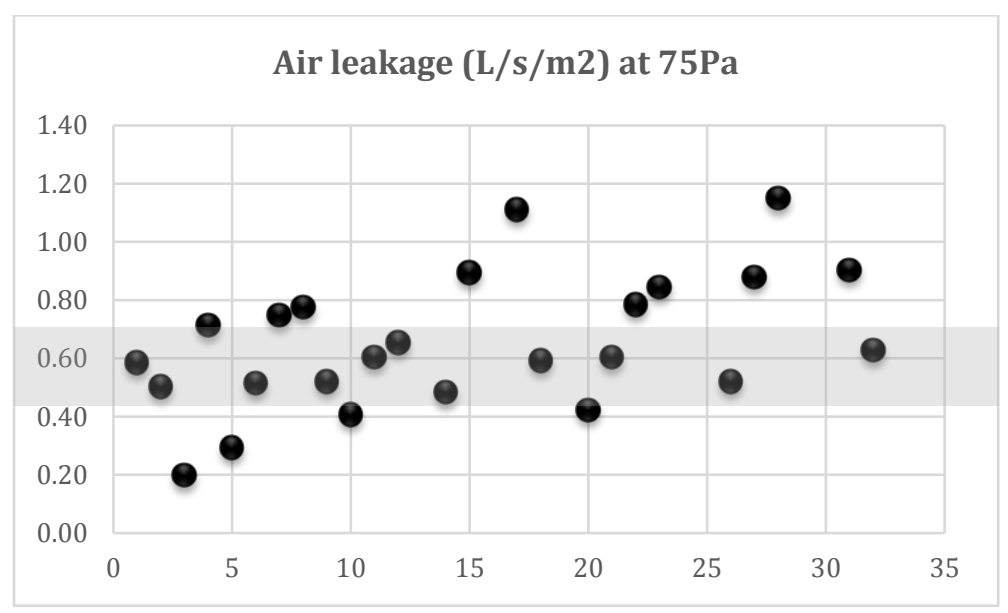

Figure 8 - Test results in 75 Pa pressure difference

As demonstrated in table below average of the test results at 100 Pascal pressure difference is calculated to be $0.78\left(\mathrm{~L} / \mathrm{s} / \mathrm{m}^{2}\right)$. Approximately $48 \%$ of the results are higher than the average rate. Most of the results are in range of 0.60 to $0.85\left(\mathrm{~L} / \mathrm{s} / \mathrm{m}^{2}\right)$ which is shown in grey in the table below. The minimum measured value is $0.34\left(\mathrm{~L} / \mathrm{s} / \mathrm{m}^{2}\right)$ and the maximum measured value is $1.36\left(\mathrm{~L} / \mathrm{s} / \mathrm{m}^{2}\right)$. (Refer to figure 9)

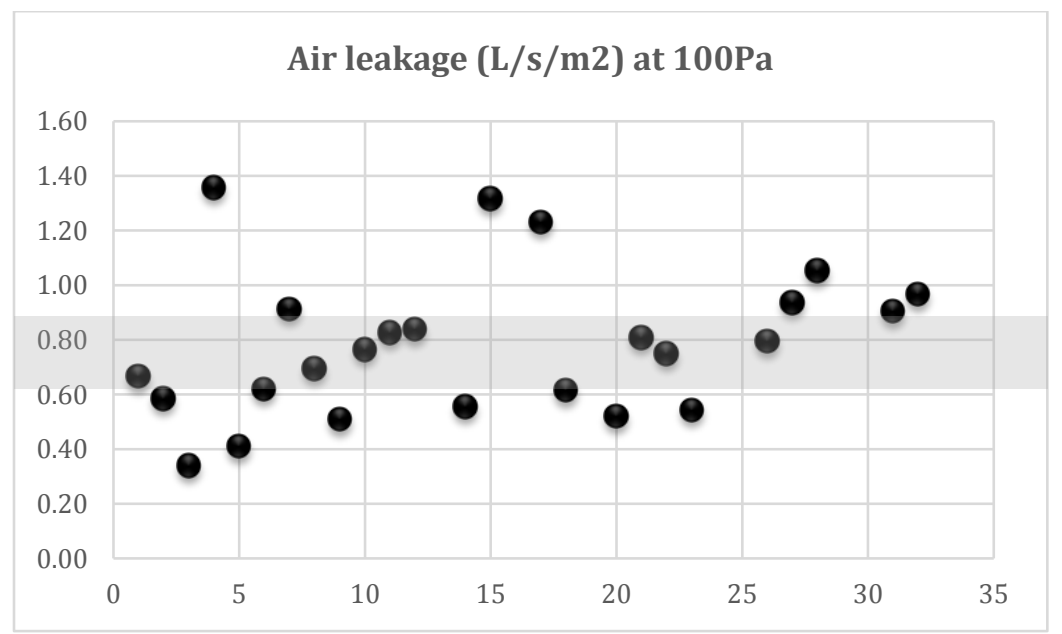

Figure 9 - Test results in 100 Pa pressure difference 


\section{Analysis and Findings}

\section{The Standard Field Test Pressure (75 Pascal):}

Among all field air leakage tests at 75 Pascal, $80 \%$ of the test results are above $0.5\left(\mathrm{~L} / \mathrm{s} / \mathrm{m}^{2}\right)$ and $20 \%$ are below that. (Refer to figure 10)

\section{Air leakage rates at 75 pa}

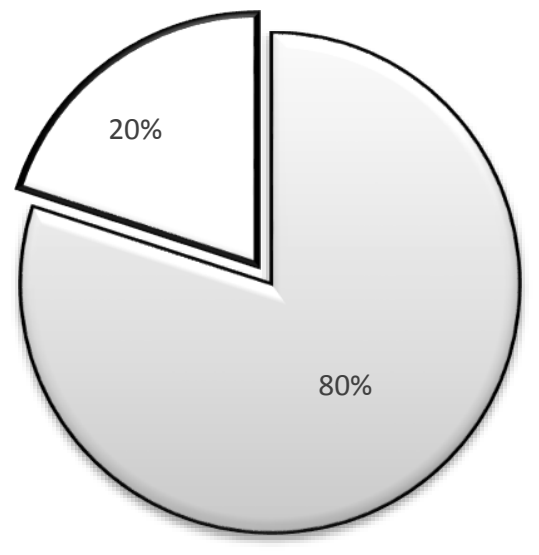

口Air leakage rate above $0.5\left(\mathrm{~L} / \mathrm{s} / \mathrm{m}^{2}\right)$ पAir leakage rate below $0.5\left(\mathrm{~L} / \mathrm{s} / \mathrm{m}^{2}\right)$

Figure 10 - Air leakage results at 75 Pascal

Based on valid 25 test results, various statistical measures have been determined. A box plot showing the minimum value, the maximum value, the median and the interquartile ranges are shown in Figure 11.

The frequency distribution of the air leakage measurements using a bin interval of 0.25 $\left(\mathrm{L} / \mathrm{s} / \mathrm{m}^{2}\right)$ is demonstrated in Figure 12. Bin limits are considered starting from 0.19 and ending to 1.19. (Refer to figure 11 and table 9)

The median value is $0.604\left(\mathrm{~L} / \mathrm{s} / \mathrm{m}^{2}\right)$ with an interquartile range of 0.5 to 0.8 and the maximum and minimum measured values of $0.198\left(\mathrm{~L} / \mathrm{s} / \mathrm{m}^{2}\right)$ and $1.155\left(\mathrm{~L} / \mathrm{s} / \mathrm{m}^{2}\right)$ respectively. 


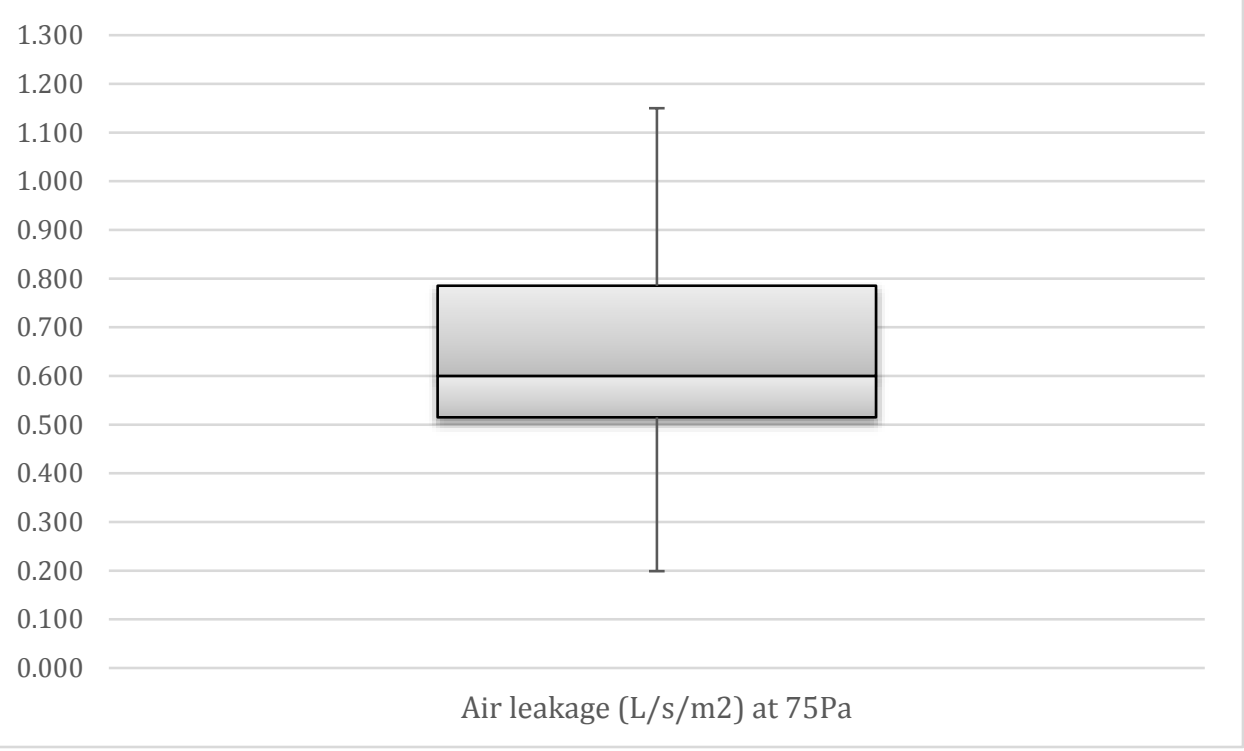

Figure11 - Box plot of Sample Air Leakage Rate at $75 \mathrm{~Pa}$

\begin{tabular}{|c|c|c|}
\hline Bin Limits & Frequency & Percentage \\
\hline $\mathbf{0 . 1 9 - 0 . 4 4}$ & 4 & $16 \%$ \\
\hline $\mathbf{0 . 4 4 - 0 . 6 9}$ & 11 & $44 \%$ \\
\hline $\mathbf{0 . 6 9 - 0 . 9 4}$ & 8 & $32 \%$ \\
\hline $\mathbf{0 . 9 4 - 1 . 1 9}$ & 2 & $8 \%$ \\
\hline Grand Total & 25 & $100 \%$ \\
\hline
\end{tabular}

Table 9 - Frequency distribution pivot table

Based on 25 measurements, the mean air leakage rate of the tests is $0.65\left(\mathrm{~L} / \mathrm{s} / \mathrm{m}^{2}\right)$ and the standard deviation is $0.231\left(\mathrm{~L} / \mathrm{s} / \mathrm{m}^{2}\right)$. The distribution follows a normal Gaussian distribution. The frequency of the occurrence in various bin limits are also plotted in figure below.(Refer to figure 12) 


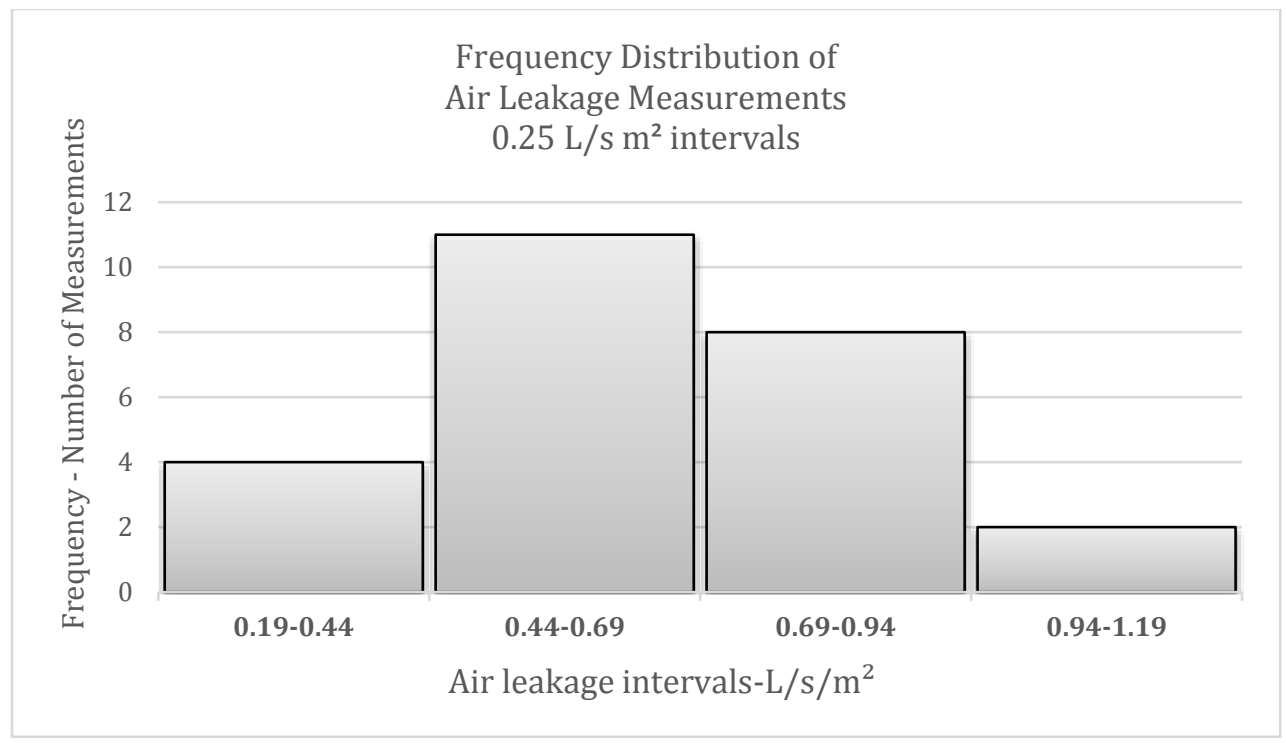

Figure 12 - Frequency Distribution of Air Leakage Measurements

The maximum frequency percentage, which covers almost $44 \%$ of the total test results is in range of 0.44 to $0.69\left(\mathrm{~L} / \mathrm{s} / \mathrm{m}^{2}\right)$. Approximately $28 \%$ of the test results lie within the first standard deviation (SD) above and below the mean and $64 \%$ of the test results lie within the second standard deviations of the mean.

No mode is applicable to the achievable range of results. The average of the squared differences from the mean, which is defined as sample variance is calculated as 0.05 .

The distribution follows a unimodal shape (Has just one peak). The distribution histogram is not completely symmetric and is slightly skewed right. The skewness is 0.3 and excess kurtosis is calculated as 0.06 and the frequency distribution histogram shows a slightly leptokurtic distribution which is very close to mesokurtic (Normal distribution).

Considering the random selection and the low threshold sampling (almost 25 samples), the confidence level (95.0\%) is calculated as 0.09 .

A summary of the various air leakage rates that can be used for comparison purposes are listed in below Table. The air leakage rates stipulated in A440.4-07, Table D3 for sliding doors have been used. The values in A440.4-07 are not provided in a manner that are consistent with present standards and the rates shown in Table 10 had to be normalized to the area of the door from the crack length. (Refer to table 10) 


\begin{tabular}{|l|c|}
\hline \multicolumn{1}{|c|}{ Source } & Air leakage (L/s/. $\mathbf{m}^{\mathbf{2}}$ ) \\
\hline Laboratory Tested Value (Used for Certification1) & 0.500 \\
\hline Mean of Field Tested Value & 0.653 \\
\hline Median of Field Tested Value & 0.604 \\
\hline Minimum of Field Tested Value & 0.198 \\
\hline Maximum of Field Tested Value & 1.155 \\
\hline 1.5 x Laboratory Value (AAMA 502 Allowable) & 0.750 \\
\hline A440.4-07 Allowable - A1 & 0.977 \\
\hline A440.4-07 Allowable - A2 & 0.577 \\
\hline A440.4-07 Allowable - A3 & 0.350 \\
\hline
\end{tabular}

Table 10 - Air Leakage Rates for Comparative Analysis

In comparing the field measured air leakage rates with different benchmarks, it becomes evident that the comparison is not straight forward. For instance, to compare the field measured values to the criteria set out by AAMA 502 or by A440.4-07, it is not clear if the average values should be used or that no field measured value should be greater than the criteria stated in those standards. If the latter is the case then it will be seen that 18 out of 25 or approximately $72 \%$ of the tested product will not meet the laboratory measured result, and 8 out the 25 or about $31 \%$ will not meet the AAMA 502 criteria based on the laboratory field result.

Similar conclusions can be drawn about the allowable values for A2 and A3 rated doors in A440.4-07. Only with the A1 rated doors in A440.4-7 the results show that over $90 \%$ of the tested product will meet the requirements. These results are similar to the results that are reported in Weidt et al in 1997 particularly for the products that were sliders. Another way to examine the data is the amount by which the measured values have exceeded the benchmarks. Comparing the field values of the product with the AAMA 502 benchmark it is 
noted that the highest value of 1.155 exceeds the AAMA 502 benchmark by $54 \%$. The rationale for the benchmarks is not evident in any of the publicly available document.

The dilemma that the scenario presents from a practical standpoint becomes evident in looking at the above discussion. However, this is one aspect of the issue. The bigger issue is that the measured values follow a certain distribution. This should be expected in any measurement of such performance values. In this particular instance, the measured values are distributed normally. In such a scenario, the method of sampling becomes a very important aspect of choosing to do the field tests. AAMA 502 indicates that three tests are to be performed. It is possible that the samples selected for the 3 tests would be from the $79 \%$ that would have met the AAMA 502 benchmark. What would that result tell us about the acceptability of the fenestration product relative based on the field testing. ASTM E783 provides some guidance in terms of sampling for field testing in this regard. It is recognized that practical and cost considerations often far outweigh the decisions regarding sample selection than the statistical nature of variation to be expected. 


\section{Test Variables}

There are conditions and factors which may vary from test to test and could affect the test results. Some of the obvious test variables could be counted as test dates, Interior conditions, or level of the suites on which test samples are installed and direction of test samples.

In this section test results are compared according to each test variable to find any possible trend affecting the result differences.

\section{Test Dates}

As mentioned before, air leakage tests are done in five different dates. Tests are conducted on November 11, 2016 and December 1, 3, 16 and 28, 2017. Among thirty two (32) total air leakage tests, the previously mentioned two (2) outliers on lower end belong to December 1 and 3, 2017 and the five (5) outliers on higher end belong to December 3, 16 and 28, 2017. The average temperature on November 11, 2016; December 1, 3, 16 and 28, 2017; was recorded at $10 \circ \mathrm{C}, 5 \circ \mathrm{C}, 4.75{ }^{\circ} \mathrm{C},(-6){ }^{\circ} \mathrm{C}$ and $(-1)^{\circ} \mathrm{C}$ respectively. Average air leakage test results at 75 Pascal pressure difference at mentioned dates were $0.51,0.84,0.86,0.67$ and 0.61 $\left(\mathrm{L} / \mathrm{s} / \mathrm{m}^{2}\right)$. (Refer to table 2 and 11 )

The relevance of the temperature with the average test results of the same date, is plotted in the below table. (Refer to table 11)

\begin{tabular}{|c|c|c|c|}
\hline Test date & Average temperature $\left({ }^{\circ} \mathbf{C}\right)$ & Number of tests & $\begin{array}{c}\text { Average test result at 75 Pa } \\
\text { including outliers (L/s/m } \mathbf{~} \text { ) }\end{array}$ \\
\hline Nov 11, 2016 & 10 & 7 & 0.51 \\
\hline Dec 1, 2017 & 5 & 6 & 0.84 \\
\hline Dec 1, 2017 & 4.75 & 10 & 0.86 \\
\hline Dec 1, 2017 & -6 & 5 & 0.67 \\
\hline Dec 1,2017 & -1 & 4 & 0.61 \\
\hline
\end{tabular}

Table 11 - The average results in different temperatures

\section{Test Floor Level}

The relation between test results and the floor levels on which, the test samples are installed, is demonstrated in table below. 
To make our review easier, tests are categorized in different groups, according height of the suites that samples are installed in. Different building floors are put in four (4) groups, each covering fifteen floors and ranging from the lowest to highest test floor levels. (Refer to table 12)

\begin{tabular}{|c|c|c|}
\hline Test suite level & Number of tests & $\begin{array}{c}\text { Average test result at } \mathbf{7 5} \text { Pa including outliers } \\
\left(\mathbf{L} / \mathbf{s} / \mathbf{m}^{\mathbf{2}} \mathbf{)}\right.\end{array}$ \\
\hline $\mathbf{5 - 2 0}$ & 6 & 0.69 \\
\hline $\mathbf{2 0 - 3 5}$ & 7 & 0.56 \\
\hline $\mathbf{3 5 - 5 0}$ & 11 & 0.25 \\
\hline $\mathbf{5 0 - 6 5}$ & 8 & 0.69 \\
\hline
\end{tabular}

Table 12 - Test results in different floor levels

\section{Test Elevation}

Among all the air leakage tests, nine tests are done on the sliding doors located on the northeast side of the building, six tests are done on the north-west side, eleven tests on the southeast side and three tests on the south-west side. The average test results in stated directions are $0.93,0.71,0.59$, and $0.49\left(\mathrm{~L} / \mathrm{s} / \mathrm{m}^{2}\right)$ accordingly. (Refer to table 13 )

\begin{tabular}{|c|c|c|}
\hline Test suite Direction & Number of tests & $\begin{array}{c}\text { Average test result at 75 Pa } \\
\text { including outliers } \mathbf{~} \mathbf{L} / \mathbf{s} / \mathbf{m}^{\mathbf{2}} \mathbf{)}\end{array}$ \\
\hline North-east & 9 & 0.93 \\
\hline North-west & 6 & 0.71 \\
\hline South-east & 11 & 0.59 \\
\hline South-west & 3 & 0.49 \\
\hline
\end{tabular}

Table 13 - Test results in different elevations

\section{Interior finishes}

Nine tested sliding door samples were installed in suites with complete interior finishes. These samples include test numbers 4, 7, 12, 21, 23, 26, 27 and 28, which have air leakage rate of $0.71,0.75,0.65,0.60,0.85,0.53,0.53,0.89$ and $1.16\left(\mathrm{~L} / \mathrm{s} / \mathrm{m}^{2}\right)$ air leakage rates.

The average rate of air leakage in suites with completed interior finishes is approximately $0.68\left(\mathrm{~L} / \mathrm{s} / \mathrm{m}^{2}\right)$. 


\section{Extrapolate Data from Laboratory Test Results}

Air leakage is considerably important to performance of a building fenestration system. Air leakage can occur through cracks, pores of the material, holes, and other openings. Air pressure difference produces flow. In most of the situations and locations leaky openings are not known to details. Openings contributing to the total leakage could be thin laminar passages through joints and cracks, tortuous paths through porous materials or various shapes and sizes of holes. Flow characteristics depend on the shapes and sizes of leakage paths. There may be various openings and cracks contributing to the total air leakage and it is impossible to identify, measure and calculate air leakage from each of them individually. Although it is possible to apply pressure to overall selected building enclosure system and measure flow rates and air leakage.

Air leakage results can be taken from $\mathrm{Q}=C(\Delta p)^{n}$, Where $\mathrm{Q}$ is the volume flow rate, $\mathrm{C}$ is a coefficient, $\Delta p$ is pressure difference and " $n$ " is an exponent varying between 0.5 and 1.0. When " $n$ " is assumed equal to 0.65 , it can represent many cases of wall and window air leakage.

In this serious of air leakage tests, this question could rise, that if the specimen was tested in the laboratory at 25, 50 or 100 Pascal pressure difference, what could air leakage results be. To answer this question, we need to make some assumptions and use base of the laboratory test results to find the coefficient constant.

In laboratory air leakage tests at 75 Pascal pressure difference, air leakage result is reported to be $0.5\left(\mathrm{~L} / \mathrm{S} / \mathrm{m}^{2}\right)$. Knowing all the variables, including " $\mathrm{n}$ " exponent we can find the coefficient (C), to be $0.03\left((\mathrm{~L} / \mathrm{s}) \mathrm{Pa}^{0.65}\right) / \mathrm{m}^{2}$.

Assuming an identical test condition for all other tests in different pressure differences we can say that the laboratory test results could be $0.24,0.38$ and $0.6\left(\mathrm{~L} / \mathrm{s} / \mathrm{m}^{2}\right)$ if air leakage was ever measured at 25,50 and 100 Pascal pressure difference accordingly. This air leakage rates could give us a benchmark to compare field test results in non-standard pressure differences. 


\section{Analysis of Extrapolated Air Leakage Results at Different Pressure Differences calculating from Laboratory Test Result at 75 Pascal}

As mentioned in the previous section, twenty five (25) air leakage test results at 25, 50 and 100 Pascal pressure difference will be statically reviewed based on benchmarks resulted from laboratory standard test results.

A box plot showing the minimum value, the maximum value, the median and the interquartile ranges is prepared for test results at each pressure difference. Frequency distribution of air leakage measurements using a bin interval of $0.25\left(\mathrm{~L} / \mathrm{S} / \mathrm{m}^{2}\right)$ is demonstrated in separate figures.

\section{Extrapolated Air Leakage Results at 25 Pascal Pressure Difference}

The median value of the test results at 25 Pascal pressure difference is $0.17\left(\mathrm{~L} / \mathrm{S} / \mathrm{m}^{2}\right)$ with an interquartile range of 0.05 to 0.42 and the maximum and minimum values of 0.00 $\left(\mathrm{L} / \mathrm{S} / \mathrm{m}^{2}\right)$ and $0.81\left(\mathrm{~L} / \mathrm{S} / \mathrm{m}^{2}\right)$ respectively. (Refer to figure 14 )

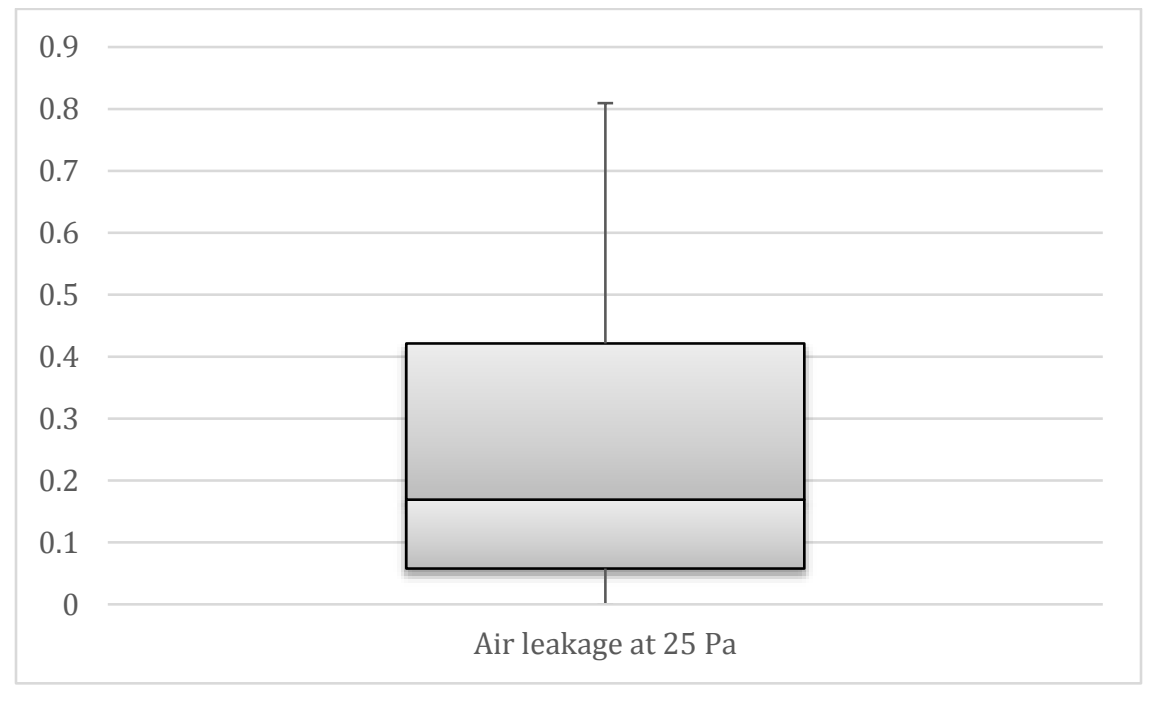

Figure 14 - Box plot of Sample Air Leakage Rate at $25 \mathrm{~Pa}$

Frequency distribution of the air leakage measurements using a bin interval of $0.25\left(\mathrm{~L} / \mathrm{S} / \mathrm{m}^{2}\right)$ is demonstrated in table and figure below. (Refer to table 14 and figure 15) 


\begin{tabular}{|l|c|c|}
\hline Row Labels & Frequency & Percentage \\
\hline $\mathbf{0 - 0 . 2 5}$ & 14 & $56 \%$ \\
\hline $\mathbf{0 . 2 5 - 0 . 5}$ & 9 & $36 \%$ \\
\hline $\mathbf{0 . 5 - 0 . 7 5}$ & 1 & $4 \%$ \\
\hline $\mathbf{0 . 7 5 - 1}$ & 1 & $4 \%$ \\
\hline Grand Total & 25 & $100 \%$ \\
\hline
\end{tabular}

Table 14 - Frequency distribution pivot table at $25 \mathrm{~Pa}$

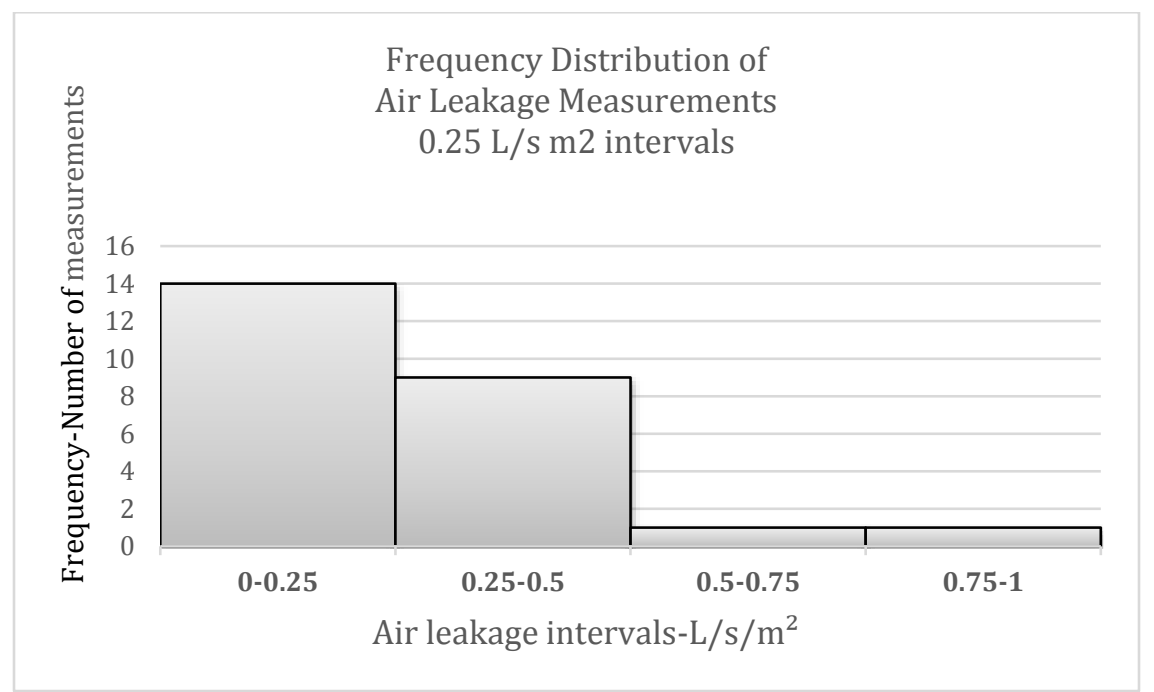

Figure 15 - Frequency Distribution of Air Leakage Measurements at $25 \mathrm{~Pa}$

The mean value is $0.23\left(\mathrm{~L} / \mathrm{s} / \mathrm{m}^{2}\right)$ and the standard deviation which measures the random errors is $0.21\left(\mathrm{~L} / \mathrm{s} / \mathrm{m}^{2}\right)$. Approximately $46 \%$ of the data lie within one standard deviation of the mean. Fifty six percent of the data lie within two standard deviation below, and 36\% of the data lie within two standard deviation above the mean value.

The maximum frequency percentage is in the range of 0.00 to $0.25\left(\mathrm{~L} / \mathrm{s} / \mathrm{m}^{2}\right)$, which covers almost $56 \%$ of total test results. The distribution is positively skewed (Skewed right). The skewness is 0.8 . The excess Kurtosis is 0.22 which indicates that the distribution is Platykurtic which is flatter than a normal distribution with a wider peak. The probability for extreme values is less for a normal distribution, and the values are wider spread around the mean. Considering the random selection and the low threshold sampling (almost 25 samples), the confidence level (95.0\%) is calculated as 0.08 . 
Figure No.18 demonstrates a comparison between the extrapolated air leakage result at 25 Pascal, which is assumed to be $0.24\left(\mathrm{~L} / \mathrm{s} / \mathrm{m}^{2}\right)$, with in-situ measured air leakage performance of the 25 teste samples.

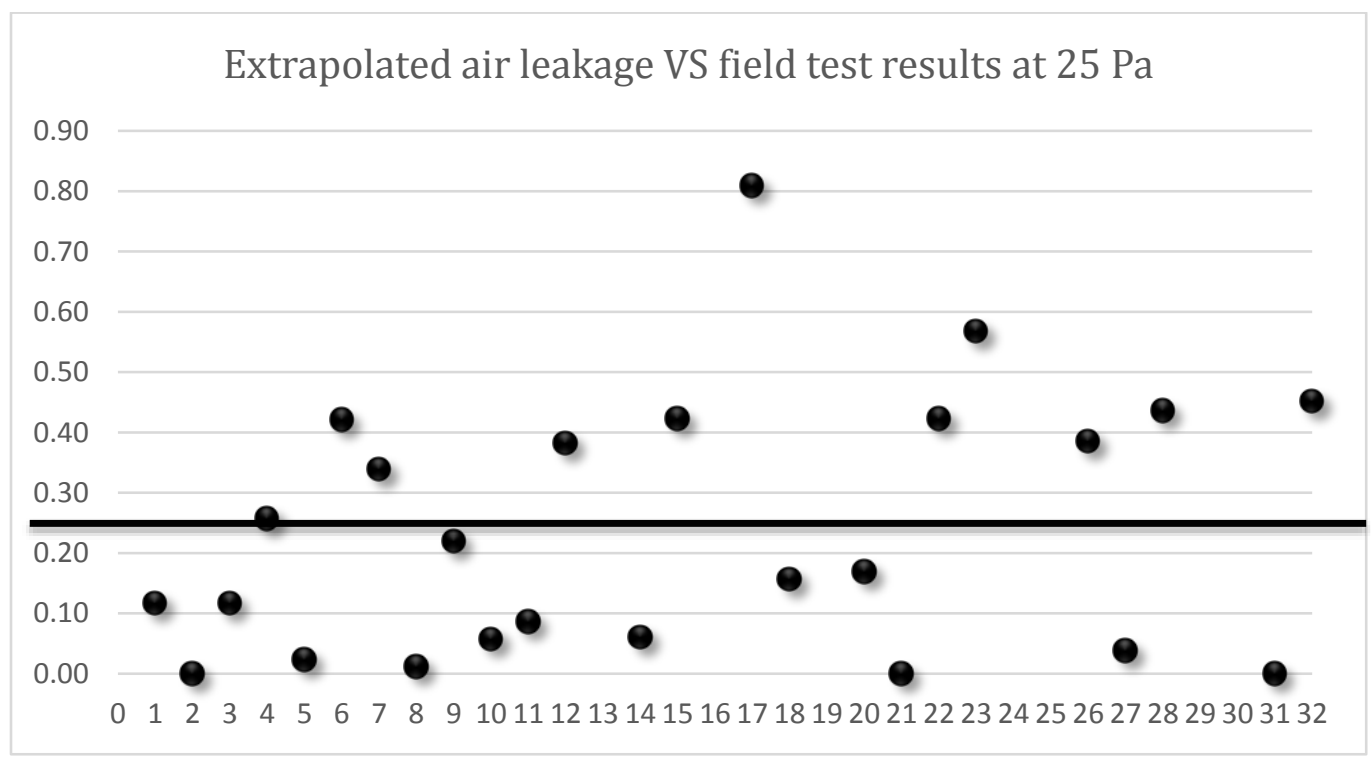

Figure 18 - Extrapolated air leakage VS field test results at $25 \mathrm{~Pa}$

Approximately $45 \%$ of air leakage field test results exceed the laboratory extrapolated result. (Refer to figure 18)

\section{Extrapolated Air Leakage at 50 Pascal Pressure Difference}

Based on the 25 test results, as demonstrated in below box plot, the median value is calculated to be $0.51\left(\mathrm{~L} / \mathrm{s} / \mathrm{m}^{2}\right)$ with an interquartile range of 0.41 to $1.07\left(\mathrm{~L} / \mathrm{s} / \mathrm{m}^{2}\right)$. The minimum and maximum air leakage test results are $0.012\left(\mathrm{~L} / \mathrm{s} / \mathrm{m}^{2}\right)$ and $1.075\left(\mathrm{~L} / \mathrm{s} / \mathrm{m}^{2}\right)$ respectively. (Refer to figure 19)

Frequency distribution of the air leakage measurements using a bin interval of $0.25\left(\mathrm{~L} / \mathrm{S} / \mathrm{m}^{2}\right)$ is demonstrated in table and figure below. Bin limits are considered starting from 0.01 $\left(\mathrm{L} / \mathrm{s} / \mathrm{m}^{2}\right)$ and ending to $1.26\left(\mathrm{~L} / \mathrm{s} / \mathrm{m}^{2}\right)$. (Refer to table 15 and figure 20) 


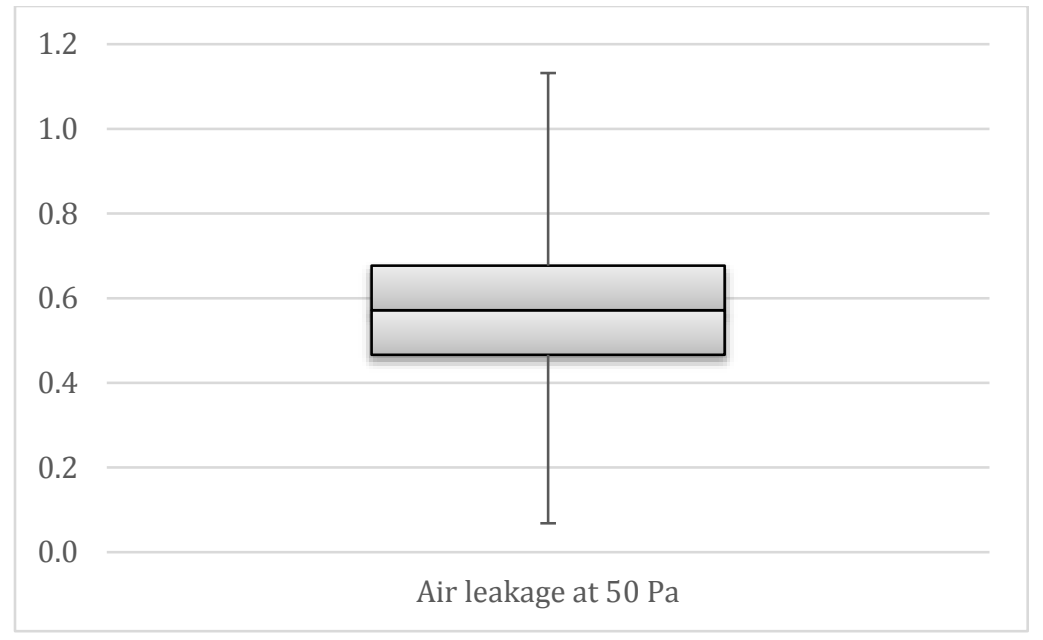

Figure 19 - Box plot of Sample Air Leakage Rate at 50 Pa

\begin{tabular}{|c|c|c|}
\hline Row Labels & Frequency & Percentage \\
\hline $\mathbf{0 . 3 3 - 0 . 5 8}$ & 7 & $18 \%$ \\
\hline $\mathbf{0 . 5 8 - 0 . 8 3}$ & 10 & $38 \%$ \\
\hline $\mathbf{0 . 8 3 - 1 . 0 8}$ & 5 & $24 \%$ \\
\hline $\mathbf{1 . 0 8 - 1 . 3 3}$ & 2 & $13 \%$ \\
\hline $\mathbf{1 . 3 3 - 1 . 5 8}$ & 1 & $7 \%$ \\
\hline Grand Total & 25 & $100 \%$ \\
\hline
\end{tabular}

Table 15 - Frequency distribution pivot table at $50 \mathrm{~Pa}$

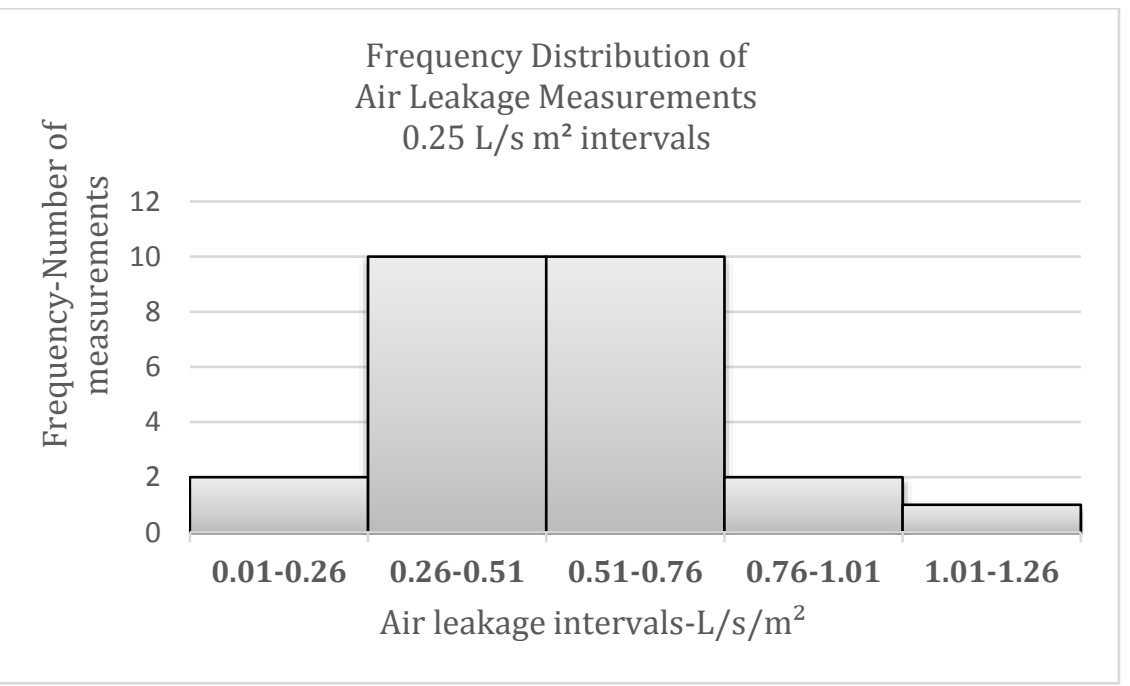

Figure 20 - Frequency Distribution of Air Leakage Measurements at $50 \mathrm{~Pa}$

The mean value is $0.54\left(\mathrm{~L} / \mathrm{s} / \mathrm{m}^{2}\right)$ and the standard deviation which measures the random errors is $0.23\left(\mathrm{~L} / \mathrm{s} / \mathrm{m}^{2}\right)$. Approximately $40 \%$ of the data lie within one standard deviation 
of the mean. Forty eight percent of data lie within two standard deviation below, and $48 \%$ of the data lie within two standard deviation above the mean value. The maximum frequency percentage is equal in the range of 0.26 to $0.51\left(\mathrm{~L} / \mathrm{s} / \mathrm{m}^{2}\right)$ and 0.51 to 0.76 $\left(\mathrm{L} / \mathrm{s} / \mathrm{m}^{2}\right)$, which covers almost $80 \%$ of the total test results.

The distribution is positively skewed (Skewed right). The skewness is calculated to be 0.4. The excess Kurtosis is 0.97 which indicates that distribution is Platykurtic which is flatter than a normal distribution with a wider peak. The probability for extreme values is less compared to normal distribution, and the values are wider spread around the mean. Considering the random selection and low threshold sampling (almost 25 samples), the confidence level (95.0\%) is calculated as 0.09 .

Figure 21, demonstrates comparison between the extrapolated air leakage result at 50 Pascal, which is expected to be $0.38\left(\mathrm{~L} / \mathrm{s} / \mathrm{m}^{2}\right)$, with the in-situ measured performance of the sliding doors.

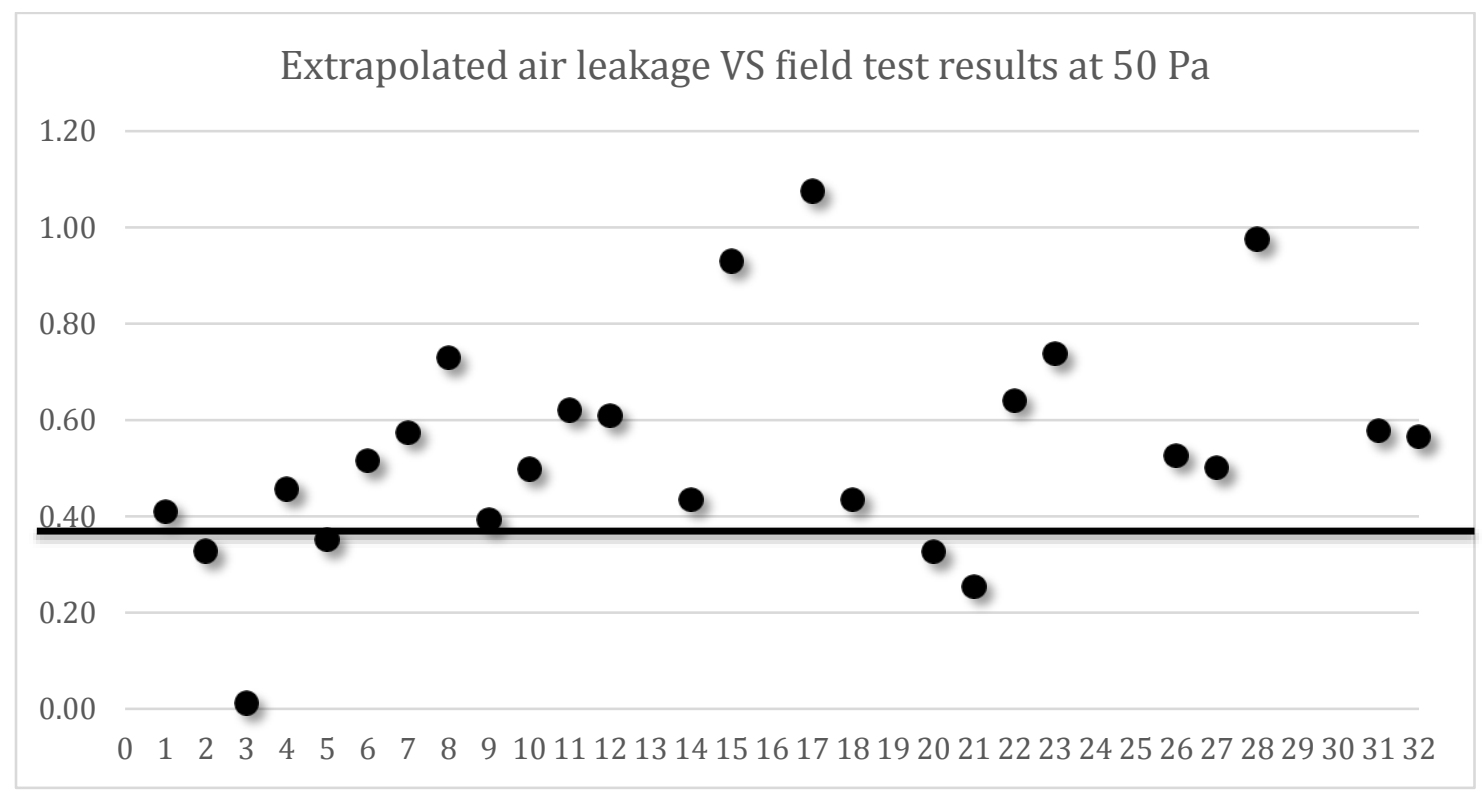

Figure 21 - Extrapolated air leakage VS field test results at $50 \mathrm{~Pa}$

The Figure shows that approximately $76 \%$ of the tests exceed the laboratory extrapolated results when tested in the field. (Refer to figure 21) 


\section{Extrapolated Air Leakage at 100 Pascal Pressure Difference}

Based on the 25 test results a box plot shows the median value is $0.76\left(\mathrm{~L} / \mathrm{s} / \mathrm{m}^{2}\right)$ with an interquartile range of 0.0 .6 to 0.9 . The minimum and maximum test results are $0.33\left(\mathrm{~L} / \mathrm{s} / \mathrm{m}^{2}\right)$ and $1.35\left(\mathrm{~L} / \mathrm{s} / \mathrm{m}^{2}\right)$ respectively. (Refer to figure 22$)$

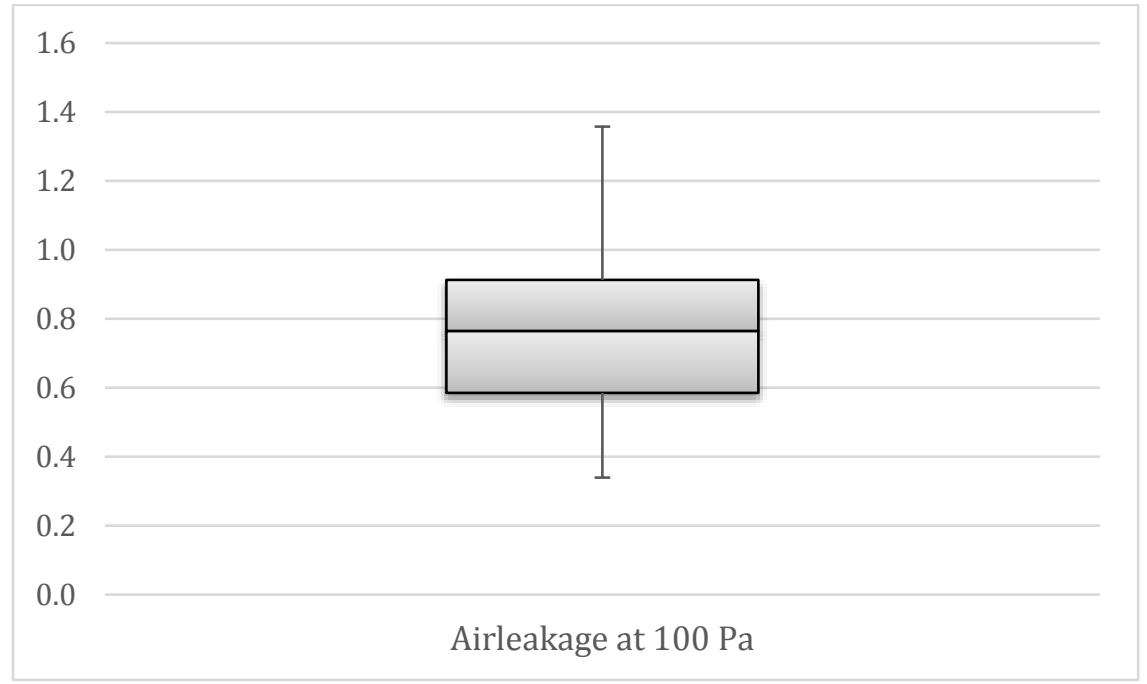

Figure 22 - Box plot of Sample Air Leakage Rate at $100 \mathrm{~Pa}$

The frequency and percentage of the occurrence in various bin limits are plotted in table 16. Bin limits are considered starting from $0.33\left(\mathrm{~L} / \mathrm{s} / \mathrm{m}^{2}\right)$ and ending to $1.58\left(\mathrm{~L} / \mathrm{s} / \mathrm{m}^{2}\right)$ with the frequency of $0.25\left(\mathrm{~L} / \mathrm{s} / \mathrm{m}^{2}\right)$. (Refer to table 16 and figure 23)

\begin{tabular}{|c|c|c|}
\hline Row Labels & Frequency & Percentage \\
\hline $\mathbf{0 . 3 3 - 0 . 5 8}$ & 7 & $18 \%$ \\
\hline $\mathbf{0 . 5 8 - 0 . 8 3}$ & 10 & $38 \%$ \\
\hline $\mathbf{0 . 8 3 - 1 . 0 8}$ & 5 & $24 \%$ \\
\hline $\mathbf{1 . 0 8 - 1 . 3 3}$ & 2 & $13 \%$ \\
\hline $\mathbf{1 . 3 3 - 1 . 5 8}$ & 1 & $7 \%$ \\
\hline Grand Total & 25 & $100 \%$ \\
\hline
\end{tabular}

Table 16 - Frequency distribution pivot table at $100 \mathrm{~Pa}$

The mean value is $0.78\left(\mathrm{~L} / \mathrm{s} / \mathrm{m}^{2}\right)$ and the standard deviation which measures the random errors is $0.26\left(\mathrm{~L} / \mathrm{s} / \mathrm{m}^{2}\right)$. Approximately $38 \%$ of the data lie within one standard deviation 
of the mean. Thirty one percent (31\%) of the data lie within two standard deviation below, and $28 \%$ of the data lie within two standard deviation above the mean value.

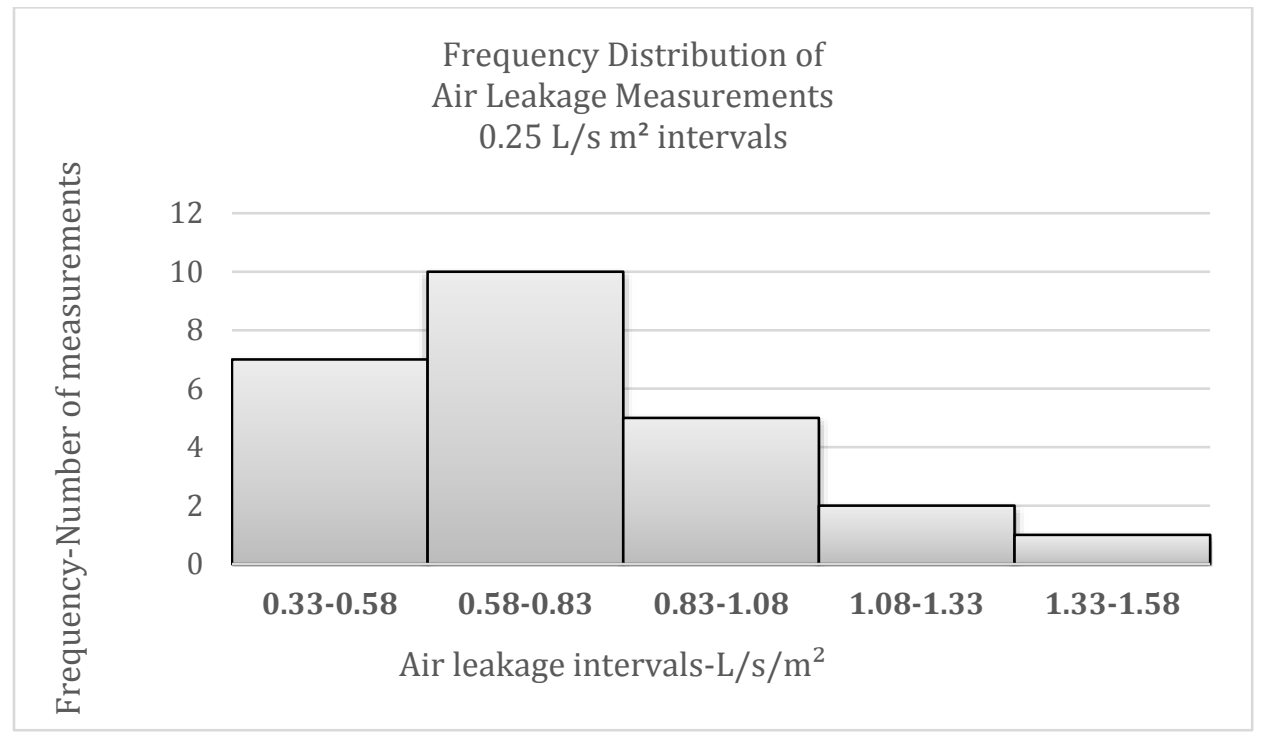

Figure 23 - Frequency Distribution of Air Leakage Measurements at $100 \mathrm{~Pa}$

The maximum frequency percentage is in the range of 0.58 to $0.83\left(\mathrm{~L} / \mathrm{s} / \mathrm{m}^{2}\right)$, which covers almost $38 \%$ of the total test results.

The distribution is negatively skewed (Skewed left). The skewness is calculated to be 0.6. The excess Kurtosis is 0.02 which indicates that the distribution is Platykurtic which is flatter than a normal distribution with a wider peak. The probability for extreme values is less than probability for normal distributions, and the values are wider spread around the mean. Considering the random selection and the low threshold sampling (almost 25 samples), the confidence level $(95.0 \%)$ is calculated as 0.1 .

Figure 24, demonstrates a comparison between the extrapolated air leakage result at 100 Pascal, which is expected to be $0.78\left(\mathrm{~L} / \mathrm{s} / \mathrm{m}^{2}\right)$, with the in-situ measured performance of the tested sliding doors. 


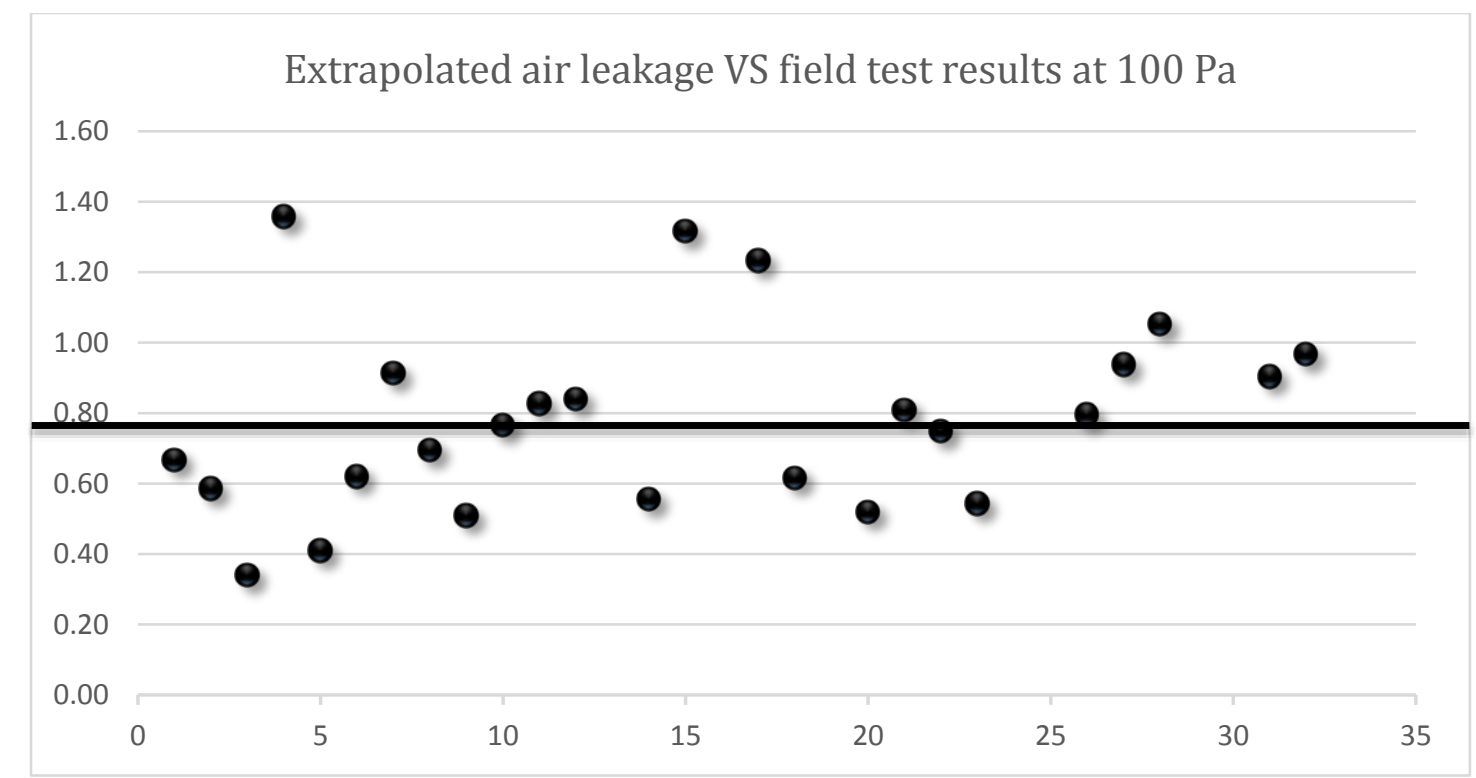

Figure 24 - Extrapolated air leakage VS field test results at $100 \mathrm{~Pa}$

The table shows that approximately $48 \%$ of the tests exceed the laboratory extrapolated results when tested in-situ field. (Refer to figure 24) 


\section{Chapter 6}

\section{Overview of the Study and Analysis}

This study, with focusing on the field air tightness performance of newly installed windows, is done by measuring field air leakage rates of newly installed sliding doors in a 70 storey high-rise building in Toronto. The height of the building offered a better sampling opportunity as the thirty-two samples were randomly selected from over three hundred installed sliding doors.

The field's temperature corrected air leakage results were compared to the laboratory performance report of the same product to evaluate the certified performance correlation with the actual produced, transported, and installed fenestration products.

Along with the statistical review of the measured performances, to evaluate the air tightness performance into some details, the influence of some of the variables on air leakage rates also has been studied.

The average test results at 25,50,75, 100 Pascal for 25 valid tests were calculated to be 0.24 , $0.54,0.65$ and $0.78\left(\mathrm{~L} / \mathrm{s} / \mathrm{m}^{2}\right)$ and $40 \%, 44 \%, 44 \%$ and $48 \%$ of the tests were exceeding the average results at each specified test pressure difference accordingly.

Among the twenty-five (25), valid field air leakage tests at standard test pressure of 75 Pascal, $80 \%$ of the results were above $0.5\left(\mathrm{~L} / \mathrm{s} / \mathrm{m}^{2}\right)$ which is the achieved laboratory test result. The extrapolated air leakage for 25, 50 and 100 Pascal pressure differences were calculated to be $0.24,0.38$ and $0.6\left(\mathrm{~L} / \mathrm{s} / \mathrm{m}^{2}\right)$ and roughly $45 \%, 76 \%$ and $48 \%$ of the test results exceeded the expected air leakage rates at each pressure difference accordingly.

A summary of the various air leakage rates at standard pressure difference of 75 Pascal, that can be used for comparison are listed in Table 10. As previously discussed the values in A440.4-07 had to be normalized to the area of the door from the crack length. In comparing the field measured air leakage rates with different benchmarks, it becomes evident that the comparison is not straight forward due to some reasons including

- Lack of clear rational for comparison benchmarks set by different standards, 
- Lack of clearly defined methods of sampling considering distribution figures

- Practical and cost considerations which often far outweigh the decisions regarding sample selection than the statistical nature of variation to be expected.

Considering previously noted test variables indicated that at 75 Pascal pressure difference in this study, test results shows no trend or relation with the test dates and different exterior air temperatures. This may not support the theory of not getting affected by exterior air temperature but It could be due to unequal number of tests on each day specifically in the colder days or random sampling. Test results at different pressure differences show no relation with their location and floor height. Some factors could affect the result such as small electrical heaters in each of the suites in lower floors or Industrial heaters in upper floor's corridors which could affect the air pressure and temperature. The average air leakage results in suites with installed and taped gypsum boards and sealed exterior and interior interfaces, was measured to be lower than the total average test results.

In thermography scan of the windows, no significant changes captured before, in during and after the monitoring. This could be due to insufficient test duration as if we want to capture frames with lower temperature resulting from air flow (air leakage) we may require to increase the flow duration. Thermography scanning helped identifying the colder spots on sliding doors, which were mainly including frame corners, between operable sashes and window track, and meeting stiles.

Smoke pencil test helped identifying primary location of the leakage in few test samples with obviously higher leakage rates. This leakage areas were mostly related to weather stripping or hardware irregularities on hand rails (Refer to the appendix test description and results). 


\section{Conclusion}

The purpose of this study was to examine the nature of differences between the air leakages determined in a laboratory condition to that measured in the field for the same products that is newly installed. The results indicated that in conducting tests based on random sampling the measured values will follow a distribution with a mean and a variance.

Sampling from newly installed windows eliminate factors such as aging and degrading. In this particular case measurements made on sliding door indicate that the air leakage test results follow a normal distribution. The mean value of the field measurements is higher than the laboratory measurements but are within the range of the AAMA 502 allowable values. However, there are values that are greater than the allowable rates

Based on this work it can be said that it is important to base the comparison of field and laboratory tested values on the recognition that these measurements will be based on some variations. The nature of such variations need to be further studied and taken into account when comparing field and laboratory values. 


\section{References}

AAMA, WDMA, CSA, (2011), AAMA/WDMA/CSA101/I.S.2/A440-11, NAFS North American Fenestration Standard/Specification for windows, doors and skylights, AAMA, WDMA, Illinois, CSA, Ontario, 2011.

AAMA, (2012), AAMA502-12, Voluntary Specification for Field Testing of Newly Installed Fenestration Products, AAMA, Illinois, 2012.

AAMA (ND-No Date), Air and Water Leakage Resistance Testing of Installed Windows and Doors, http://www.aamanet.org/upload/file/Water_Resistance_Testing_of_Windows_and_Do ors-FINAL.pdf Last accessed, June 11, 2017.

Anne, K., \& Goedken. (2007), Control air leakage, save energy. Buildings, 30.

ASTM E783-02 (2010). Standard test method for field measurement of air leakage through installed exterior windows and doors (Vol. 2, pp. 2-7). ASTM International, West Conshohocken, PA, 2010.

ASTM Standard. (2012). ASTM E283 standard test method for determining rate of air leakage through exterior windows, curtain walls, and doors under specified pressure diffrence across the specimen. In A. International, ASTM E283 standard. West Conshohocken, West Conshohocken: ASTM International. Retrieved from www.astm.org.

ASTM Standard. (2012). ASTM E783 Standard test method for determining rate of air leakage through exterior windows, curtain walls, and doors under specified pressure diffrence across the specimen. In I. ASTM, ASTM E783 Standard. West Conshohocken: ASTM International. Retrieved from International, ASTM.

Bassett, M. R. (1992). House airtightness variation. Passive and Low Energy Architecture, 19(19).

Becker, R. (2009). Air leakage of curtain walls - Diagnostics and Remediation. Journal of Building Physics, 34(1), 57-75. Haifa: Israel Institute of Technology, National Building Research Institute.

Baker, P. (2014), windows and water leakage testing - BSC Experts Session 2014, Water Leakage Testing Expert Session-Presentation, November 20, 2014, Building Science Corporation.

Bracke, W., Laverge, J., Van Den Bossche, N., \& Janssens, A. (2016). Durability and measurement uncertainty of airtightness in extremely airtight dwellings. International Journal of Ventilation, 14(4), 383-393. 
Burridge, M. (1988). Selection of windows and doors by performance. Construction and Building Materials, 2(1), 42-46.

Burridge, M. (1988). Selection of windows and doors by performance. Construction and Building Materials, 2(1), 42-46.

Canada Mortgage and Housing Corporation(CMHC). (2007). Air leakage characteristics, test method and specifications for large buildings. Canada Mortgage and Housing Corporation .

Canadian standard association (CSA). (2004). Energy performance of windows and other fenestration system/User guide to CSA A440.2-04. Canadian standard association (CSA).

CSA Group. (2017). Testing and certification. Retrieved from CSA Group: http://www.csagroup.org/

d'Ambrosio Alfano, F. R., Dell'Isola, M., Ficco, G., Palella, B. I., \& Riccio, G. (2016). Experimental air-tightness analysis in Mediterranean buildings after windows retrofit. Sustainability (Switzerland), 8(10), 1-10.

Daoud, O. E. K. (1992). Defects in aluminum windows and impact on dust and air infiltration. J.Perform.Constr.Facil, 6 (1), 12-33.

Daoud, O., Maheshwari, G., \& Al-Shami, H. (1991). Measured field performance of aluminium windows in Kuwait. Energy and Buildings, 75-83.

Delmotte, C., \& Laverge, J. (2011). Interlaboratory test for the determination of repeatability and reproducibility of buildings airtightness measurements. 32nd AIVC Conference; 1st Tight Vent Conference: Towards Optimal Airtightness Performance, (October 2011).

Domhagen, F. (2016). Yearly Variations in Airtightness of Detached Wooden Houses Simulations and Laboratory Measurements to Investigate Causes and Consequences. CHALMERS University of Technology.

Elmahdy, A. H. (2003). Quantification of air leakage effects on the condensation resistance of windows / Discussion. ASHRAE Transactions Science Database Pg., 109.

Fennell, H. C., \& Haehnel, J. (2005). Setting airtightness standards. ASHRAE Journal, 47(9), 26-31.

Gillott, M. C., Loveday, D. L., White, J., Wood, C. J., Chmutina, K., \& Vadodaria, K. (2016). Improving the airtightness in an existing UK dwelling: The challenges, the measures and their effectiveness. Building and Environment, 95. 
Gonçalves, M. D., \& Jutras, R. (2007). Evaluating the Field Performance of Windows and Curtain Walls of Large Buildings. Airtightness of Buildings, 1-14.

Gowri, K., Winiarski, D., \& Jarnagin, R. (2009). Infiltration Modeling Guidelines for Commercial Building Energy Analysis. Contract, (September), 21.

Hassouneh, K., Alshboul, A., \& Al-Salaymeh, A. (2012). Influence of infiltration on the energy losses in residential buildings in Amman. Sustainable Cities and Society (Vol. 5, pp. 27).

Hubbs, B. (2016). Onshore vs. offshore facades. RDH Building science. Toronto: RDH.

enry, R., Patenaude, A., Hakim, E., \& John, W. (1998). Measurements of window air leakage at cold temperatures and impact on annual energy performance of a house. ASHRAE Transactions, 104(Pt 1B), 1254-1260.

Ihm, P., Park, L., Krarti, M., \& Seo, D. (2012). Impact of window selection on the energy performance of residential buildings in South Korea. Energy Policy.

Jaugelis, A. (2014, 09,10). NAFS Foundation. Retrieved from RDH: http://rdh.com/nafs/nafs_in_canada_intro/

Jokisalo, J., Kurnitski, J., Korpi, M., Kalamees, T., \& Vinha, J. (2009). Building leakage, infiltration, and energy performance analyses for Finnish detached houses. Building and Environment, 44(2), 377-387.

Kalamees, T. (2007). Air tightness and air leakages of new lightweight single-family detached houses in Estonia. Building and Environment, 42(6), 2369-2377.

Kalamees, T., Korpi, M., Eskola, L., Kurnitski, J., \& Vinha, J. (2008). The distribution of the air leakage places and thermal bridges in Finnish detached houses and apartment buildings. Proceedings of the 8th Symposium on Building Physics in the Nordic Countries, 1095-1102.

Kim, A. ., \& Shaw, C. . (1986). Seasonal variation in air tightness of two detached houses. Measured Air Leakage of Buildings. ASTM STP 904, H. R. Trechsel and P. L. Lagus, Eds., American Society for Testing and Materials, 17-32.

Klems, J. H. (1983). Methods of estimating air infiltration through windows. Energy and Buildings, 5, 243-252.

Laverge, J., Delghust, M., Van Den Bossche, N., \& Janssens, A. (2014). Airtightness assessment of single family houses in Belgium. International Journal of Ventilation, 12(4), 379-389. 
Leakage, A., Manual, C., \& Buildings, E. M. R. (2007). Research report air leakage control manual existing multi-unit residential buildings. Canada Mortgage and Housing Corporation.

Mh, S., \& Journal, I. (2014). Estimates of uncertainty in multi-zone air leakage measurements Erin L . Hult and Max H. Sherman Environmental Energy Technologies Division March 2014. Airtightness of Buildings, 12(March), 359-368.

Orme, M. (2001). Estimates of the energy impact of ventilation and associated financial expenditures. Energy and Buildings, 33(3), 199-205.

Probst, 0. (2004). Cooling load of buildings and code compliance. Applied Energy, 77(2), 171186.

Proskiw, G. (1992). Variations in Airtightness of Houses Constructed with Polyethylene and. Thermal Insulation and Building Envelopes, 20(April 1997), 278-296.

Proskiw, G., \& Phillips, B. (2008). an Examination of Air Pressure and Air Movement Patterns. In Building Enclosure Science and Technology (BEST) (pp. 1-25).

Ramos, N. M. M., Almeida, R. M. S. F., Curado, A., Pereira, P. F., Manuel, S., \& Maia, J. (2015). Airtightness and ventilation in a mild climate country rehabilitated social housing buildings - What users want and what they get. Building and Environment, 92.

RDH Building Engineering Ltd. (2013). Air Leakage Control in Multi-Unit Residential Buildings.

Ricketts, L. (2016). Impact of Large Building Airtightness Requirements.

Ridley, I., Fox, J., Oreszczyn, T., \& Hong, S. (2003). The Impact of Replacement Windows on Air Infiltration and Indoor Air Quality in Dwellings. Int. J. Vent., 1(3), 209-218.

Sandberg, P. I., \& Sikander, E. (2005). Airtightness issues in the building process. The 7th Symposium on Building Physics in the Nordic Countries.

Sherman, M. (2008). Infiltration in ASHRAE' s Residential Ventilation Standards, 115(October).

Sherman, M. H. (1980). Air infiltration in buildings. University of California.

Shrestha Som, André, D., Diana Hun, Ng, L., Steven Emmerich, \& Dalgleish, L. (2016). Online Airtightness Savings Calculator for Commercial Buildings in the US, Canada and China Diana Hun , PhD. OAK RIDGE National Laboratory.

Spinu, M., Ap, L., \& Erickson, B. (2011). Designing the New World Symphony Impact of Air Leakage on the Building Envelope Myths and facts about airtightness. The Construction Specifier. 
T.F.Provan, J.D.Younger, Provan, T. F., \& Younger, J. D. (1986). Air Infiltration Characteristics of Windows. Energy and Buildings, 9, 281-292.

Tamura, G. T., \& Wilson, A. G. (1963). Air leakage and pressure measurements on two occupied houses. Of the ASHRAE Journal, 5(12), 65-73.

Touchie, M. F., Binkley, C., \& Pressnail, K. D. (2013). Correlating energy consumption with multi-unit residential building characteristics in the city of Toronto. Energy and Buildings, 66.

Trudeu, T. (2016, August). Quality Offshore. Glass Canada, pp. 14-17.

Urquhart, R., Richman, R., \& Finch, G. (2015). The effect of an enclosure retrofit on air leakage rates for a multi-unit residential case-study building. Energy and Buildings, 86, $35-44$.

Waite, M. B., \& O’Brien, S. M. (2010). Air leakage: Difficulties in measurement, quantification, and energy simulation.

Weidt, J., \& Weidt, J. (1979). Airleakage in newly installed residential windows. US Department of Energy and Lawrence Berkeley National Laboratory.

Weidt John, Weidt Jenny, \& Stephen, S. (1979). Field air leakage of newly installed residential window. US Department of Energy and Lawrence Berkeley National Laboratory.

Wilson, A. G., \& Sasaki, J. R. (1972). Evaluation of window airtightness performance. National Reaserch Council of Canada: Performance Concept in Building, 1, 2-5.

Windows, T. E., Walls, C., Installed, T., \& Windows, E. (2000). Standard Test Method for Determining the Rate of Air Leakage Through Exterior Windows, Curtain Walls , and Doors Under Specified Pressure and Temperature Differences Across the, 4(Reapproved), 1-7.

Woods, T. (1995). Air leakage retrofits for Highrises, 19(October), 161-172.

Younes, C., Shdid, C. a., \& Bitsuamlak, G. (2012). Air infiltration through building envelopes: A review. Journal of Building Physics, 35, 267-302. 
Appendixes 


\section{Appendix A \\ Laboratory Sample Description}




\section{Laboratory Sample Description}

The sample description information is taken from the manufacturer laboratory test report. The laboratory test report shows no modification required on the sliding door. As reported by the Architectural testing laboratory, the sliding door has achieved an air tightness rating of $0.5 \mathrm{l} / \mathrm{s} / \mathrm{m}^{2}\left(0.1 \mathrm{cfm} / \mathrm{ft}^{2}\right)$, as per ASTM E283 test standard.

Operation type: Thermally broken aluminum exterior sliding door

Frame: $149 \mathrm{~mm}$ wide

FG1 Sealed Unit: Double glazed sealed units, $35 \mathrm{~mm}$ thick with STC rating of 33 .

$6 \mathrm{~mm}$ clear ESR42, annealed

$23 \mathrm{~mm}$ Black warm edge spacer with argon gas

$6 \mathrm{~mm}$ clear annealed

Frame Finish:

Exterior: DURANAR SUNSTORM XL, cosmetic gray mica with clear top coat

Interior: DURACRON gloss white

Hardware:

Pull handle on each side

Single point hook lock

Interior side lock lever

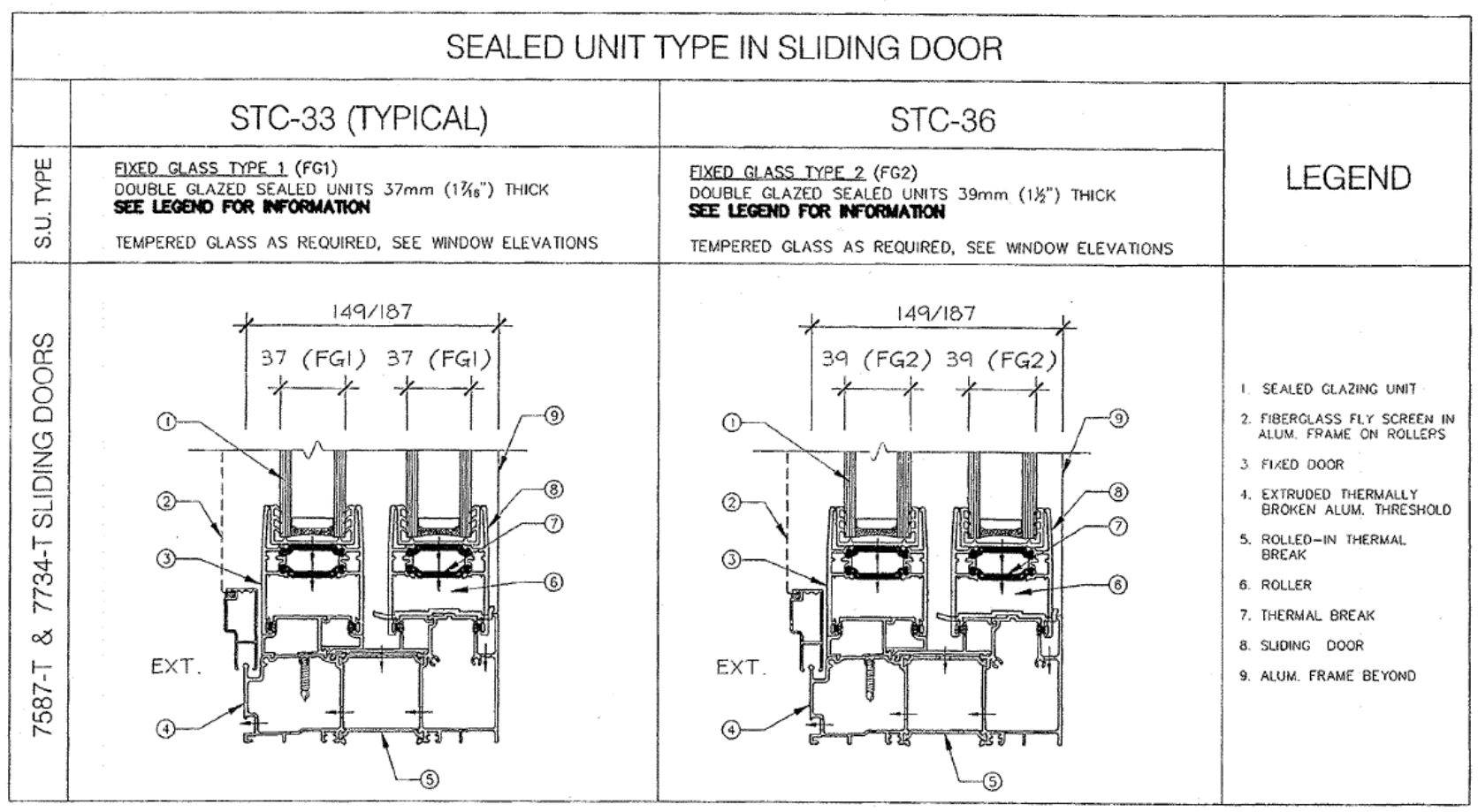

Figure 1: Sealed unit types and details 


\section{Performance Requirements:}

Met requirements set out by O.B.C 2012

\begin{tabular}{|l|l|l|l|l|l|l|}
\hline & $\begin{array}{l}\text { Air } \\
\text { tightness }\end{array}$ & $\begin{array}{l}\text { Water } \\
\text { tightness }\end{array}$ & \multicolumn{2}{|l|}{ Wind Load } & \multicolumn{2}{|l|}{$\begin{array}{l}\text { Thermal } \\
\text { performance }\end{array}$} \\
\hline & $\begin{array}{l}\text { Product } \\
\left(\mathbf{l} / \mathbf{m}^{\mathbf{2}}\right)\end{array}$ & $\begin{array}{l}\text { (Pa) 0BC } \\
\mathbf{1 2}\end{array}$ & Deflection & Overload & $\begin{array}{l}\text { U- } \\
\text { Value }\end{array}$ & SHGC \\
\hline $\begin{array}{l}\text { Sliding } \\
\text { Door }\end{array}$ & $\begin{array}{l}0.5 \text { @ } 75 \\
\mathrm{~Pa}\end{array}$ & 412 & 2.24 & 3.13 & 0.40 & 0.28 \\
\hline
\end{tabular}

*As per NAFS-11 window standard, Canadian rating table 6.4

\section{Product Size:}

\begin{tabular}{|l|l|l|}
\hline Size & Height (millimeter) & Width(millimeter) \\
\hline Overall Door frame size & 2260 & 1830 \\
\hline Operable panel & 890 & 1716 \\
Fixed Panel & 890 & 1716 \\
\hline
\end{tabular}

\section{Frame Construction:}

\begin{tabular}{|c|c|c|}
\hline Frame member & Materia/Joint cut & Description/Detail \\
\hline Head, sill, and jambs & Aluminum & $\begin{array}{l}\text { Thermally broken, dual-strutted, extruded } \\
\text { aluminum with } 49 \mathrm{~mm} \text { wide polyamide thermal } \\
\text { break ( } 43 \mathrm{~mm} \text { separation). } \\
\text { Head, jambs, and sill utilized a Snap-On PVC cover. }\end{array}$ \\
\hline All corners & $\begin{array}{l}\text { Square-cut and } \\
\text { butted aluminum }\end{array}$ & $\begin{array}{l}\text { Sealed with butyl tape and secured with four \# } \\
8 \times 1 \text { " long pan head screws per corner. }\end{array}$ \\
\hline
\end{tabular}

\section{Panel Construction:}

\begin{tabular}{|c|c|c|}
\hline Panel member & Material/Joint type & Description/Detail \\
\hline Rails and stiles & Aluminum & $\begin{array}{l}\text { Thermally improved dual-strutted, extruded } \\
\text { aluminum with } 49 \mathrm{~mm} \text { wide polyamide thermal break } \\
\text { ( } 43 \mathrm{~mm} \text { separation). }\end{array}$ \\
\hline All corners & Mitered & $\begin{array}{l}\text { Sealed with sealant and secured with two aluminum } \\
\text { corners and one plastic corner bracket. The plastic } \\
\text { corner bracket was secured to each panel member } \\
\text { with three \#8x1 long pan head screws on each side } \\
\text { and a } 1 / 4 " x 3 / 4 " \text { long Allen head screw secured } \\
\text { diagonally through the corner bracket. The corner keys } \\
\text { were also secured to the members with epoxy glue. }\end{array}$ \\
\hline
\end{tabular}




\section{Weather Stripping:}

\begin{tabular}{|l|l|l|}
\hline Description & Quantity & Location \\
\hline $\begin{array}{l}\text { 0.270" backed by 0.260" high polypile } \\
\text { 0.270" backed by 0.260" high polypile }\end{array}$ & 2 Raws & $\begin{array}{l}\text { All fixed and operable panel rails and } \\
\text { operable panel lock stile }\end{array}$ \\
\hline $\begin{array}{l}\text { Composite dust plugs (Plastic holder, } \\
\text { foam pad and finned pile) }\end{array}$ & 4 & $\begin{array}{l}\text { Fixed and operable interlocks } \\
\text { Two per end of interlock stile each } \\
\text { aligned with stile center fine pile }\end{array}$ \\
\hline
\end{tabular}

Glazing:

\begin{tabular}{|l|l|l|l|l|}
\hline Glass type & Spacer type & Interior Lite & Exterior Lite & Glazing method \\
\hline $\mathbf{1 "} 1 G$ & Aluminum box & $1 / 4 "$ tempered & $1 / 4 "$ tempered & $\begin{array}{l}\text { Channel glazed with a } \\
\text { wraparound PVC gasket and } \\
\text { sealed with a silicone cap } \\
\text { bead }\end{array}$ \\
\hline
\end{tabular}

\begin{tabular}{|l|l|l|l|}
\hline Location & Quantity & Daylight Opening & Glass Bite \\
\cline { 3 - 4 } & & Millimeters & Inches \\
\hline Operable panel & 1 & $725 \times 1600$ & $5 / 8 "$ \\
\hline Fixed panel & 1 & $725 \times 1600$ & $5 / 8 "$ \\
\hline
\end{tabular}

\section{Air leakage Test results}

\begin{tabular}{|c|c|c|}
\hline Title of the test & Results & Allowed \\
\hline $\begin{array}{l}\text { Air leakage } \\
\text { Infiltration per ASTM E283 at } 75 \mathrm{~Pa} \text { ( } 1.57 \text { psf) }\end{array}$ & $\begin{array}{l}0.5 \mathrm{l} / \mathrm{s} / \mathrm{m}^{2}(0.1 \\
\left.\mathrm{cfm} / \mathrm{ft}^{2}\right)\end{array}$ & $\begin{array}{l}1.5 \mathrm{l} / \mathrm{s} / \\
\mathrm{m}^{2}(0.3 \\
\left.\mathrm{cfm} / \mathrm{ft}^{2}\right)\end{array}$ \\
\hline $\begin{array}{l}\text { Air leakage } \\
\text { Exfiltration per ASTM E283 at } 75 \text { Pa (1.57 psf) }\end{array}$ & $\begin{array}{l}0.5 \mathrm{l} / \mathrm{s} / \mathrm{m}^{2}(0.1 \\
\left.\mathrm{cfm} / \mathrm{ft}^{2}\right)\end{array}$ & $\begin{array}{l}1.5 \mathrm{l} / \mathrm{s} / \\
\mathrm{m}^{2}(0.3 \\
\left.\mathrm{cfm} / \mathrm{ft}^{2}\right)\end{array}$ \\
\hline Canadian Air infiltration/exfiltration level & A3 & $\begin{array}{l}0.5 \mathrm{l} / \mathrm{s} / \mathrm{m}^{2} \\
(0.1 \\
\left.\mathrm{cfm} / \mathrm{ft}^{2}\right)\end{array}$ \\
\hline
\end{tabular}

Tables 1,2,3,4,5,6 and 7: Test sample description (Reference: Laboratory test report and window shop drawing) 
Appendix B

Population Identification Tables 
Population Identification Tables

\begin{tabular}{|c|c|c|c|c|c|c|c|c|c|c|c|}
\hline L+A5:L61evel & WLevel-3b & WLevel-1b & WLevel-1a & WLevel-4a & WLevel-3a & WLevel-5c & WLevel-5b & WLevel-2 & WLevel-5a & WLevel-4b & W8-4b \\
\hline 6 & W6-3b & W6-1b & W6-1a & W6-4a & W6-3a & W6-5c & W6-5b & W6-2 & W6-5a & W6-4b & \\
\hline 7 & $W 7-3 b$ & W7-1b & W7-1a & W7-4a & W7-3a & $W 7-5 c$ & $W 7-5 b$ & W7-2 & W7-5a & $w 7-4 b$ & W8-4b \\
\hline 8 & W7-3b & W7-1b & W7-1a & W7-4a & W7-3a & W7-5c & W7-5b & W7-2 & W7-5a & $W 7-4 b$ & W8-4b \\
\hline 9 & W7-3b & W7-1b & W7-1a & W7-4a & W7-3a & W7-5c & W7-5b & W7-2 & W7-5a & W7-4b & $W 8-4 b$ \\
\hline 10 & W10-3b & W10-1b & W10-1a & W10-4a & W10-3a & W10-5c & W10-5b & \begin{tabular}{|l|}
$\mathrm{W} 10-2$ \\
\end{tabular} & W10-5a & W10-4b & \\
\hline 11 & W11-3b & W11-1b & W11-1a & W11-4a & W11-3a & W11-5c & W11-5b & W11-2 & W11-5a & W11-4b & \\
\hline 12 & W12-3b & W12-1b & W12-1a & W12-4a & W12-3a & W12-5c & W12-5b & W12-2 & W12-5a & W12-4b & \\
\hline 13 & W12-3b & W12-1b & W12-1a & W12-4a & W12-3a & W12-5c & W12-5b & W12-2 & W12-5a & W12-4b & \\
\hline 14 & W7-3b & W7-1b & W7-1a & W7-4a & W7-3a & W7-5c & W7-5b & $W 7-2$ & W7-5a & W7-4b & W8-4b \\
\hline 15 & W10-3b & W10-1b & W10-1a & W10-4a & W10-3a & W10-5c & W10-5b & W10-2 & W10-5a & W10-4b & \\
\hline 16 & W7-3b & W7-1b & W7-1a & W7-4a & W7-3a & W7-5c & W7-5b & W7-2 & W7-5a & W7-4b & W8-4b \\
\hline 17 & W11-3b & W11-1b & W11-1a & W11-4a & W11-3a & W11-5c & W11-5b & W11-2 & W11-5a & W11-4b & \\
\hline 18 & W11-3b & W11-1b & W11-1a & W11-4a & W11-3a & W11-5c & W11-5b & W11-2 & W11-5a & W11-4b & \\
\hline 19 & W7-3b & W7-1b & W7-1a & W7-4a & W7-3a & W7-5c & W7-5b & W7-2 & W7-5a & W7-4b & W8-4b \\
\hline 20 & W7-3b & W7-1b & W7-1a & W7-4a & W7-3a & $W 7-5 c$ & $W 7-5 b$ & W7-2 & W7-5a & $w 7-4 b$ & W8-4b \\
\hline 21 & W21-3b & W21-1b & W21-1a & W21-4a & W21-3a & W21-5c & W21-5b & W21-2 & W21-5a & W21-4b & \\
\hline 22 & W22-3b & W22-1b & W22-1a & W22-4a & W22-3a & W22-5c & W22-5b & W22-2 & W22-5a & $W 22-4 b$ & \\
\hline 23 & W23-3b & W23-1b & W23-1a & W23-4a & W23-3a & W23-5c & W23-5b & W23-2 & W23-5a & W23-4b & \\
\hline 24 & W24-3b & W24-1b & W24-1a & W24-4a & W24-3a & W24-5c & W24-5b & W24-2 & W24-5a & W24-4b & \\
\hline 25 & W25-3b & W25-1b & W25-1a & W25-4a & W25-3a & W25-5c & $\mathrm{W} 25-5 \mathrm{~b}$ & W25-2 & W25-5a & W25-4b & \\
\hline 26 & W21-3b & W21-1b & W21-1a & W21-4a & W21-3a & W21-5c & W21-5b & W21-2 & W21-5a & W21-4b & \\
\hline 27 & \begin{tabular}{|l|} 
\\
\end{tabular} & W27-1b & W27-1a & W27-4a & W27-3a & W27-5c & W27-5b & W27-2 & W27-5a & W27-4b & \\
\hline 28 & W21-3b & W21-1b & W21-1a & W21-4a & W21-3a & W21-5c & W21-5b & W21-2 & W21-5a & W21-4b & \\
\hline 29 & W22-3b & W22-1b & W22-1a & W22-4a & W22-3a & W22-5c & W22-5b & W22-2 & W22-5a & W22-4b & \\
\hline \multicolumn{12}{|l|}{30} \\
\hline 31 & $W 27-3 b$ & W27-1b & W27-1a & $w 27-4 a$ & W27-3a & W27-5c & W27-5b & W27-2 & W27-5a & $W 27-4 b$ & \\
\hline 32 & $\mathrm{~W} 27-3 \mathrm{~b}$ & W27-1b & W27-1a & W27-4a & W27-3a & $W 27-5 c$ & W27-5b & W27-2 & W27-5a & $W 27-4 b$ & \\
\hline 33 & W23-3b & W23-1b & W23-1a & W23-4a & W23-3a & W23-5c & W23-5b & W23-2 & W23-5a & W23-4b & \\
\hline 34 & W23-3b & W23-1b & W23-1a & W23-4a & W23-3a & W23-5c & W23-5b & W23-2 & W23-5a & W23-4b & \\
\hline 35 & W27-3b & W27-1b & W27-1a & W27-4a & W27-3a & $W 27-5 c$ & W27-5b & W27-2 & W27-5a & $W 27-4 b$ & \\
\hline 36 & W22-3b & W22-1b & W22-1a & W22-4a & W22-3a & W22-5c & W22-5b & W22-2 & W22-5a & W22-4b & \\
\hline 37 & W21-3b & W21-1b & W21-1a & W21-4a & W21-3a & W21-5c & W21-5b & w21-2 & W21-5a & W21-4b & \\
\hline 38 & W21-3b & W21-1b & W21-1a & W21-4a & W21-3a & W21-5c & W21-5b & W21-2 & W21-5a & W21-4b & \\
\hline 39 & $W 22-3 b$ & $\mathrm{~W} 22-1 \mathrm{~b}$ & W22-1a & W22-4a & W22-3a & W22-5c & $\mathrm{W} 22-5 \mathrm{~b}$ & W22-2 & W22-5a & $W 22-4 b$ & \\
\hline 40 & W22-3b & W22-1b & W22-1a & W22-4a & W22-3a & W22-5c & $W 22-5 b$ & W22-2 & W22-5a & W22-4b & \\
\hline
\end{tabular}

Table 1- Different Fenestration Types and their distributions (Part A) 


\begin{tabular}{|c|c|c|c|c|c|c|c|c|c|c|c|}
\hline 41 & W41-3b & W41-1b & W41-1a & W41-4a & W41-3a & W41-5c & W41-5b & W41-2 & W41-5a & W41-4b & \\
\hline 42 & W42-3b & W42-1b & W42-1a & W42-4a & W42-3a & W42-5c & W42-5b & W42-2 & W42-5a & W42-4b & \\
\hline 43 & W43-3b & W43-1b & W43-1a & W43-4a & W43-3a & W43-5c & W43-5b & W43-2 & W43-5a & W43-4b & \\
\hline 44 & W44-3b & W44-1b & W44-1a & W44-4a & W44-3a & W44-5c & W44-5b & W44-2 & W44-5a & W44-4b & \\
\hline 45 & W45-3b & W45-1b & W45-1a & W45-4a & W45-3a & W45-5c & W45-5b & $W 45-2$ & W45-5a & W45-4b & \\
\hline 46 & W46-3b & W46-1b & W46-1a & W46-4a & W46-3a & W46-5c & W46-5b & W46-2 & W46-5a & W46-4b & \\
\hline 47 & W47-3b & W47-1b & W47-1a & W47-4a & W47-3a & W47-5c & W47-5b & W47-2 & W47-5a & W47-4b & \\
\hline 48 & W48-3b & W48-1b & W48-1a & W48-4a & W48-3a & W48-5c & W48-5b & W48-2 & W48-5a & W48-4b & \\
\hline 49 & W48-3b & W48-1b & W48-1a & W48-4a & W48-3a & W48-5c & W48-5b & W48-2 & W48-5a & W48-4b & \\
\hline 50 & W47-3b & W47-1b & W47-1a & W47-4a & W47-3a & W47-5c & W47-5b & W47-2 & W47-5a & W47-4b & \\
\hline 51 & & & & & & & & & & & \\
\hline 52 & W47-3b & W47-1b & W47-1a & W47-4a & W47-3a & W47-5c & W47-5b & W47-2 & W47-5a & W47-4b & \\
\hline 53 & W48-3b & W48-1b & W48-1a & W48-4a & W48-3a & W48-5c & W48-5b & W48-2 & W48-5a & W48-4b & \\
\hline 54 & W48-3b & W48-1b & W48-1a & W48-4a & W48-3a & W48-5c & W48-5b & W48-2 & W48-5a & W48-4b & \\
\hline 55 & W55-3b & W55-1b & W55-1a & W55-4a & W55-3a & W55-5c & W55-5b & W55-2 & W55-5a & W55-4b & \\
\hline 56 & W56-3b & W56-1b & W56-1a & W56-4a & W56-3a & W56-5c & W56-5b & W56-2 & W56-5a & W56-4b & \\
\hline 57 & W57-3b & W57-1b & W57-1a & W57-4a & W57-3a & W57-5c & W57-5b & W57-2 & W57-5a & W57-4b & \\
\hline 58 & W58-3b & W58-1b & W58-1a & W58-4a & W58-3a & W58-5c & W58-5b & W58-2 & W58-5a & W58-4b & \\
\hline 59 & & & & & & & & & & & \\
\hline 60 & W58-3b & W58-1b & W58-1a & W58-4a & W58-3a & W58-5c & W58-5b & W58-2 & W58-5a & W58-4b & \\
\hline 61 & W61-3b & W61-1b & W61-1a & W61-4a & W61-3a & W61-5c & W61-5b & W61-2 & W61-5a & W61-4b & \\
\hline 62 & W61-3b & W61-1b & W61-1a & W61-4a & W61-3a & W61-5c & w61-5b & W61-2 & W61-5a & W61-4b & \\
\hline 63 & W58-3b & W58-1b & W58-1a & W58-4a & W58-3a & W58-5c & W58-5b & W58-2 & W58-5a & W58-4b & \\
\hline 64 & W57-3b & W57-1b & W57-1a & W57-4a & W57-3a & W57-5c & W57-5b & W57-2 & W57-5a & W57-4b & \\
\hline 65 & W58-3b & W58-1b & W58-1a & W58-4a & W58-3a & W58-5c & W58-5b & W58-2 & W58-5a & W58-4b & \\
\hline 66 & W66-3b & W66-1b & W66-1a & W66-4a & W66-3a & W66-5c & W66-5b & W66-2 & W66-5a & W66-4b & \\
\hline 67 & W67-3b & W67-1b & W67-1a & W67-4a & W67-3a & W67-5c & W67-5b & W67-2 & W67-5a & W67-4b & \\
\hline 68 & W68-3b & W68-1b & W68-1a & W68-4a & W68-3a & W68-5c & W68-5b & W68-2 & W68-5a & W68-4b & \\
\hline 69 & W69-3b & W69-1b & W69-1a & w69-4a & W69-3a & W69-5c & W69-5b & W69-2 & W69-5a & W69-4b & \\
\hline 70 & & & & & & & & & & & \\
\hline 71 & W70-3b & W70-1b & W70-1a & W70-4a & W70-3a & W70-5c & W70-5b & W70-2 & W70-5a & W70-4b & \\
\hline
\end{tabular}

Table 1- Different Fenestration Types and their distributions (Part B) 


\begin{tabular}{|c|c|c|c|c|c|c|c|c|c|c|c|}
\hline Level & WLevel-3b & WLevel-1b & WLevel-1a & WLevel-4a & WLevel-3a & WLevel-5c & WLevel-5b & WLevel-2 & WLevel-5a & WLevel-4b & W8-4a \\
\hline 6 & W6-3b & W6-1b & w6-1a & W6-4a (1 DTG1) & w6-3a & w6-5c & W6-5b & W6-2 & W6-5a & W6-4b (2 DTG1) & \\
\hline 7 & $\omega 7-3 b$ & $W 7-1 \mathrm{~b}$ & W7-1a & W7-4a (2 DTG1) & W7-3a & $W 7-5 c$ & $W 7-5 b$ & W7-2 & W7-5a & W7-4b (2 DTG1) & W8-4a (2 DTG1) \\
\hline 8 & $w 7-3 b$ & W7-1b & W7-1a & W7-4a (2 DTG1) & W7-3a & $W 7-5 c$ & W7-5b & $W 7-2$ & W7-5a & W7-4b (2 DTG1) & W8-4a (2 DTG1) \\
\hline 9 & $\omega 7-3 b$ & $\omega 7-1 \mathrm{~b}$ & W7-1a & W7-4a (2 DTG1) & W7-3a & $W 7-5 c$ & $W 7-5 b$ & $W 7-2$ & W7-5a & W7-4b (2 DTG1) & W8-4a (2 DTG1) \\
\hline 10 & W10-3b & W10-1b & W10-1a & W10-4a (2 DTG1) & W10-3a & W10-5c & W10-5b & W10-2 & W10-5a & W10-4b (2 DTG1) & \\
\hline 11 & W11-3b & W11-1b & W11-1a & W11-4a & W11-3a & W11-5c & W11-5b (1 DTG1) & W11-2 & W11-5a (1 DTG1) & W11-4b & \\
\hline 12 & W12-3b & W12-1b & W12-1a & W12-4a (2 DTG1) & W12-3a & W12-5c & W12-5b & W12-2 & W12-5a & W12-4b (2 DTG1) & \\
\hline 13 & W12-3b & W12-1b & W12-1a & W12-4a (2 DTG1) & W12-3a & W12-5c & W12-5b & W12-2 & W12-5a & W12-4b (2 DTG1) & \\
\hline 14 & W7-3b & W7-1b & W7-1a & W7-4a (2 DTG1) & W7-3a & W7-5c & W7-5b & $W 7-2$ & W7-5a & W7-4b (2 DTG1) & W8-4a (2 DTG1) \\
\hline 15 & W10-3b & W10-1b & W10-1a & W10-4a (2 DTG1) & W10-3a & W10-5c & W10-5b & W10-2 & W10-5a & W10-4b (2 DTG1) & \\
\hline 16 & W7-3b & W7-1b & W7-1a & W7-4a (2 DTG1) & W7-3a & W7-5c & W7-5b & $W 7-2$ & W7-5a & W7-4b (2 DTG1) & W8-4a (2 DTG1) \\
\hline 17 & W11-3b (1 DTG1) & W11-1b & W11-1a & W11-4a & W11-3a & W11-5c & W11-5b & W11-2 & W11-5a & W11-4b & \\
\hline 18 & W11-3b & W11-1b & W11-1a & W11-4a & W11-3a & W11-5c & W11-5b & W11-2 & W11-5a & W11-4b & \\
\hline 19 & W7-3b & W7-1b & W7-1a & W7-4a (2 DTG1) & W7-3a & W7-5c & W7-5b & W7-2 & W7-5a & W7-4b (2 DTG1) & W8-4a (2 DTG1) \\
\hline 20 & $W 7-3 b$ & $W 7-1 b$ & W7-1a & W7-4a (2 DTG1) & W7-3a & $\omega 7-5 c$ & W7-5b & W7-2 & w7-5a & W7-4b (2 DTG1) & W8-4a (2 DTG1) \\
\hline 21 & W21-3b & W21-1b & W21-1a & W21-4a (2 DTG1) & W21-3a (2 DTG1) & W21-5c & W21-5b (2 DTG1) & W21-2 & W21-5a & W21-4b (2 DTG1) & \\
\hline 22 & W22-3b (1 DTG1) & W22-1b & W22-1a & W22-4a (1 DTG1) & W22-3a (2 DTG2) & W22-5c & W22-5b (2 DTG1) & W22-2 & W22-5a & W22-4b (2 DTG1) & \\
\hline 23 & W23-3b (1 DTG2) & W23-1b & W23-1a & W23-4a (1 DTG2) & W23-3a (2 DTG2) & W23-5c & W23-5b (2 DTG2) & W23-2 & W23-5a & W23-4b (2 DTG2) & \\
\hline 24 & W24-3b & W24-1b & W24-1a & W24-4a (2 DTG1) & W24-3a (2 DTG1) & W24-5c & W24-5b (2 DTG1) & W24-2 & W24-5a & W24-4b (2 DTG2) & \\
\hline 25 & W25-3b & W25-1b & W25-1a & W25-4a (2 DTG1) & W25-3a (2 DTG1) & W25-5c & W25-5b (2 DTG1) & W25-2 & W25-5a & W25-4b (2 DTG1) & \\
\hline 26 & W21-3b & W21-1b & W21-1a & W21-4a (2 DTG1) & W21-3a (2 DTG1) & W21-5c & W21-5b (2 DTG1) & W21-2 & W21-5a & W21-4b (2 DTG1) & \\
\hline 27 & W27-3b (1 DTG1) & W27-1b & W27-1a & W27-4a (2 DTG1) & W27-3a (2 DTG1) & W27-5c & W27-5b (2 DTG1) & W27-2 & W27-5a & W27-4b (2 DTG1) & \\
\hline 28 & W21-3b & W21-1b & W21-1a & W21-4a (2 DTG1) & W21-3a (2 DTG1) & W21-5c & W21-5b (2 DTG1) & W21-2 & W21-5a & W21-4b (2 DTG1) & \\
\hline 29 & W22-3b (1 DTG1) & W22-1b & W22-1a & W22-4a (1 DTG1) & W22-3a (2 DTG2) & W22-5c & W22-5b (2 DTG1) & W22-2 & W22-5a & W22-4b (2 DTG1) & \\
\hline 30 & & & & & & & & & & & \\
\hline 31 & W27-3b (1 DTG1) & W27-1b & W27-1a & W27-4a (2 DTG1) & W27-3a (2 DTG1) & W27-5c & W27-5b (2 DTG1) & W27-2 & W27-5a & W27-4b (2 DTG1) & \\
\hline 32 & W27-3b (1 DTG1) & W27-1b & W27-1a & W27-4a (2 DTG1) & W27-3a (2 DTG1) & W27-5c & W27-5b (2 DTG1) & W27-2 & W27-5a & W27-4b (2 DTG1) & \\
\hline 33 & W23-3b (1 DTG2) & W23-1b & W23-1a & W23-4a (1 DTG2) & W23-3a (2 DTG2) & W23-5c & W23-5b (2 DTG2) & W23-2 & W23-5a & W23-4b (2 DTG2) & \\
\hline 34 & W23-3b (1 DTG2) & W23-1b & W23-1a & W23-4a (1 DTG2) & W23-3a (2 DTG2) & W23-5c & W23-5b (2 DTG2) & W23-2 & W23-5a & W23-4b (2 DTG2) & \\
\hline 35 & W27-3b (1 DTG1) & W27-1b & W27-1a & W27-4a (2 DTG1) & W27-3a (2 DTG1) & W27-5c & W27-5b (2 DTG1) & W27-2 & W27-5a & W27-4b (2 DTG1) & \\
\hline 36 & W22-3b (1 DTG1) & W22-1b & W22-1a & W22-4a (1 DTG1) & W22-3a (2 DTG2) & W22-5c & W22-5b (2 DTG1) & W22-2 & W22-5a & W22-4b (2 DTG1) & \\
\hline 37 & W21-3b & W21-1b & W21-1a & W21-4a (2 DTG1) & W21-3a (2 DTG1) & W21-5c & W21-5b (2 DTG1) & W21-2 & W21-5a & W21-4b (2 DTG1) & \\
\hline 38 & W21-3b (1 DTG1) & W21-1b & W21-1a & W21-4a (2 DTG1) & W21-3a (2 DTG1) & W21-5c & W21-5b (2 DTG1) & W21-2 & W21-5a & W21-4b (2 DTG1) & \\
\hline 39 & W22-3b (1 DTG1) & W22-1b & W22-1a & W22-4a (1 DTG1) & W22-3a (2 DTG2) & W22-5c & W22-5b (2 DTG1) & W22-2 & W22-5a & W22-4b (2 DTG1) & \\
\hline
\end{tabular}

Table 2- Sliding Door Types and their Distributions (Part A) 


\begin{tabular}{|c|c|c|c|c|c|c|c|c|c|c|c|}
\hline 40 & W22-3b (1 DTG1) & W22-1b & W22-1a & W22-4a (1 DTG1) & W22-3a (2 DTG2) & W22-5c & W22-5b (2 DTG1) & W22-2 & W22-5a & W22-4b (2 DTG1) & \\
\hline 41 & W41-3b (1 DTG1) & W41-1b & W41-1a (2 DTG1) & W41-4a (2DTG1) & W41-3a (2DTG1) & W41-5c & W41-5b (2DTG1) & W41-2 & W41-5a & W41-4b (2DTG1) & \\
\hline 42 & W42-3b (1 DTG1) & W42-1b (1 DTG1) & W42-1a (2 DTG1) & W42-4a (2 DTG1) & W42-3a (2 DTG1) & W42-5c & W42-5b (2 DTG1) & W42-2 & W42-5a & W42-4b (2 DTG1) & \\
\hline 43 & W43-3b & W43-1b (1 DTG1) & W43-1a (2 DTG1) & W43-4a (2 DTG1) & W43-3a (2 DTG1) & W43-5c & W43-5b (2 DTG1) & W43-2 & W43-5a & W43-4b (2 DTG1) & \\
\hline 44 & W44-3b & W44-1b (1 DTG1) & W44-1a (2 DTG1) & W44-4a (2 DTG1) & W44-3a (2 DTG1) & W44-5c & W44-5b (2 DTG1) & W44-2 & W44-5a & W44-4b (2 DTG1) & \\
\hline 45 & W45-3b & W45-1b (1 DTG1) & W45-1a (2 DTG1) & W45-4a (2 DTG1) & W45-3a (2 DTG1) & W45-5c & W45-5b (2 DTG1) & $W 45-2$ & W45-5a & W45-4b (2 DTG1) & \\
\hline 46 & W46-3b & W46-1b (1 DTG1) & W46-1a (2 DTG1) & W46-4a (2 DTG1) & W46-3a (2 DTG1) & W46-5c & W46-5b (2 DTG1) & W46-2 & W46-5a & W46-4b (2 DTG1) & \\
\hline 47 & W47-3b & W47-1b (1 DTG1) & W47-1a (2 DTG1) & W47-4a (2 DTG1) & W47-3a (2 DTG1) & W47-5c & W47-5b (2 DTG1) & $W 47-2$ & W47-5a & W47-4b (2 DTG1) & \\
\hline 48 & W48-3b & W48-1b (1 DTG1) & W48-1a (2 DTG1) & W48-4a (2 DTG1) & W48-3a (2 DTG1) & W48-5c & W48-5b (2 DTG1) & W48-2 & W48-5a & W48-4b (2 DTG1) & \\
\hline 49 & W48-3b & W48-1b (1 DTG1) & W48-1a (2 DTG1) & W48-4a (2 DTG1) & W48-3a (2 DTG1) & W48-5c & W48-5b (2 DTG1) & $W 48-2$ & W48-5a & W48-4b (2 DTG1) & \\
\hline 50 & W47-3b & W47-1b (1 DTG1) & W47-1a (2 DTG1) & W47-4a (2 DTG1) & W47-3a (2 DTG1) & W47-5c & W47-5b (2 DTG1) & W47-2 & W47-5a & W47-4b (2 DTG1) & \\
\hline 51 & & & & & & & & & & & \\
\hline 52 & W47-3b & W47-1b (1 DTG1) & W47-1a (2 DTG1) & W47-4a (2 DTG1) & W47-3a (2 DTG1) & W47-5c & W47-5b (2 DTG1) & W47-2 & W47-5a & W47-4b (2 DTG1) & \\
\hline 53 & W48-3b & W48-1b (1 DTG1) & W48-1a (2 DTG1) & W48-4a (2 DTG1) & W48-3a (2 DTG1) & W48-5c & W48-5b (2 DTG1) & $W 48-2$ & W48-5a & W48-4b (2 DTG1) & \\
\hline 54 & W48-3b & W48-1b (1 DTG1) & W48-1a (2 DTG1) & W48-4a (2 DTG1) & W48-3a (2 DTG1) & W48-5c & W48-5b (2 DTG1) & $W 48-2$ & W48-5a & W48-4b (2 DTG1) & \\
\hline 55 & W55-3b & W55-1b (1 DTG1) & W55-1a (2 DTG1) & W55-4a (2 DTG1) & W55-3a (2 DTG1) & W55-5c & W55-5b (2 DTG1) & W55-2 & W55-5a & W55-4b (2 DTG1) & \\
\hline 56 & W56-3b & W56-1b (1 DTG1) & W56-1a (2 DTG1) & W56-4a(2 DTG1) & W56-3a(2 DTG1) & W56-5c & W56-5b(2 DTG1) & W56-2 & W56-5a & W56-4b(2 DTG1) & \\
\hline 57 & W57-3b & W57-1b (1 DTG1) & W57-1a (2 DTG1) & W57-4a (2 DTG1) & W57-3a (2 DTG1) & W57-5c & W57-5b (2 DTG1) & W57-2 & W57-5a & W57-4b (2 DTG1) & \\
\hline 58 & W58-3b & W58-1b (1 DTG1) & W58-1a (2 DTG1) & W58-4a (2 DTG1) & W58-3a (2 DTG1) & W58-5c & W58-5b (2 DTG1) & W58-2 & W58-5a & W58-4b (2 DTG1) & \\
\hline 59 & & & & & & & & & & & \\
\hline 60 & W58-3b & W58-1b (1 DTG1) & W58-1a (2 DTG1) & W58-4a (2 DTG1) & W58-3a (2 DTG1) & W58-5c & W58-5b (2 DTG1) & W58-2 & W58-5a & W58-4b (2 DTG1) & \\
\hline 61 & W61-3b & W61-1b (1 DTG1) & W61-1a (2 DTG1) & W61-4a (2 DTG1) & W61-3a (2 DTG1) & W61-5c & W61-5b (2 DTG1) & W61-2 & W61-5a & W61-4b (2 DTG1) & \\
\hline 62 & W61-3b & W61-1b (1 DTG1) & W61-1a (2 DTG1) & W61-4a (2 DTG1) & W61-3a (2 DTG1) & W61-5c & W61-5b (2 DTG1) & W61-2 & W61-5a & W61-4b (2 DTG1) & \\
\hline 63 & W58-3b & W58-1b (1 DTG1) & W58-1a (2 DTG1) & W58-4a (2 DTG1) & W58-3a (2 DTG1) & W58-5c & W58-5b (2 DTG1) & W58-2 & W58-5a & W58-4b (2 DTG1) & \\
\hline 64 & W57-3b & W57-1b (1 DTG1) & W57-1a (2 DTG1) & W57-4a (2 DTG1) & W57-3a (2 DTG1) & W57-5c & W57-5b (2 DTG1) & W57-2 & W57-5a & W57-4b (2 DTG1) & \\
\hline 65 & W58-3b & W58-1b (1 DTG1) & W58-1a (2 DTG1) & W58-4a (2 DTG1) & W58-3a (2 DTG1) & W58-5c & W58-5b (2 DTG1) & W58-2 & W58-5a & W58-4b (2 DTG1) & \\
\hline 66 & W66-3b & W66-1b (1 DTG1) & W66-1a (2 DTG1) & W66-4a (2 DTG1) & W66-3a (2 DTG1) & W66-5c & W66-5b (2 DTG1) & W66-2 & W66-5a & W66-4b (2 DTG1) & \\
\hline 67 & W67-3b & W67-1b (1 DTG1) & W67-1a (2 DTG1) & W67-4a (2 DTG1) & W67-3a (2 DTG1) & W67-5c & W67-5b (2 DTG1) & W67-2 & W67-5a & W67-4b (2 DTG1) & \\
\hline 68 & W68-3b & W68-1b (1 DTG1) & W68-1a (2 DTG1) & W68-4a (2 DTG1) & W68-3a (2 DTG1) & W68-5c & W68-5b (2 DTG1) & W68-2 & W68-5a & W68-4b (2 DTG1) & \\
\hline 69 & W69-3b & W69-1b (2 DTG1) & W69-1a (2 DTG1) & W69-4a (2 DTG1) & W69-3a (2 DTG1) & W69-5c & W69-5b (2 DTG1) & W69-2 & W69-5a & W69-4b (2 DTG1) & \\
\hline 70 & & & & & & & & & & & \\
\hline 71 & W70-3b & W70-1b & W70-1a & W70-4a & w70-3a & W70-5c & W70-5b & W70-2 & W70-5a & W70-4b & \\
\hline
\end{tabular}

Table 2- Sliding Door Types and their Distributions (Part B) 


\begin{tabular}{|c|c|c|c|c|c|c|c|c|c|c|c|}
\hline Level & WLevel-3b & WLevel-1b & WLevel-1a & WLevel-4a & WLevel-3a & WLevel-5c & WLevel-5b & WLevel-2 & WLevel-5a & WLevel-4b & W8-4a \\
\hline 6 & & & & W6-4a (1 DTG1) & & & & & & W6-4b (2 DTG1) & \\
\hline 7 & & & & W7-4a (2 DTG1) & & & & & & W7-4b (2 DTG1) & W8-4a (2 DTG1) \\
\hline 8 & & & & W7-4a (2 DTG1) & & & & & & W7-4b (2 DTG1) & W8-4a (2 DTG1) \\
\hline 9 & & & & W7-4a (2 DTG1) & & & & & & W7-4b (2 DTG1) & W8-4a (2 DTG1) \\
\hline 10 & & & & W10-4a (2 DTG1) & & & & & & W10-4b (2 DTG1) & \\
\hline 11 & & & & & & & W11-5b (1 DTG1) & & W11-5a (1 DTG1) & & \\
\hline 12 & & & & W12-4a (2 DTG1) & & & & & & W12-4b (2 DTG1) & \\
\hline 13 & & & & W12-4a (2 DTG1) & & & & & & W12-4b (2 DTG1) & \\
\hline 14 & & & & W7-4a (2 DTG1) & & & & & & W7-4b (2 DTG1) & W8-4a (2 DTG1) \\
\hline 15 & & & & W10-4a (2 DTG1) & & & & & & W10-4b (2 DTG1) & \\
\hline 16 & & & & W7-4a (2 DTG1) & & & & & & W7-4b (2 DTG1) & W8-4a (2 DTG1) \\
\hline 17 & W11-3b (1 DTG1) & & & & & & & & & & \\
\hline 18 & & & & & & & & & & & \\
\hline 19 & & & & W7-4a (2 DTG1) & & & & & & W7-4b (2 DTG1) & W8-4a (2 DTG1) \\
\hline 20 & & & & W7-4a (2 DTG1) & & & & & & W7-4b (2 DTG1) & W8-4a (2 DTG1) \\
\hline 21 & & & & W21-4a (2 DTG1) & W21-3a (2 DTG1) & & W21-5b (2 DTG1) & & & W21-4b (2 DTG1) & \\
\hline 22 & W22-3b (1 DTG1) & & & W22-4a (1 DTG1) & W22-3a (2 DTG2) & & W22-5b (2 DTG1) & & & W22-4b (2 DTG1) & \\
\hline 23 & W23-3b (1 DTG2) & & & W23-4a (1 DTG2) & W23-3a (2 DTG2) & & W23-5b (2 DTG1) & & & W23-4b (2 DTG1) & \\
\hline 24 & & & & W24-4a (2 DTG1) & W24-3a (2 DTG1) & & W24-5b (2 DTG1) & & & W24-4b (2 DTG2) & \\
\hline 25 & & & & W25-4a (2 DTG1) & W25-3a (2 DTG1) & & W25-5b (2 DTG1) & & & W25-4b (2 DTG1) & \\
\hline 26 & & & & W21-4a (2 DTG1) & W21-3a (2 DTG1) & & W21-5b (2 DTG1) & & & W21-4b (2 DTG1) & \\
\hline 27 & W27-3b (1 DTG1) & & & W27-4a (2 DTG1) & W27-3a (2 DTG1) & & W27-5b (2 DTG1) & & & W27-4b (2 DTG1) & \\
\hline 28 & & & & W21-4a (2 DTG1) & W21-3a (2 DTG1) & & W21-5b (2 DTG1) & & & W21-4b (2 DTG1) & \\
\hline 29 & W22-3b (1 DTG1) & & & W22-4a (1 DTG1) & W22-3a (2 DTG2) & & W22-5b (2 DTG1) & & & W22-4b (2 DTG1) & \\
\hline 30 & & & & & & & & & & & \\
\hline 31 & W27-3b (1 DTG1) & & & W27-4a (2 DTG1) & W27-3a (2 DTG1) & & W27-5b (2 DTG1) & & & W27-4b (2 DTG1) & \\
\hline 32 & W27-3b (1 DTG1) & & & W27-4a (2 DTG1) & W27-3a (2 DTG1) & & W27-5b (2 DTG1) & & & W27-4b (2 DTG1) & \\
\hline 33 & W23-3b (1 DTG1) & & & W23-4a (1 DTG1) & W23-3a (2 DTG1) & & W23-5b (2 DTG1) & & & W23-4b (2 DTG1) & \\
\hline 34 & W23-3b (1 DTG1) & & & W23-4a (1 DTG1) & W23-3a (2 DTG1) & & W23-5b (2 DTG1) & & & W23-4b (2 DTG1) & \\
\hline 35 & W27-3b (1 DTG1) & & & W27-4a (2 DTG1) & W27-3a (2 DTG1) & & W27-5b (2 DTG1) & & & W27-4b (2 DTG1) & \\
\hline 36 & W22-3b (1 DTG1) & & & W22-4a (1 DTG1) & W22-3a (2 DTG2) & & W22-5b (2 DTG1) & & & W22-4b (2 DTG1) & \\
\hline 37 & & & & W21-4a (2 DTG1) & W21-3a (2 DTG1) & & W21-5b (2 DTG1) & & & W21-4b (2 DTG1) & \\
\hline 38 & & & & W21-4a (2 DTG1) & W21-3a (2 DTG1) & & W21-5b (2 DTG1) & & & W21-4b (2 DTG1) & \\
\hline 39 & W22-3b (1 DTG1) & & & W22-4a (1 DTG1) & W22-3a (2 DTG2) & & W22-5b (2 DTG1) & & & W22-4b (2 DTG1) & \\
\hline
\end{tabular}

Table 3- Type 1 Distribution (Part A) 


\begin{tabular}{|c|c|c|c|c|c|c|c|c|c|c|}
\hline 40 & W22-3b (1 DTG1) & & & W22-4a (1 DTG1) & W22-3a (2 DTG2) & WW22-5b (2 DTG1) & & & W22-4b (2 DTG1) & \\
\hline 41 & W41-3b (1 DTG1) & & W41-1a (2 DTG1) & W41-4a (2DTG1) & W41-3a (2DTG1) & W41-5b (2DTG1) & & & W41-4b (2DTG1) & \\
\hline 42 & W42-3b (1 DTG1) & W42-1b (1 DTG1) & W42-1a (2 DTG1) & W42-4a (2 DTG1) & W42-3a (2 DTG1) & W42-5b (2 DTG1) & & & W42-4b (2 DTG1) & \\
\hline 43 & & W43-1b (1 DTG1) & W43-1a (2 DTG1) & W43-4a (2 DTG1) & W43-3a (2 DTG1) & W43-5b (2 DTG1) & & & W43-4b (2 DTG1) & \\
\hline 44 & & W44-1b (1 DTG1) & W44-1a (2 DTG1) & W44-4a (2 DTG1) & W44-3a (2 DTG1) & W44-5b (2 DTG1) & & & W44-4b (2 DTG1) & \\
\hline 45 & & W45-1b (1 DTG1) & W45-1a (2 DTG1) & W45-4a (2 DTG1) & W45-3a (2 DTG1) & W45-5b (2 DTG1) & & & W45-4b (2 DTG1) & \\
\hline 46 & & W46-1b (1 DTG1) & W46-1a (2 DTG1) & W46-4a (2 DTG1) & W46-3a (2 DTG1) & W46-5b (2 DTG1) & & & W46-4b (2 DTG1) & \\
\hline 47 & & W47-1b (1 DTG1) & W47-1a (2 DTG1) & W47-4a (2 DTG1) & W47-3a (2 DTG1) & W47-5b (2 DTG1) & & & W47-4b (2 DTG1) & \\
\hline 48 & & W48-1b (1 DTG1) & W48-1a (2 DTG1) & W48-4a (2 DTG1) & W48-3a (2 DTG1) & W48-5b (2 DTG1) & & & W48-4b (2 DTG1) & \\
\hline 49 & & W48-1b (1 DTG1) & W48-1a (2 DTG1) & W48-4a (2 DTG1) & W48-3a (2 DTG1) & W48-5b (2 DTG1) & & & W48-4b (2 DTG1) & \\
\hline 50 & & W47-1b (1 DTG1) & W47-1a (2 DTG1) & W47-4a (2 DTG1) & W47-3a (2 DTG1) & \begin{tabular}{l|l}
$047-5 b$ & $(2$ DTG1)
\end{tabular} & & & W47-4b (2 DTG1) & \\
\hline 51 & & & & & & & & & & \\
\hline 52 & & W47-1b (1 DTG1) & W47-1a (2 DTG1) & W47-4a (2 DTG1) & W47-3a (2 DTG1) & W47-5b (2 DTG1) & & & W47-4b (2 DTG1) & \\
\hline 53 & & W48-1b (1 DTG1) & W48-1a (2 DTG1) & W48-4a (2 DTG1) & W48-3a (2 DTG1) & W48-5b (2 DTG1) & & & W48-4b (2 DTG1) & \\
\hline 54 & & W48-1b (1 DTG1) & W48-1a (2 DTG1) & W48-4a (2 DTG1) & W48-3a (2 DTG1) & W48-5b (2 DTG1) & & & W48-4b (2 DTG1) & \\
\hline 55 & & W55-1b (1 DTG1) & W55-1a (2 DTG1) & W55-4a (2 DTG1) & W55-3a (2 DTG1) & W55-5b (2 DTG1) & & & W55-4b (2 DTG1) & \\
\hline 56 & & W56-1b (1 DTG1) & W56-1a (2 DTG1) & W56-4a(2 DTG1) & W56-3a(2 DTG1) & W56-5b(2 DTG1) & & & W56-4b(2 DTG1) & \\
\hline 57 & & W57-1b (1 DTG1) & W57-1a (2 DTG1) & W57-4a (2 DTG1) & W57-3a (2 DTG1) & W57-5b (2 DTG1) & & & W57-4b (2 DTG1) & \\
\hline 58 & & W58-1b (1 DTG1) & W58-1a (2 DTG1) & W58-4a (2 DTG1) & W58-3a (2 DTG1) & W58-5b (2 DTG1) & & & W58-4b (2 DTG1) & \\
\hline 59 & & & & & & & & & & \\
\hline 60 & & W58-1b (1 DTG1) & W58-1a (2 DTG1) & W58-4a (2 DTG1) & W58-3a (2 DTG1) & W58-5b (2 DTG1) & & & W58-4b (2 DTG1) & \\
\hline 61 & & W61-1b (1 DTG1) & W61-1a (2 DTG1) & W61-4a (2 DTG1) & W61-3a (2 DTG1) & W61-5b (2 DTG1) & & & W61-4b (2 DTG1) & \\
\hline 62 & & W61-1b (1 DTG1) & W61-1a (2 DTG1) & W61-4a (2 DTG1) & W61-3a (2 DTG1) & W61-5b (2 DTG1) & & & W61-4b (2 DTG1) & \\
\hline 63 & & W58-1b (1 DTG1) & W58-1a (2 DTG1) & W58-4a (2 DTG1) & W58-3a (2 DTG1) & W58-5b (2 DTG1) & & & W58-4b (2 DTG1) & \\
\hline 64 & & W57-1b (1 DTG1) & W57-1a (2 DTG1) & W57-4a (2 DTG1) & W57-3a (2 DTG1) & W57-5b (2 DTG1) & & & W57-4b (2 DTG1) & \\
\hline 65 & & W58-1b (1 DTG1) & W58-1a (2 DTG1) & W58-4a (2 DTG1) & W58-3a (2 DTG1) & W58-5b (2 DTG1) & & & W58-4b (2 DTG1) & \\
\hline 66 & & W66-1b (1 DTG1) & W66-1a (2 DTG1) & W66-4a (2 DTG1) & W66-3a (2 DTG1) & W66-5b (2 DTG1) & & & W66-4b (2 DTG1) & \\
\hline 67 & & W67-1b (1 DTG1) & W67-1a (2 DTG1) & W67-4a (2 DTG1) & W67-3a (2 DTG1) & W67-5b (2 DTG1) & & & W67-4b (2 DTG1) & \\
\hline 68 & & W68-1b (1 DTG1) & W68-1a (2 DTG1) & W68-4a (2 DTG1) & W68-3a (2 DTG1) & W68-5b (2 DTG1) & & & W68-4b (2 DTG1) & \\
\hline 69 & & W69-1b (2 DTG1) & W69-1a (2 DTG1) & W69-4a (2 DTG1) & W69-3a (2 DTG1) & W69-5b (2 DTG1) & & & W69-4b (2 DTG1) & \\
\hline 70 & & & & & & & & & & \\
\hline 71 & & & & & & & & & & \\
\hline
\end{tabular}

Table 3- Type 1 Distribution (Part B) 


\begin{tabular}{|c|c|c|c|c|c|c|c|c|c|c|c|}
\hline Level & WLevel-3b & WLevel-1b & WLevel-1a & WLevel-4a & WLevel-3a & WLevel-5c & WLevel-5b & $\begin{array}{l}\text { WLevel- } \\
2\end{array}$ & WLevel-5a & WLevel-4b & W8-4a \\
\hline 6 & & & & W6-4a (1 DTG1) & & & & & & W6-4b (2 DTG1) & \\
\hline 7 & & & & W7-4a (2 DTG1) & & & & & & W7-4b (2 DTG1) & W8-4a (2 DTG1) \\
\hline 8 & & & & W7-4a (2 DTG1) & & & & & & W7-4b (2 DTG1) & W8-4a (2 DTG1) \\
\hline 9 & & & & W7-4a (2 DTG1) & & & & & & W7-4b (2 DTG1) & W8-4a (2 DTG1) \\
\hline 10 & & & & W10-4a (2 DTG1) & & & & & & W10-4b (2 DTG1) & \\
\hline 11 & & & & & & & W11-5b (1 DTG1) & & W11-5a (1 DTG1) & & \\
\hline 12 & & & & W12-4a (2 DTG1) & & & & & & W12-4b (2 DTG1) & \\
\hline 13 & & & & W12-4a (2 DTG1) & & & & & & W12-4b (2 DTG1) & \\
\hline 14 & & & & W7-4a (2 DTG1) & & & & & & W7-4b (2 DTG1) & W8-4a (2 DTG1) \\
\hline 15 & & & & W10-4a (2 DTG1) & & & & & & W10-4b (2 DTG1) & \\
\hline 16 & & & & W7-4a (2 DTG1) & & & & & & W7-4b (2 DTG1) & W8-4a (2 DTG1) \\
\hline 17 & W11-3b (1 DTG1) & & & & & & & & & & \\
\hline \multicolumn{12}{|l|}{18} \\
\hline 19 & & & & W7-4a (2 DTG1) & & & & & & W7-4b (2 DTG1) & W8-4a (2 DTG1) \\
\hline 20 & & & & W7-4a (2 DTG1) & & & & & & W7-4b (2 DTG1) & W8-4a (2 DTG1) \\
\hline 21 & & & & W21-4a (2 DTG1) & W21-3a (2 DTG1) & & W21-5b (2 DTG1) & & & W21-4b (2 DTG1) & \\
\hline 22 & W22-3b (1 DTG1) & & & W22-4a (1 DTG1) & W22-3a (2 DTG2) & & W22-5b (2 DTG1) & & & W22-4b (2 DTG1) & \\
\hline 23 & W23-3b (1 DTG2) & & & W23-4a (1 DTG2) & W23-3a (2 DTG2) & & W23-5b (2 DTG1) & & & W23-4b (2 DTG1) & \\
\hline 24 & & & & W24-4a (2 DTG1) & W24-3a (2 DTG1) & & W24-5b (2 DTG1) & & & W24-4b (2 DTG2) & \\
\hline 25 & & & & W25-4a (2 DTG1) & W25-3a (2 DTG1) & & W25-5b (2 DTG1) & & & W25-4b (2 DTG1) & \\
\hline 26 & & & & W21-4a (2 DTG1) & W21-3a (2 DTG1) & & W21-5b (2 DTG1) & & & W21-4b (2 DTG1) & \\
\hline 27 & W27-3b (1 DTG1) & & & W27-4a (1DTG1) & W27-3a (2 DTG1) & & W27-5b (2 DTG1) & & & W27-4b (2 DTG1) & \\
\hline 28 & & & & W21-4a (2 DTG1) & W21-3a (2 DTG1) & & W21-5b (2 DTG1) & & & W21-4b (2 DTG1) & \\
\hline 29 & W22-3b (1 DTG1) & & & W22-4a (1 DTG1) & W22-3a (2 DTG2) & & W22-5b (2 DTG1) & & & W22-4b (2 DTG1) & \\
\hline \multicolumn{12}{|l|}{30} \\
\hline 31 & W27-3b (1 DTG1) & & & W27-4a (2 DTG1) & W27-3a (2 DTG1) & & W27-5b (2 DTG1) & & & W27-4b (2 DTG1) & \\
\hline 32 & W27-3b (1 DTG1) & & & W27-4a (2 DTG1) & W27-3a (2 DTG1) & & W27-5b (2 DTG1) & & & W27-4b (2 DTG1) & \\
\hline 33 & W23-3b (1 DTG1) & & & W23-4a (1 DTG1) & W23-3a (2 DTG1) & & W23-5b (2 DTG1) & & & W23-4b (2 DTG1) & \\
\hline 34 & W23-3b (1 DTG1) & & & W23-4a (1 DTG1) & W23-3a (2 DTG1) & & W23-5b (2 DTG1) & & & W23-4b (2 DTG1) & \\
\hline 35 & W27-3b (1 DTG1) & & & W27-4a (2 DTG1) & W27-3a (2 DTG1) & & W27-5b (2 DTG1) & & & W27-4b (2 DTG1) & \\
\hline 36 & W22-3b (1 DTG1) & & & W22-4a (2 DTG1) & W22-3a (2 DTG2) & & W22-5b (2 DTG1) & & & W22-4b (2 DTG1) & \\
\hline 37 & & & & W21-4a (2 DTG1) & W21-3a (2 DTG1) & & W21-5b (2 DTG1) & & & W21-4b (2 DTG1) & \\
\hline 38 & & & & W21-4a (2 DTG1) & W21-3a (2 DTG1) & & W21-5b (2 DTG1) & & & W21-4b (2 DTG1) & \\
\hline 39 & W22-3b (1 DTG1) & & & W22-4a (1 DTG1) & W22-3a (2 DTG2) & & W22-5b (2 DTG1) & & & W22-4b (2 DTG1) & \\
\hline
\end{tabular}

Table 4- Excluding other Sizes than $2.26 \mathrm{~cm}$ x $1.83 \mathrm{~cm}$ in Type 1 Distribution (Part A) 


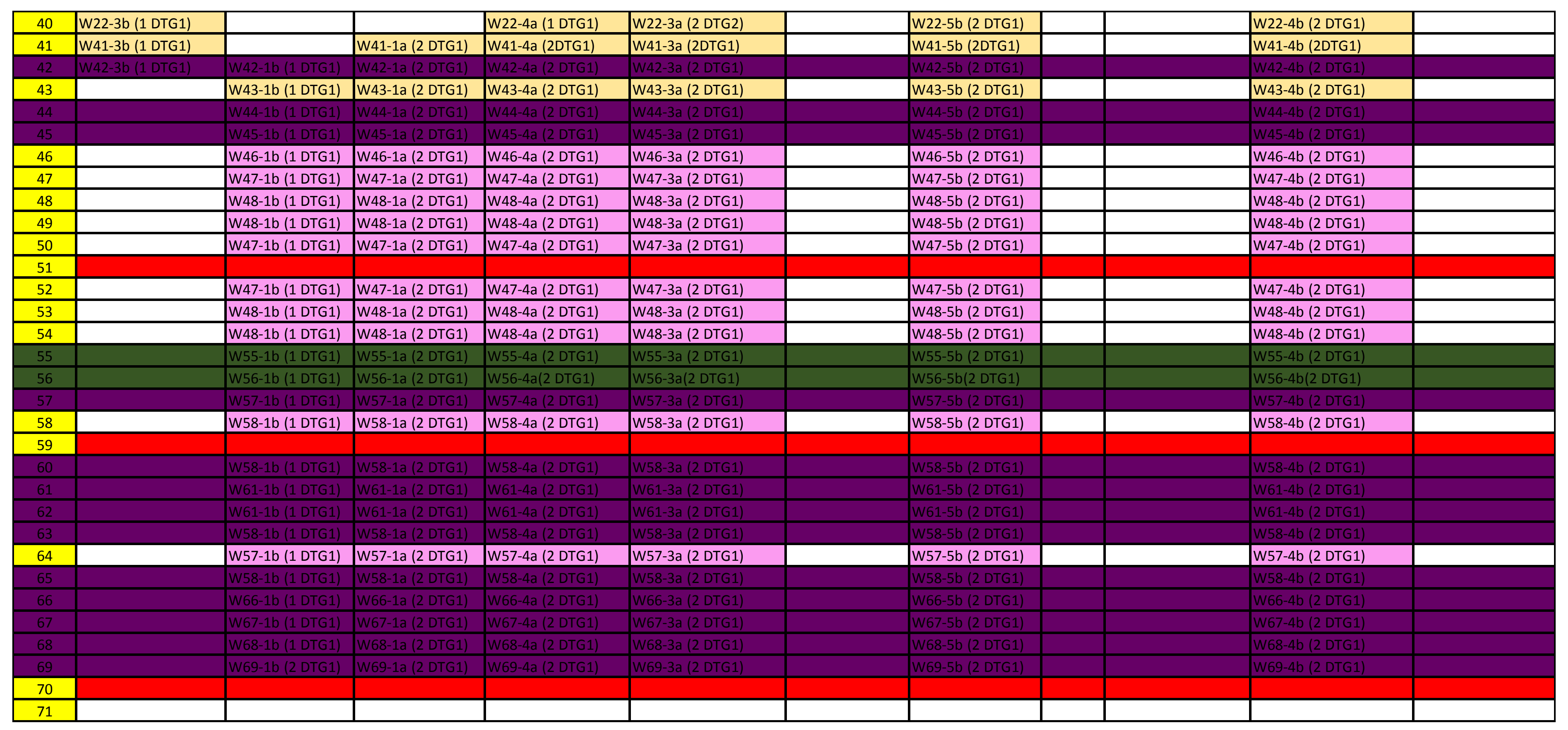

Table 4- Excluding other Sizes than $2.26 \mathrm{~cm}$ x $1.83 \mathrm{~cm}$ in Type 1 Distribution (Part B) 


\begin{tabular}{|c|c|c|c|c|c|c|c|c|c|c|c|}
\hline Level & WLevel-3b & WLevel-1b & WLevel-1a & WLevel-4a & WLevel-3a & WLevel-5c & WLevel-5b & \begin{tabular}{|l|} 
WLevel-2 \\
\end{tabular} & WLevel-5a & WLevel-4b & W8-4a \\
\hline 6 & & & & 1 & & & & & & 2.3 & \\
\hline 7 & & & & 4.5 & & & & & & 6.7 & 8.9 \\
\hline 8 & & & & 10.11 & & & & & & 12.13 & 14.15 \\
\hline 9 & & & & 16.17 & & & & & & 18.19 & 20.21 \\
\hline 10 & & & & 22.23 & & & & & & 24.25 & \\
\hline 11 & & & & & & & 25 & & 26 & & \\
\hline \multicolumn{12}{|l|}{12} \\
\hline \multicolumn{12}{|l|}{13} \\
\hline 14 & & & & 27 & & & & & & 28.29 & 30.31 \\
\hline 15 & & & & 32.33 & & & & & & 34.35 & \\
\hline 16 & & & & 36.37 & & & & & & 38.39 & 40 \\
\hline 17 & 41 & & & & & & & & & & \\
\hline \multicolumn{12}{|l|}{18} \\
\hline 19 & & & & 42.43 & & & & & & 44.45 & 46.47 \\
\hline 20 & & & & 48.49 & & & & & & 50.51 & 52.53 \\
\hline 21 & & & & 54.55 & 56.57 & & 58.59 & & & 60.61 & \\
\hline 22 & 62.63 & & & 64.65 & 66.67 & & 68.69 & & & 70.71 & \\
\hline \multicolumn{12}{|l|}{23} \\
\hline \multicolumn{12}{|l|}{24} \\
\hline 25 & & & & 72.73 & 74.75 & & 76.77 & & & 78.79 & \\
\hline 26 & & & & 80.81 & 82.83 & & 84.85 & & & 86.87 & \\
\hline 27 & 88 & & & 89.9 & 91.92 & & 93.94 & & & 95.96 & \\
\hline 28 & & & & 97.98 & 99.10 & & 101.102 & & & 103.104 & \\
\hline 29 & 105 & & & 106 & 107.108 & & 109.110 & & & 111.112 & \\
\hline \multicolumn{12}{|l|}{30} \\
\hline 31 & 113 & & & 114.115 & 116.117 & & 118.119 & & & 120.121 & \\
\hline 32 & 122 & & & 123.124 & 125.126 & & 127.128 & & & 129.130 & \\
\hline \multicolumn{12}{|l|}{33} \\
\hline 34 & & & & & & & & & & & \\
\hline 35 & 131 & & & 132.133 & 134.135 & & 136.137 & & & 138.139 & \\
\hline 36 & 140 & & & 141.142 & 143.144 & & 145.146 & & & 147.148 & \\
\hline 37 & & & & 149.150 & 151.152 & & 153.154 & & & 155.156 & \\
\hline 38 & & & & 157.158 & 159.160 & & 161.162 & & & 163.164 & \\
\hline 39 & 165 & & & 166 & 167.168 & & 169.170 & & & 171.172 & \\
\hline
\end{tabular}

Table 5- Labeling and numbering type 1 (Size $2.26 \mathrm{~cm} \times 1.83 \mathrm{~cm}$ ) (Part A) 


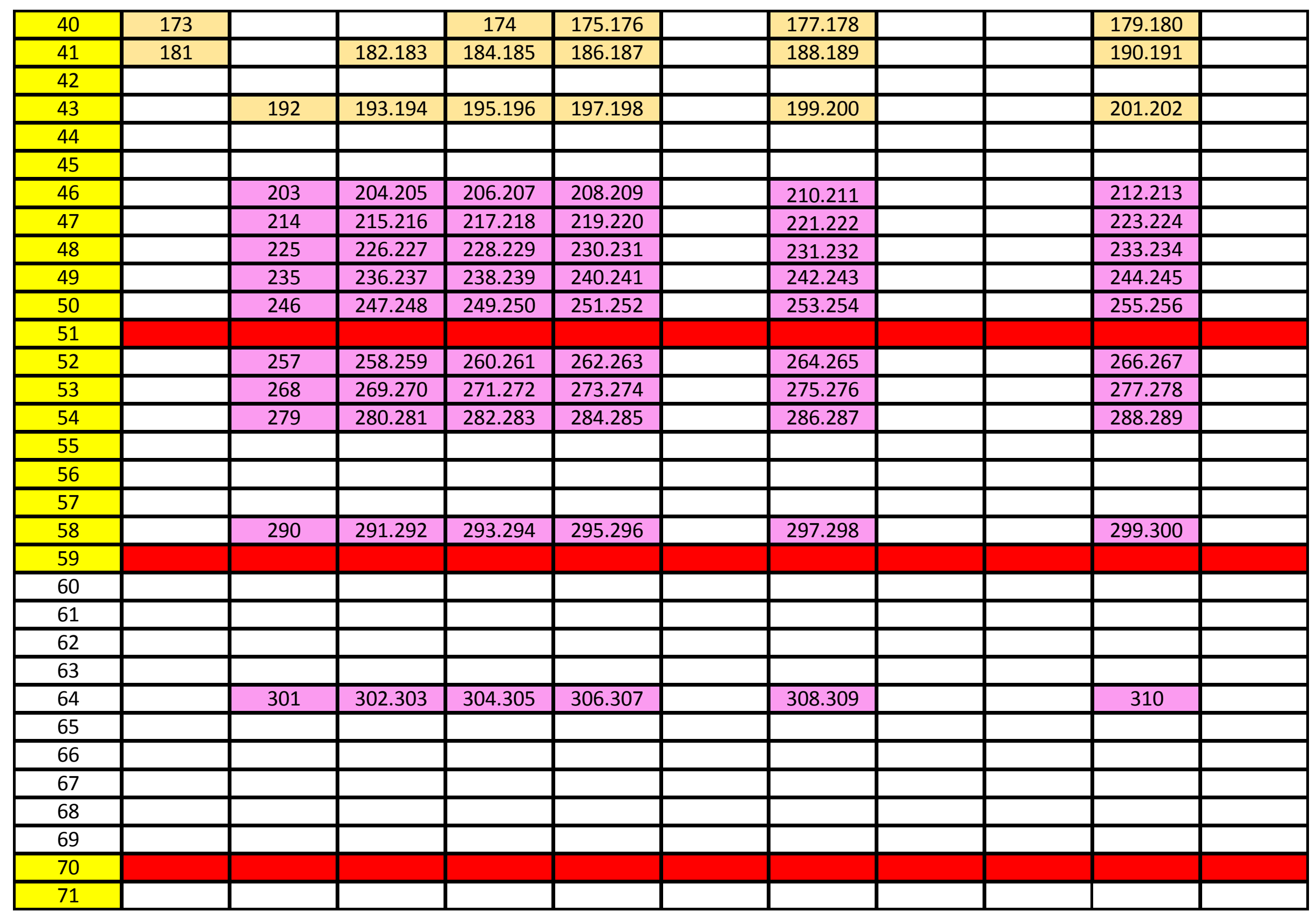

Table 5- Labeling and numbering type 1 (Size $2.26 \mathrm{~cm} \times 1.83 \mathrm{~cm}$ ) (Part B) 


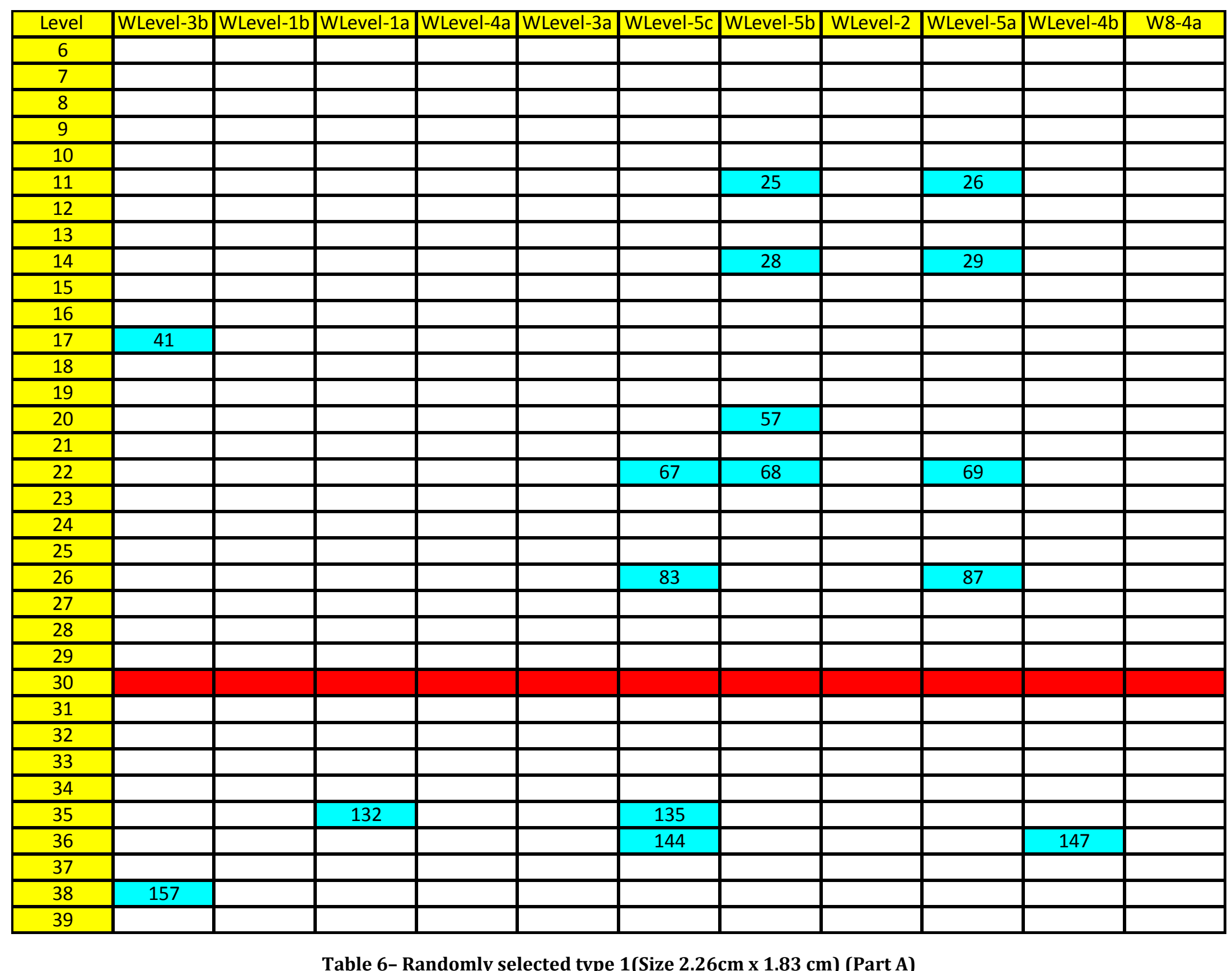




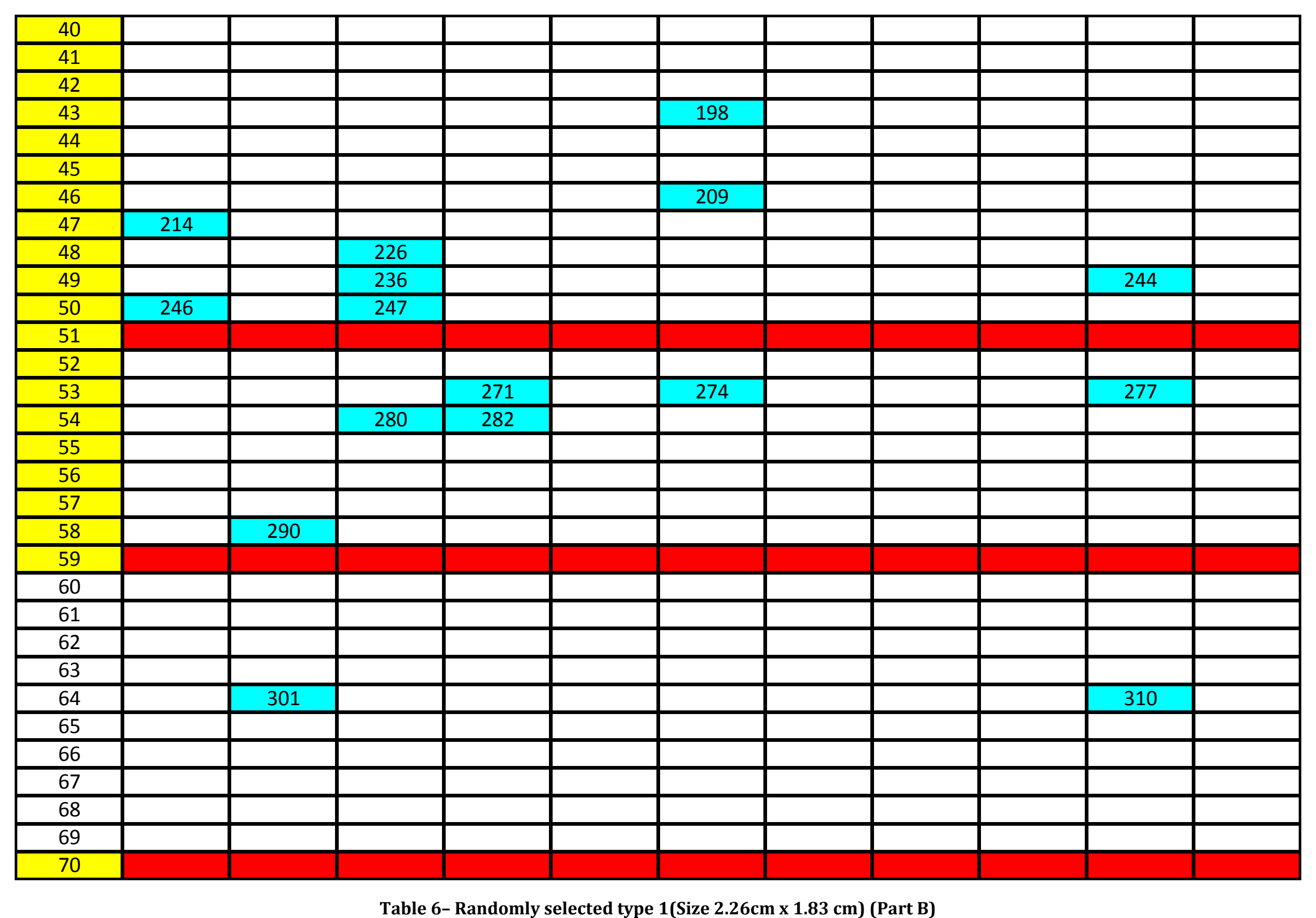




\begin{tabular}{|c|c|c|c|c|c|c|c|c|c|c|c|c|c|}
\hline Test Number & Sample size & $\begin{array}{c}\text { sample } \\
\text { number }\end{array}$ & Direction & Test Time & Test date & Temp Inside $\left({ }^{\circ} \mathrm{C}\right)$ & Temp out side $\left({ }^{\circ} \mathrm{C}\right)$ & Wind Speed & $\begin{array}{l}\text { Relative } \\
\text { Humidity }\end{array}$ & $\begin{array}{c}\text { Construction } \\
\text { Level }\end{array}$ & Marketing Level & Suit No. & Type \\
\hline 1 & $2260 \times 1830$ & 25 & SW & 8:00 a.m & $11 / 19 / 2016$ & $12^{\circ} \mathrm{C}$ & $10 \cdot \mathrm{C}$ & W20 KPH & $80 \%$ & 47 & 52 & E10 & $4 a$ \\
\hline 2 & $2260 \times 1830$ & 26 & $\mathrm{NE}$ & 9:00 a.m & $11 / 19 / 2016$ & $12{ }^{\circ} \mathrm{C}$ & $10 \cdot \mathrm{C}$ & W20 KPH & $80 \%$ & 46 & 51 & E05 & $5 b$ \\
\hline 3 & $2260 \times 1830$ & 28 & $\mathrm{NE}$ & 10:00 a.m & $11 / 19 / 2016$ & $12{ }^{\circ} \mathrm{C}$ & $10 \cdot \mathrm{C}$ & W20 KPH & $80 \%$ & 43 & 48 & E05 & $5 b$ \\
\hline 4 & $2260 \times 1830$ & 29 & SE & 11:00 a.m & $11 / 19 / 2016$ & $12{ }^{\circ} \mathrm{C}$ & $10{ }^{\circ} \mathrm{C}$ & W20 KPH & $80 \%$ & 20 & 25 & E07 & $4 b$ \\
\hline 5 & $2260 \times 1830$ & 41 & SW & 12:00 p.m & $11 / 19 / 2016$ & $12^{\circ} \mathrm{C}$ & $10 \cdot \mathrm{C}$ & WSW26 KPH & $80 \%$ & 16 & 21 & E10 & $4 a$ \\
\hline 6 & $2260 \times 1830$ & 57 & $\mathrm{NE}$ & 01:00 p.m & $11 / 19 / 2016$ & $12{ }^{\circ} \mathrm{C}$ & $10 \cdot \mathrm{C}$ & WSW26 KPH & $80 \%$ & 14 & 19 & E06 & $5 b$ \\
\hline 7 & $2260 \times 1830$ & 67 & $\mathrm{SE}$ & 02:00 p.m & $11 / 19 / 2016$ & $12{ }^{\circ} \mathrm{C}$ & $10^{\circ} \mathrm{C}$ & WSW26 KPH & $80 \%$ & 14 & 19 & E07 & $4 \mathrm{~b}$ \\
\hline 8 & $2260 \times 1830$ & 68 & NW & 10:27 a.m & $1 / 12 / 2016$ & $7 \circ \mathrm{C}$ & $5{ }^{\circ} \mathrm{C}$ & WSW $38 \mathrm{KPH}$ & $70 \%$ & 64 & 69 & E03 & $1 \mathrm{~b}$ \\
\hline 9 & $2260 \times 1830$ & 69 & SE & 11:49 a.m & $1 / 12 / 2016$ & $7 \circ \mathrm{C}$ & $5^{\circ} \mathrm{C}$ & WSW $38 \mathrm{KPH}$ & $70 \%$ & 64 & 69 & E07 & $4 \mathrm{~b}$ \\
\hline 10 & $2260 \times 1830$ & 83 & NW & 12:32 p.m & $1 / 12 / 2016$ & $7 \circ \mathrm{C}$ & $5^{\circ} \mathrm{C}$ & W 24 KPH & $70 \%$ & 58 & 63 & E03 & $1 b$ \\
\hline 11 & $2260 \times 1830$ & 87 & $\mathrm{SE}$ & 1:14 p.m & $1 / 12 / 2016$ & $7 \circ \mathrm{C}$ & $5{ }^{\circ} \mathrm{C}$ & W $24 \mathrm{KPH}$ & $70 \%$ & 54 & 59 & E09 & $4 a$ \\
\hline 12 & $2260 \times 1830$ & 132 & SE & 3.23 p.m & $1 / 12 / 2016$ & $7 \circ \mathrm{C}$ & $5{ }^{\circ} \mathrm{C}$ & W24 KPh & $70 \%$ & 10 & 15 & E07 & $4 \mathrm{~b}$ \\
\hline 13 & $2260 \times 1830$ & 135 & $\mathrm{NE}$ & 4:15 p.m & $1 / 12 / 2016$ & $7 \circ \mathrm{C}$ & $5^{\circ} \mathrm{C}$ & W24 KPh & $70 \%$ & 10 & 15 & E06 & $5 b$ \\
\hline 14 & $2260 \times 1830$ & 144 & SE & 8:54 a.m & $3 / 12 / 2016$ & $5^{\circ} \mathrm{C}$ & $2^{\circ} \mathrm{C}$ & NW $11 \mathrm{KPH}$ & $50 \%$ & 53 & 58 & E09 & $4 a$ \\
\hline 15 & $2260 \times 1830$ & 147 & SE & 9:30 a.m & $3 / 12 / 2016$ & $5^{\circ} \mathrm{C}$ & $2{ }^{\circ} \mathrm{C}$ & NW $11 \mathrm{KPH}$ & $50 \%$ & 53 & 58 & E07 & $4 b$ \\
\hline 16 & $2260 \times 1830$ & 157 & NE & 10.10 a.m & $3 / 12 / 2016$ & $7 \circ \mathrm{C}$ & $4{ }^{\circ} \mathrm{C}$ & WNW $25 \mathrm{KPH}$ & $50 \%$ & 53 & 58 & E06 & $5 b$ \\
\hline 17 & $2260 \times 1830$ & 198 & NW & 10.30 a.m & $3 / 12 / 2016$ & $7 \circ \mathrm{C}$ & $4^{\circ} \mathrm{C}$ & WNW $25 \mathrm{KPH}$ & $50 \%$ & 50 & 55 & E04 & $1 a$ \\
\hline 18 & $2260 \times 1830$ & 209 & sW & 11:12 a.m & $3 / 12 / 2016$ & $8^{\circ} \mathrm{C}$ & $5{ }^{\circ} \mathrm{C}$ & WNW 25KPH & $50 \%$ & 50 & 55 & E10 & $4 a$ \\
\hline 19 & $2260 \times 1830$ & 214 & sW & 12:00 p.m & $3 / 12 / 2016$ & $9 \circ \mathrm{C}$ & $6^{\circ} \mathrm{C}$ & NW 22KPH & $50 \%$ & 38 & 43 & E10 & $4 a$ \\
\hline 20 & $2260 \times 1830$ & 226 & NW & 1:01 p.m & $3 / 12 / 2016$ & $10^{\circ} \mathrm{C}$ & $7{ }^{\circ} \mathrm{C}$ & WNW $20 \mathrm{KPH}$ & $50 \%$ & 35 & 40 & E04 & $1 a$ \\
\hline 21 & $2260 \times 1830$ & 236 & $\mathrm{NE}$ & 1:25 p.m & $3 / 12 / 2016$ & $10^{\circ} \mathrm{C}$ & $7^{\circ} \mathrm{C}$ & WNW $20 \mathrm{KPH}$ & $50 \%$ & 35 & 40 & E05 & $5 b$ \\
\hline 22 & $2260 \times 1830$ & 244 & SE & 2:14 p.m & $3 / 12 / 2016$ & $10^{\circ} \mathrm{C}$ & $7{ }^{\circ} \mathrm{C}$ & NW 24KHP & $50 \%$ & 26 & 31 & E07 & $4 \mathrm{~b}$ \\
\hline 23 & $2260 \times 1830$ & 246 & NE & 2:46 p.m & $3 / 12 / 2016$ & $8{ }^{\circ} \mathrm{C}$ & $5{ }^{\circ} \mathrm{C}$ & NW $18 \mathrm{KPH}$ & $50 \%$ & 26 & 31 & E05 & $5 b$ \\
\hline 24 & $2260 \times 1830$ & 247 & $\mathrm{SE}$ & 8:30 a.m & $16 / 12 / 2016$ & - & $(-7)^{\circ} \mathrm{C}$ - Feels $(-17)$ & W31KPH & $60 \%$ & 36 & 41 & E07 & $4 \mathrm{~b}$ \\
\hline 25 & $2260 \times 1830$ & 271 & $\mathrm{NE}$ & 10:00 a.m & $16 / 12 / 2016$ & - & $(-6)^{\circ} \mathrm{C}$ - Feels $(-17)$ & W31KPH & $60 \%$ & 36 & 41 & E05 & $5 c$ \\
\hline 26 & $2260 \times 1830$ & 274 & $\mathrm{NE}$ & 12:17 p.m & $16 / 12 / 2016$ & - & $(-5) \circ \mathrm{C}$ - Feels $(-14)$ & WSW29KPH & $60 \%$ & 23 & 27 & E06 & $5 c$ \\
\hline 27 & $2260 \times 1830$ & 277 & SE & 1:40 p.m & $16 / 12 / 2016$ & - & $(-5)^{\circ} \mathrm{C}$ - Feels $(-12)$ & WSW24KPH & $60 \%$ & 23 & 27 & E07 & $5 a$ \\
\hline 28 & $2260 \times 1830$ & 280 & NE & 2:50 p.m & $16 / 12 / 2016$ & - & $(-5)^{\circ} \mathrm{C}$ - Feels $(-12)$ & WSW24KPH & $60 \%$ & 23 & 27 & E05 & $5 c$ \\
\hline 29 & $2260 \times 1830$ & 282 & SE & 10.00 a.m & $12 / 28 / 2016$ & Very Hot & $(0){ }^{\circ} \mathrm{C}$ - Feels (-8) & W25KPH & $60 \%$ & 49 & 54 & E07 & $4 \mathrm{~b}$ \\
\hline 30 & $2260 \times 1830$ & 290 & NW & 12:10 p.m & $12 / 28 / 2016$ & Very Hot & $(0) \cdot C$ - Feels $(-8)$ & W25KPH & $60 \%$ & 49 & 54 & E04 & 1a \\
\hline 31 & $2260 \times 1830$ & 301 & NW & 2.00 p.m & $12 / 28 / 2016$ & Very Hot & $(0){ }^{\circ} \mathrm{C}$ - Feels $(-8)$ & W25KPH & $60 \%$ & 48 & 53 & E04 & 1a \\
\hline 32 & $2260 \times 1830$ & 310 & NW & 3.30 p.m & $12 / 28 / 2016$ & Normal temp & $(-1)^{\circ} \mathrm{C}$ - Feels (-8) & W25KPH & $60 \%$ & 54 & 59 & E04 & $1 a$ \\
\hline
\end{tabular}

Table 7- Test results 


\begin{tabular}{|c|c|c|c|c|c|c|c|c|c|c|c|}
\hline \multicolumn{4}{|c|}{ Extraneous Air leakage } & \multicolumn{4}{|c|}{ Total air leakage } & \multirow[b]{2}{*}{$\begin{array}{l}\text { Air leakage in } \\
25 \mathrm{~Pa}\end{array}$} & \multirow[b]{2}{*}{$\begin{array}{c}\text { Air leakage in } \\
50 \mathrm{~Pa}\end{array}$} & \multirow[b]{2}{*}{$\begin{array}{c}\text { Air leakage in } \\
75 \mathrm{~Pa}\end{array}$} & \multirow[b]{2}{*}{$\begin{array}{l}\text { Air leakage in } \\
100 \mathrm{~Pa}\end{array}$} \\
\hline SCFM in $25 \mathrm{~Pa}$ & SCFM in $50 \mathrm{~Pa}$ & SCFM in $75 \mathrm{~Pa}$ & SCFM in $100 \mathrm{~Pa}$ & SCFM in $25 \mathrm{~Pa}$ & SCFM in $50 \mathrm{~Pa}$ & SCFM in $75 \mathrm{~Pa}$ & SCFM in $100 \mathrm{~Pa}$ & & & & \\
\hline 8.5 & 9 & 9.8 & 10.5 & 9.5 & 12.5 & 14.8 & 16.2 & 0.022 & 0.079 & 0.112 & 0.13 \\
\hline 10.5 & 10.6 & 12.2 & 13.8 & 10.1 & 13.4 & 16.5 & 18.8 & -0.009 & 0.063 & 0.097 & 0.11 \\
\hline 8.8 & 14 & 15.1 & 16.8 & 9.8 & 14.1 & 16.8 & 19.7 & 0.022 & 0.002 & 0.038 & 0.07 \\
\hline 11.8 & 14.3 & 15.4 & 17.9 & 14 & 18.2 & 21.5 & 29.5 & 0.049 & 0.088 & 0.137 & 0.26 \\
\hline 9.8 & 10.8 & 12.9 & 13.8 & 10 & 13.8 & 15.4 & 17.3 & 0.004 & 0.067 & 0.056 & 0.08 \\
\hline 7.2 & 9.4 & 10.2 & 11.4 & 10.8 & 13.8 & 14.6 & 16.7 & 0.081 & 0.099 & 0.099 & 0.12 \\
\hline 8.9 & 11.4 & 12.5 & 13.9 & 11.8 & 16.3 & 18.9 & 21.7 & 0.065 & 0.110 & 0.144 & 0.18 \\
\hline 12.2 & 13.5 & 14.7 & 16.8 & 12.3 & 19.8 & 21.4 & 22.8 & 0.002 & 0.142 & 0.151 & 0.13 \\
\hline 7.2 & 9.2 & 10.8 & 11.8 & 9.1 & 12.6 & 15.3 & 16.2 & 0.043 & 0.076 & 0.101 & 0.10 \\
\hline 9.8 & 10.5 & 12.2 & 14.7 & 10.3 & 14.8 & 15.5 & 20.9 & 0.011 & 0.097 & 0.074 & 0.14 \\
\hline 8.1 & 9.4 & 11.9 & 12.4 & 8.8 & 14.7 & 16.8 & 19.1 & 0.016 & 0.119 & 0.110 & 0.15 \\
\hline 8.7 & 9.7 & 11.8 & 12.6 & 11.8 & 14.9 & 17.1 & 19.4 & 0.070 & 0.117 & 0.119 & 0.15 \\
\hline 7.8 & 9.8 & 10.3 & 11.3 & 20.5 & 23.8 & 27.1 & 30.1 & 0.285 & 0.314 & 0.377 & 0.42 \\
\hline 10.9 & 11 & 12.3 & 13.8 & 11.4 & 14.6 & 16.3 & 18.4 & 0.011 & 0.081 & 0.090 & 0.10 \\
\hline 8.3 & 9.2 & 12.8 & 13.2 & 11.8 & 16.9 & 20.2 & 24.1 & 0.079 & 0.173 & 0.166 & 0.24 \\
\hline 6.2 & 6.9 & 1.15 & 9 & 10.1 & 14.05 & 17.5 & 21.3 & 0.088 & 0.161 & 0.367 & 0.28 \\
\hline 8.4 & 9.1 & 10.1 & 12.2 & 15.1 & 18 & 19.3 & 22.4 & 0.151 & 0.200 & 0.207 & 0.23 \\
\hline 7.6 & 8.9 & 10.5 & 12 & 8.9 & 12.5 & 15.4 & 17.1 & 0.029 & 0.081 & 0.110 & 0.11 \\
\hline 8.9 & 12.2 & 14.05 & 16.2 & 9 & 12.5 & 14.4 & 16.4 & 0.002 & 0.007 & 0.008 & 0.00 \\
\hline 6.8 & 8.5 & 10.5 & 11.9 & 8.2 & 11.2 & 14 & 16.2 & 0.031 & 0.061 & 0.079 & 0.10 \\
\hline 8.5 & 11.2 & 11.4 & 13.2 & 7.9 & 13.3 & 16.4 & 19.9 & -0.013 & 0.047 & 0.112 & 0.15 \\
\hline 7.8 & 8.7 & 8.9 & 11.3 & 11.3 & 14 & 15.4 & 17.5 & 0.079 & 0.119 & 0.146 & 0.14 \\
\hline 8.5 & 12.2 & 15.3 & 20.4 & 13.2 & 18.3 & 22.3 & 24.9 & 0.106 & 0.137 & 0.157 & 0.10 \\
\hline 7.8 & 11 & 14.1 & 15.8 & 8.9 & 12.4 & 14.9 & 16.9 & 0.025 & 0.031 & 0.018 & 0.02 \\
\hline 7.8 & 8.9 & 10.1 & 12.7 & 8.1 & 9.2 & 11.1 & 12.2 & 0.007 & 0.007 & 0.022 & -0.01 \\
\hline 11.2 & 15.3 & 17.8 & 19.9 & 14.2 & 19.4 & 21.9 & 26.1 & 0.067 & 0.092 & 0.092 & 0.14 \\
\hline 9.9 & 11.2 & 12.9 & 14.8 & 10.2 & 15.1 & 19.8 & 22.1 & 0.007 & 0.088 & 0.155 & 0.16 \\
\hline 11.8 & 13.5 & 15.4 & 16.8 & 15.2 & 21.1 & 24.4 & 25 & 0.076 & 0.171 & 0.202 & 0.18 \\
\hline 3.8 & 7.9 & 9.8 & 12.1 & 3.8 & 7.2 & 10.5 & 13.1 & 0.000 & -0.016 & 0.016 & 0.02 \\
\hline \multirow[t]{2}{*}{7.1} & 12.2 & 17.2 & 19.7 & 4 & 12.7 & 15.2 & 19.8 & -0.070 & 0.011 & -0.045 & 0.00 \\
\hline & 7.2 & 7.5 & 8.7 & 8.1 & 11.8 & 14.7 & 15.9 & 0.182 & 0.103 & 0.162 & 0.16 \\
\hline 8.2 & 12.3 & 14.8 & 16.2 & 11.8 & 16.8 & 19.8 & 23.9 & 0.081 & 0.101 & 0.112 & 0.17 \\
\hline
\end{tabular}

Table 8- Test results 


\begin{tabular}{|c|c|c|c|c|c|c|c|c|c|c|c|c|c|c|c|}
\hline $\begin{array}{c}\text { Temp standard } \\
\text { flow (SCFM) at } \\
25 \mathrm{~Pa}\end{array}$ & $\begin{array}{c}\text { Temp standard } \\
\text { flow (SCFM) at } \\
50 \mathrm{~Pa}\end{array}$ & $\begin{array}{c}\text { Temp standard } \\
\text { flow (SCFM) at } \\
75 \mathrm{~Pa}\end{array}$ & $\begin{array}{c}\text { Temp standard } \\
\text { flow (SCFM) at } \\
100 \mathrm{~Pa}\end{array}$ & $\begin{array}{l}\text { Temp standard } \\
\text { flow }(L / s) \text { at 25Pa }\end{array}$ & $\begin{array}{c}\text { Temp standard } \\
\text { flow }(\mathrm{L} / \mathrm{s}) \text { at } 50 \mathrm{~Pa}\end{array}$ & $\begin{array}{c}\text { Temp standard } \\
\text { flow (L/s) at 75Pa }\end{array}$ & $\mid \begin{array}{c}\text { Temp standard } \\
\text { flow }(\mathrm{L} / \mathrm{s}) \text { at } 100 \mathrm{~Pa}\end{array}$ & $\begin{array}{c}\text { Air leakage } \\
(\mathrm{L} / \mathrm{s}) / \mathrm{m} 2 \mathrm{mat} 25 \mathrm{~Pa}\end{array}$ & $\begin{array}{c}\text { Air leakage } \\
(\mathrm{L} / \mathrm{s}) / \mathrm{m} 2 \mathrm{2at} 50 \mathrm{~Pa}\end{array}$ & $\begin{array}{c}\text { Air leakage } \\
(\mathrm{L} / \mathrm{s}) / \mathrm{m} 2 \mathrm{at} 75 \mathrm{~Pa}\end{array}$ & $\begin{array}{c}\text { Air leakage } \\
(\mathrm{L} / \mathrm{s}) / \mathrm{m} 2 \mathrm{at} 100 \mathrm{~Pa}\end{array}$ & $\begin{array}{c}\text { Standardized Air } \\
\text { leakage } \\
\left(\text { SCFM/ } / \mathrm{ft}^{2}\right) \text { at } 25 \\
\text { pa }\end{array}$ & $\begin{array}{c}\text { Standardized Air } \\
\text { leakage } \\
\left(\text { SCFM/ } / \mathrm{ft}^{2}\right) \text { at } 50 \\
\text { pa }\end{array}$ & $\begin{array}{c}\text { Standardized Air } \\
\text { leakage } \\
\left(\text { SCFM/ } / \mathrm{ft}^{2}\right) \text { at } 75 \\
\text { pa }\end{array}$ & $\begin{array}{c}\text { Standardized Air } \\
\text { leakage } \\
\left(\text { SCFM/ } / \mathrm{ft}^{2}\right) \text { at } 100 \\
\text { pa }\end{array}$ \\
\hline 1.030 & 3.605 & 5.150 & 5.870 & 0.484 & 1.694 & 2.420 & 2.759 & 0.117 & 0.410 & 0.585 & 0.667 & 0.023 & 0.081 & 0.116 & 0.132 \\
\hline-0.412 & 2.884 & 4.429 & 5.150 & -0.194 & 1.355 & 2.081 & 2.420 & -0.047 & 0.328 & 0.503 & 0.585 & -0.009 & 0.065 & 0.099 & 0.116 \\
\hline 1.030 & 0.103 & 1.751 & 2.987 & 0.484 & 0.048 & 0.823 & 1.404 & 0.117 & 0.012 & 0.199 & 0.339 & 0.023 & 0.002 & 0.039 & 0.067 \\
\hline 2.266 & 4.017 & 6.282 & 11.947 & 1.065 & 1.888 & 2.953 & 5.615 & 0.257 & 0.456 & 0.714 & 1.358 & 0.051 & 0.090 & 0.141 & 0.268 \\
\hline 0.206 & 3.090 & 2.575 & 3.605 & 0.097 & 1.452 & 1.210 & 1.694 & 0.023 & 0.351 & 0.293 & 0.410 & 0.005 & 0.069 & 0.058 & 0.081 \\
\hline 3.708 & 4.532 & 4.532 & 5.458 & 1.743 & 2.130 & 2.130 & 2.565 & 0.421 & 0.515 & 0.515 & 0.620 & 0.083 & 0.102 & 0.102 & 0.123 \\
\hline 2.987 & 5.047 & 6.591 & 8.033 & 1.404 & 2.372 & 3.098 & 3.776 & 0.339 & 0.573 & 0.749 & 0.913 & 0.067 & 0.113 & 0.148 & 0.180 \\
\hline 0.109 & 6.839 & 7.273 & 6.513 & 0.051 & 3.214 & 3.418 & 3.061 & 0.012 & 0.729 & 0.775 & 0.694 & 0.002 & 0.144 & 0.153 & 0.137 \\
\hline 2.063 & 3.691 & 4.885 & 4.776 & 0.969 & 1.735 & 2.296 & 2.245 & 0.220 & 0.393 & 0.521 & 0.509 & 0.050 & 0.089 & 0.118 & 0.115 \\
\hline 0.543 & 4.668 & 3.582 & 6.730 & 0.255 & 2.194 & 1.684 & 3.163 & 0.058 & 0.497 & 0.407 & 0.765 & 0.013 & 0.113 & 0.092 & 0.173 \\
\hline 0.760 & 5.458 & 5.319 & 7.273 & 0.357 & 2.565 & 2.500 & 3.418 & 0.086 & 0.620 & 0.604 & 0.827 & 0.021 & 0.150 & 0.146 & 0.200 \\
\hline 3.365 & 5.355 & 5.753 & 7.382 & 1.582 & 2.517 & 2.704 & 3.469 & 0.382 & 0.609 & 0.654 & 0.839 & 0.092 & 0.147 & 0.158 & 0.203 \\
\hline 13.786 & 14.419 & 18.237 & 20.408 & 6.480 & 6.777 & 8.571 & 9.592 & 1.567 & 1.639 & 2.073 & 2.319 & 0.379 & 0.396 & 0.501 & 0.561 \\
\hline 0.532 & 3.827 & 4.252 & 4.890 & 0.250 & 1.799 & 1.999 & 2.298 & 0.060 & 0.435 & 0.483 & 0.556 & 0.015 & 0.105 & 0.117 & 0.134 \\
\hline 3.721 & 8.186 & 7.867 & 11.588 & 1.749 & 3.847 & 3.698 & 5.446 & 0.423 & 0.930 & 0.894 & 1.317 & 0.102 & 0.225 & 0.216 & 0.318 \\
\hline 4.146 & 7.601 & 17.382 & 13.076 & 1.949 & 3.573 & 8.170 & 6.146 & 0.471 & 0.864 & 1.975 & 1.486 & 0.114 & 0.209 & 0.478 & 0.359 \\
\hline 7.123 & 9.462 & 9.781 & 10.844 & 3.348 & 4.447 & 4.597 & 5.097 & 0.809 & 1.075 & 1.112 & 1.232 & 0.196 & 0.260 & 0.269 & 0.298 \\
\hline 1.382 & 3.827 & 5.209 & 5.422 & 0.650 & 1.799 & 2.448 & 2.548 & 0.157 & 0.435 & 0.592 & 0.616 & 0.038 & 0.105 & 0.143 & 0.149 \\
\hline 0.106 & 0.319 & 0.372 & 0.213 & 0.050 & 0.150 & 0.175 & 0.100 & 0.012 & 0.036 & 0.042 & 0.024 & 0.003 & 0.009 & 0.010 & 0.006 \\
\hline 1.488 & 2.870 & 3.721 & 4.571 & 0.700 & 1.349 & 1.749 & 2.149 & 0.169 & 0.326 & 0.423 & 0.520 & 0.041 & 0.079 & 0.102 & 0.126 \\
\hline-0.638 & 2.233 & 5.316 & 7.123 & -0.300 & 1.049 & 2.498 & 3.348 & -0.072 & 0.254 & 0.604 & 0.809 & -0.018 & 0.061 & 0.146 & 0.196 \\
\hline 3.721 & 5.635 & 6.910 & 6.591 & 1.749 & 2.648 & 3.248 & 3.098 & 0.423 & 0.640 & 0.785 & 0.749 & 0.102 & 0.155 & 0.190 & 0.181 \\
\hline 4.997 & 6.485 & 7.442 & 4.784 & 2.348 & 3.048 & 3.498 & 2.249 & 0.568 & 0.737 & 0.846 & 0.544 & 0.137 & 0.178 & 0.204 & 0.131 \\
\hline 1.260 & 1.603 & 0.916 & 1.260 & 0.592 & 0.754 & 0.431 & 0.592 & 0.143 & 0.182 & 0.104 & 0.143 & 0.035 & 0.044 & 0.025 & 0.035 \\
\hline 0.344 & 0.344 & 1.145 & -0.573 & 0.161 & 0.161 & 0.538 & -0.269 & 0.039 & 0.039 & 0.130 & -0.065 & 0.009 & 0.009 & 0.031 & -0.016 \\
\hline 3.389 & 4.631 & 4.631 & 7.003 & 1.593 & 2.177 & 2.177 & 3.292 & 0.385 & 0.526 & 0.526 & 0.796 & 0.093 & 0.127 & 0.127 & 0.192 \\
\hline 0.339 & 4.405 & 7.794 & 8.246 & 0.159 & 2.070 & 3.663 & 3.876 & 0.039 & 0.501 & 0.886 & 0.937 & 0.009 & 0.121 & 0.214 & 0.227 \\
\hline 3.841 & 8.585 & 10.166 & 9.262 & 1.805 & 4.035 & 4.778 & 4.353 & 0.436 & 0.976 & 1.155 & 1.053 & 0.106 & 0.236 & 0.279 & 0.255 \\
\hline 0.000 & -0.773 & 0.773 & 1.105 & 0.000 & -0.363 & 0.363 & 0.519 & 0.000 & -0.088 & 0.088 & 0.126 & 0.000 & -0.021 & 0.021 & 0.030 \\
\hline \multirow[t]{2}{*}{-3.424} & 0.552 & -2.209 & 0.110 & -1.609 & 0.260 & -1.038 & 0.052 & -0.389 & 0.063 & -0.251 & 0.013 & -0.094 & 0.015 & -0.061 & 0.003 \\
\hline & 5.081 & 7.953 & 7.953 & & 2.388 & 3.738 & 3.738 & & 0.577 & 0.904 & 0.904 & & 0.140 & 0.219 & 0.219 \\
\hline 3.977 & 4.971 & 5.523 & 8.506 & 1.869 & 2.336 & 2.596 & 3.998 & 0.452 & 0.565 & 0.628 & 0.967 & 0.109 & 0.137 & 0.152 & 0.234 \\
\hline
\end{tabular}

Table 9- Test results 
Appendix C Raw Data Collection 


\section{Field Test Reposts}

\section{Test No.1}

\begin{tabular}{|l|l|}
\hline Date & $11 / 19 / 2016$ \\
\hline Time & $7: 30 \mathrm{AM}$ \\
\hline Suite & E10 \\
\hline Level & 47 construction/52 marketing \\
\hline
\end{tabular}

\section{Sample Description}

\begin{tabular}{|l|l|}
\hline Model & Double glazed, Argon gas filled \\
\hline Door type & $6 \mathrm{~mm}$ ESR42 Temp (PURCH) / 1" Black spacer/6 mm CLR Temp (PURCH) \\
\hline Size & $2260 \mathrm{~mm} \times 1830 \mathrm{~mm}$ \\
\hline Operation type & Sliding door \\
\hline
\end{tabular}

\section{Ambient Test Condition}

\begin{tabular}{|l|l|}
\hline Temperature inside & $12 \circ \mathrm{C}$ \\
\hline Temperature outside & $10 \circ \mathrm{C}$ \\
\hline Density of air at test site & $1.24 \mathrm{Kg} / \mathrm{m} 3$ \\
\hline Relative humidity & $80 \%$ \\
\hline Wind speed & W20 KPH \\
\hline
\end{tabular}

\section{Visual Observation}

Discontinuity of weather stripping. Improper sealing at the top jamb of door frame panel. Discontinuity of exterior caulking at door frame and soffit interface. The backer rod was observable.

\section{Readings}

Air flow rate at nonstandard condition

\begin{tabular}{|l|l|l|l|l|}
\hline Pressure difference & $\mathbf{0 . 1}(\mathbf{2 5}$ pa) & $\mathbf{0 . 2}$ (50 pa) & $\mathbf{0 . 3}$ (75 pa) & $\mathbf{0 . 4}(100$ pa) \\
\hline Air flow Q (Scfm) & 8.5 & 9 & 9.8 & 10.5 \\
\hline
\end{tabular}

Extraneous air flow rate at nonstandard condition

\begin{tabular}{|l|l|l|l|l|}
\hline Pressure difference & $\mathbf{0 . 1}(\mathbf{2 5}$ pa) & $0.2(50$ pa) & 0.3 (75 pa) & $0.4(100$ pa) \\
\hline Air flow EQ (Scfm) & 9.5 & 12.5 & 14.8 & 16.2 \\
\hline
\end{tabular}

Air leakage rate

\begin{tabular}{|c|c|c|c|c|}
\hline$Q d=E Q-Q(S c f m)$ & 0.1 (25 pa) & 0.2 (50 pa) & 0.3 (75 pa) & $0.4(100$ pa) \\
\hline $\begin{array}{l}\text { Temperature corrected Flow Rate } \\
\text { (Scfm) }\end{array}$ & 1 & 3.5 & 5 & 5.7 \\
\hline $\begin{array}{l}\text { Temperature corrected Flow Rate } \\
\text { (L/s) }\end{array}$ & 1.030 & 3.605 & 5.150 & 5.870 \\
\hline Standard air leakage $\left(\mathrm{L} / \mathrm{s} / \mathrm{m}^{2}\right)$ & 0.484 & 1.694 & 2.420 & 2.759 \\
\hline Standardized air leakage $\left(\mathrm{Scfm} / \mathrm{ft}^{2}\right)$ & 0.117 & 0.410 & 0.585 & 0.667 \\
\hline$Q d=E Q-Q(S c f m)$ & 0.023 & 0.081 & 0.116 & 0.132 \\
\hline
\end{tabular}



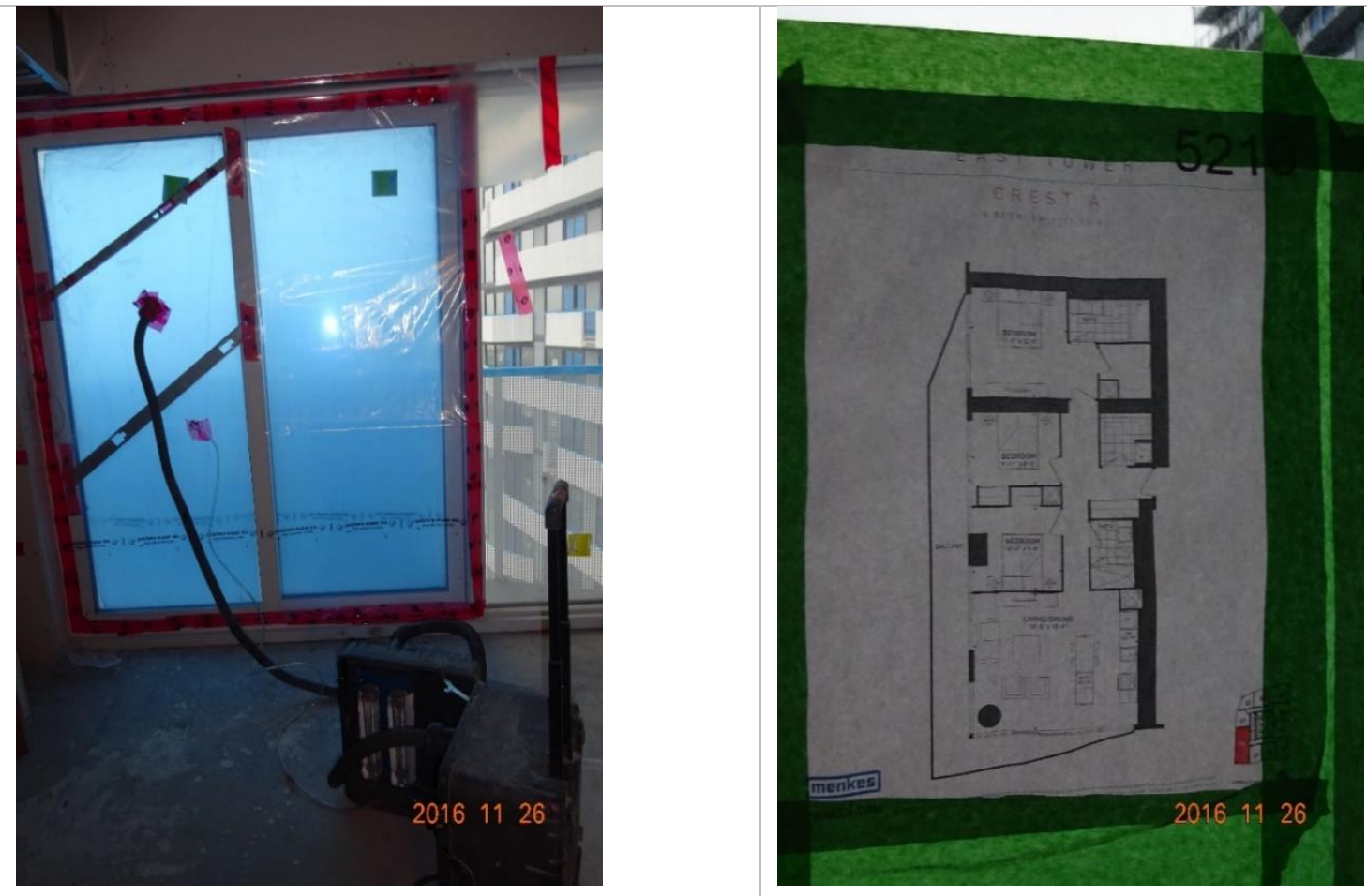

Interior view

Unit plan and location of the test unit
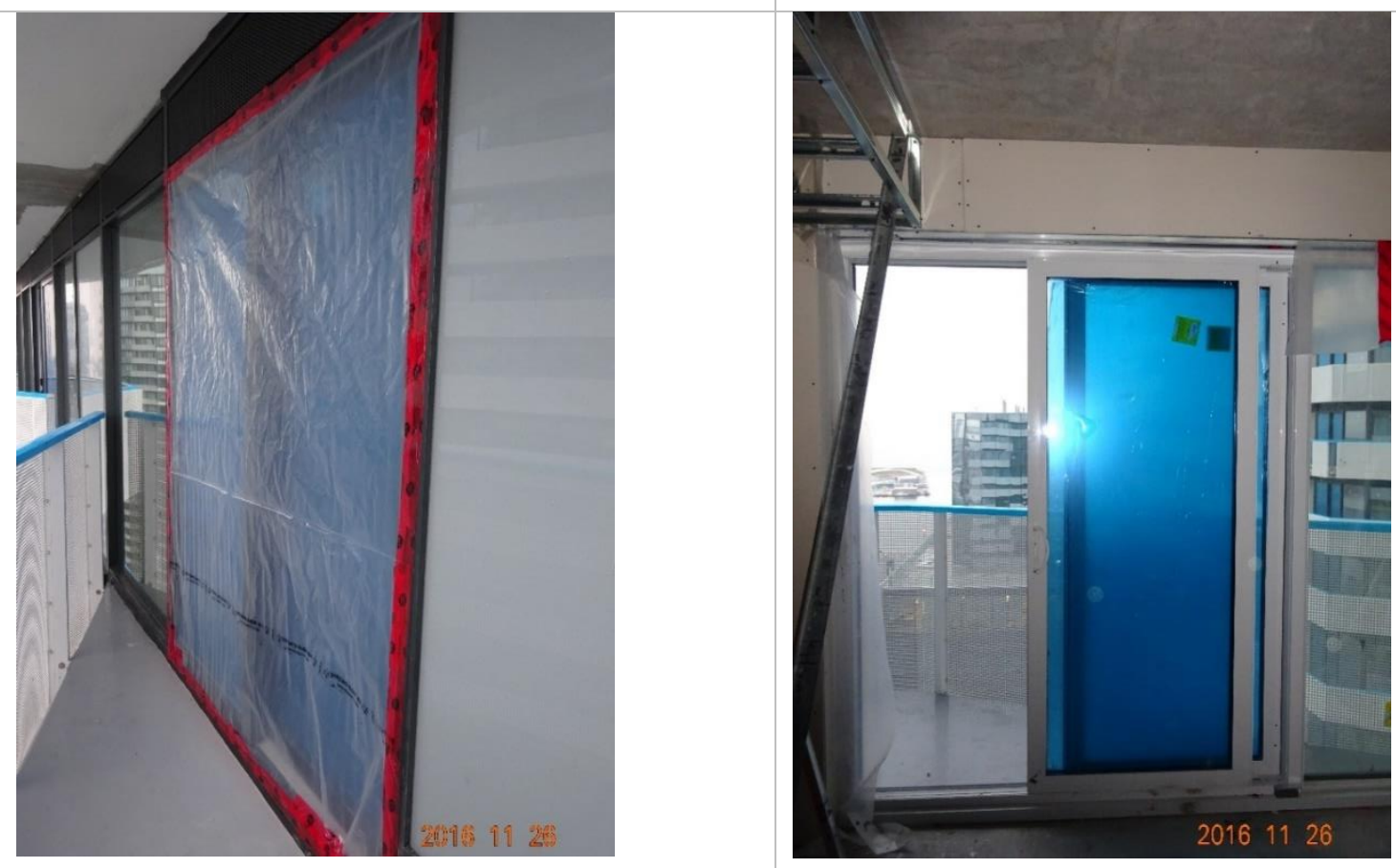

Exterior view

Interior view 


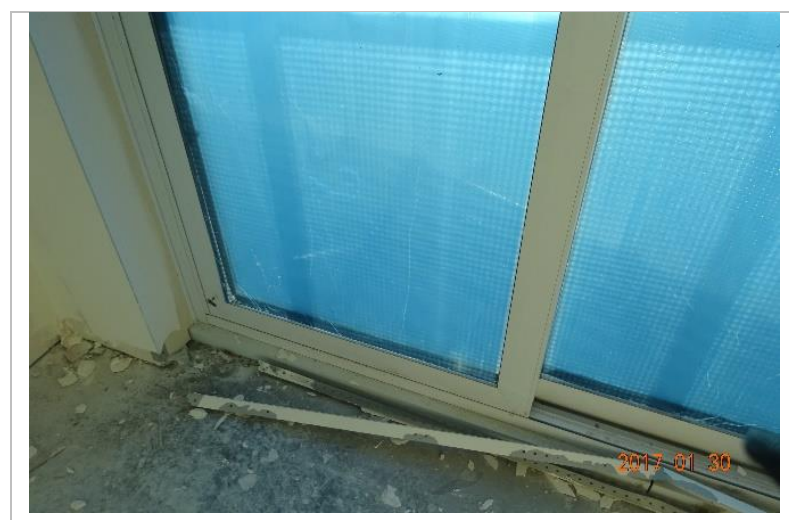

Door track

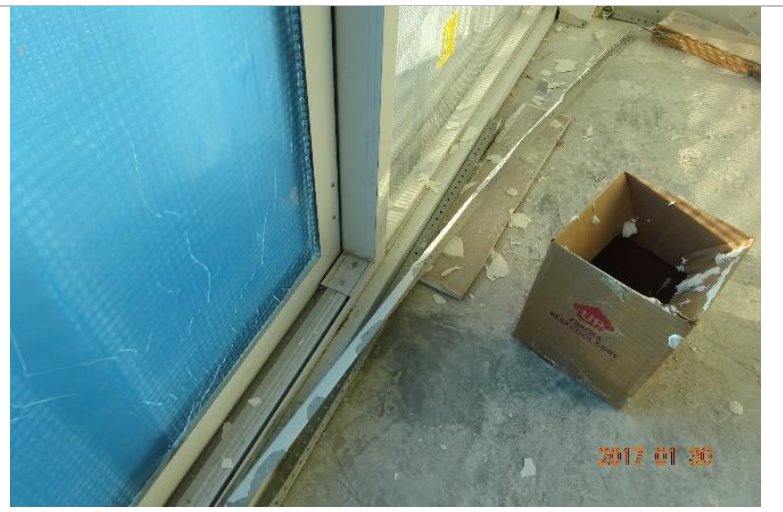

Door track

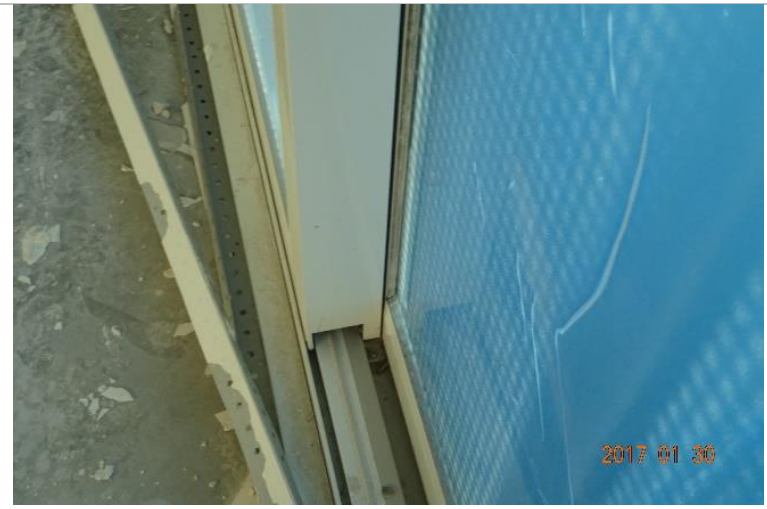

Door track

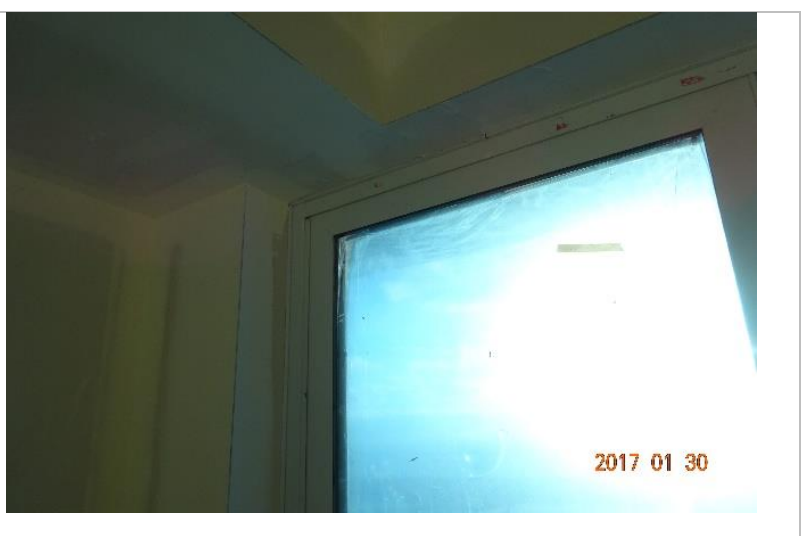

Interior view of door head

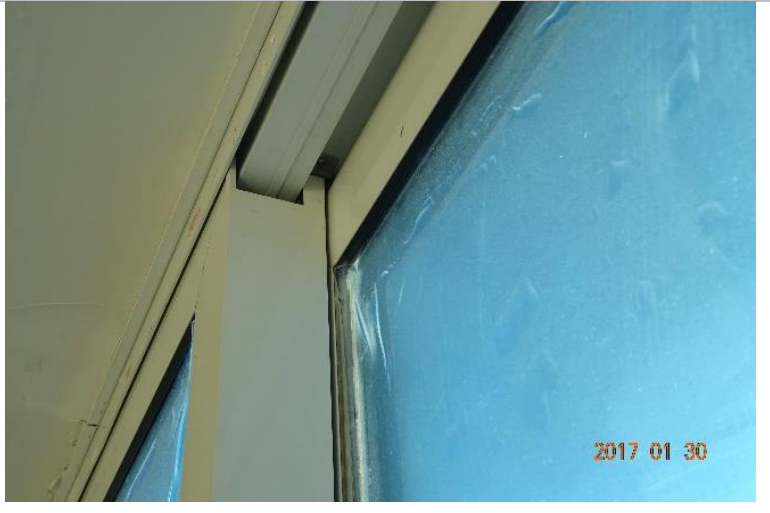

Meeting stile at door head

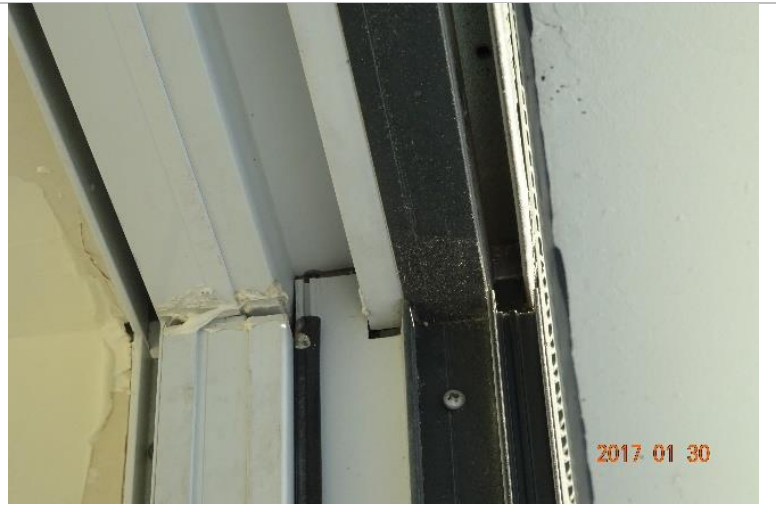

Fixed frame panel joint and weather stripping 


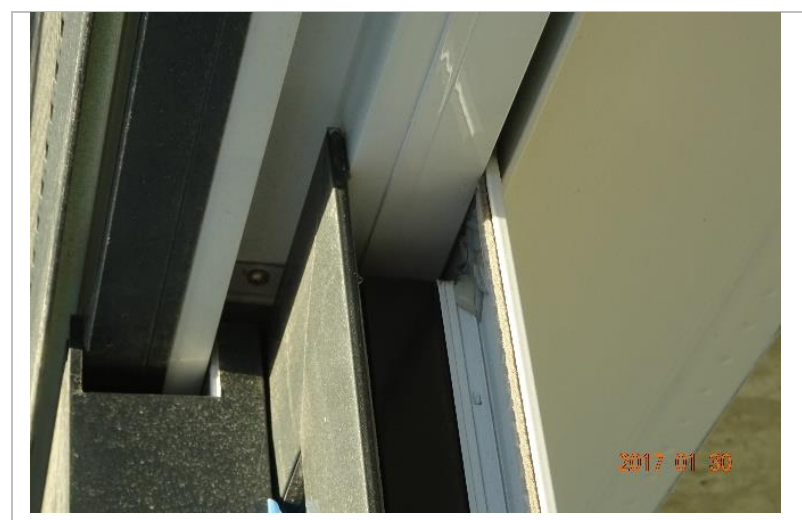

Door head track

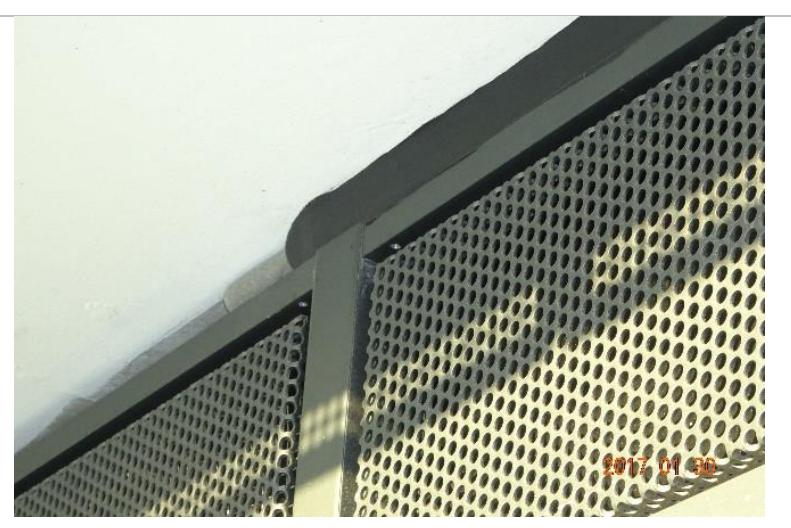

Door head exterior interfaces

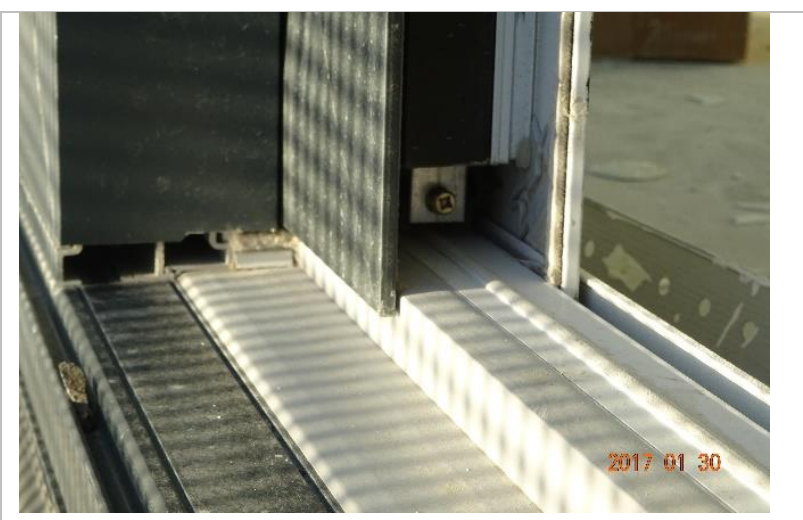

Dust plug

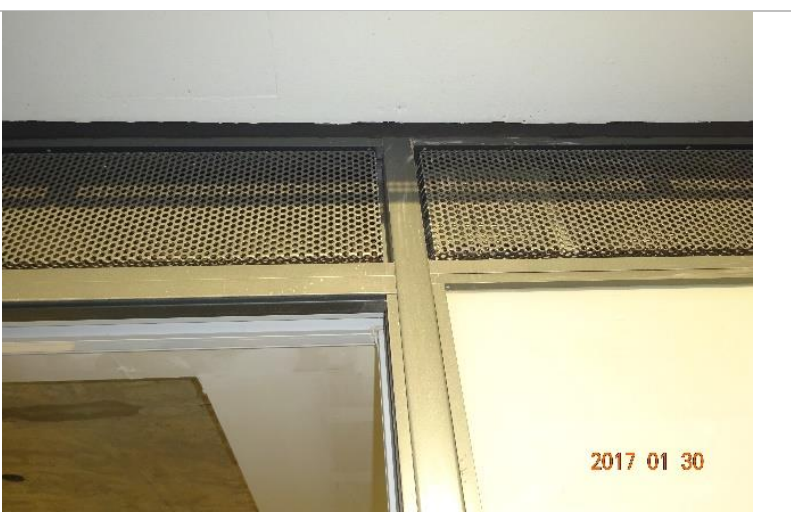

Door head exterior interfaces

\section{Discussion}

As it is shown in the calculation above at the standard test pressure condition of 75 Pascal, air leakage will exceed the lab achieved results and reach to $0.58\left(\mathrm{~L} / \mathrm{s} / \mathrm{m}^{2}\right)$. Despite the higher rate of air leakage, the door has not failed as the air leakage rate does not exceed the allowed range.

The exterior interfaces joint and caulking may not be considered as part of the test specimen, but due to continuity of side frames to the concrete soffit above, if interior joint sealants has any failure, sliding door may show higher rates of air infiltration.

Discontinuity of weather stripping at door meeting stile may also contribute to slightly higher ranges of air leakage rate than the standard one. 


\section{Test No.2}

\begin{tabular}{|l|l|}
\hline Date & $11 / 19 / 2016$ \\
\hline Time & $9: 00 \mathrm{AM}$ \\
\hline Suite & E05 \\
\hline Level & 46 construction/51 marketing \\
\hline
\end{tabular}

\section{Sample Description}

\begin{tabular}{|l|l|}
\hline Model & Double glazed, Argon gas filled \\
\hline Door type & $6 \mathrm{~mm}$ ESR42 Temp (PURCH) / 1" Black spacer/6 mm CLR Temp (PURCH) \\
\hline Assembly Type & $5 \mathrm{~b}$ \\
\hline Size & $2260 \mathrm{~mm} \times 1830 \mathrm{~mm}$ \\
\hline Operation type & Sliding door \\
\hline
\end{tabular}

\section{Ambient Test Condition}

\begin{tabular}{|l|l|}
\hline Temperature inside & $12{ }^{\circ} \mathrm{C}$ \\
\hline Temperature outside & $10 \circ \mathrm{C}$ \\
\hline Density of air at test site & $1.24 \mathrm{Kg} / \mathrm{m} 3$ \\
\hline Relative humidity & $80 \%$ \\
\hline Wind speed & W20 KPH
\end{tabular}

\section{Visual Observation}

No specific deficiency observed at the time of review. Extra bead of sealant is applied at fixed frame corner joints.

\section{Readings}

Air flow rate at nonstandard condition

\begin{tabular}{|l|l|l|l|l|}
\hline Pressure difference & $\mathbf{0 . 1}(\mathbf{2 5}$ PA) & $\mathbf{0 . 2}$ (50 PA) & $\mathbf{0 . 3}$ (75 PA) & $\mathbf{0 . 4}(100$ PA) \\
\hline Air flow Q (Scfm) & 10.5 & 10.6 & 12.2 & 13.8 \\
\hline
\end{tabular}

Extraneous air flow rate at nonstandard condition

\begin{tabular}{|l|l|l|l|l|}
\hline Pressure difference & 0.1 (25 PA) & $0.2(50$ PA) & 0.3 (75 PA) & 0.4 (100 PA) \\
\hline Air flow EQ (Scfm) & 10.1 & 13.9 & 16.5 & 18.8 \\
\hline
\end{tabular}

Air leakage rate

\begin{tabular}{|c|c|c|c|c|}
\hline Pressure difference & 0.1 (25 PA) & 0.2 (50 PA) & 0.3 (75 PA) & 0.4 (100 PA) \\
\hline$Q d=E Q-Q(S c f m)$ & -0.4 & 3.3 & 4.3 & 5 \\
\hline $\begin{array}{l}\text { Temperature corrected Flow Rate } \\
\text { (Scfm) }\end{array}$ & -0.412 & 2.884 & 4.429 & 5.150 \\
\hline $\begin{array}{l}\text { Temperature corrected Flow Rate } \\
\text { (L/s) }\end{array}$ & -0.194 & 1.355 & 2.081 & 2.420 \\
\hline Standard air leakage $\left(\mathrm{L} / \mathrm{s} / \mathrm{m}^{2}\right)$ & -0.047 & 0.328 & 0.503 & 0.585 \\
\hline Standardized air leakage $\left(\mathrm{Scfm} / \mathrm{ft}^{2}\right)$ & -0.009 & 0.065 & 0.099 & 0.116 \\
\hline
\end{tabular}




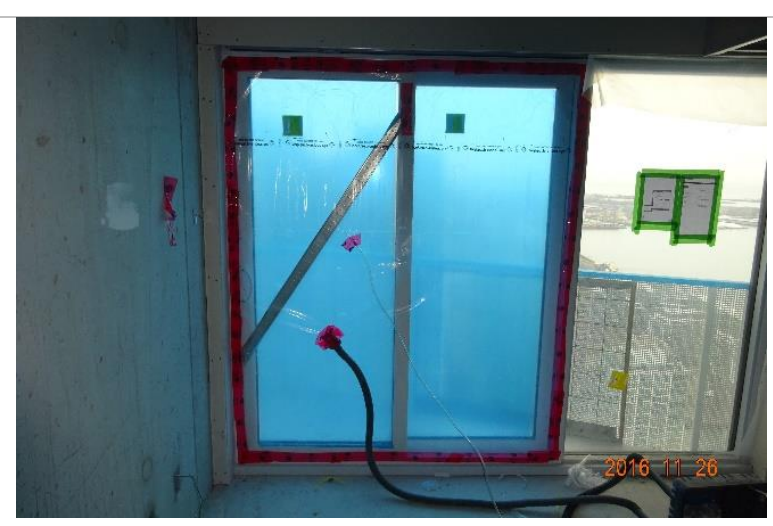

Interior view

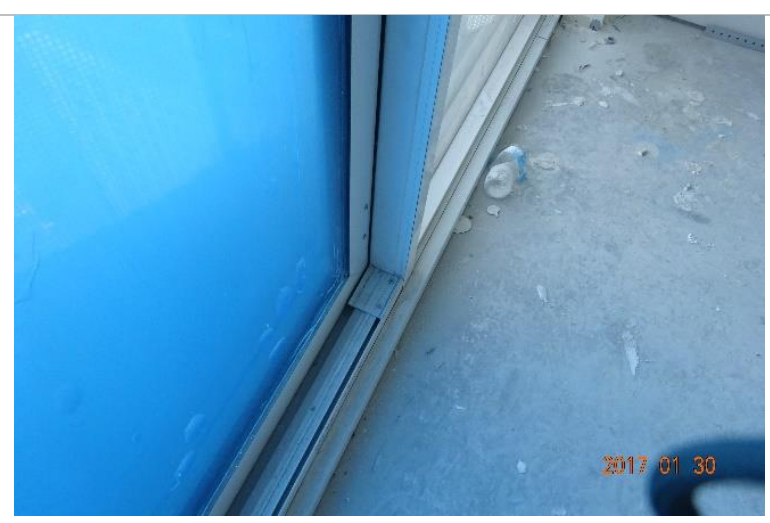

Door sill track

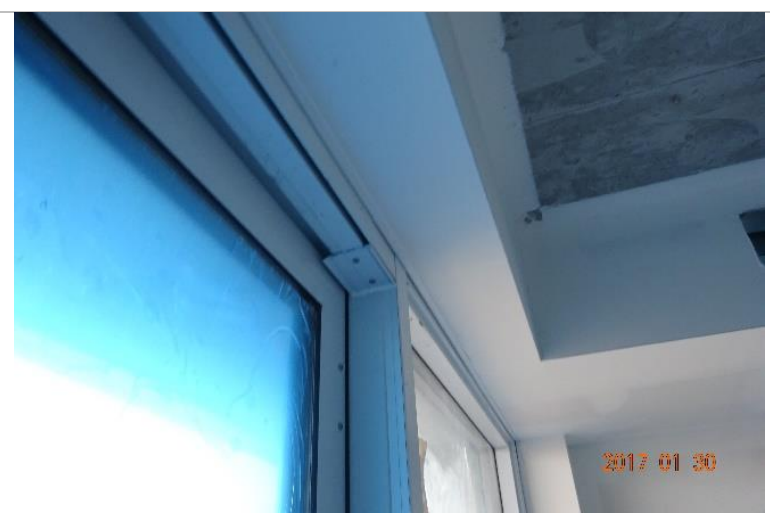

Door head track

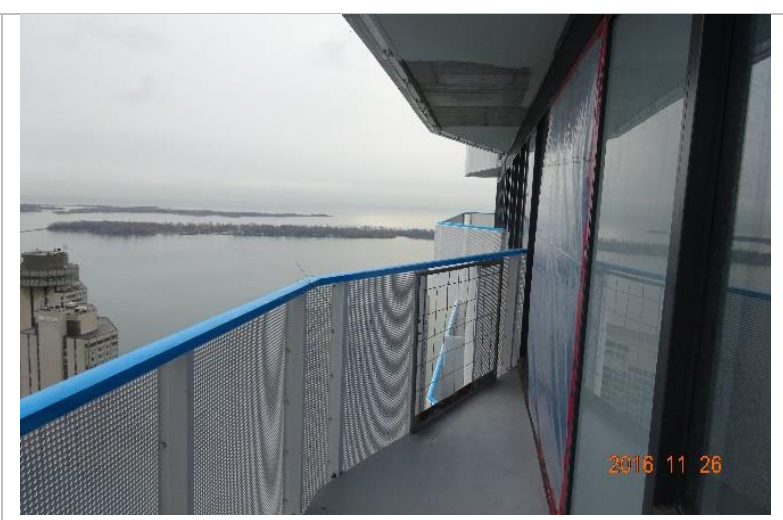

Exterior view

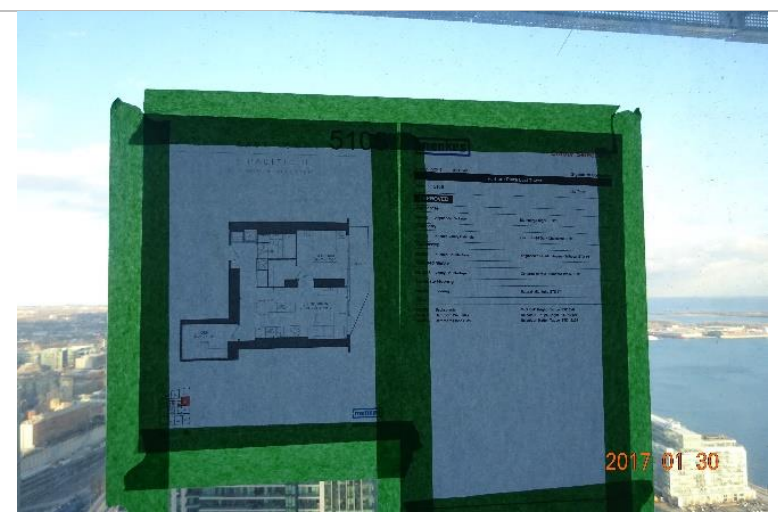

Unit plan and location of the test unit

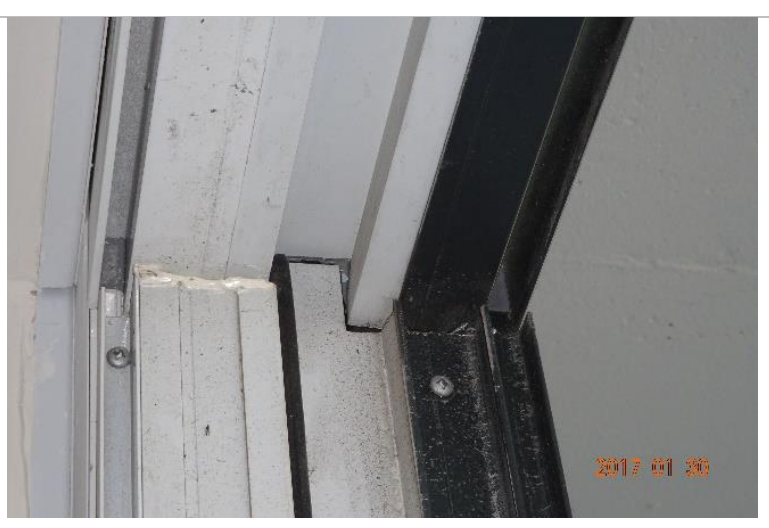

Fixed frame panel joint and weather stripping 

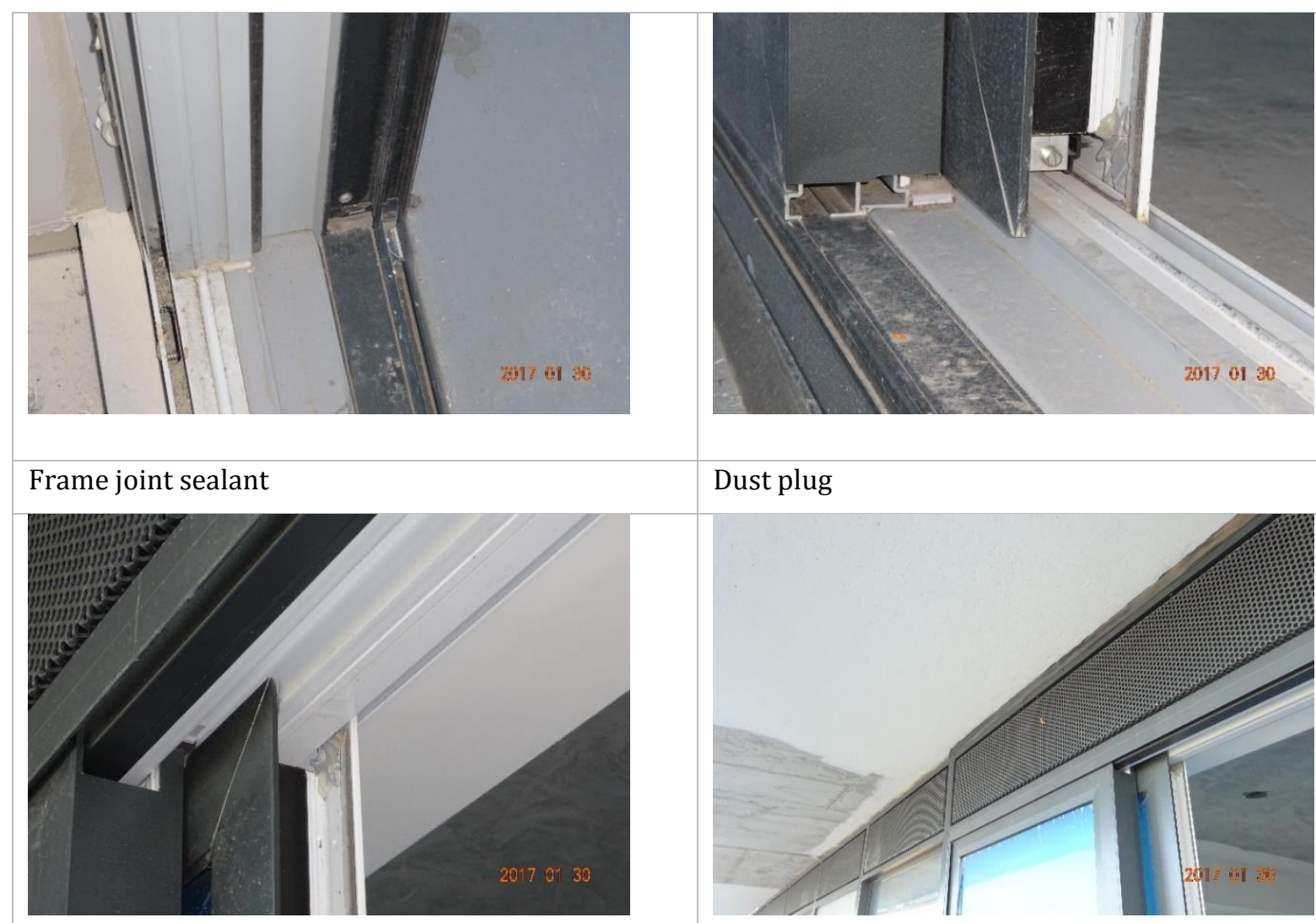

Dust plug
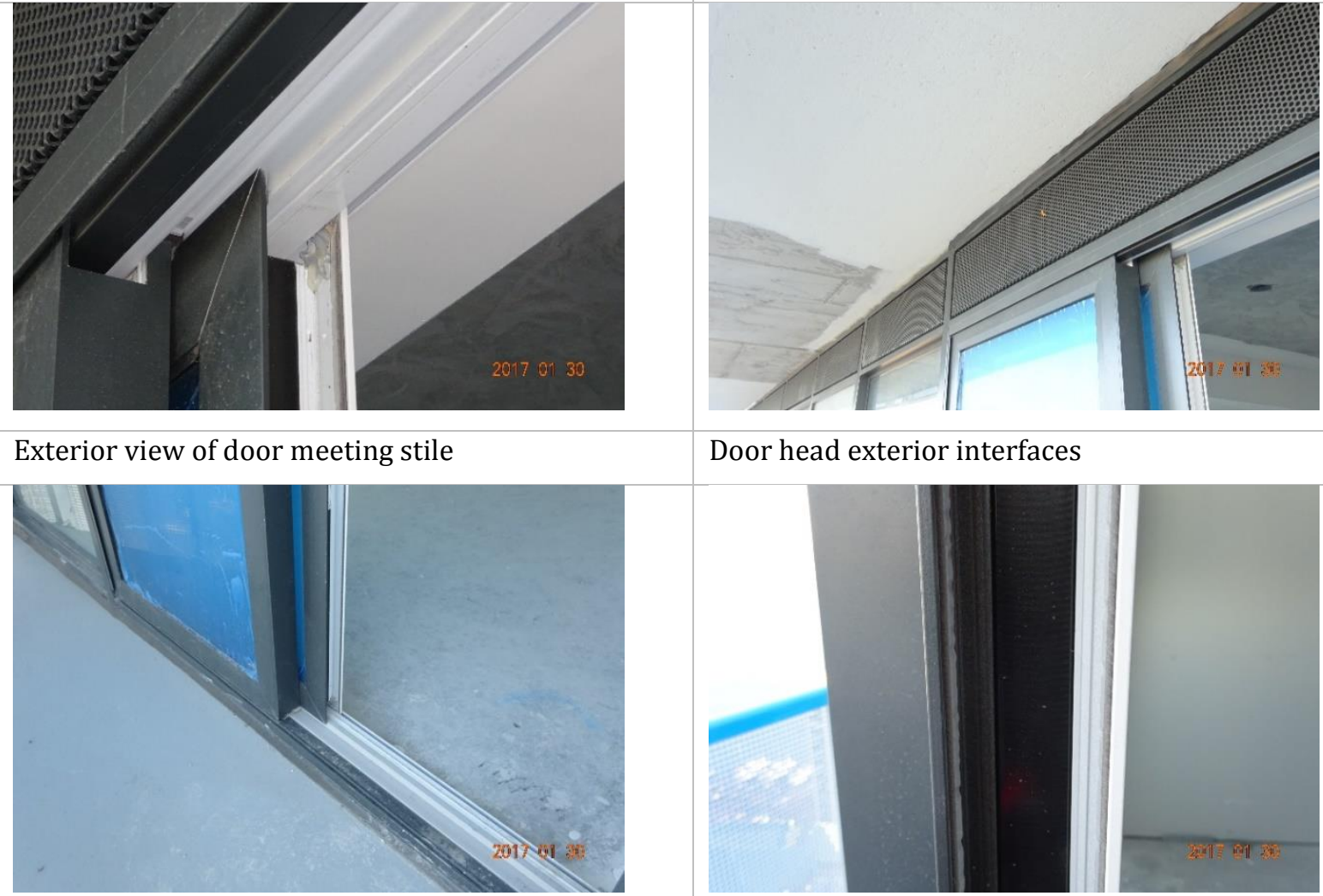

Door head exterior interfaces

Meeting stile at door sill

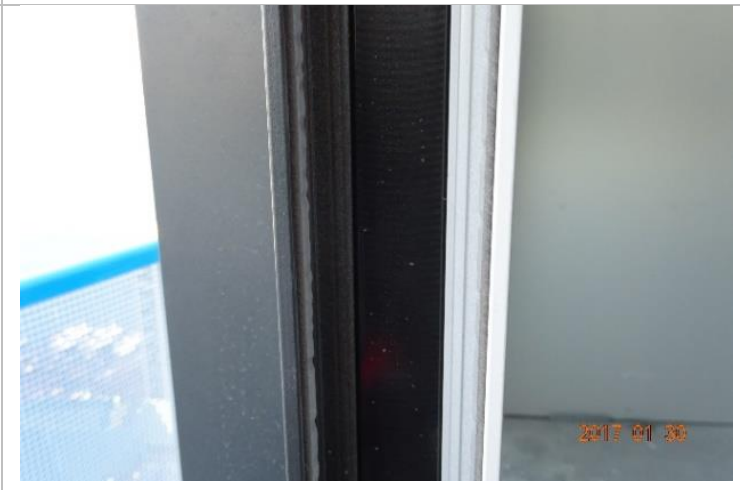

Weather stripping at meeting stile

\section{Discussion:}

The visual inspection was showing that the door assembly is in a good shape. Extra sealant was observed, applied at fixed frame panel joints. The door has achieved the lab tested air tightness test result and performed well. 


\section{Test No.3}

\begin{tabular}{|l|l|}
\hline Date & $11 / 19 / 2016$ \\
\hline Time & $10: 00 \mathrm{AM}$ \\
\hline Suite & E05 \\
\hline Level & 43 construction/48 marketing \\
\hline
\end{tabular}

\section{Sample Description}

\begin{tabular}{|l|l|}
\hline Model & Double glazed, Argon gas filled \\
\hline Door type & $6 \mathrm{~mm}$ ESR42 Temp (PURCH) / 1" Black spacer/6 mm CLR Temp (PURCH) \\
\hline Assembly Type & $5 \mathrm{~b}$ \\
\hline Size & $2260 \mathrm{~mm} \times 1830 \mathrm{~mm}$ \\
\hline Operation type & Sliding door \\
\hline
\end{tabular}

\section{Ambient Test Condition}

\begin{tabular}{|l|l|}
\hline Temperature inside & $12^{\circ} \mathrm{C}$ \\
\hline Temperature outside & $10^{\circ} \mathrm{C}$ \\
\hline Density of air at test site & $1.24 \mathrm{Kg} / \mathrm{m} 3$ \\
\hline Relative humidity & $80 \%$ \\
\hline Wind speed & W20 KPH \\
\hline
\end{tabular}

\section{Visual Observation}

No specific deficiency observed at the time of review

\section{Readings}

Air flow rate at nonstandard condition

\begin{tabular}{|l|l|l|l|l|}
\hline Pressure difference & $\mathbf{0 . 1}$ (25 PA) & $\mathbf{0 . 2}$ (50 PA) & $\mathbf{0 . 3}$ (75 PA) & 0.4 (100 PA) \\
\hline Air flow Q (Scfm) & 8.8 & 14 & 15.1 & 16.8
\end{tabular}

Extraneous air flow rate at nonstandard condition

\begin{tabular}{|l|l|l|l|l|}
\hline Pressure difference & $\mathbf{0 . 1}(\mathbf{2 5}$ PA) & $\mathbf{0 . 2}$ (50 PA) & $\mathbf{0 . 3}$ (75 PA) & $\mathbf{0 . 4}(100$ PA) \\
\hline Air flow EQ (Scfm) & 9.8 & 14.1 & 16.8 & 19.7 \\
\hline
\end{tabular}

Air leakage rate

\begin{tabular}{|c|c|c|c|c|}
\hline Pressure difference & 0.1 (25 PA) & 0.2 (50 PA) & 0.3 (75 PA) & 0.4 (100 PA) \\
\hline$Q d=E Q-Q(S c f m)$ & 1 & 0.1 & 1.7 & 3.1 \\
\hline $\begin{array}{l}\text { Temperature corrected Flow Rate } \\
\text { (Scfm) }\end{array}$ & 1.030 & 0.103 & 1.751 & 2.987 \\
\hline $\begin{array}{l}\text { Temperature corrected Flow Rate } \\
\text { (L/s) }\end{array}$ & 0.484 & 0.048 & 0.823 & 1.404 \\
\hline Standard air leakage $\left(\mathrm{L} / \mathrm{s} / \mathrm{m}^{2}\right)$ & 0.117 & 0.012 & 0.199 & 0.339 \\
\hline Standardized air leakage $\left(\mathrm{Scfm} / \mathrm{ft}^{2}\right)$ & 0.023 & 0.002 & 0.039 & 0.067 \\
\hline
\end{tabular}



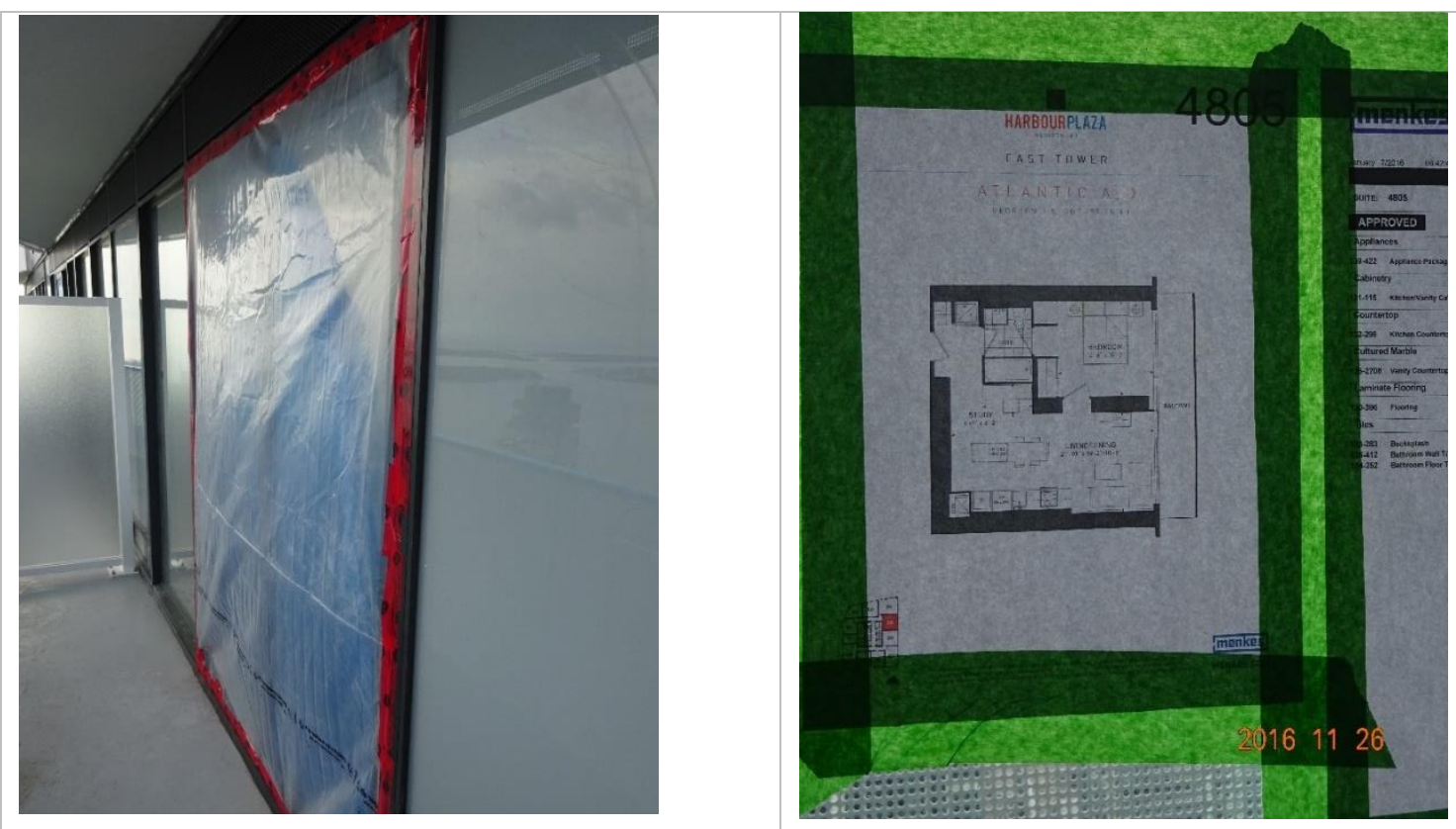

\section{Exterior view}

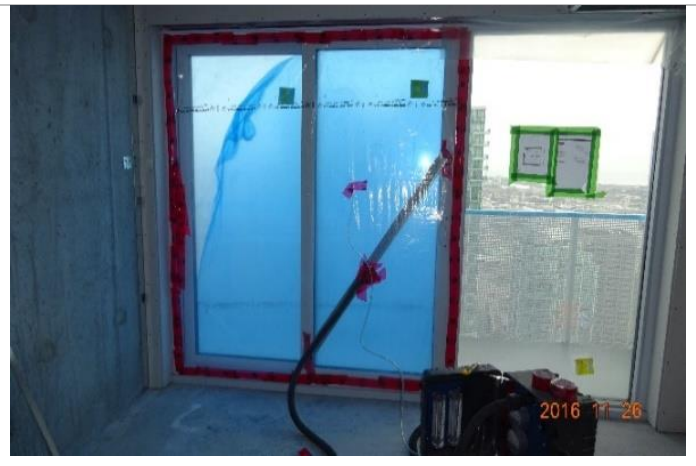

Interior view

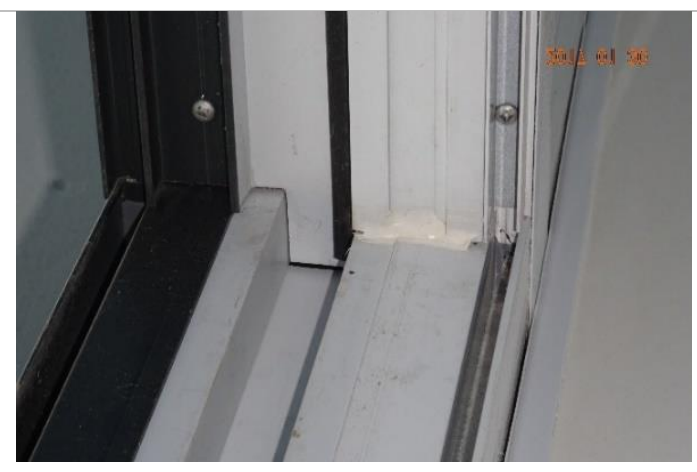

door sill sliding track

\section{Interior view}

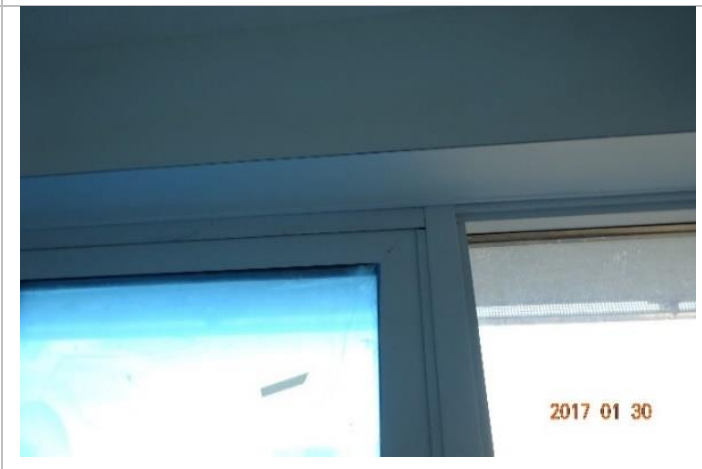

Fixed frame panel

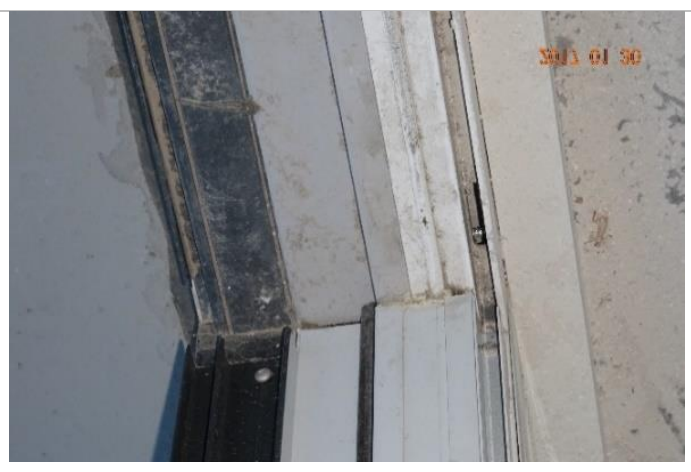

door sill sliding track 


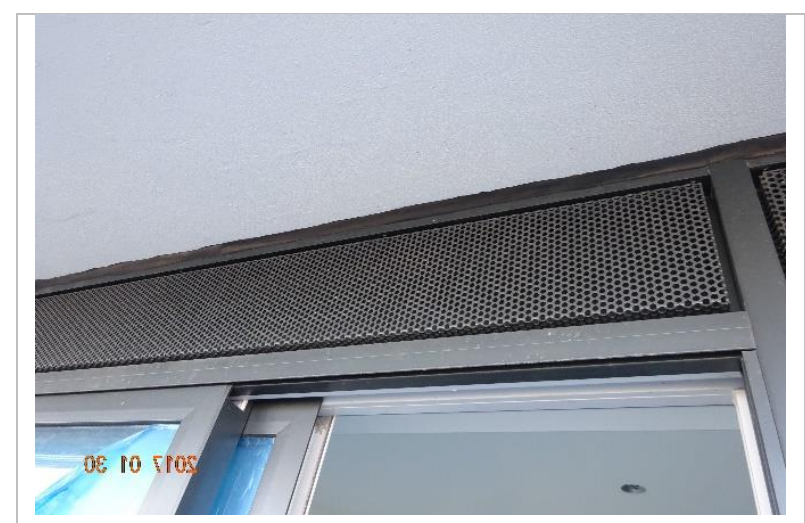

Door head exterior interfaces

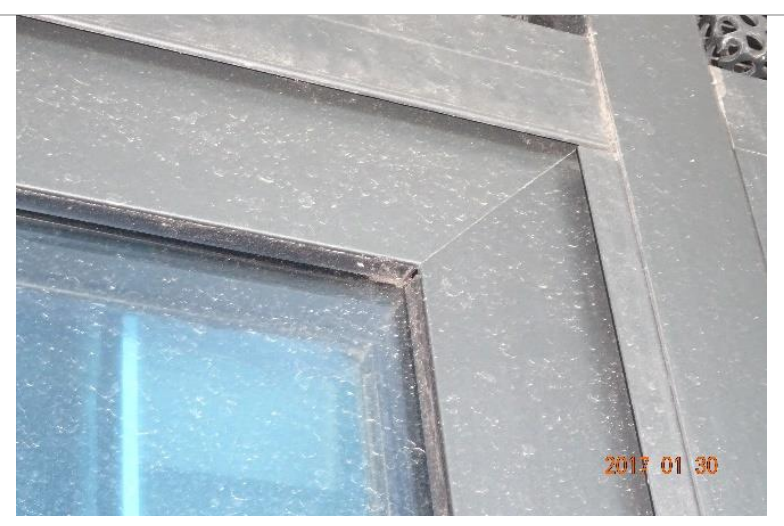

Fixed frame joint

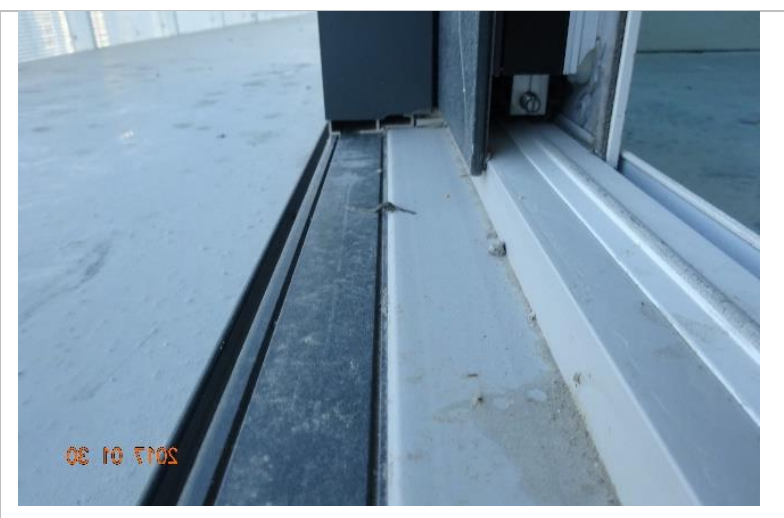

Dust plug

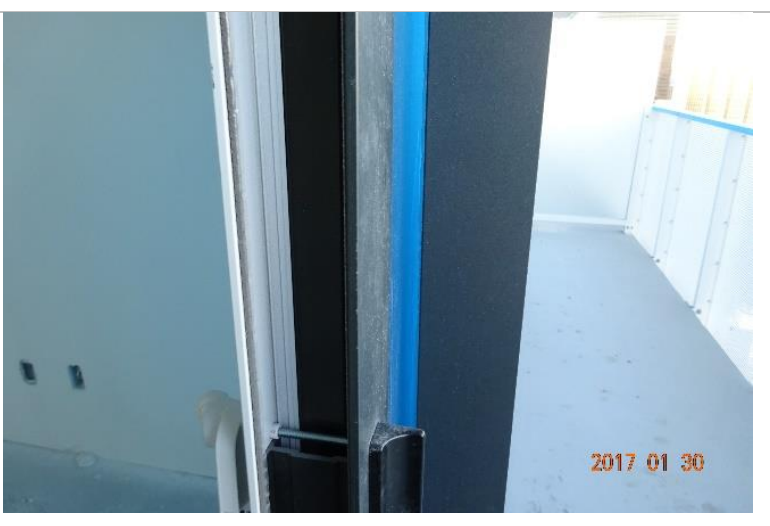

Weather stripping

\section{Discussion:}

As the air leakage rates are lower than the minimum lab achieved result, there may be an error during conducting field test such as reading higher extraneous air leakage rates due to improper installation of exterior chamber. 


\section{Test No.4}

\begin{tabular}{|l|l|}
\hline Date & $11 / 19 / 2016$ \\
\hline Time & $11: 00 \mathrm{AM}$ \\
\hline Suite & E07 \\
\hline Level & 20 construction/25 marketing \\
\hline
\end{tabular}

\section{Sample Description}

\begin{tabular}{|l|l|}
\hline Model & Double glazed, Argon gas filled \\
\hline Door type & $6 \mathrm{~mm}$ ESR42 Temp (PURCH) / 1" Black spacer /6 mm CLR Temp (PURCH) \\
\hline Assembly Type & $4 \mathrm{~b}$ \\
\hline Size & $2260 \mathrm{~mm} \times 1830 \mathrm{~mm}$ \\
\hline Operation type & Sliding door \\
\hline
\end{tabular}

\section{Ambient Test Condition}

\begin{tabular}{|l|l|}
\hline Temperature inside & $12{ }^{\circ} \mathrm{C}$ \\
\hline Temperature outside & $10 \circ \mathrm{C}$ \\
\hline Density of air at test site & $1.24 \mathrm{Kg} / \mathrm{m} 3$ \\
\hline Relative humidity & $80 \%$ \\
\hline Wind speed & $\mathrm{W} 20 \mathrm{KPH}$ \\
\hline
\end{tabular}

\section{Visual Observation}

No specific deficiency observed at the time of review.

\section{Readings}

Air flow rate at nonstandard condition

\begin{tabular}{|l|l|l|l|l|}
\hline Pressure difference & $\mathbf{0 . 1}$ (25 PA) & $\mathbf{0 . 2}$ (50 PA) & $\mathbf{0 . 3}$ (75 PA) & $\mathbf{0 . 4}(100$ PA) \\
\hline Air flow Q (Scfm) & 11.8 & 14.3 & 15.4 & 17.9 \\
\hline
\end{tabular}

Extraneous air flow rate at nonstandard condition

\begin{tabular}{|l|l|l|l|l|}
\hline Pressure difference & 0.1 (25 PA) & 0.2 (50 PA) & 0.3 (75 PA) & 0.4 (100 PA) \\
\hline Air flow EQ (Scfm) & 14 & 18.2 & 21.5 & 29.5 \\
\hline
\end{tabular}

Air leakage rate

\begin{tabular}{|c|c|c|c|c|}
\hline Pressure difference & 0.1 (25 PA) & 0.2 (50 PA) & 0.3 (75 PA) & $0.4(100 \mathrm{PA})$ \\
\hline$Q d=E Q-Q(S c f m)$ & 2.2 & 3.9 & 6.1 & 11.6 \\
\hline $\begin{array}{l}\text { Temperature corrected Flow Rate } \\
\text { (Scfm) }\end{array}$ & 2.26 & 4.01 & 6.28 & 11.94 \\
\hline $\begin{array}{l}\text { Temperature corrected Flow Rate } \\
(\mathrm{L} / \mathrm{s})\end{array}$ & 1.06 & 1.88 & 2.95 & 5.61 \\
\hline Standard air leakage $\left(\mathrm{L} / \mathrm{s} / \mathrm{m}^{2}\right)$ & 0.25 & 0.45 & 0.71 & 1.35 \\
\hline Standardized air leakage $\left(\mathrm{Scfm} / \mathrm{ft}^{2}\right)$ & 0.05 & 0.09 & 0.14 & 0.26 \\
\hline
\end{tabular}




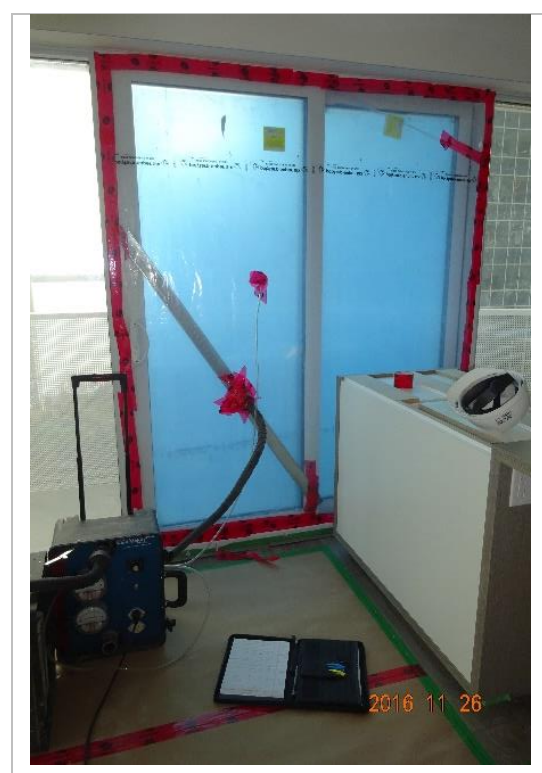

Interior view

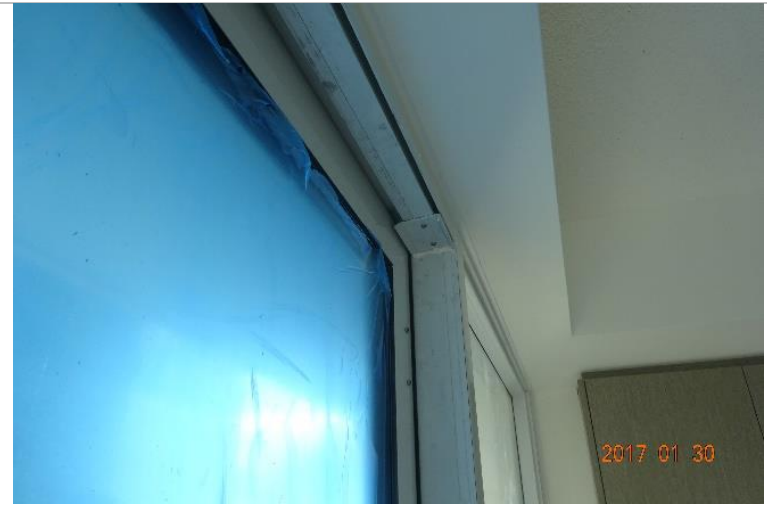

Interior view

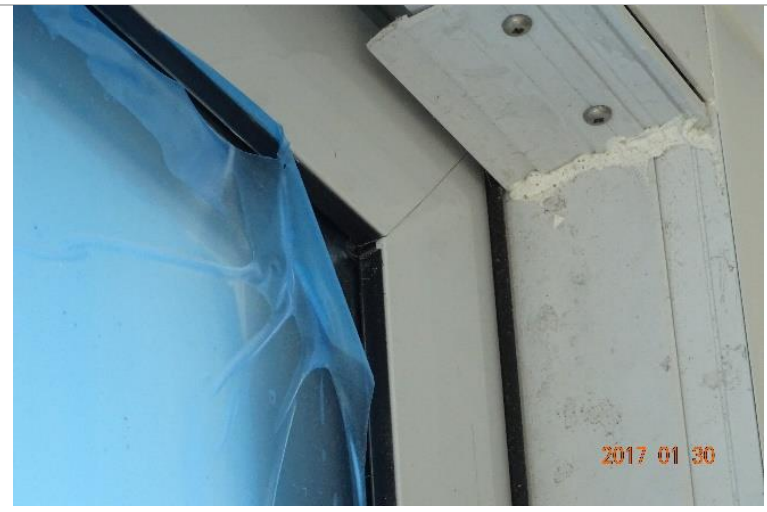

Interior view

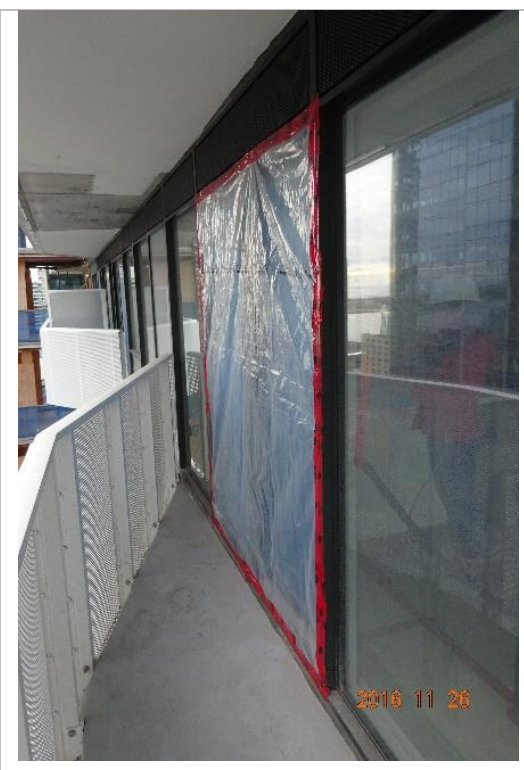

\section{Exterior view}

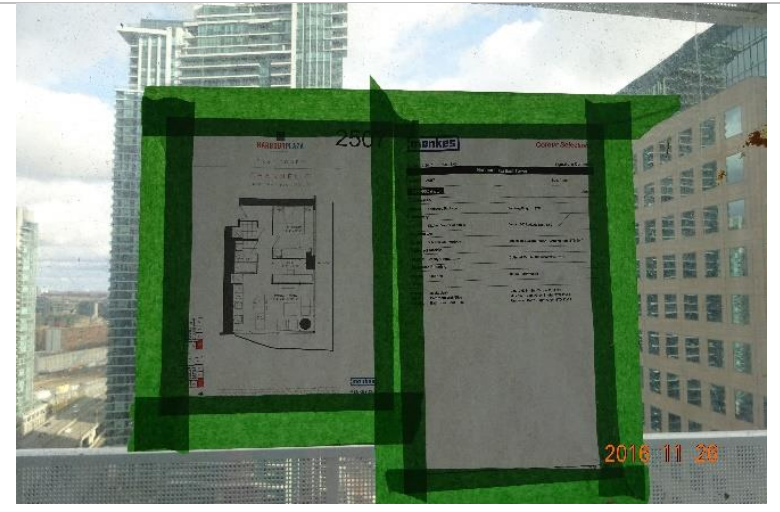

Suite plan

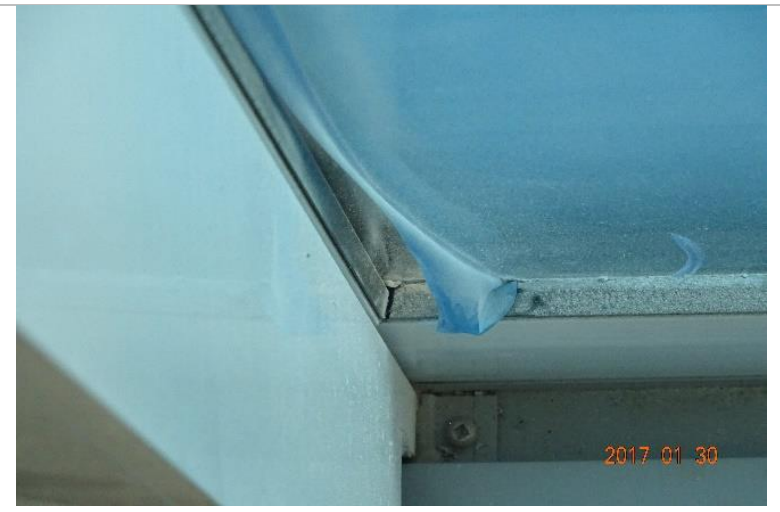

Interior view 

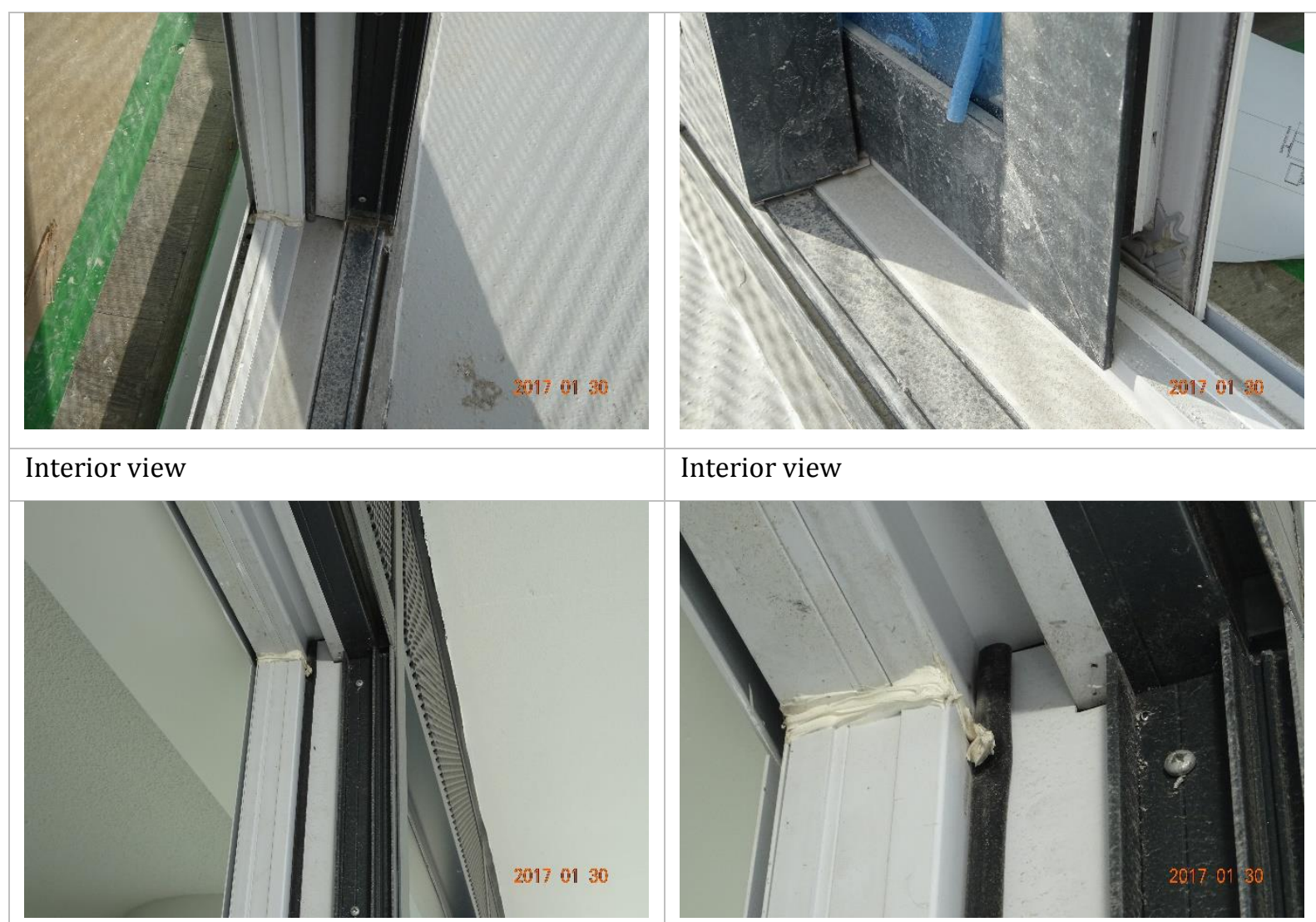

Interior view
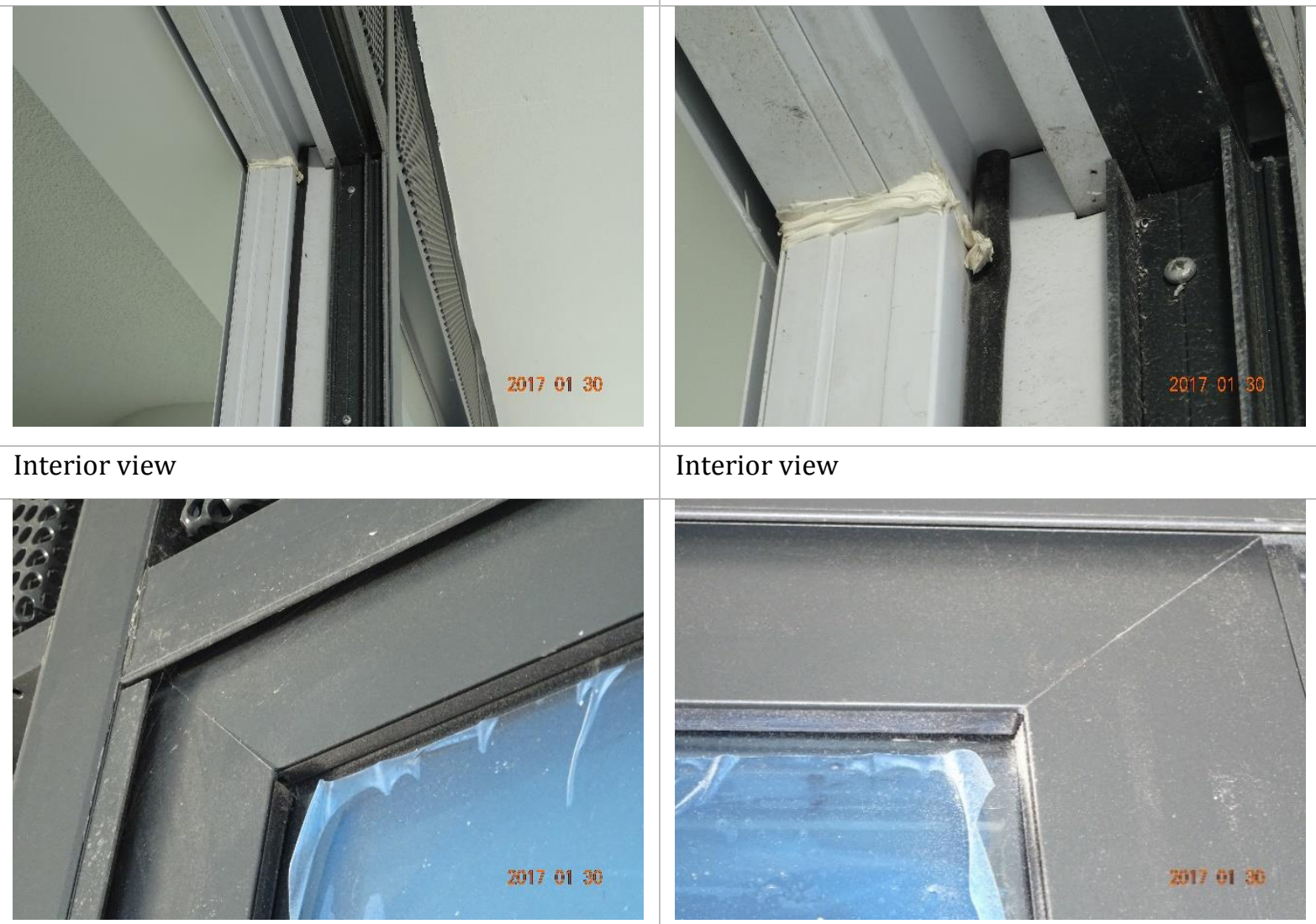

\section{Interior view}

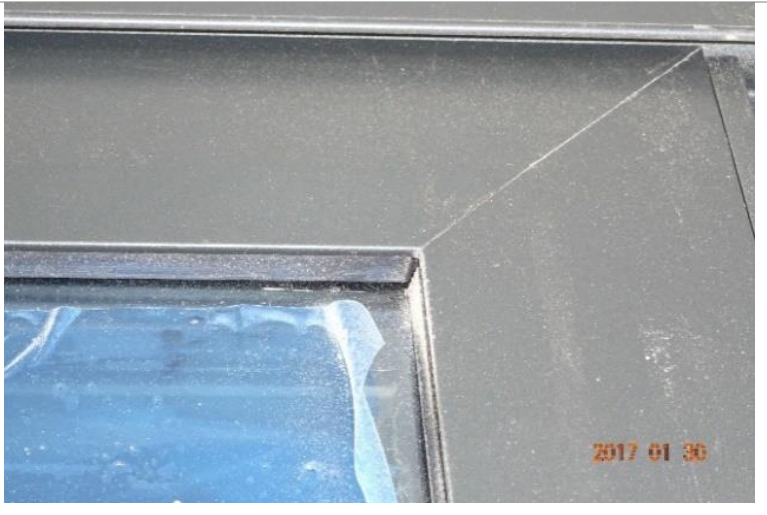

Exterior view

Exterior view 


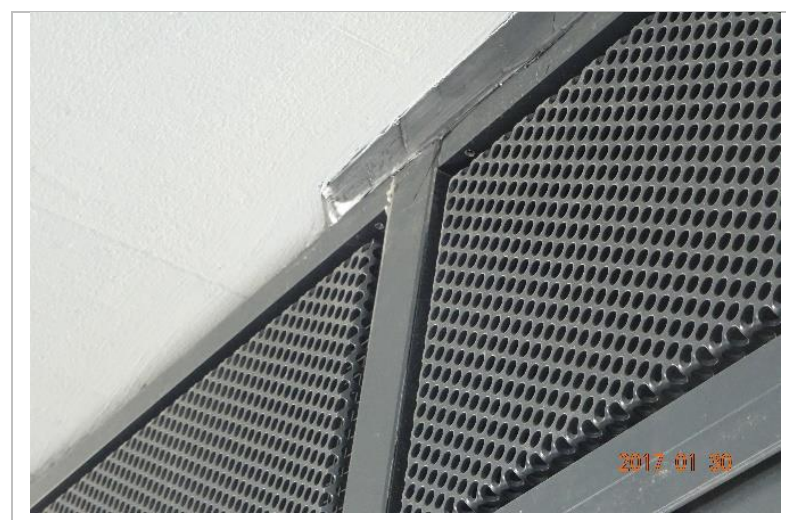

Exterior View

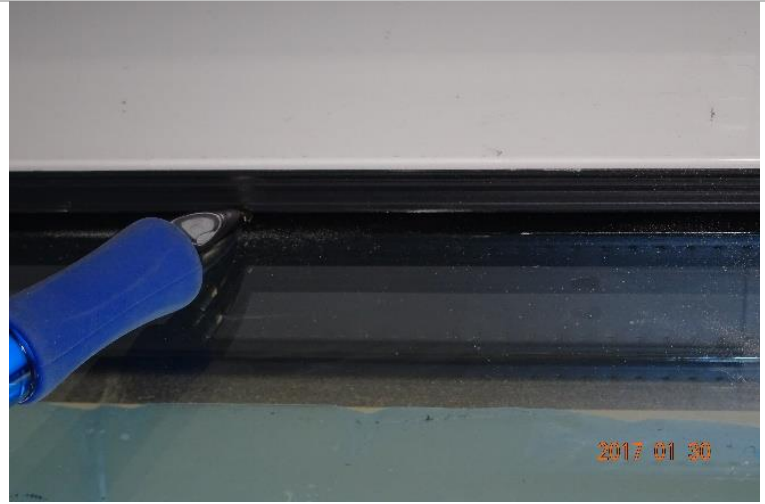

Interior view

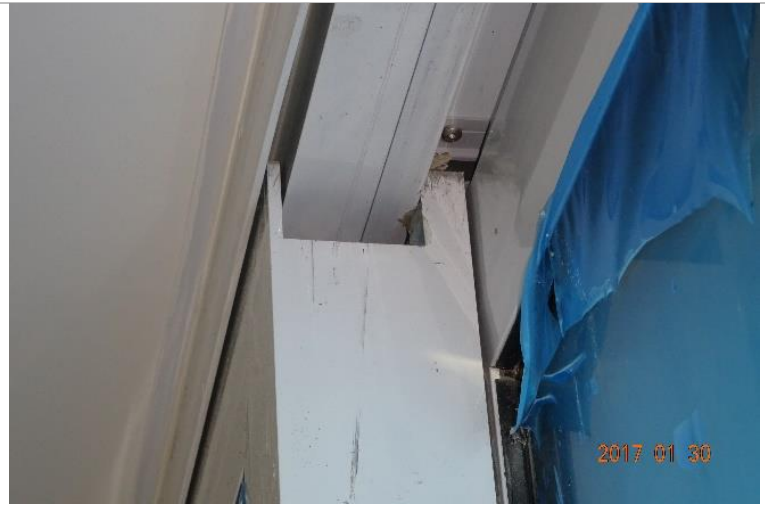

Interior view

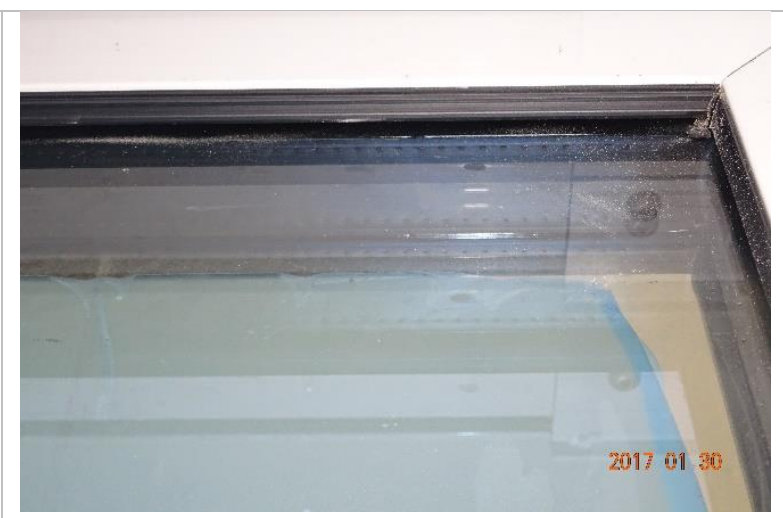

Interior view

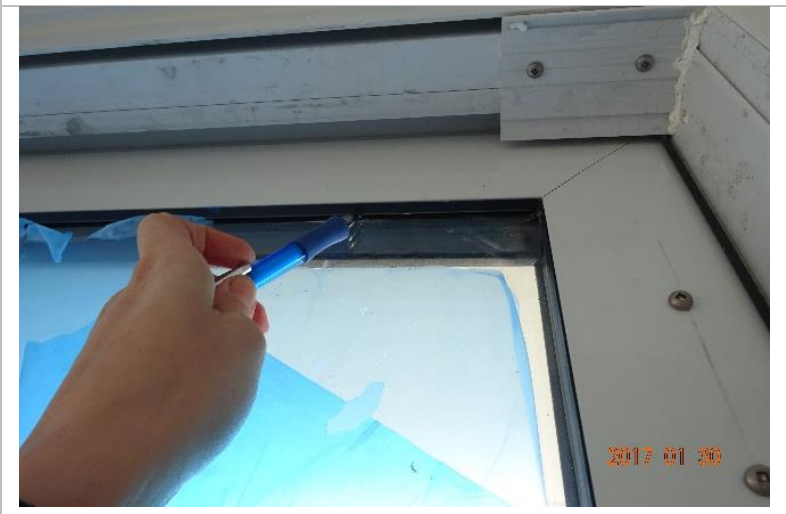

Interior view

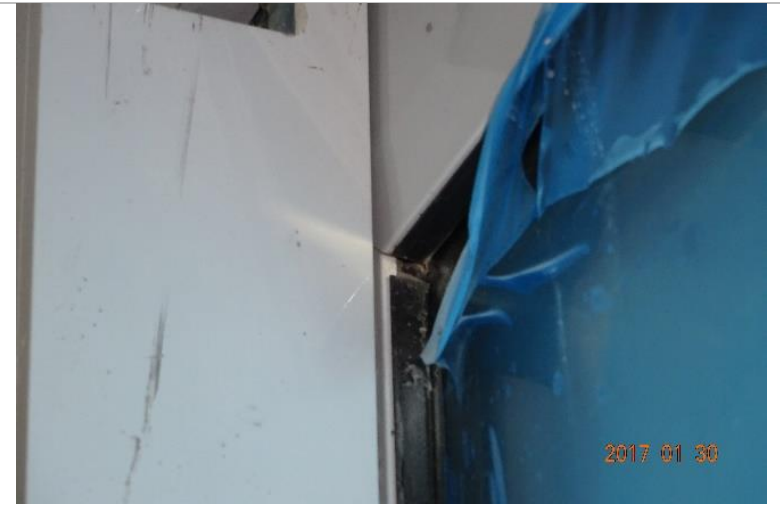

Interior view

\section{Discussion:}

Test sample exceeded laboratory test results. There was a gap between weather rubber stripping to glass pane. 


\section{Test No.5}

\begin{tabular}{|l|l|}
\hline Date & $11 / 19 / 2016$ \\
\hline Time & $1: 00 \mathrm{PM}$ \\
\hline Suite & E10 \\
\hline Level & 17 construction/22 marketing \\
\hline
\end{tabular}

\section{Sample Description}

\begin{tabular}{|l|l|}
\hline Model & Double glazed, Argon gas filled \\
\hline Door type & $6 \mathrm{~mm}$ ESR42 Temp (PURCH) / 1" Black spacer/6 mm CLR Temp (PURCH) \\
\hline Assembly Type & $4 \mathrm{a}$ \\
\hline Size & $2260 \mathrm{~mm} \times 1830 \mathrm{~mm}$ \\
\hline Operation type & Sliding door \\
\hline
\end{tabular}

\section{Ambient Test Condition}

\begin{tabular}{|l|l|}
\hline Temperature inside & $12 \circ \mathrm{C}$ \\
\hline Temperature outside & $10 \circ \mathrm{C}$ \\
\hline Density of air at test site & $1.24 \mathrm{Kg} / \mathrm{m} 3$ \\
\hline Relative humidity & $80 \%$ \\
\hline Wind speed & WSW26 KPH \\
\hline
\end{tabular}

\section{Visual Observation}

Door does not have any deficiency in the visual inspection.

\section{Readings}

Air flow rate at nonstandard condition

\begin{tabular}{|l|l|l|l|l|}
\hline Pressure difference & 0.1 (25 PA) & $\mathbf{0 . 2}$ (50 PA) & $\mathbf{0 . 3}$ (75 PA) & 0.4 (100 PA) \\
\hline Air flow Q (Scfm) & 9.8 & 10.8 & 12.9 & 13.8
\end{tabular}

Extraneous air flow rate at nonstandard condition

\begin{tabular}{|l|l|l|l|l|}
\hline Pressure difference & 0.1 (25 PA) & 0.2 (50 PA) & 0.3 (75 PA) & 0.4 (100 PA) \\
\hline Air flow EQ (Scfm) & 10 & 13.8 & 15.4 & 17.3 \\
\hline
\end{tabular}

Air leakage rate

\begin{tabular}{|c|c|c|c|c|}
\hline Pressure difference & 0.1 (25 PA) & 0.2 (50 PA) & 0.3 (75 PA) & 0.4 (100 PA) \\
\hline$Q d=E Q-Q(S c f m)$ & 0.2 & 2 & 1.5 & 3.5 \\
\hline $\begin{array}{l}\text { Temperature corrected Flow Rate } \\
\text { (Scfm) }\end{array}$ & 0.206 & 3.090 & 2.575 & 3.605 \\
\hline $\begin{array}{l}\text { Temperature corrected Flow Rate } \\
(\mathrm{L} / \mathrm{s})\end{array}$ & 0.097 & 1.452 & 1.210 & 1.694 \\
\hline Standard air leakage $\left(\mathrm{L} / \mathrm{s} / \mathrm{m}^{2}\right)$ & 0.023 & 0.351 & 0.293 & 0.410 \\
\hline Standardized air leakage $\left(\mathrm{Scfm} / \mathrm{ft}^{2}\right)$ & 0.005 & 0.069 & 0.058 & 0.081 \\
\hline
\end{tabular}




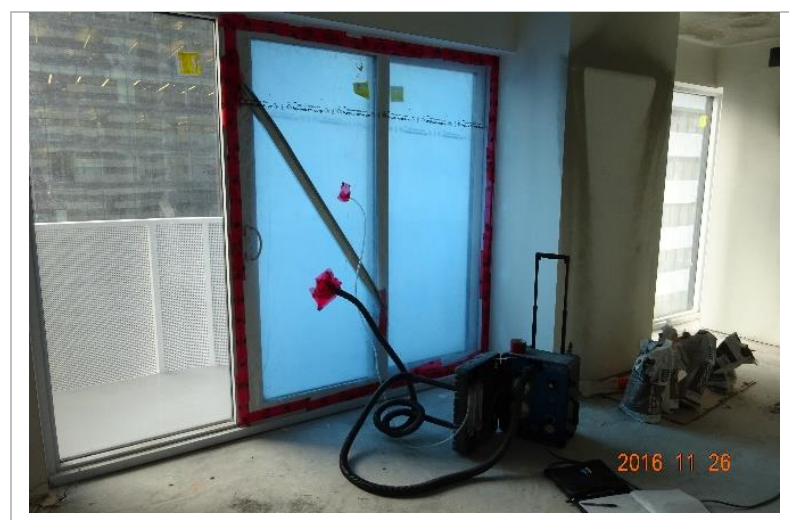

Interior view

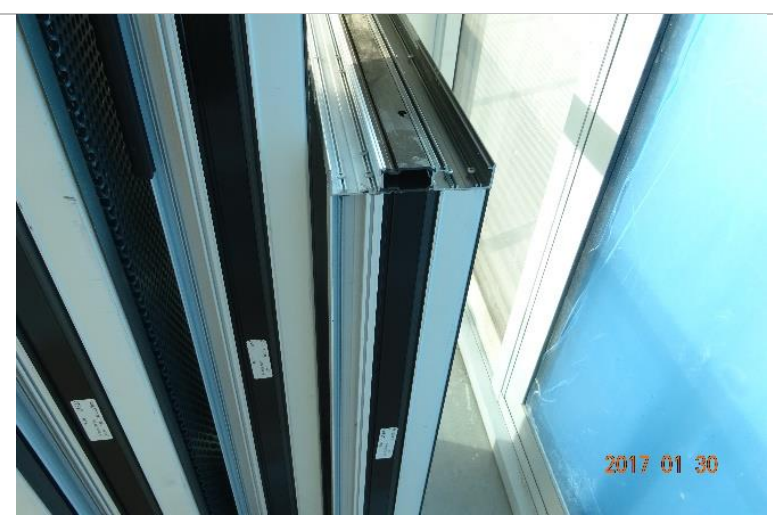

Door frames

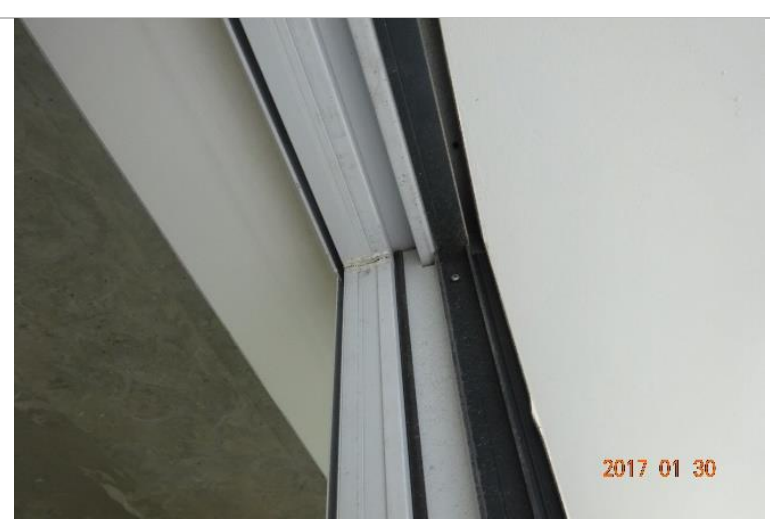

Interior view of frame corners

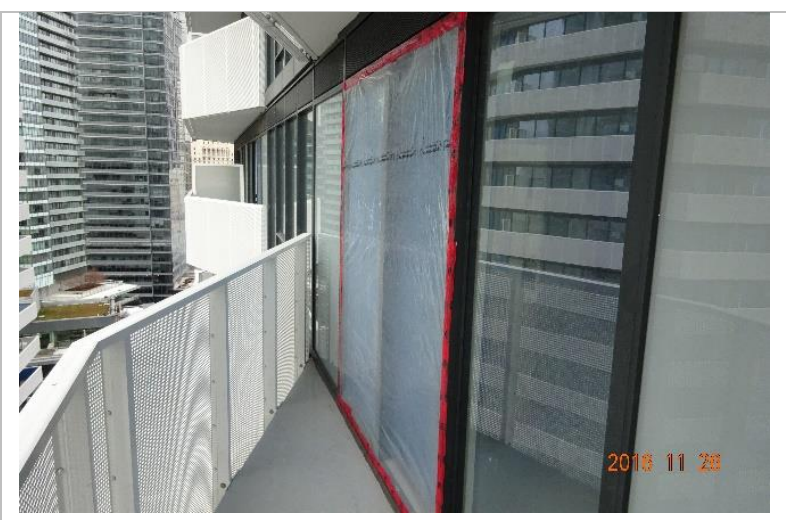

Exterior view

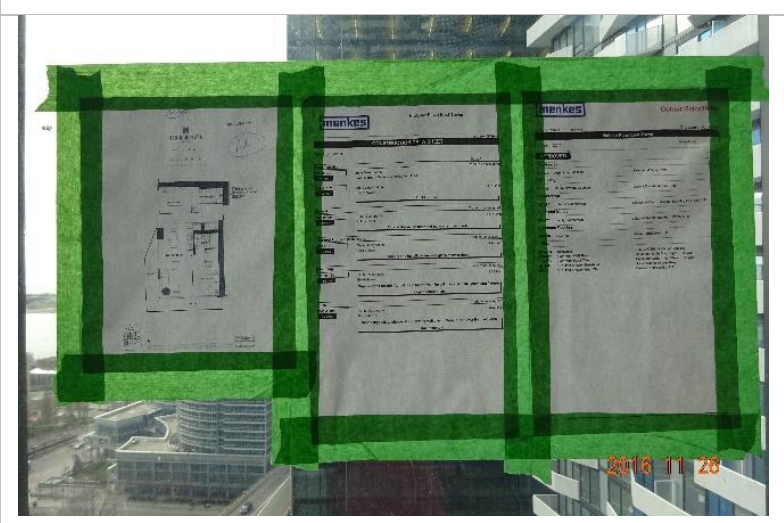

Suite plan

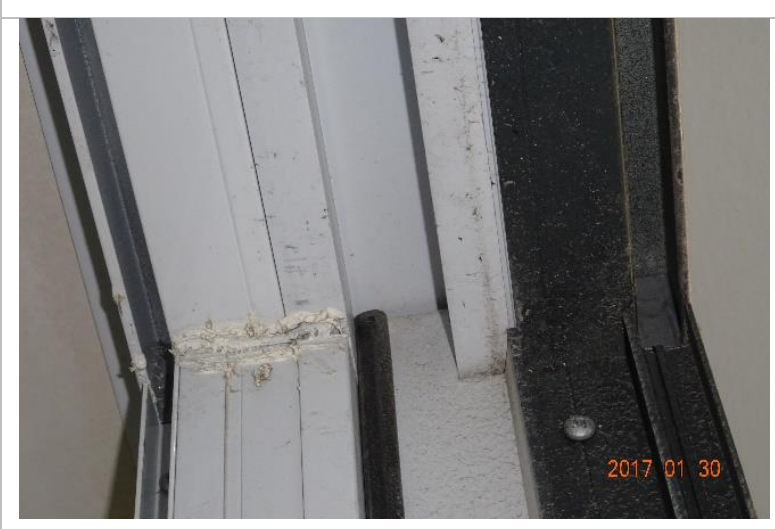

Interior view of frame corners 


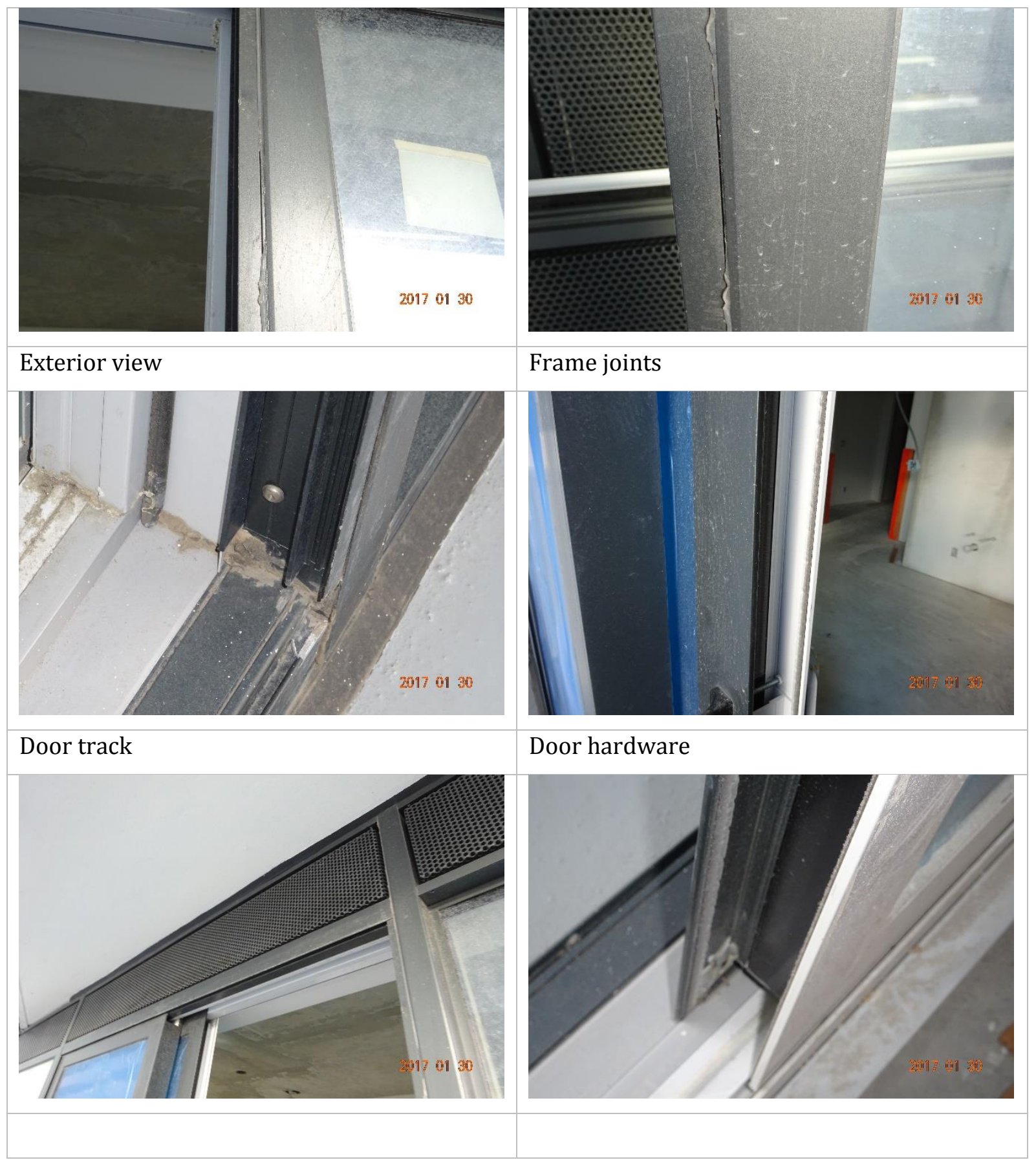

\section{Discussion}

Test specimen air lekage exceeded the laboratory test results at 75 pascals pressure difference. 


\section{Test No.6}

\begin{tabular}{|l|l|}
\hline Date & $11 / 19 / 2016$ \\
\hline Time & $1: 30 \mathrm{PM}$ \\
\hline Suite & E06 \\
\hline Level & 14 construction/19 marketing \\
\hline
\end{tabular}

\section{Sample Description}

\begin{tabular}{|l|l|}
\hline Model & Double glazed, Argon gas filled \\
\hline Door type & $6 \mathrm{~mm}$ ESR42 Temp (PURCH) / 1" Black spacer/6 mm CLR Temp (PURCH) \\
\hline Assembly Type & $5 \mathrm{~b}$ \\
\hline Size & $2260 \mathrm{~mm} \times 1830 \mathrm{~mm}$ \\
\hline Operation type & Sliding door \\
\hline
\end{tabular}

\section{Ambient Test Condition}

\begin{tabular}{|l|l|}
\hline Temperature inside & $12{ }^{\circ} \mathrm{C}$ \\
\hline Temperature outside & $10 \circ \mathrm{C}$ \\
\hline Density of air at test site & $1.24 \mathrm{Kg} / \mathrm{m} 3$ \\
\hline Relative humidity & $80 \%$ \\
\hline Wind speed & WSW26 KPH \\
\hline
\end{tabular}

\section{Visual Observation}

No deficiency observed at the time of review. Localized discontinuous sealant at frame joints.

\section{Readings}

Air flow rate at nonstandard condition

\begin{tabular}{|l|l|l|l|l|}
\hline Pressure difference & $\mathbf{0 . 1}(\mathbf{2 5}$ pa) & $\mathbf{0 . 2}(\mathbf{5 0}$ pa) & $\mathbf{0 . 3}(\mathbf{7 5}$ pa) & $\mathbf{0 . 4}(\mathbf{1 0 0}$ pa) \\
\hline Air flow Q (Scfm) & 7.2 & 9.4 & 10.2 & 11.4
\end{tabular}

Extraneous air flow rate at nonstandard condition

\begin{tabular}{|l|l|l|l|l|}
\hline Pressure difference & $\mathbf{0 . 1}(\mathbf{2 5}$ pa) & $0.2(50$ pa) & $0.3(75$ pa) & $0.4(100$ pa) \\
\hline Air flow EQ (Scfm) & 10.8 & 13.8 & 14.6 & 16.7 \\
\hline
\end{tabular}

Air leakage rate

\begin{tabular}{|c|c|c|c|c|}
\hline Pressure difference & 0.1 (25 pa) & 0.2 (50 pa) & 0.3 (75 pa) & $0.4(100$ pa) \\
\hline$Q d=E Q-Q(S c f m)$ & 3.6 & 4.4 & 4.4 & 5.3 \\
\hline $\begin{array}{l}\text { Temperature corrected Flow Rate } \\
\text { (Scfm) }\end{array}$ & 3.70 & 4.53 & 4.53 & 5.45 \\
\hline $\begin{array}{l}\text { Temperature corrected Flow Rate } \\
(\mathrm{L} / \mathrm{s})\end{array}$ & 1.74 & 2.13 & 2.13 & 2.56 \\
\hline Standard air leakage $\left(\mathrm{L} / \mathrm{s} / \mathrm{m}^{2}\right)$ & 0.42 & 0.51 & 0.51 & 0.62 \\
\hline Standardized air leakage $\left(\mathrm{Scfm} / \mathrm{ft}^{2}\right)$ & 0.08 & 0.10 & 0.10 & 0.12 \\
\hline
\end{tabular}




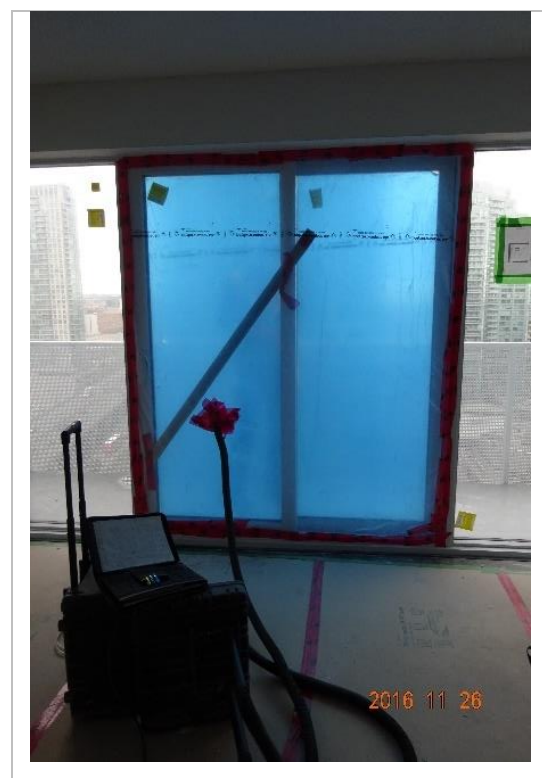

Interior view

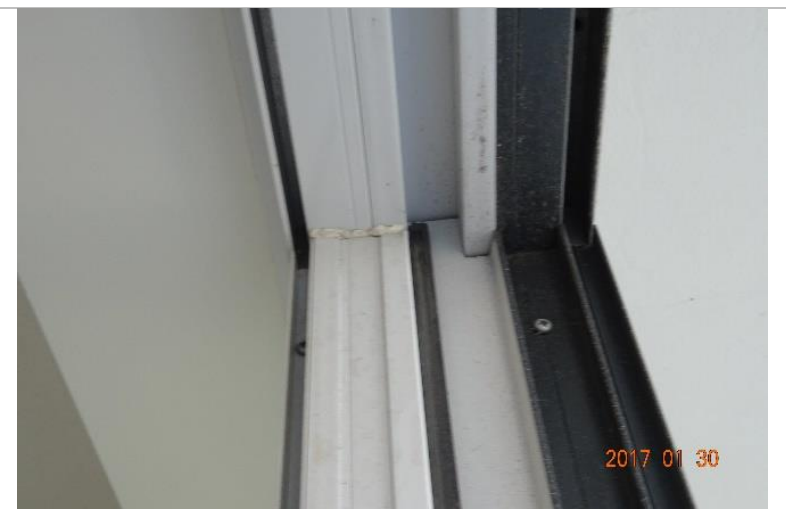

Frame joints

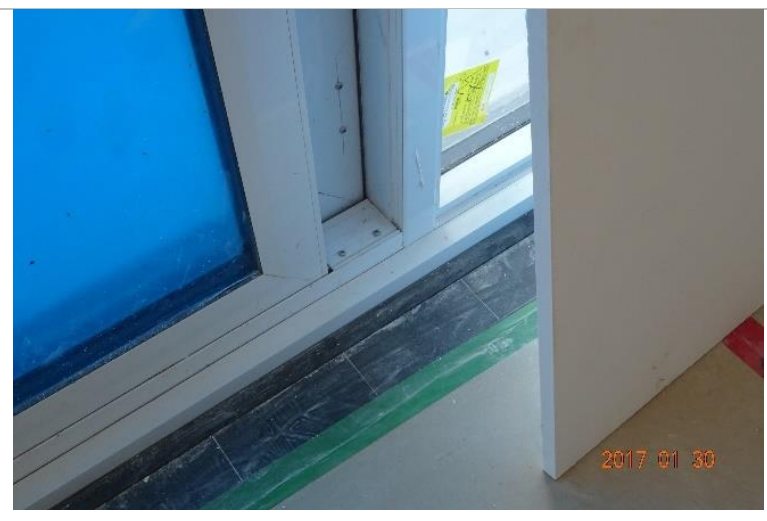

Interior view

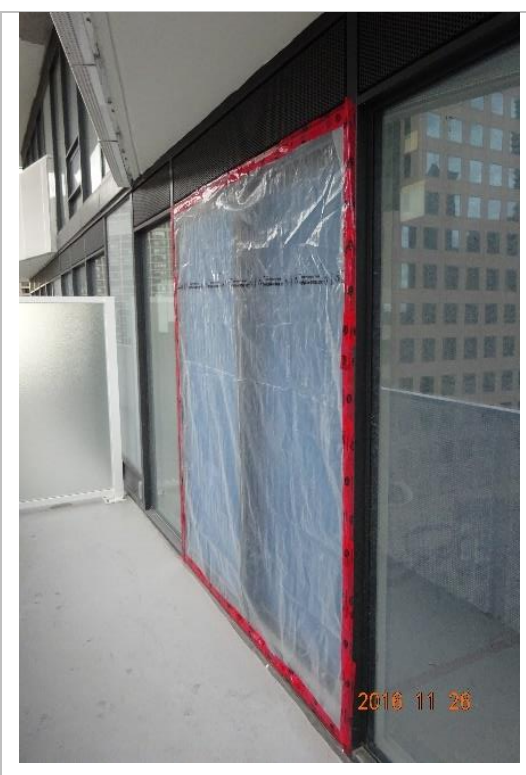

Exterior view

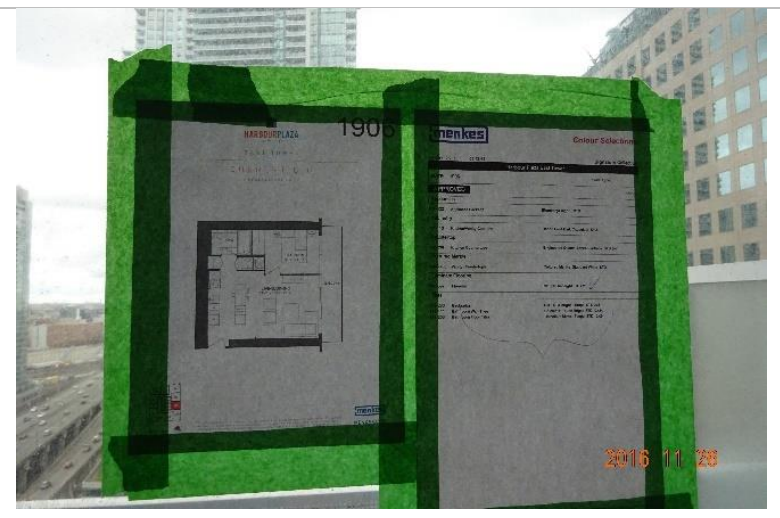

Suite plan

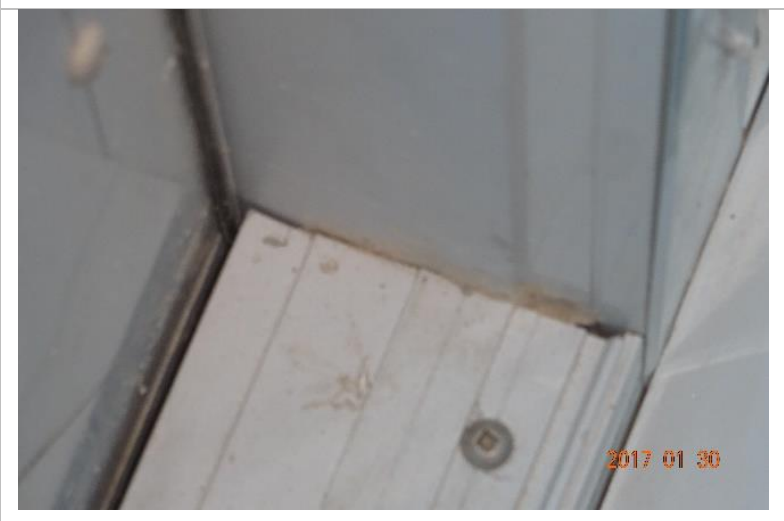

Frame joints 


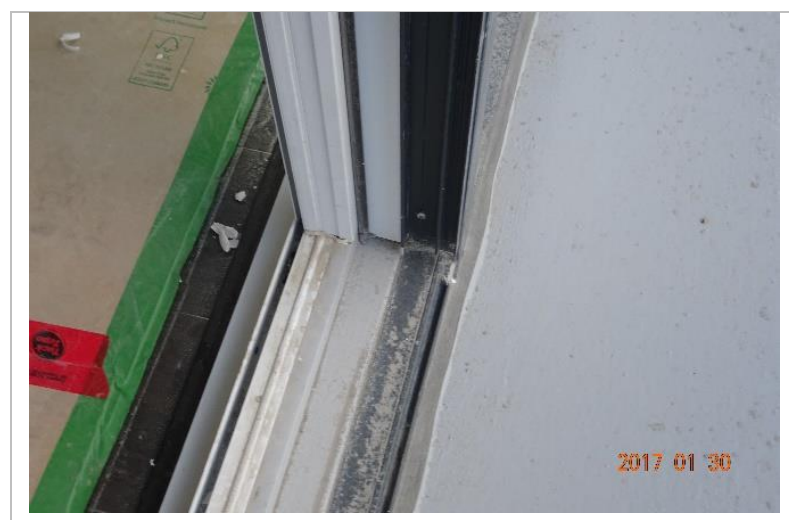

Door track

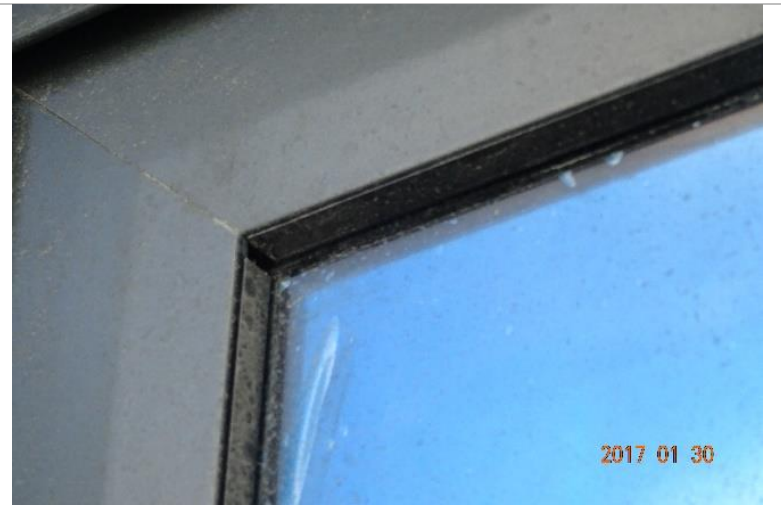

Frame joints

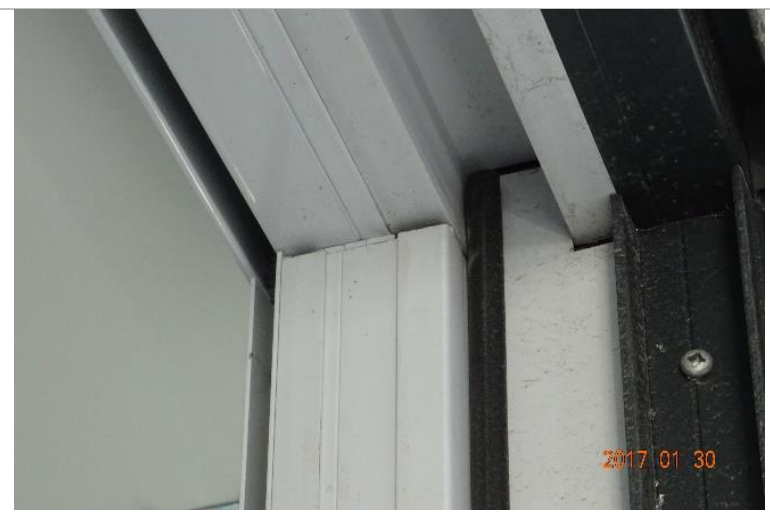

Frame joints

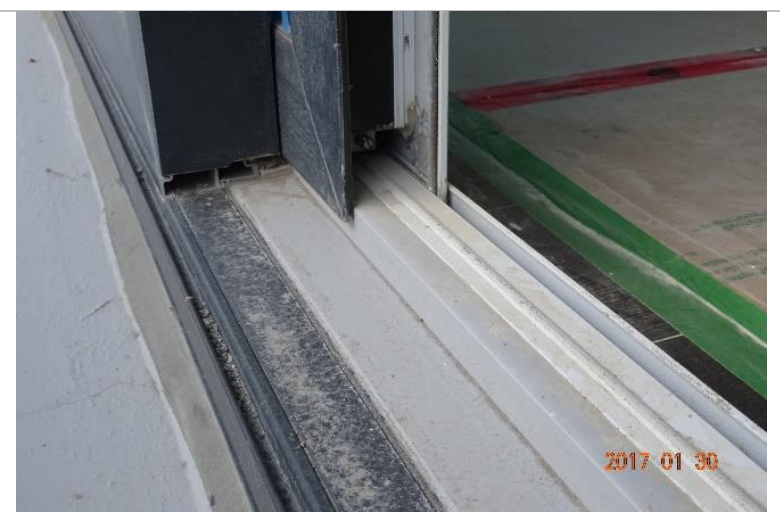

Door track

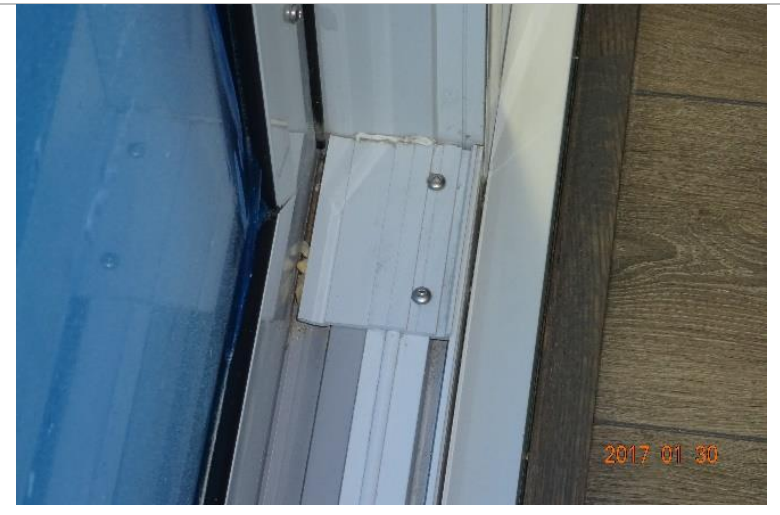

Frame joints

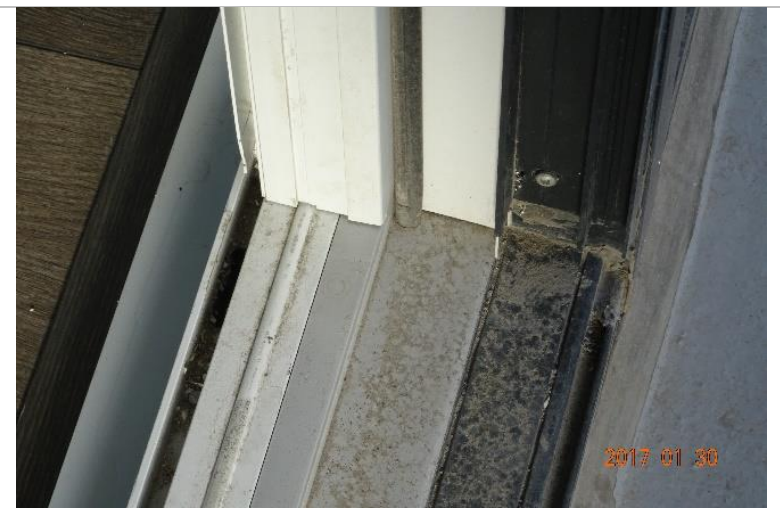

Door sill 


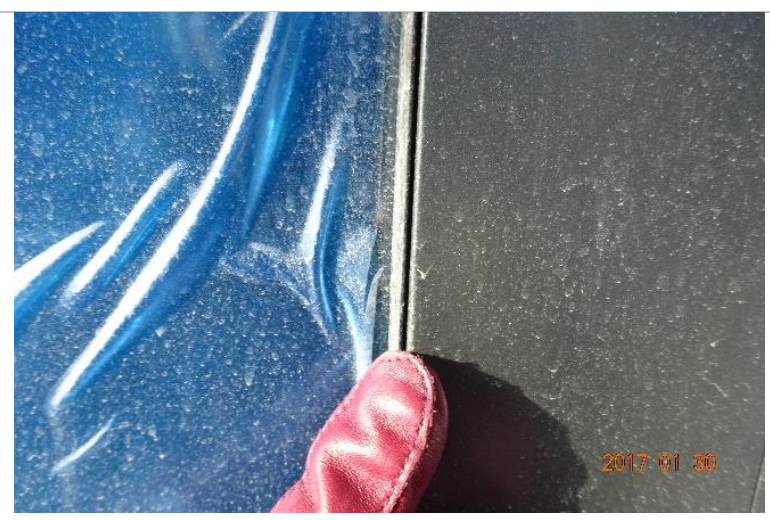

Glass to frame joint

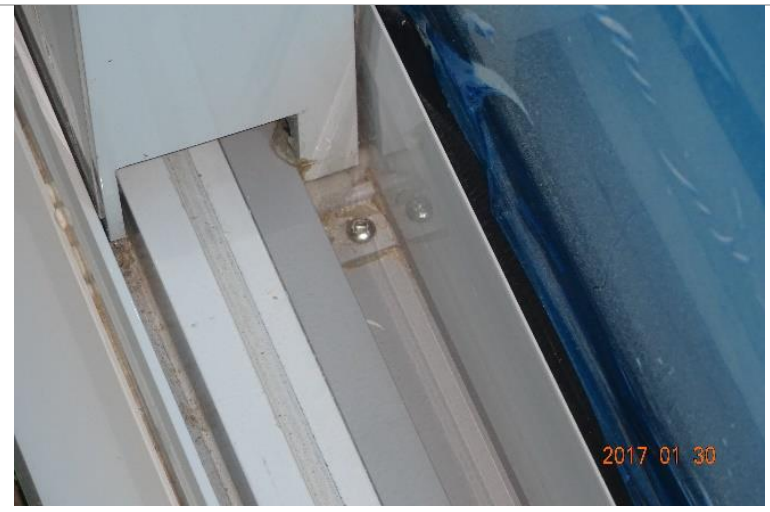

Door sill track

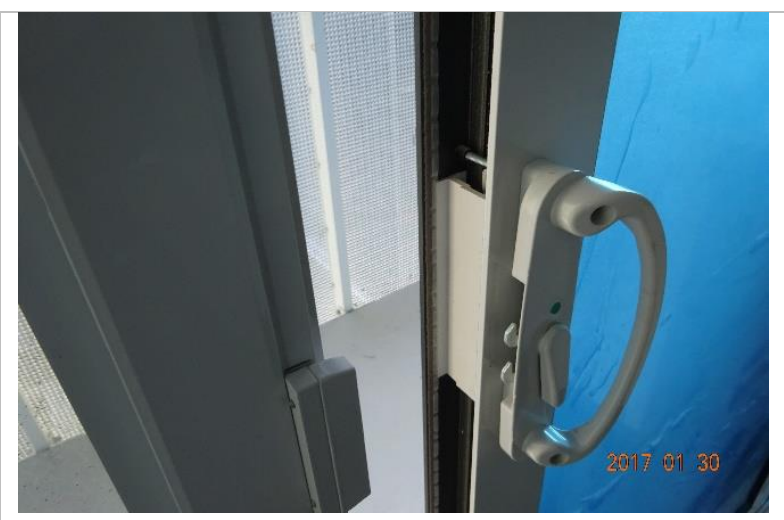

Door hardware

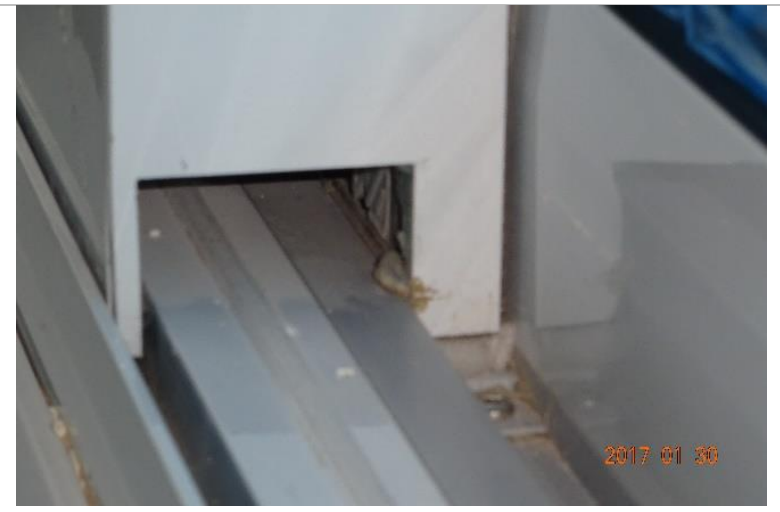

Dust plug area

\section{Discussion}

Despite of localized discontinuity at frame joints sealants, air leakage rate is approximately equal to laboratory test results. The exterior frame join sealants are secondary air leakage lines of defense. 


\section{Test No.7}

\begin{tabular}{|l|l|}
\hline Date & $11 / 19 / 2016$ \\
\hline Time & $2: 00 \mathrm{PM}$ \\
\hline Suite & E07 \\
\hline Level & 14 construction/19 marketing \\
\hline
\end{tabular}

\section{Sample Description}

\begin{tabular}{|l|l|}
\hline Model & Double glazed, Argon gas filled \\
\hline Door type & $6 \mathrm{~mm}$ ESR42 Temp (PURCH) / 1" Black spacer /6 mm CLR Temp (PURCH) \\
\hline Assembly Type & $4 \mathrm{~b}$ \\
\hline Size & $2260 \mathrm{~mm} \times 1830 \mathrm{~mm}$ \\
\hline Operation type & Sliding door \\
\hline
\end{tabular}

\section{Ambient Test Condition}

\begin{tabular}{|l|l|}
\hline Temperature inside & $12{ }^{\circ} \mathrm{C}$ \\
\hline Temperature outside & $10 \circ \mathrm{C}$ \\
\hline Density of air at test site & $1.24 \mathrm{Kg} / \mathrm{m} 3$ \\
\hline Relative humidity & $80 \%$ \\
\hline Wind speed & WSW26 KPH
\end{tabular}

\section{Visual Observation}

No deficiency observed in the sample.

\section{Readings}

Air flow rate at nonstandard condition

\begin{tabular}{|l|l|l|l|l|}
\hline Pressure difference & $\mathbf{0 . 1}(\mathbf{2 5}$ pa) & $\mathbf{0 . 2}(\mathbf{5 0}$ pa) & $\mathbf{0 . 3}(\mathbf{7 5}$ pa) & $\mathbf{0 . 4}(\mathbf{1 0 0}$ pa) \\
\hline Air flow Q (Scfm) & 8.9 & 11.4 & 12.5 & 13.9
\end{tabular}

Extraneous air flow rate at nonstandard condition

\begin{tabular}{|l|l|l|l|l|}
\hline Pressure difference & $\mathbf{0 . 1}(\mathbf{2 5}$ pa) & $\mathbf{0 . 2}(\mathbf{5 0}$ pa) & $\mathbf{0 . 3}(\mathbf{7 5}$ pa) & $\mathbf{0 . 4}(\mathbf{1 0 0}$ pa) \\
\hline Air flow EQ (Scfm) & 11.8 & 16.3 & 18.9 & 21.7 \\
\hline
\end{tabular}

Air leakage rate

\begin{tabular}{|c|c|c|c|c|}
\hline Pressure difference & 0.1 (25 pa) & 0.2 (50 pa) & 0.3 (75 pa) & $0.4(100$ pa) \\
\hline$Q d=E Q-Q(S c f m)$ & 2.9 & 4.9 & 6.4 & 7.8 \\
\hline $\begin{array}{l}\text { Temperature corrected Flow Rate } \\
\text { (Scfm) }\end{array}$ & 2.987 & 5.047 & 6.591 & 8.033 \\
\hline $\begin{array}{l}\text { Temperature corrected Flow Rate } \\
(\mathrm{L} / \mathrm{s})\end{array}$ & 1.404 & 2.372 & 3.098 & 3.776 \\
\hline Standard air leakage $\left(\mathrm{L} / \mathrm{s} / \mathrm{m}^{2}\right)$ & 0.339 & 0.573 & 0.749 & 0.913 \\
\hline Standardized air leakage $\left(\mathrm{Scfm} / \mathrm{ft}^{2}\right)$ & 0.067 & 0.113 & 0.148 & 0.180 \\
\hline
\end{tabular}




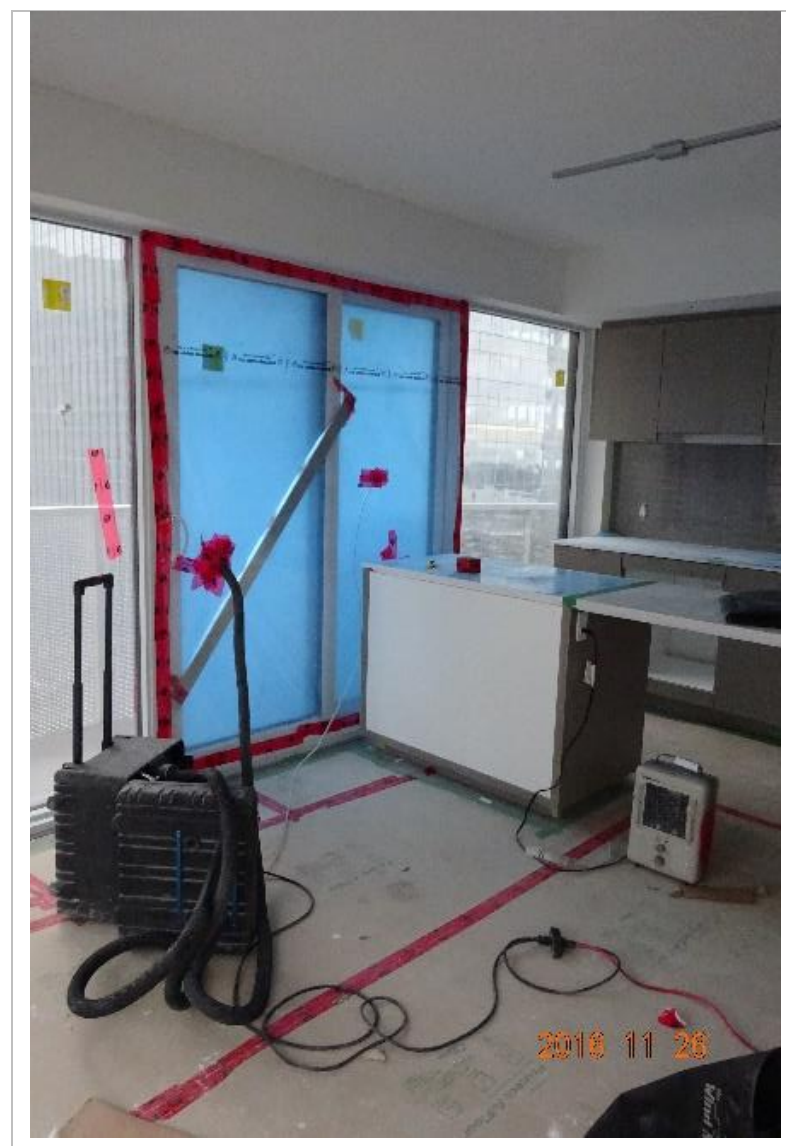

Interior view

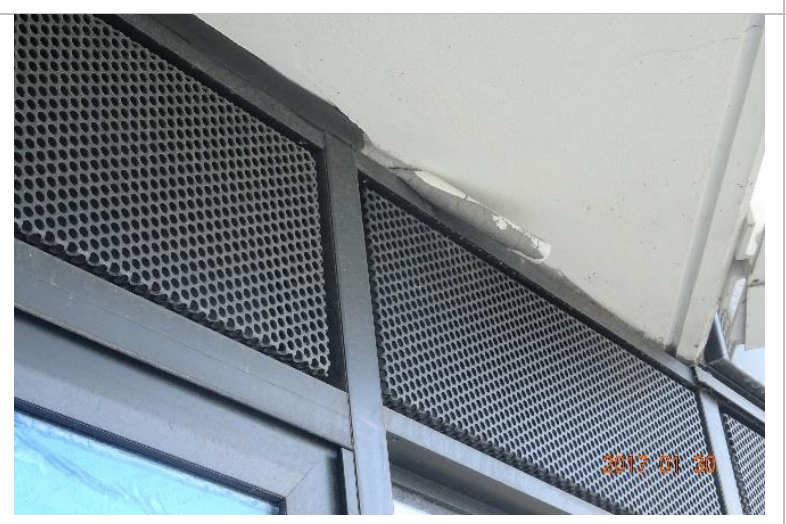

Exterior view

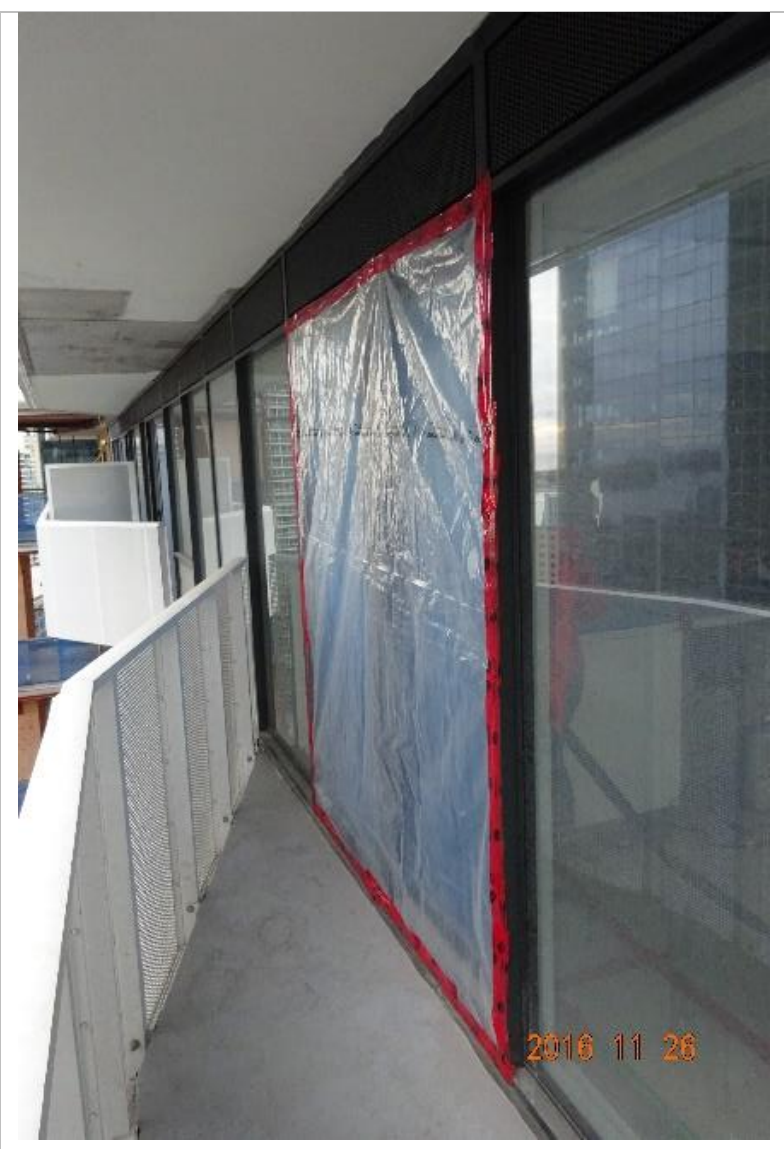

Exterior view

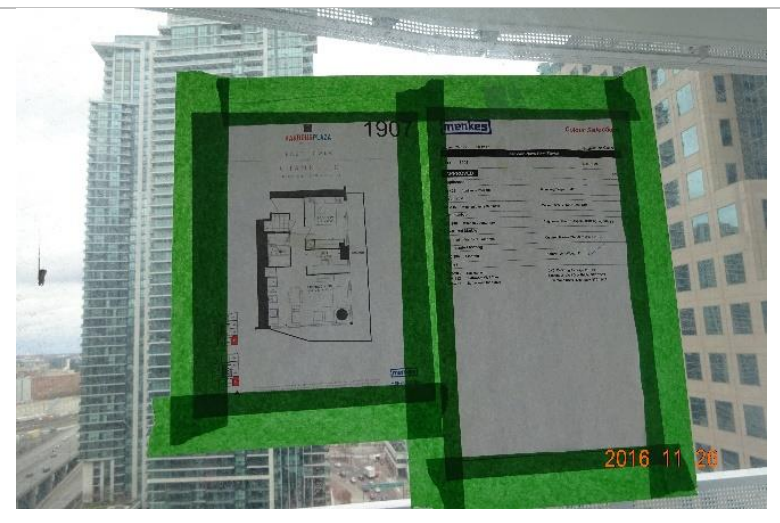

Suite plan 

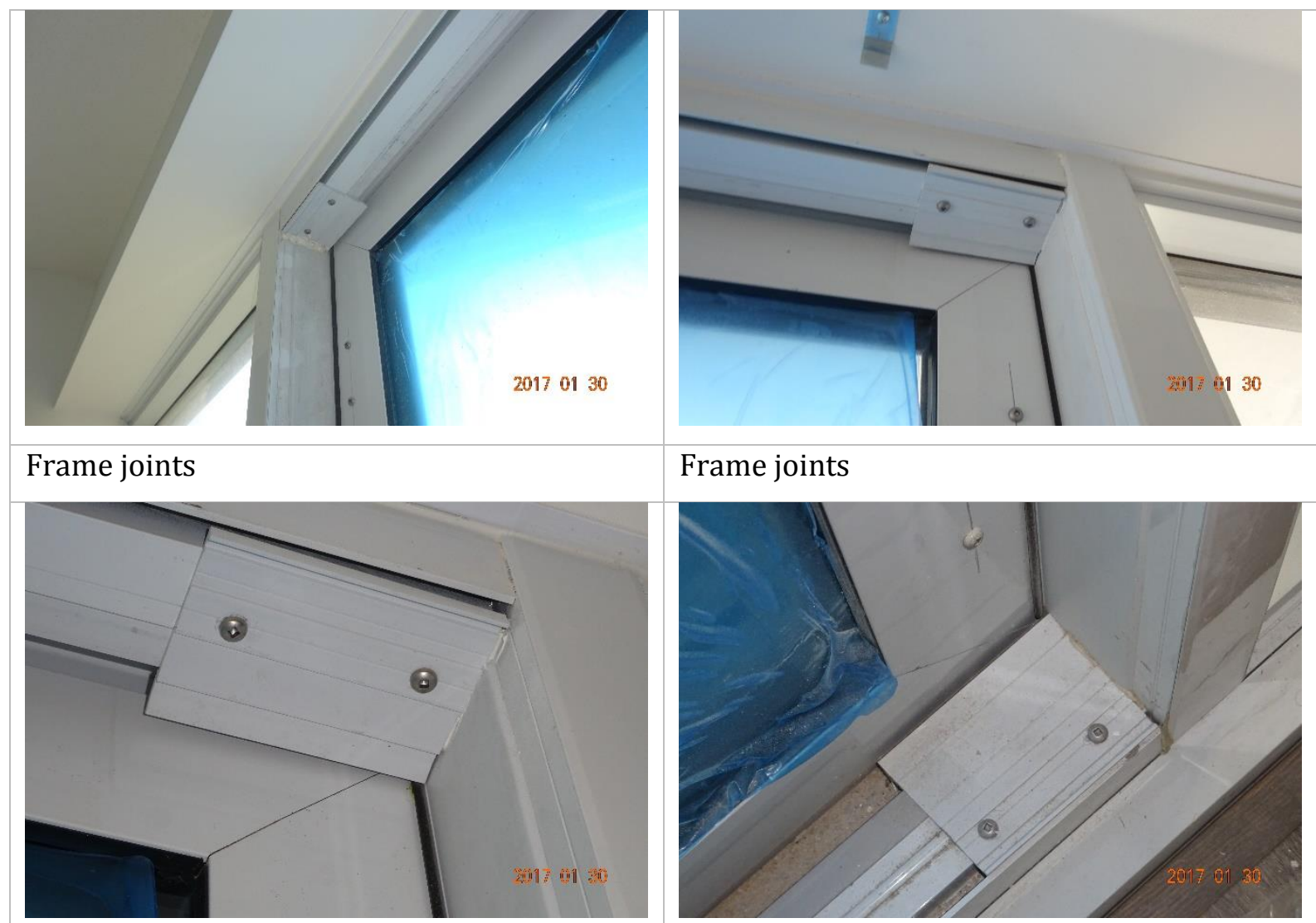

Frame joints

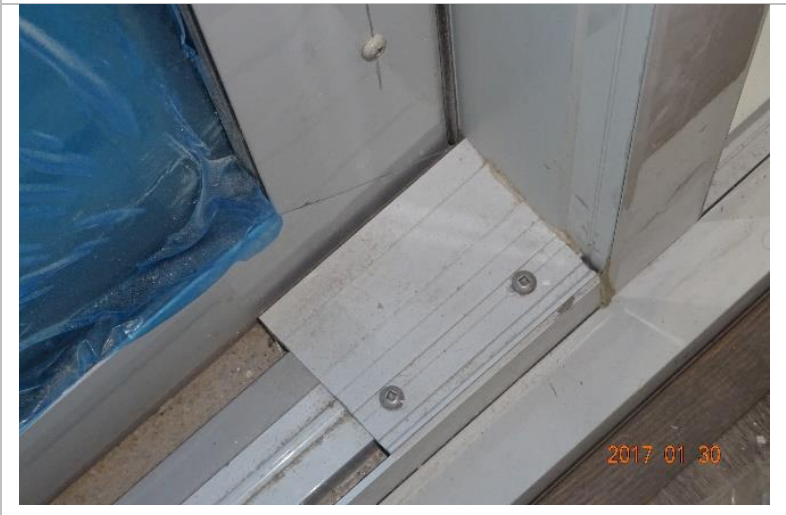

Frame joints

Frame joints

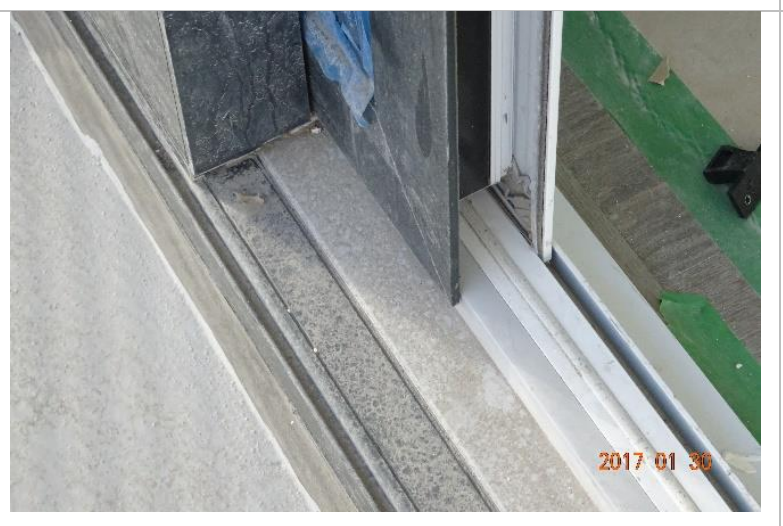

Door sill

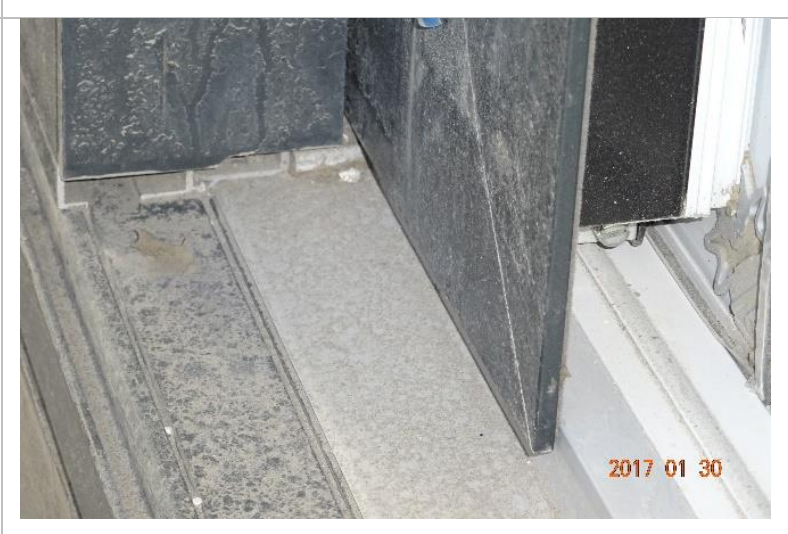

Door sill 


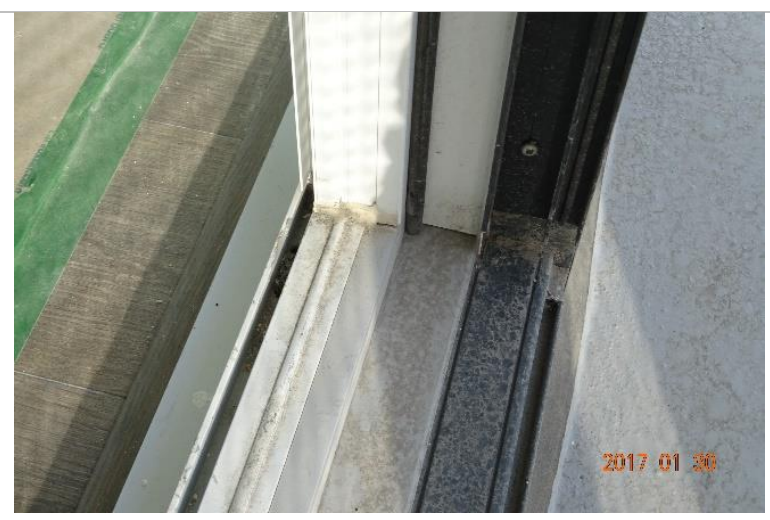

Door track

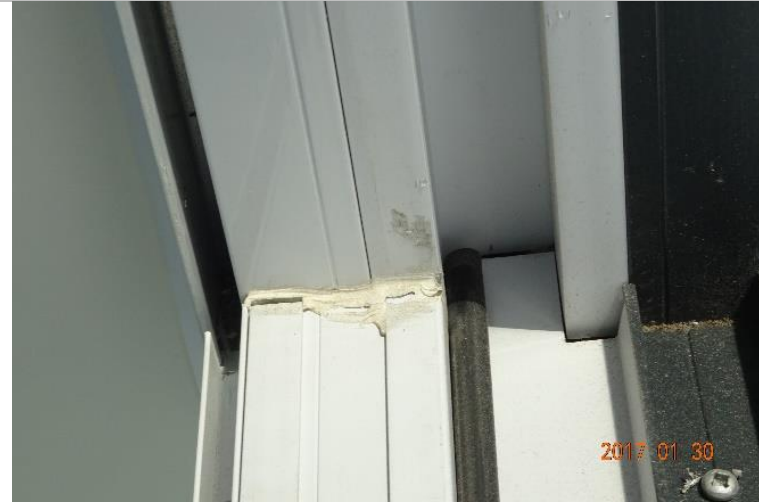

Frame joints

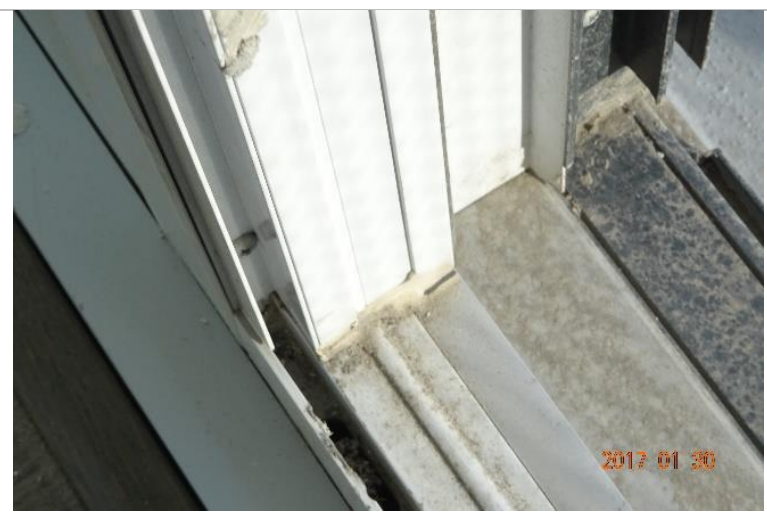

Frame joints

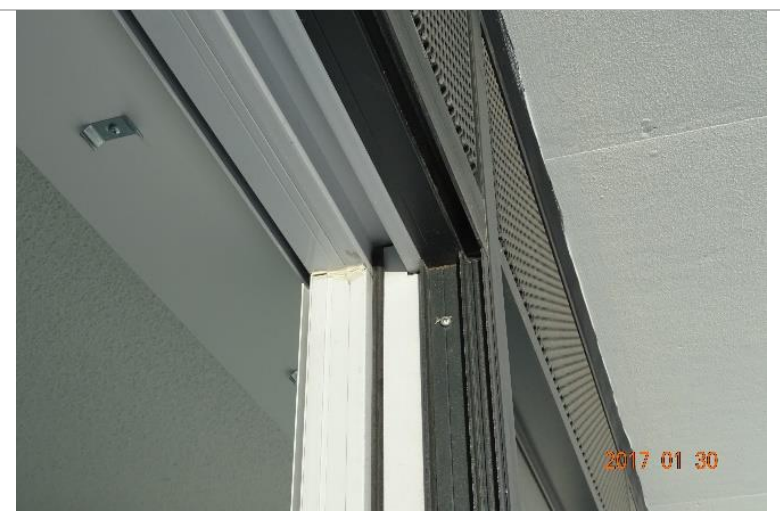

Head track

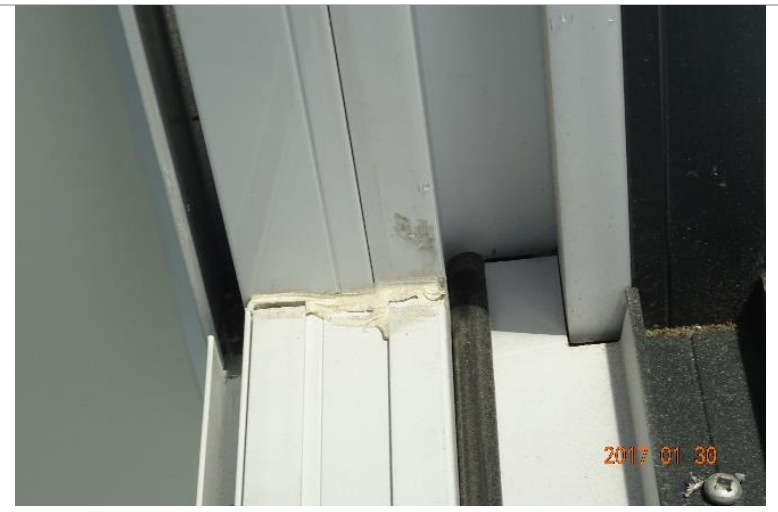

Frame joints

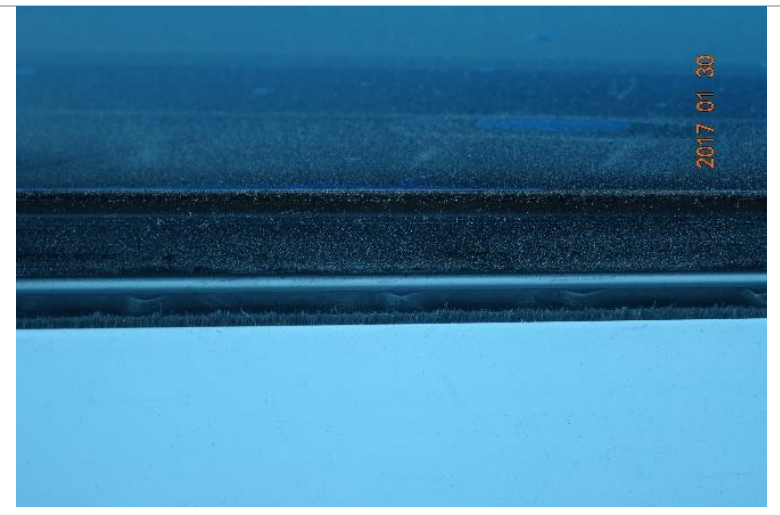

Glazing to frame joints

\section{Discussion}

This test specimen is exceeding laboratory test results. Exterior soffit to door frame sealants are not properly done and could contribute to overall air leakage in case of any interior door secant failures. 


\section{Test No.8}

\begin{tabular}{|l|l|}
\hline Date & $12 / 01 / 2016$ \\
\hline Time & $10: 27 \mathrm{AM}$ \\
\hline Suite & E03 \\
\hline Level & 64 construction/69 marketing \\
\hline
\end{tabular}

\section{Sample Description}

\begin{tabular}{|l|l|}
\hline Model & Double glazed, Argon gas filled \\
\hline Door type & $6 \mathrm{~mm}$ ESR42 Temp (PURCH) / 1" Black spacer /6 mm CLR Temp (PURCH) \\
\hline Assembly Type & 1a or 1b \\
\hline Size & $2260 \mathrm{~mm} \times 1830 \mathrm{~mm}$ \\
\hline Operation type & Sliding door \\
\hline
\end{tabular}

\section{Ambient Test Condition}

\begin{tabular}{|l|l|}
\hline Temperature inside & $7 \circ \mathrm{C}$ \\
\hline Temperature outside & $5 \circ \mathrm{C}($ Feels like $-3 \circ \mathrm{C})$ \\
\hline Density of air at test site & $1.307 \mathrm{Kg} / \mathrm{m} 3$ \\
\hline Relative humidity & $70 \%$ \\
\hline Wind speed & WSW $38 \mathrm{KPH}$
\end{tabular}

\section{Visual Observation}

No deficiency observed in the sample.

\section{Readings}

Air flow rate at nonstandard condition

\begin{tabular}{|l|l|l|l|l|}
\hline Pressure difference & $\mathbf{0 . 1}(\mathbf{2 5}$ pa) & $\mathbf{0 . 2}(50$ pa) & $\mathbf{0 . 3}$ (75 pa) & $0.4(100$ pa) \\
\hline Air flow Q (Scfm) & 12.2 & 13.5 & 14.7 & 16.8
\end{tabular}

Extraneous air flow rate at nonstandard condition

\begin{tabular}{|l|l|l|l|l|}
\hline Pressure difference & $\mathbf{0 . 1}(\mathbf{2 5}$ pa) & $\mathbf{0 . 2}(\mathbf{5 0}$ pa) & $\mathbf{0 . 3}(\mathbf{7 5}$ pa) & $\mathbf{0 . 4}(\mathbf{1 0 0}$ pa) \\
\hline Air flow EQ (Scfm) & 12.3 & 19.8 & 21.4 & 22.8 \\
\hline
\end{tabular}

Air leakage rate

\begin{tabular}{|c|c|c|c|c|}
\hline Pressure difference & 0.1 (25 pa) & 0.2 (50 pa) & 0.3 (75 pa) & $0.4(100$ pa) \\
\hline$Q d=E Q-Q(S c f m)$ & 2.9 & 4.9 & 6.4 & 7.8 \\
\hline $\begin{array}{l}\text { Temperature corrected Flow Rate } \\
\text { (Scfm) }\end{array}$ & 0.109 & 6.839 & 7.273 & 6.513 \\
\hline $\begin{array}{l}\text { Temperature corrected Flow Rate } \\
(\mathrm{L} / \mathrm{s})\end{array}$ & 0.051 & 3.214 & 3.418 & 3.061 \\
\hline Standard air leakage $\left(\mathrm{L} / \mathrm{s} / \mathrm{m}^{2}\right)$ & 0.012 & 0.729 & 0.775 & 0.694 \\
\hline Standardized air leakage $\left(\mathrm{Scfm} / \mathrm{ft}^{2}\right)$ & 0.002 & 0.144 & 0.153 & 0.137 \\
\hline
\end{tabular}




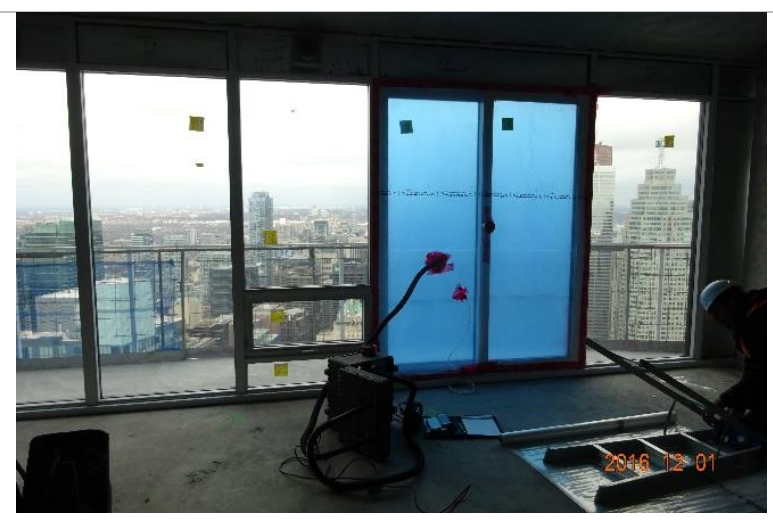

Interior view

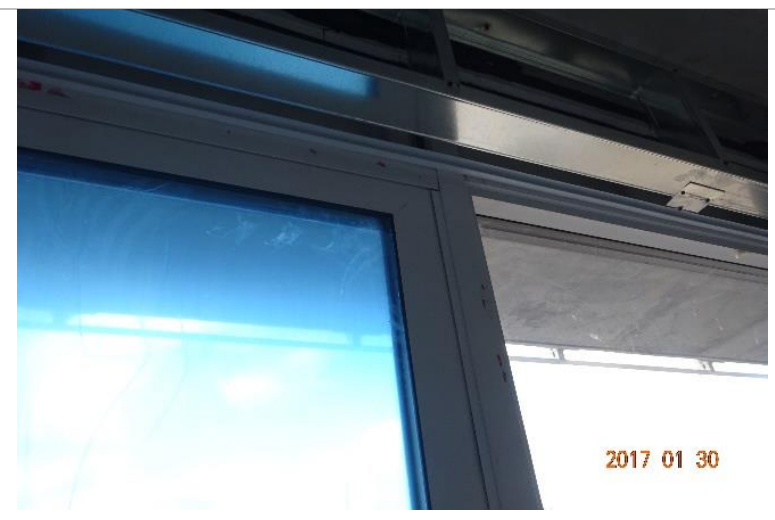

Interior view

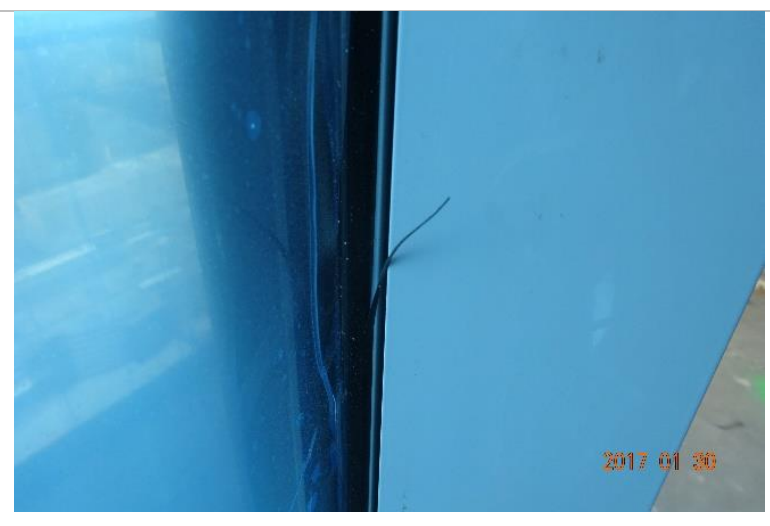

Interior view

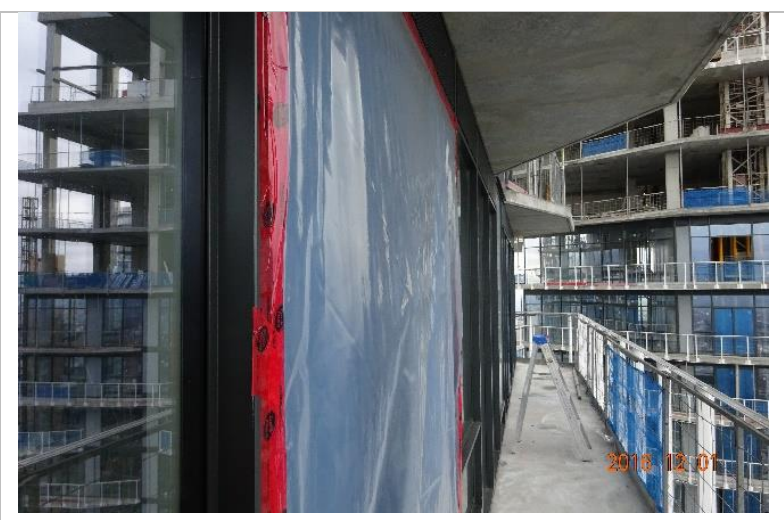

Exterior view

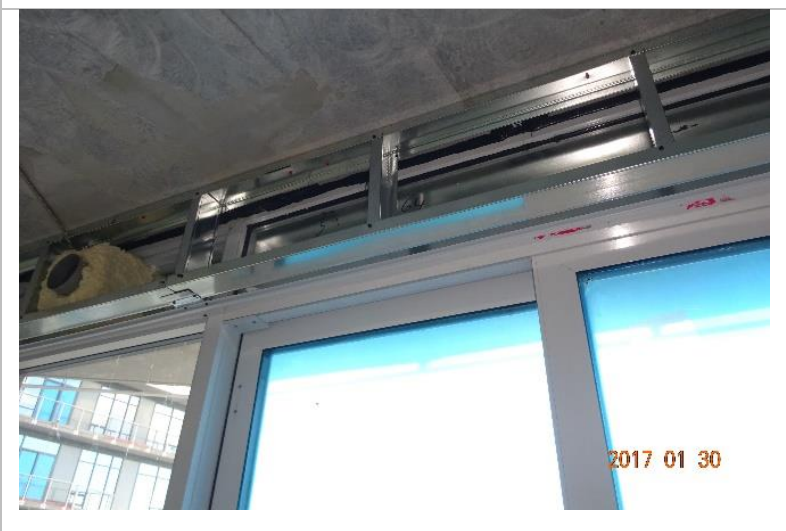

Interior view of bulk head

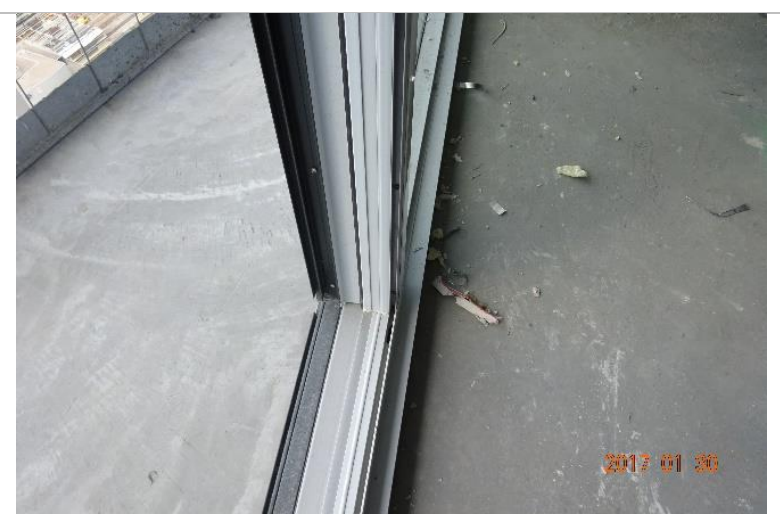

Frame joints 


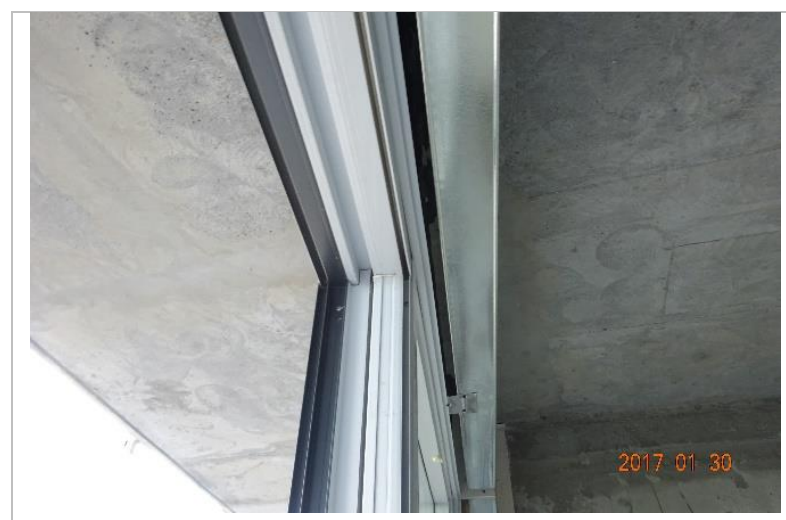

Frame joints

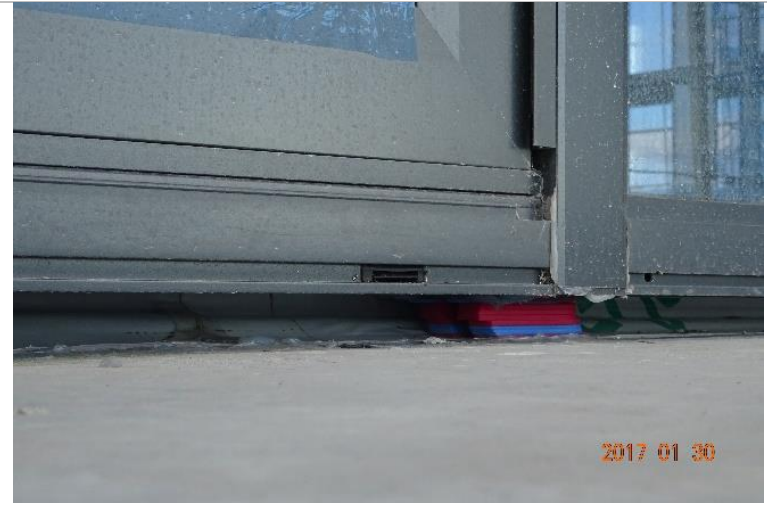

Interior view of door sill to concrete slab
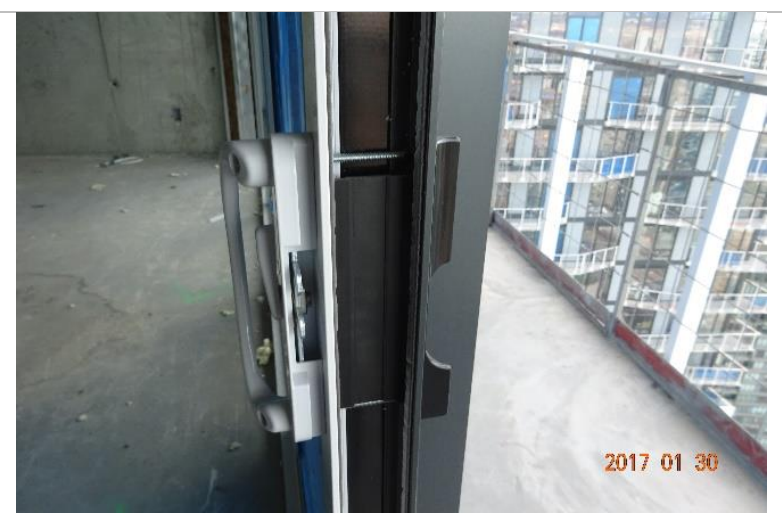

Door hardware

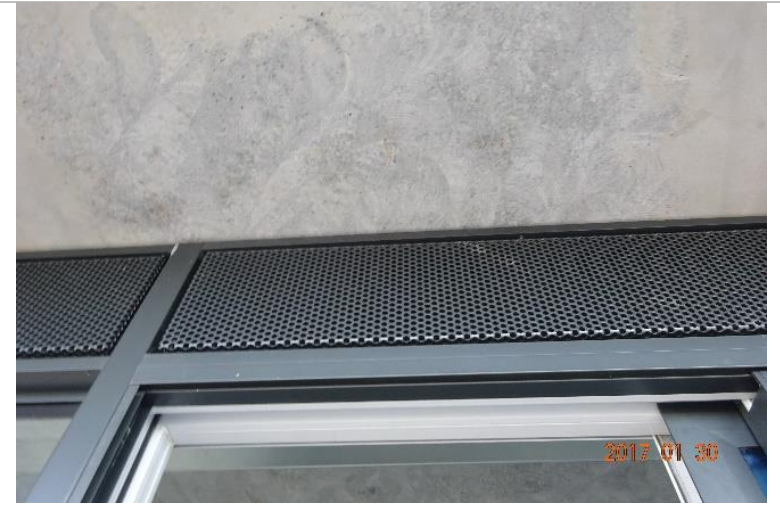

Exteriro view of soffit to door frame

\section{Discussion}

Test sample air leakage rate exceeded laboratory air leakage test result. 


\section{Test No.9}

\begin{tabular}{|l|l|}
\hline Date & $12 / 01 / 2016$ \\
\hline Time & $11: 27 \mathrm{AM}$ \\
\hline Suite & E07 \\
\hline Level & 64 construction/69 marketing \\
\hline
\end{tabular}

\section{Sample Description}

\begin{tabular}{|l|l|}
\hline Model & Double glazed, Argon gas filled \\
\hline Door type & $6 \mathrm{~mm}$ ESR42 Temp (PURCH) / 1" Black spacer/6 mm CLR Temp (PURCH) \\
\hline Assembly Type & $4 \mathrm{~b}$ \\
\hline Size & $2260 \mathrm{~mm} \times 1830 \mathrm{~mm}$ \\
\hline Operation type & Sliding door \\
\hline
\end{tabular}

\section{Ambient Test Condition}

\begin{tabular}{|l|l|}
\hline Temperature inside & $7 \circ \mathrm{C}$ \\
\hline Temperature outside & $5 \circ \mathrm{C}\left(\right.$ Feels like $\left.-3{ }^{\circ} \mathrm{C}\right)$ \\
\hline Density of air at test site & $1.307 \mathrm{Kg} / \mathrm{m} 3$ \\
\hline Relative humidity & $70 \%$ \\
\hline Wind speed & WSW $38 \mathrm{KPH}$ \\
\hline
\end{tabular}

\section{Visual Observation}

No deficiency observed in the sample.

\section{Readings}

Air flow rate at nonstandard condition

\begin{tabular}{|l|l|l|l|l|}
\hline Pressure difference & $\mathbf{0 . 1}(\mathbf{2 5}$ pa) & $\mathbf{0 . 2}$ (50 pa) & $\mathbf{0 . 3}$ (75 pa) & $\mathbf{0 . 4}(100$ pa) \\
\hline Air flow Q (Scfm) & 7.2 & 9.2 & 10.8 & 11.8
\end{tabular}

Extraneous air flow rate at nonstandard condition

\begin{tabular}{|l|l|l|l|l|}
\hline Pressure difference & $\mathbf{0 . 1}(\mathbf{2 5}$ pa) & $\mathbf{0 . 2}(\mathbf{5 0}$ pa) & $\mathbf{0 . 3}(\mathbf{7 5}$ pa) & $\mathbf{0 . 4}(\mathbf{1 0 0}$ pa) \\
\hline Air flow EQ (Scfm) & 9.1 & 12.6 & 15.3 & 16.2 \\
\hline
\end{tabular}

Air leakage rate

\begin{tabular}{|c|c|c|c|c|}
\hline Pressure difference & 0.1 (25 pa) & 0.2 (50 pa) & 0.3 (75 pa) & $0.4(100$ pa) \\
\hline$Q d=E Q-Q(S c f m)$ & 2.1 & 3.4 & 4.5 & 4.2 \\
\hline $\begin{array}{l}\text { Temperature corrected Flow Rate } \\
\text { (Scfm) }\end{array}$ & 2.063 & 3.691 & 4.885 & 4.776 \\
\hline $\begin{array}{l}\text { Temperature corrected Flow Rate } \\
(\mathrm{L} / \mathrm{s})\end{array}$ & 0.969 & 1.735 & 2.296 & 2.245 \\
\hline Standard air leakage $\left(\mathrm{L} / \mathrm{s} / \mathrm{m}^{2}\right)$ & 0.220 & 0.393 & 0.521 & 0.509 \\
\hline Standardized air leakage $\left(\mathrm{Scfm} / \mathrm{ft}^{2}\right)$ & 0.050 & 0.089 & 0.118 & 0.115 \\
\hline
\end{tabular}




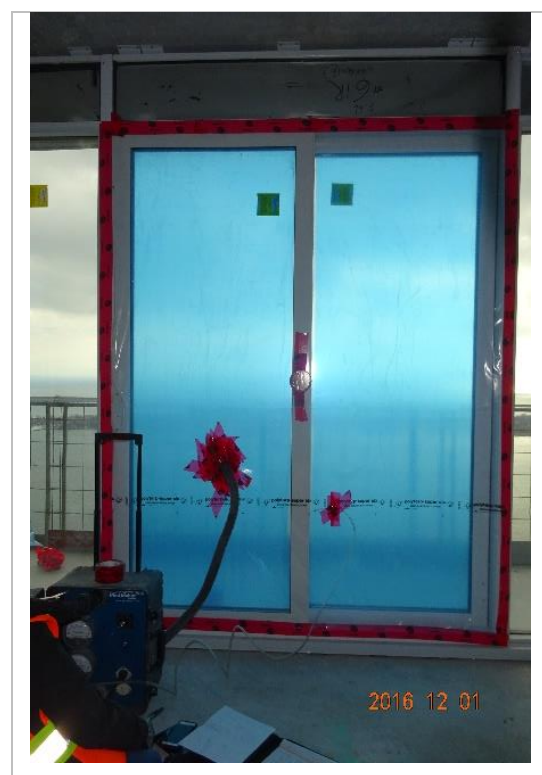

Interior view

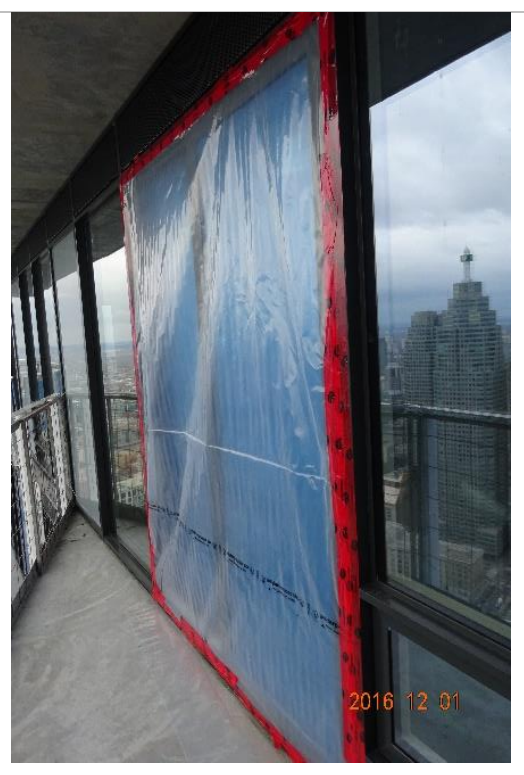

Exterior view

\section{Discussion}

Test sample air leakage slightly exceeded air leakage laboratory test result. 


\section{Test No.10}

\begin{tabular}{|l|l|}
\hline Date & $12 / 01 / 2016$ \\
\hline Time & $12: 32 \mathrm{PM}$ \\
\hline Suite & E03 \\
\hline Level & 58 construction/63 marketing \\
\hline
\end{tabular}

\section{Sample Description}

\begin{tabular}{|l|l|}
\hline Model & Double glazed, Argon gas filled \\
\hline Door type & $6 \mathrm{~mm}$ ESR42 Temp (PURCH) / 1" Black spacer /6 mm CLR Temp (PURCH) \\
\hline Assembly Type & 1a or 1b \\
\hline Size & $2260 \mathrm{~mm} \times 1830 \mathrm{~mm}$ \\
\hline Operation type & Sliding door \\
\hline
\end{tabular}

\section{Ambient Test Condition}

\begin{tabular}{|l|l|}
\hline Temperature inside & $7 \circ \mathrm{C}$ \\
\hline Temperature outside & $6 \circ \mathrm{C}\left(\right.$ Feels like $\left.-2{ }^{\circ} \mathrm{C}\right)$ \\
\hline Density of air at test site & $1.307 \mathrm{Kg} / \mathrm{m} 3$ \\
\hline Relative humidity & $70 \%$ \\
\hline Wind speed & W $24 \mathrm{KPH}$
\end{tabular}

\section{Visual Observation}

No deficiency observed at the time of review.

\section{Readings}

Air flow rate at nonstandard condition

\begin{tabular}{|l|l|l|l|l|}
\hline Pressure difference & $\mathbf{0 . 1}(\mathbf{2 5}$ pa) & $\mathbf{0 . 2}(\mathbf{5 0}$ pa) & $\mathbf{0 . 3}(\mathbf{7 5}$ pa) & $\mathbf{0 . 4}(\mathbf{1 0 0}$ pa) \\
\hline Air flow Q (Scfm) & 9.8 & 10.5 & 12.2 & 14.7
\end{tabular}

Extraneous air flow rate at nonstandard condition

\begin{tabular}{|l|l|l|l|l|}
\hline Pressure difference & $\mathbf{0 . 1}(\mathbf{2 5}$ pa) & $0.2(50$ pa) & $0.3(75$ pa) & $0.4(100$ pa) \\
\hline Air flow EQ (Scfm) & 10.3 & 14.8 & 15.5 & 20.9 \\
\hline
\end{tabular}

Air leakage rate

\begin{tabular}{|c|c|c|c|c|}
\hline Pressure difference & 0.1 (25 pa) & 0.2 (50 pa) & 0.3 (75 pa) & $0.4(100$ pa) \\
\hline$Q d=E Q-Q(S c f m)$ & 0.5 & 4.3 & 3.3 & 6.2 \\
\hline $\begin{array}{l}\text { Temperature corrected Flow Rate } \\
\text { (Scfm) }\end{array}$ & 0.543 & 4.668 & 3.582 & 6.730 \\
\hline $\begin{array}{l}\text { Temperature corrected Flow Rate } \\
\text { (L/s) }\end{array}$ & 0.255 & 2.194 & 1.684 & 3.163 \\
\hline Standard air leakage $\left(\mathrm{L} / \mathrm{s} / \mathrm{m}^{2}\right)$ & 0.058 & 0.497 & 0.382 & 0.717 \\
\hline Standardized air leakage $\left(\mathrm{Scfm} / \mathrm{ft}^{2}\right)$ & 0.013 & 0.113 & 0.087 & 0.163 \\
\hline
\end{tabular}




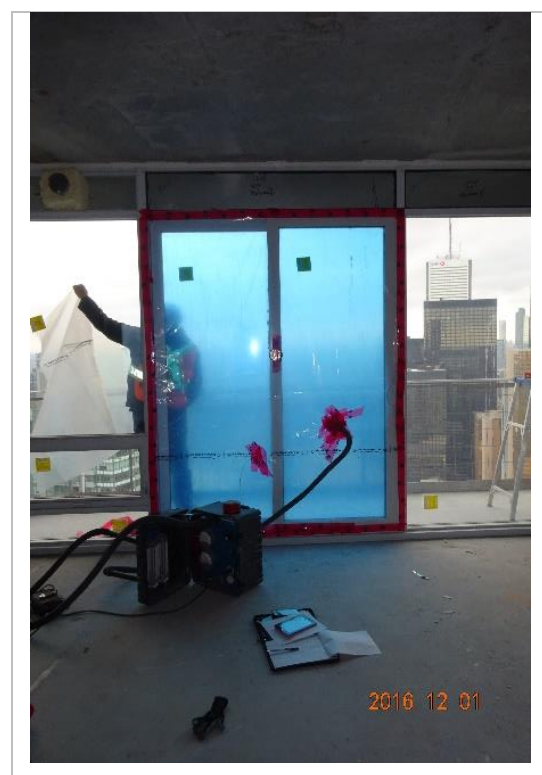

\section{Interior view}

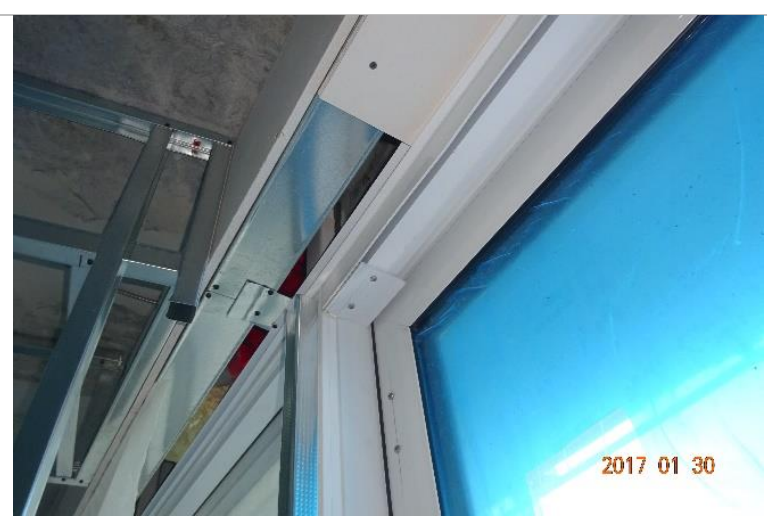

Bulk head

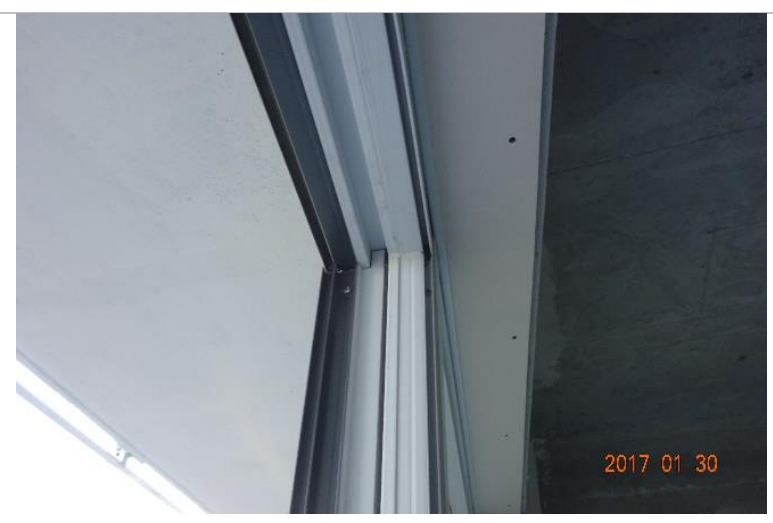

Frame joints

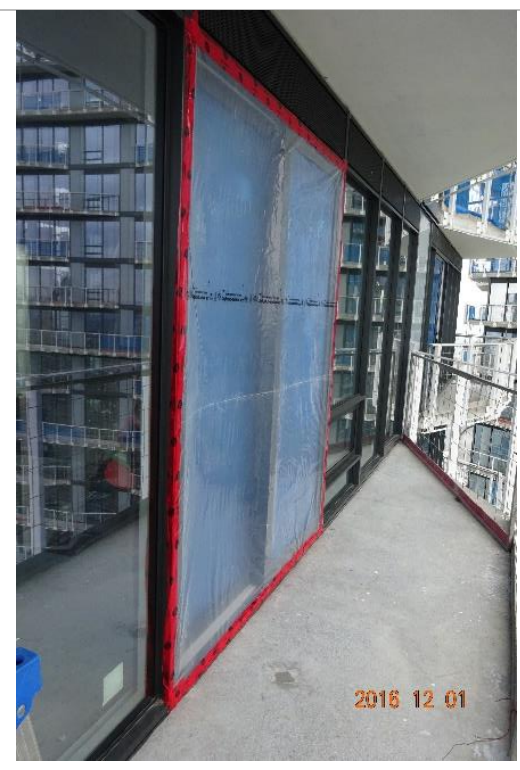

\section{Exterior view}

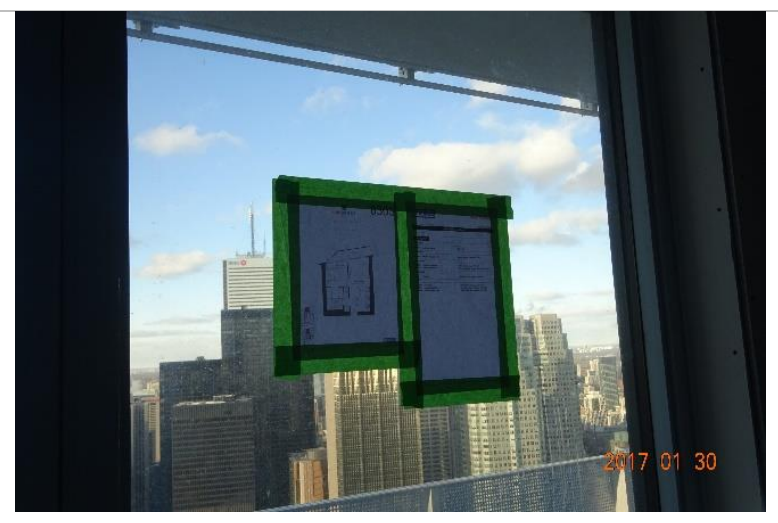

Unit plan

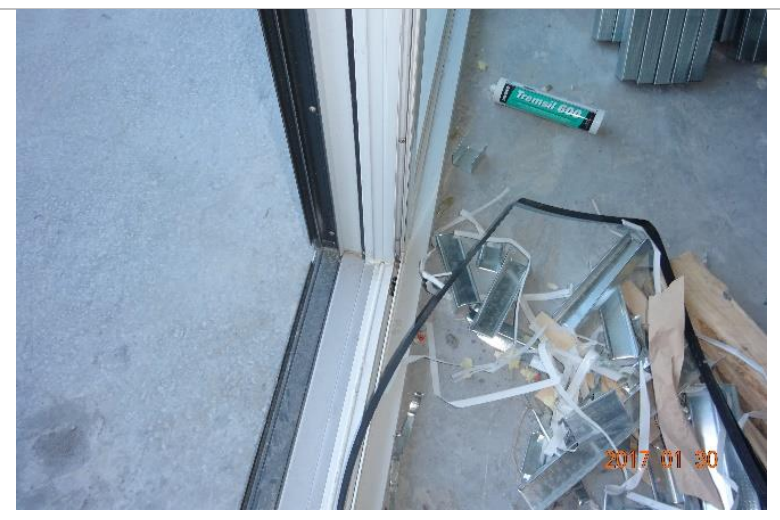

Door sill frame and track 


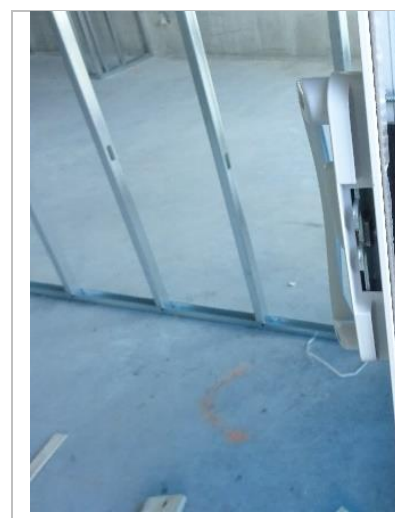

Door hardware

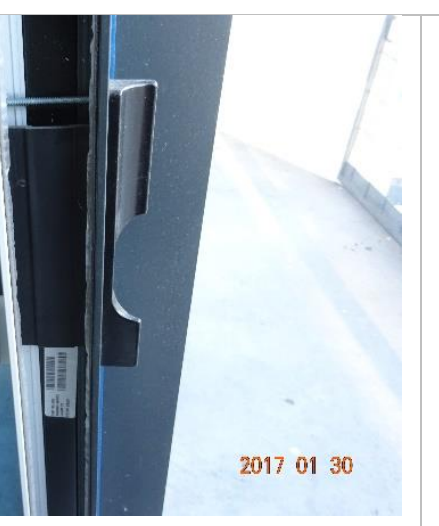

20170130

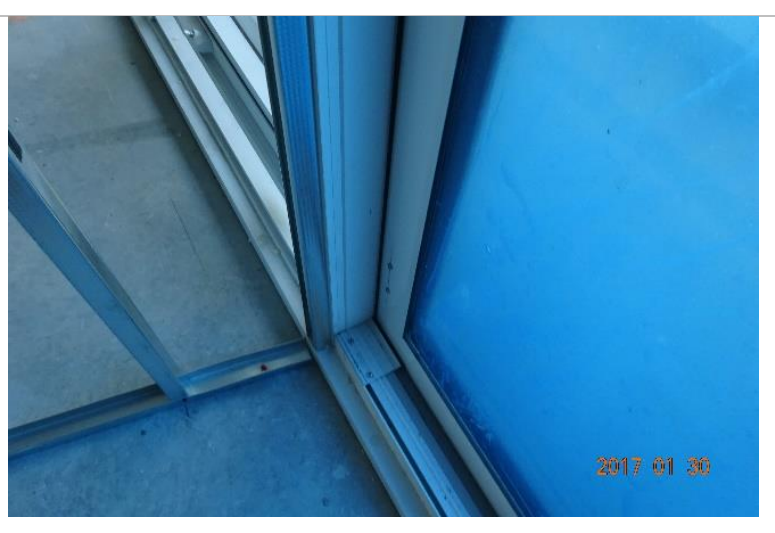

Frame joints

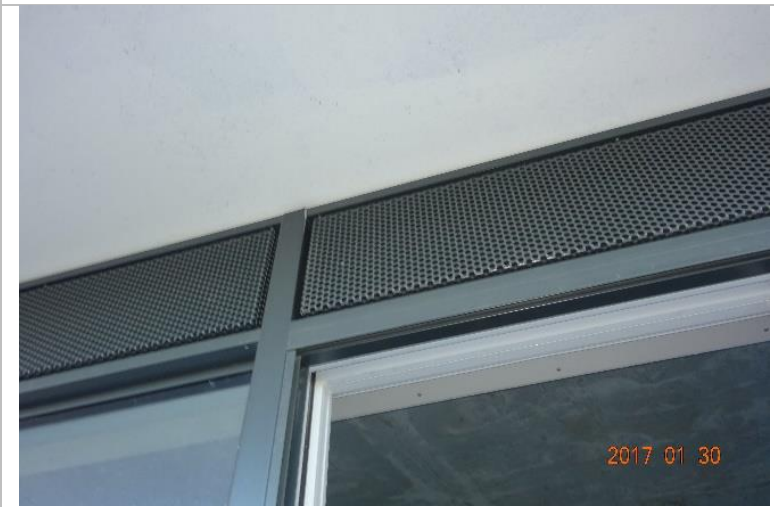

Exterior frame to soffit joints

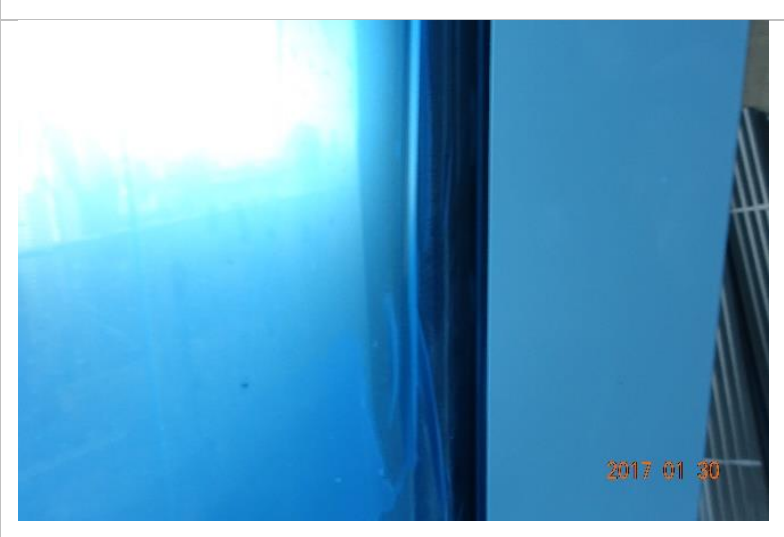

Glazing to frame joints

\section{Discussion}

Test sample air leakage result is below laboratory air leakage result at 75 pascal pressure difference. 


\section{Test No.11}

\begin{tabular}{|l|l|}
\hline Date & $12 / 01 / 2016$ \\
\hline Time & $1: 14 \mathrm{PM}$ \\
\hline Suite & E09 \\
\hline Level & 54 construction/59 marketing \\
\hline
\end{tabular}

\section{Sample Description}

\begin{tabular}{|l|l|}
\hline Model & Double glazed, Argon gas filled \\
\hline Door type & $6 \mathrm{~mm}$ ESR42 Temp (PURCH) / 1" Black spacer /6 mm CLR Temp (PURCH) \\
\hline Assembly Type & $4 \mathrm{~b}$ \\
\hline Size & $2260 \mathrm{~mm} \times 1830 \mathrm{~mm}$ \\
\hline Operation type & Sliding door \\
\hline
\end{tabular}

\section{Ambient Test Condition}

\begin{tabular}{|l|l|}
\hline Temperature inside & $5 \circ \mathrm{C}$ \\
\hline Temperature outside & $6 \circ \mathrm{C}\left(\right.$ Feels like $\left.-2{ }^{\circ} \mathrm{C}\right)$ \\
\hline Density of air at test site & $1.307 \mathrm{Kg} / \mathrm{m} 3$ \\
\hline Relative humidity & $70 \%$ \\
\hline Wind speed & W $24 \mathrm{KPH}$
\end{tabular}

\section{Visual Observation}

No deficiency observed at the time of review.

\section{Readings}

Air flow rate at nonstandard condition

\begin{tabular}{|l|l|l|l|l|}
\hline Pressure Difference & $\mathbf{0 . 1}(\mathbf{2 5}$ pa) & $\mathbf{0 . 2}(\mathbf{5 0}$ pa) & $\mathbf{0 . 3}(\mathbf{7 5}$ pa) & $\mathbf{0 . 4}(\mathbf{1 0 0}$ pa) \\
\hline Air flow Q (scfm) & 8.1 & 9.4 & 11.9 & 12.4 \\
\hline
\end{tabular}

Extraneous air flow rate at nonstandard condition

\begin{tabular}{|l|l|l|l|l|}
\hline Pressure difference & $\mathbf{0 . 1}(\mathbf{2 5} \mathbf{~ p a})$ & $\mathbf{0 . 2}(\mathbf{5 0} \mathbf{~ p a})$ & $\mathbf{0 . 3}(\mathbf{7 5} \mathbf{~ p a})$ & $\mathbf{0 . 4}(\mathbf{1 0 0} \mathbf{~ p a )}$ \\
\hline Air flow EQ (scfm) & 8.8 & 14.7 & 16.8 & 19.1 \\
\hline
\end{tabular}

Air leakage rate

\begin{tabular}{|c|c|c|c|c|}
\hline Pressure difference & 0.1 (25 pa) & 0.2 (50 pa) & 0.3 (75 pa) & $0.4(100 \mathrm{pa})$ \\
\hline$Q d=E Q-Q(S c f m)$ & 0.7 & 5.3 & 4.9 & 6.7 \\
\hline $\begin{array}{l}\text { Temperature corrected Flow Rate } \\
\text { (Scfm) }\end{array}$ & 0.760 & 5.458 & 5.319 & 7.273 \\
\hline $\begin{array}{l}\text { Temperature corrected Flow Rate } \\
(\mathrm{L} / \mathrm{s})\end{array}$ & 0.357 & 2.565 & 2.500 & 3.418 \\
\hline Standard air leakage $\left(\mathrm{L} / \mathrm{s} / \mathrm{m}^{2}\right)$ & 0.086 & 0.620 & 0.604 & 0.827 \\
\hline Standardized air leakage $\left(\mathrm{Scfm} / \mathrm{ft}^{2}\right)$ & 0.021 & 0.150 & 0.146 & 0.200 \\
\hline
\end{tabular}




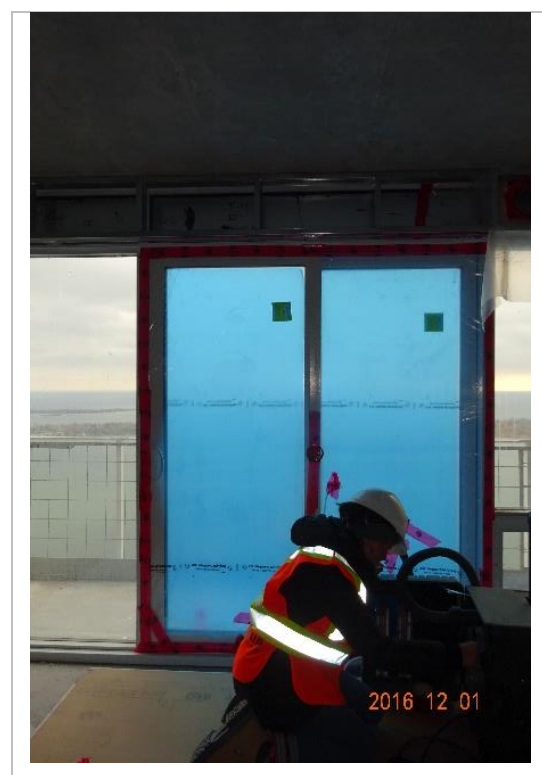

Interior view

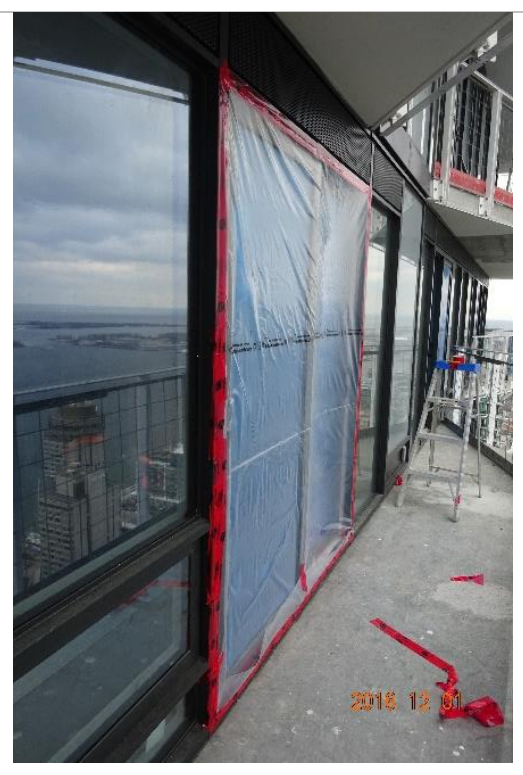

Exterior view

\section{Discussion}

Test sample air leakage result is above laboratory air leakage result at 75 pascal pressure difference. 


\section{Test No.12}

\begin{tabular}{|l|l|}
\hline Date & $12 / 01 / 2016$ \\
\hline Time & $3: 23 \mathrm{PM}$ \\
\hline Suite & E07 \\
\hline Level & 10 construction/15 marketing \\
\hline
\end{tabular}

\section{Sample Description}

\begin{tabular}{|l|l|}
\hline Model & Double glazed, Argon gas filled \\
\hline Door type & $6 \mathrm{~mm}$ ESR42 Temp (PURCH) / 1" Black spacer /6 mm CLR Temp (PURCH) \\
\hline Assembly Type & $4 \mathrm{~b}$ \\
\hline Size & $2260 \mathrm{~mm} \times 1830 \mathrm{~mm}$ \\
\hline Operation type & Sliding door \\
\hline
\end{tabular}

\section{Ambient Test Condition}

\begin{tabular}{|l|l|}
\hline Temperature inside & $5 \circ \mathrm{C}$ \\
\hline Temperature outside & $6 \circ \mathrm{C}\left(\right.$ Feels like $\left.-2{ }^{\circ} \mathrm{C}\right)$ \\
\hline Density of air at test site & $1.307 \mathrm{Kg} / \mathrm{m} 3$ \\
\hline Relative humidity & $70 \%$ \\
\hline Wind speed & W $24 \mathrm{KPH}$
\end{tabular}

\section{Visual Observation}

No deficiency observed at the time of review.

\section{Readings}

Air flow rate at nonstandard condition

\begin{tabular}{|l|l|l|l|l|}
\hline Pressure difference & $\mathbf{0 . 1}(\mathbf{2 5}$ pa) & $\mathbf{0 . 2}(\mathbf{5 0}$ pa) & $\mathbf{0 . 3}(\mathbf{7 5}$ pa) & $\mathbf{0 . 4}(\mathbf{1 0 0}$ pa) \\
\hline Air flow Q (scfm) & 8.7 & 9.7 & 11.8 & 12.6 \\
\hline
\end{tabular}

Extraneous air flow rate at nonstandard condition

\begin{tabular}{|l|l|l|l|l|}
\hline Pressure difference & $\mathbf{0 . 1}(\mathbf{2 5}$ pa) & $0.2(50$ pa) & $0.3(75$ pa) & $0.4(100$ pa) \\
\hline Air flow EQ (scfm) & 11.8 & 14.9 & 17.1 & 19.4 \\
\hline
\end{tabular}

Air leakage rate

\begin{tabular}{|c|c|c|c|c|}
\hline Pressure difference & 0.1 (25 pa) & 0.2 (50 pa) & 0.3 (75 pa) & $0.4(100$ pa) \\
\hline$Q d=E Q-Q(S c f m)$ & 3.1 & 5.2 & 5.3 & 5.8 \\
\hline $\begin{array}{l}\text { Temperature corrected Flow Rate } \\
\text { (Scfm) }\end{array}$ & 3.365 & 5.355 & 5.753 & 7.382 \\
\hline $\begin{array}{l}\text { Temperature corrected Flow Rate } \\
(\mathrm{L} / \mathrm{s})\end{array}$ & 1.582 & 2.517 & 2.704 & 3.469 \\
\hline Standard air leakage $\left(\mathrm{L} / \mathrm{s} / \mathrm{m}^{2}\right)$ & 0.382 & 0.609 & 0.654 & 0.839 \\
\hline Standardized air leakage $\left(\mathrm{Scfm} / \mathrm{ft}^{2}\right)$ & 0.092 & 0.147 & 0.158 & 0.203 \\
\hline
\end{tabular}




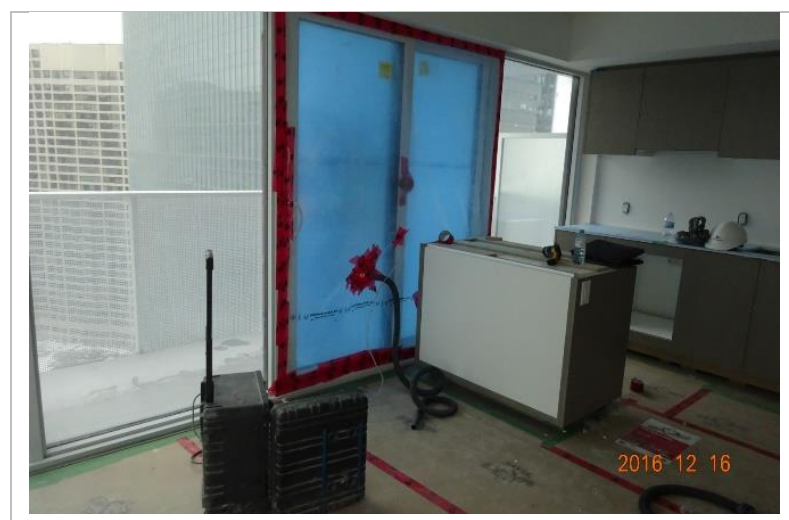

Interior view

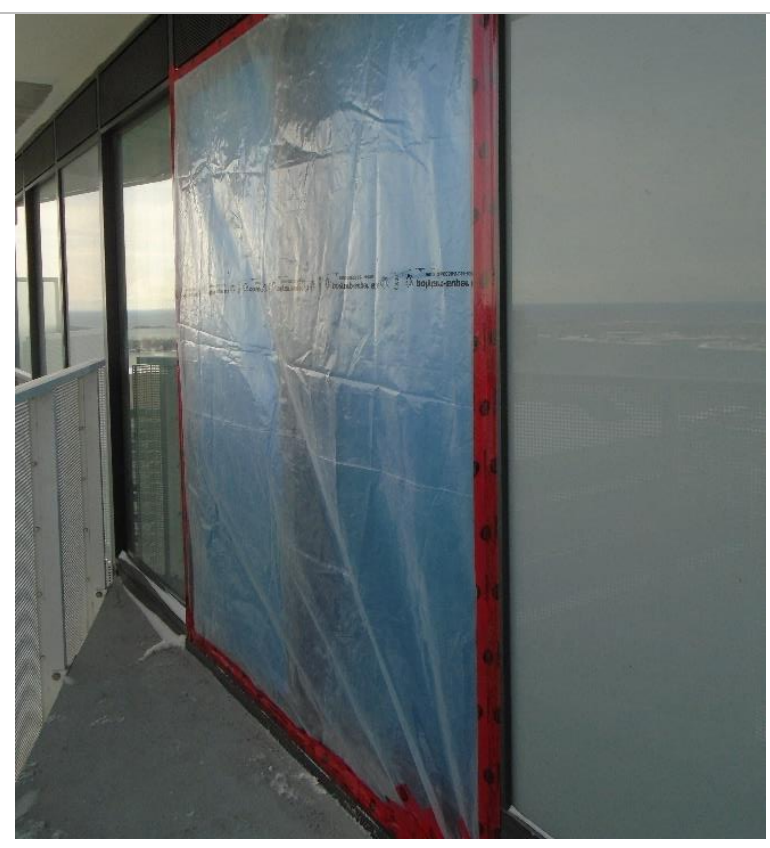

Exterior view

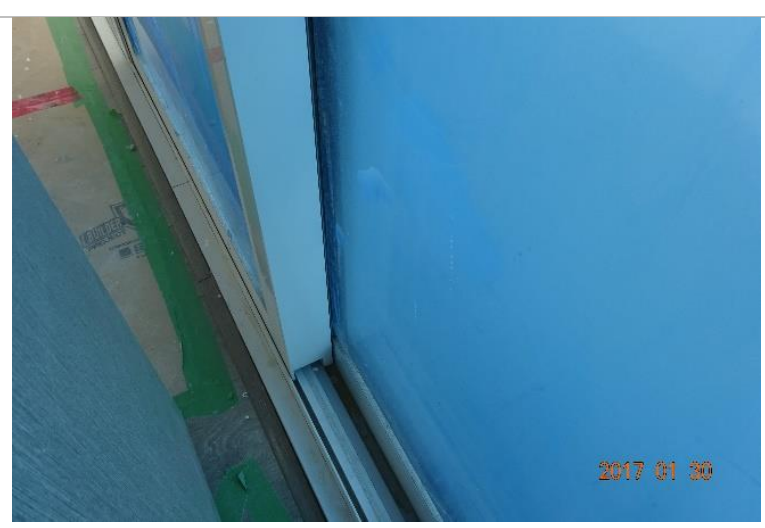

Door track

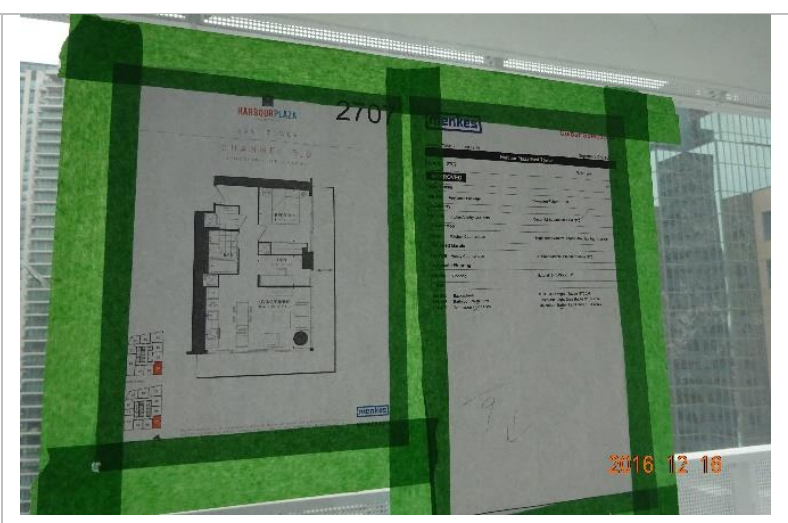

Unit paln

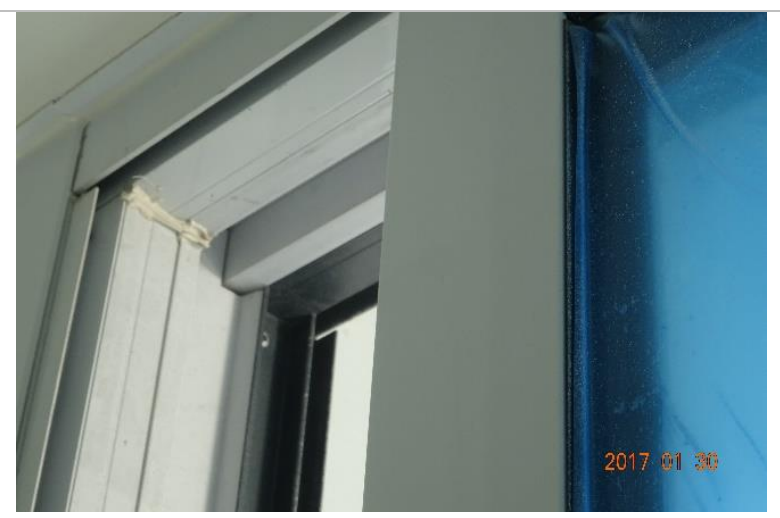

Frame joints

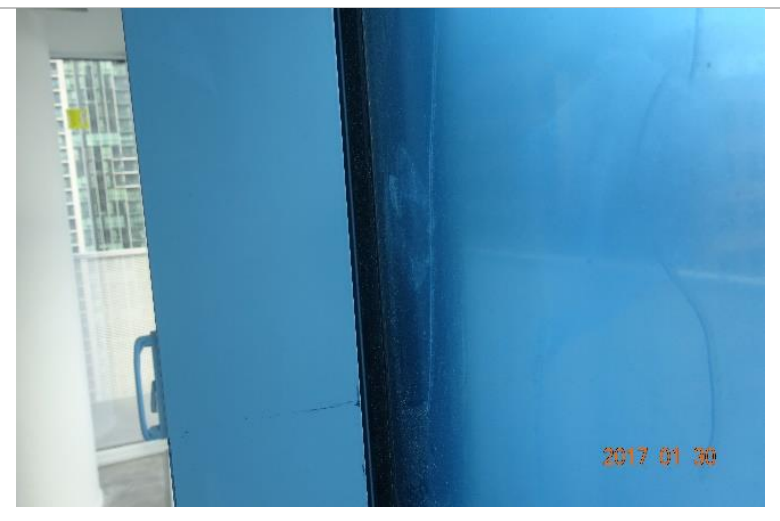

Glass to frame joint 


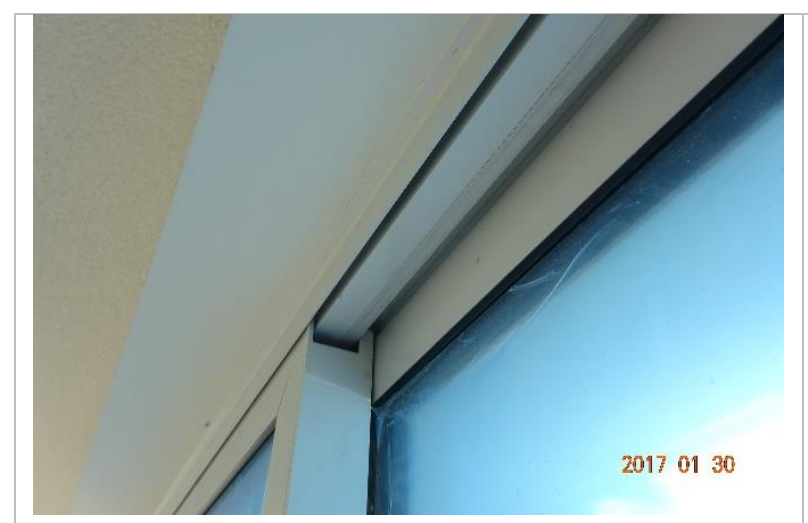

Door head

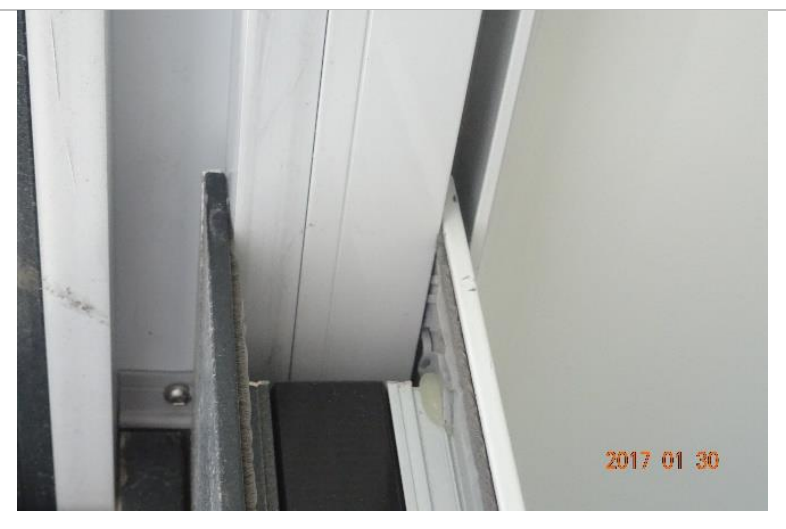

Door head

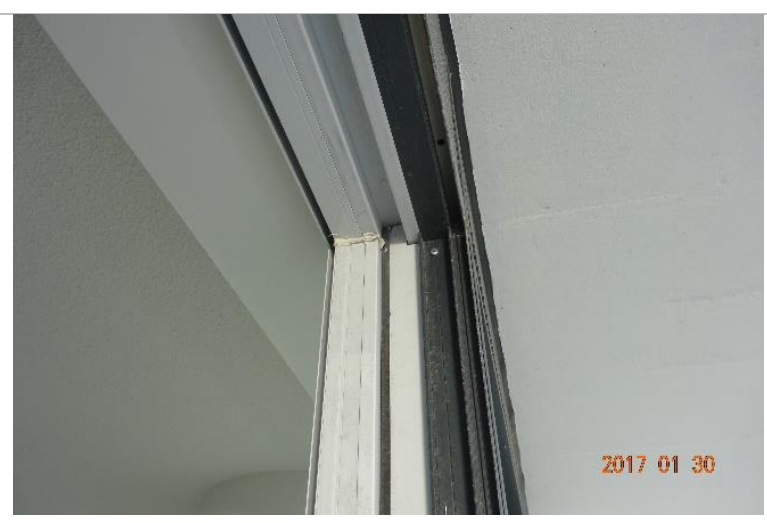

Frame joint

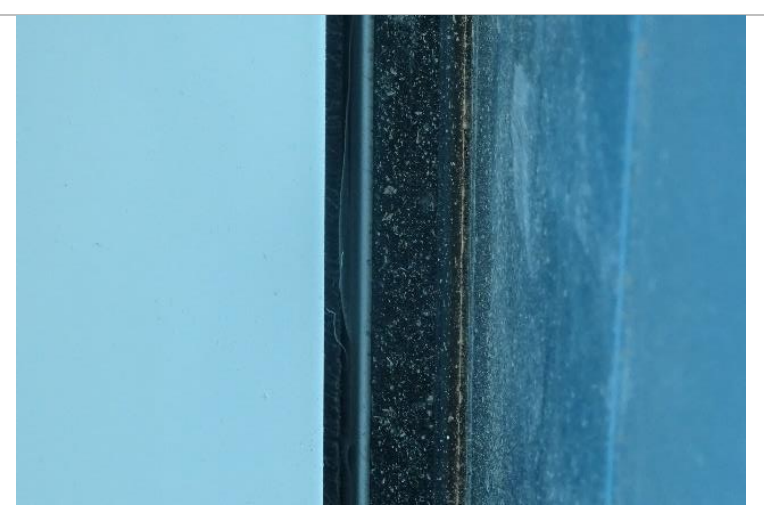

\section{Door jamb}

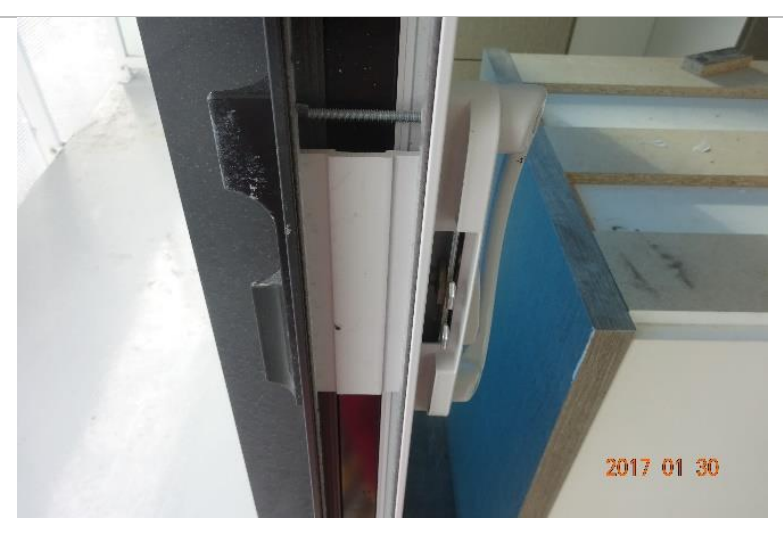

Door hardware

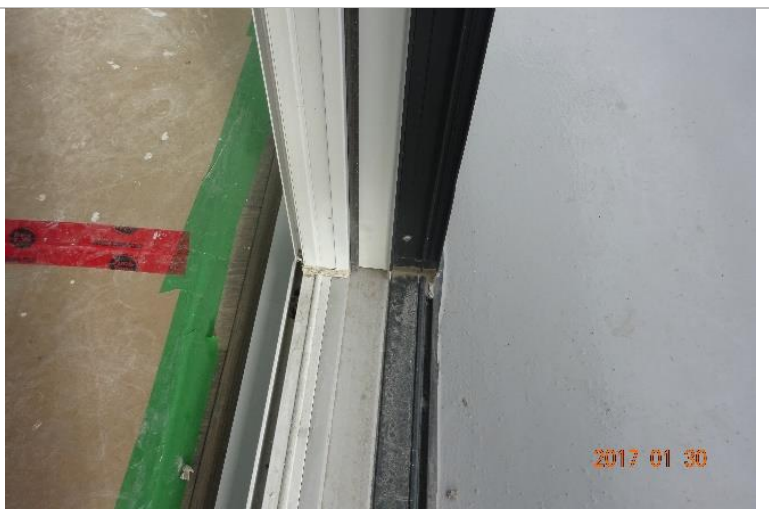

Door sill 


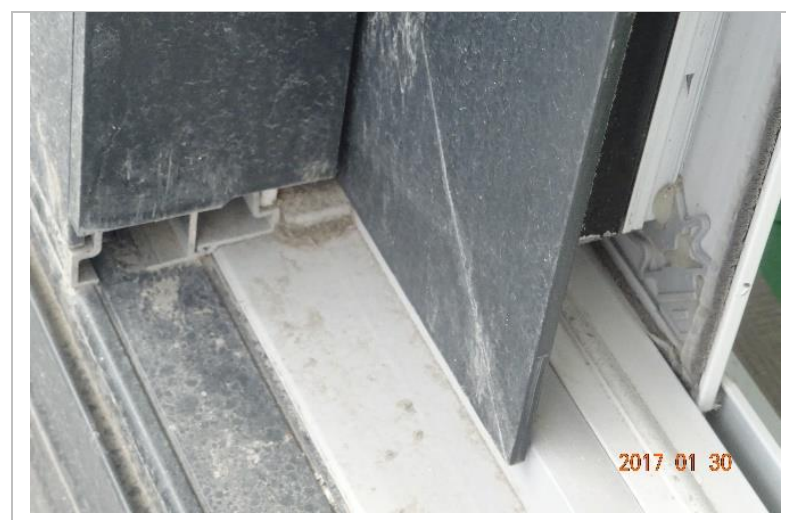

Dust plug

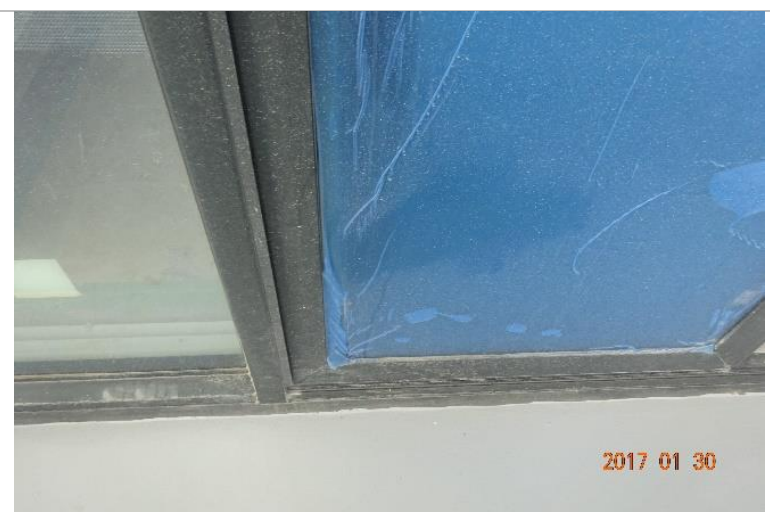

\section{Exterior view}

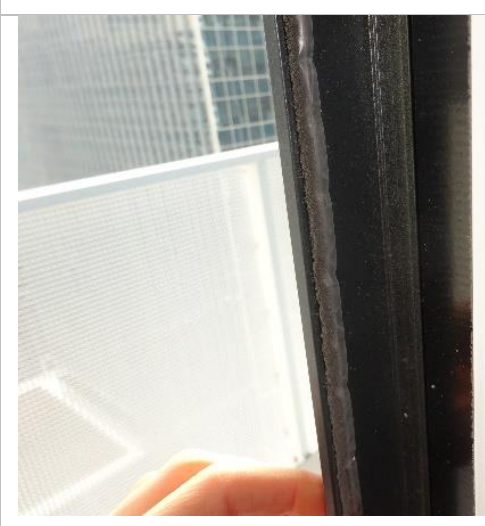

Door meeting stile

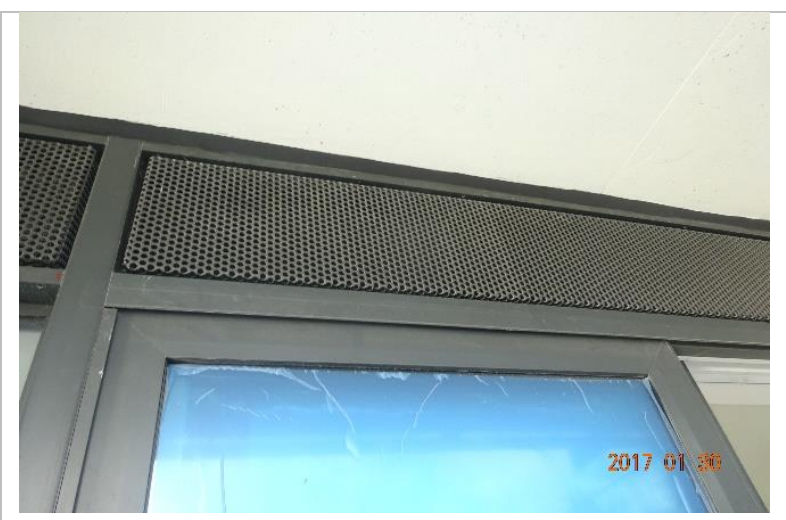

Door frame to concrete soffit

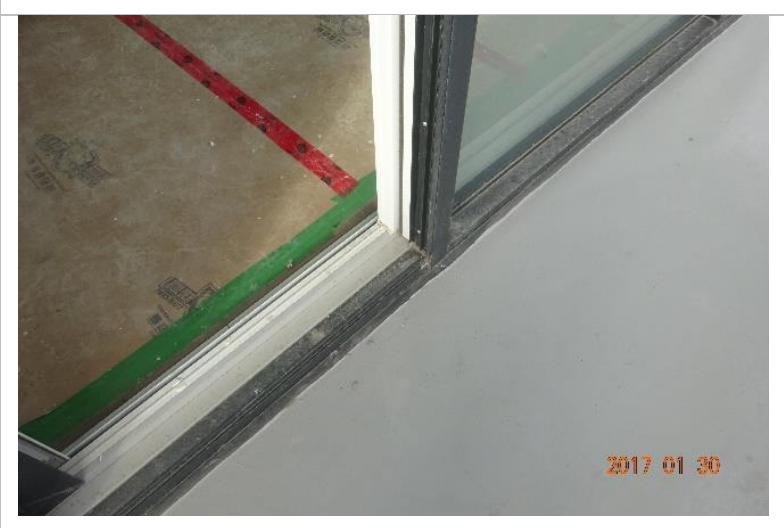

Door sill
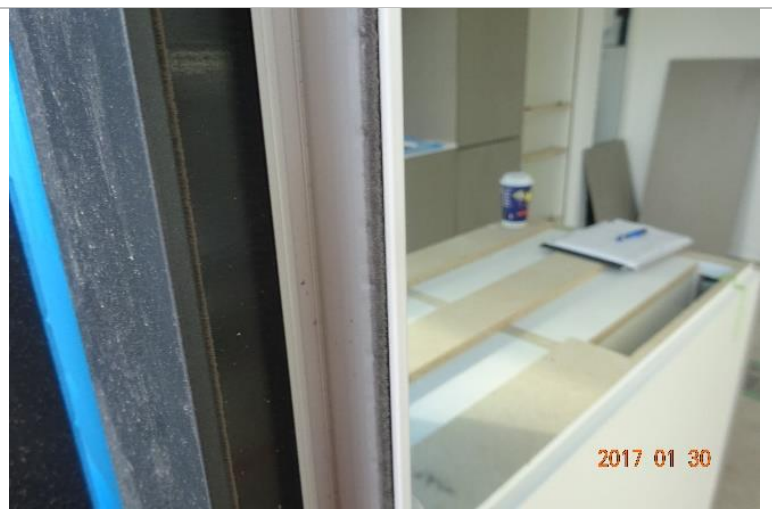

Door meeting stile 


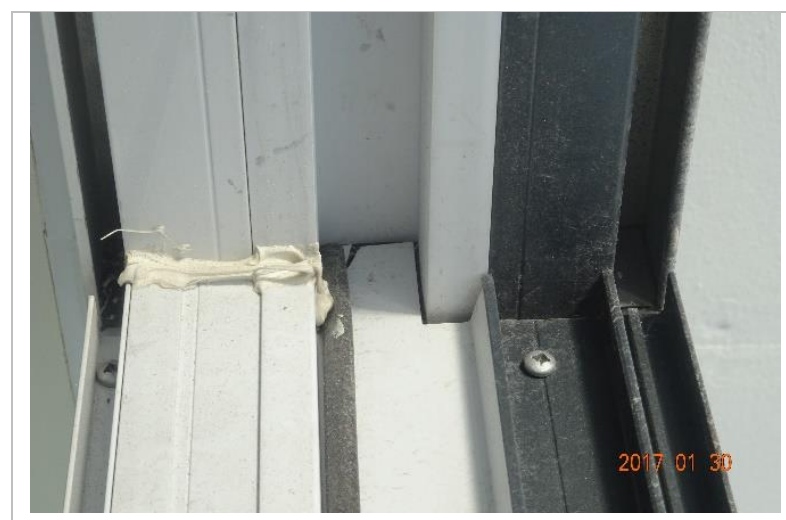

Frame joint

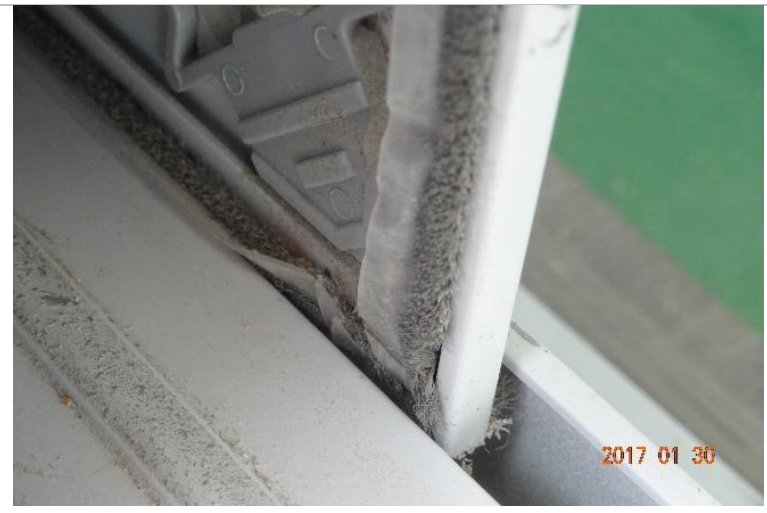

Weather stripping

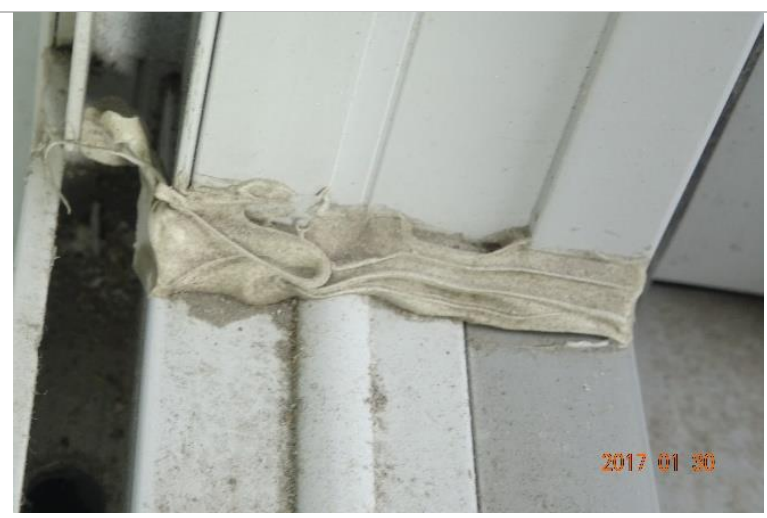

Frame joint selant

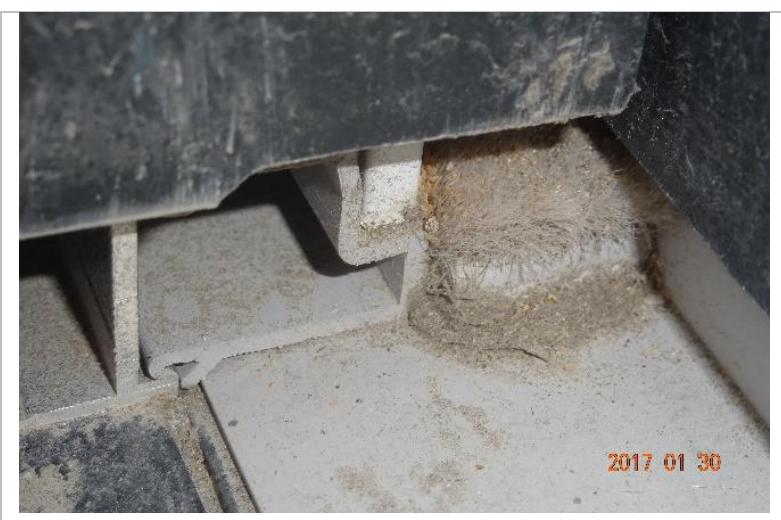

Dust plug

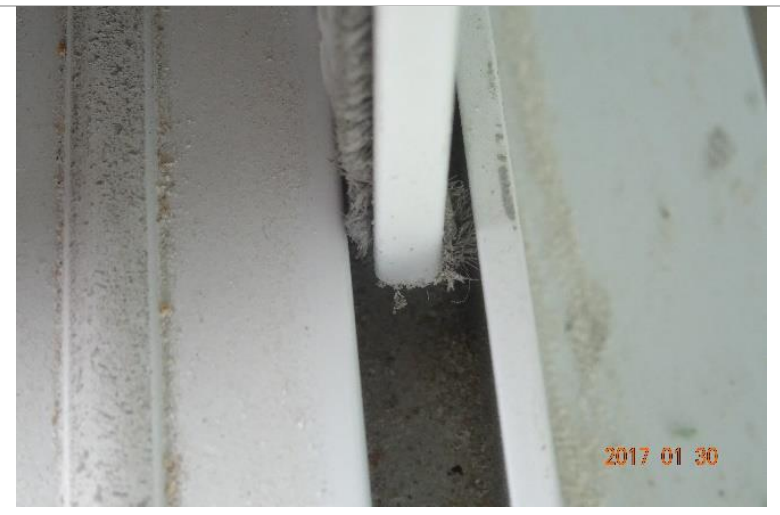

Weather stripping

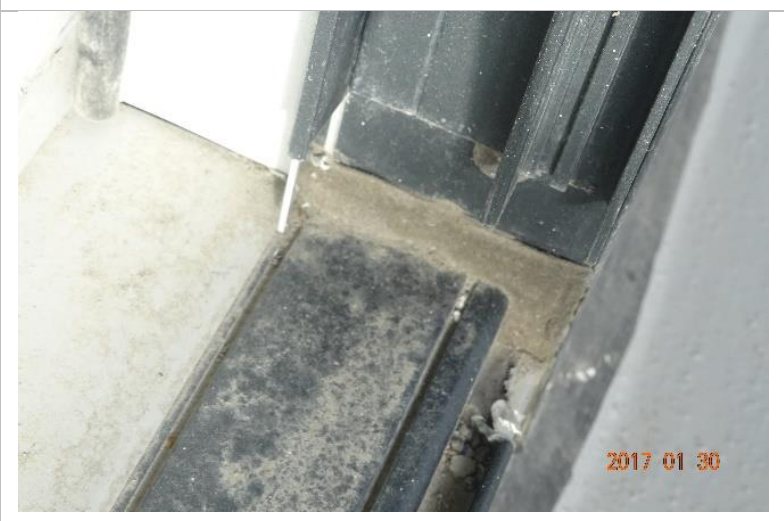

Door track joint

\section{Discussion}

Test sample air leakage result is above laboratory air leakage result at 75 pascal pressure difference. 


\section{Test No.13}

\begin{tabular}{|l|l|}
\hline Date & $12 / 01 / 2016$ \\
\hline Time & $4: 15 \mathrm{PM}$ \\
\hline Suite & E06 \\
\hline Level & 11 construction/16 marketing \\
\hline
\end{tabular}

\section{Sample Description}

\begin{tabular}{|l|l|}
\hline Model & Double glazed, Argon gas filled \\
\hline Door type & $6 \mathrm{~mm}$ ESR42 Temp (PURCH) / 1" Black spacer /6 mm CLR Temp (PURCH) \\
\hline Assembly Type & $4 \mathrm{~b}$ \\
\hline Size & $2260 \mathrm{~mm} \times 1830 \mathrm{~mm}$ \\
\hline Operation type & Sliding door \\
\hline
\end{tabular}

\section{Ambient Test Condition}

\begin{tabular}{|l|l|}
\hline Temperature inside & $5 \circ \mathrm{C}$ \\
\hline Temperature outside & $6 \circ \mathrm{C}\left(\right.$ Feels like $\left.-2{ }^{\circ} \mathrm{C}\right)$ \\
\hline Density of air at test site & $1.307 \mathrm{Kg} / \mathrm{m} 3$ \\
\hline Relative humidity & $70 \%$ \\
\hline Wind speed & W $24 \mathrm{KPH}$
\end{tabular}

\section{Visual Observation}

No deficiency observed at the time of review.

\section{Readings}

Air flow rate at nonstandard condition

\begin{tabular}{|l|l|l|l|l|}
\hline Pressure difference & $\mathbf{0 . 1}(\mathbf{2 5}$ pa) & $\mathbf{0 . 2}(\mathbf{5 0}$ pa) & $\mathbf{0 . 3}(\mathbf{7 5}$ pa) & $\mathbf{0 . 4}(\mathbf{1 0 0}$ pa) \\
\hline Air flow Q (scfm) & 7.8 & 9.8 & 10.3 & 11.3
\end{tabular}

Extraneous air flow rate at nonstandard condition

\begin{tabular}{|l|l|l|l|l|}
\hline Pressure difference & $0.1(25$ pa) & $0.2(50$ pa) & $0.3(75$ pa) & $0.4(100$ pa) \\
\hline Air flow EQ (scfm) & 20.5 & 23.8 & 27.1 & 30.1 \\
\hline
\end{tabular}

Air leakage rate

\begin{tabular}{|c|c|c|c|c|}
\hline Pressure difference & 0.1 (25 pa) & 0.2 (50 pa) & 0.3 (75 pa) & $0.4(100$ pa) \\
\hline$Q d=E Q-Q(S c f m)$ & 0.7 & 5.3 & 4.9 & 6.7 \\
\hline $\begin{array}{l}\text { Temperature corrected Flow Rate } \\
\text { (Scfm) }\end{array}$ & 13.786 & 14.419 & 18.237 & 20.408 \\
\hline $\begin{array}{l}\text { Temperature corrected Flow Rate } \\
(\mathrm{L} / \mathrm{s})\end{array}$ & 6.480 & 6.777 & 8.571 & 9.592 \\
\hline Standard air leakage $\left(\mathrm{L} / \mathrm{s} / \mathrm{m}^{2}\right)$ & 1.567 & 1.639 & 2.073 & 2.319 \\
\hline Standardized air leakage $\left(\mathrm{Scfm} / \mathrm{ft}^{2}\right)$ & 0.379 & 0.396 & 0.501 & 0.561 \\
\hline
\end{tabular}




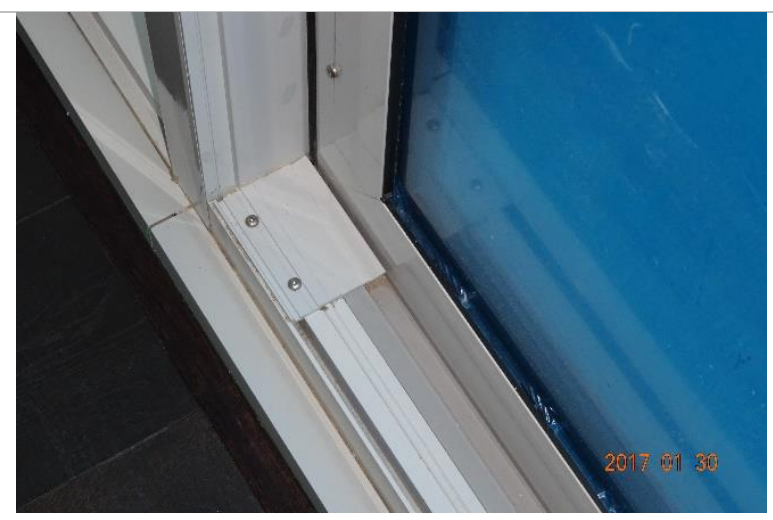

Frame joints

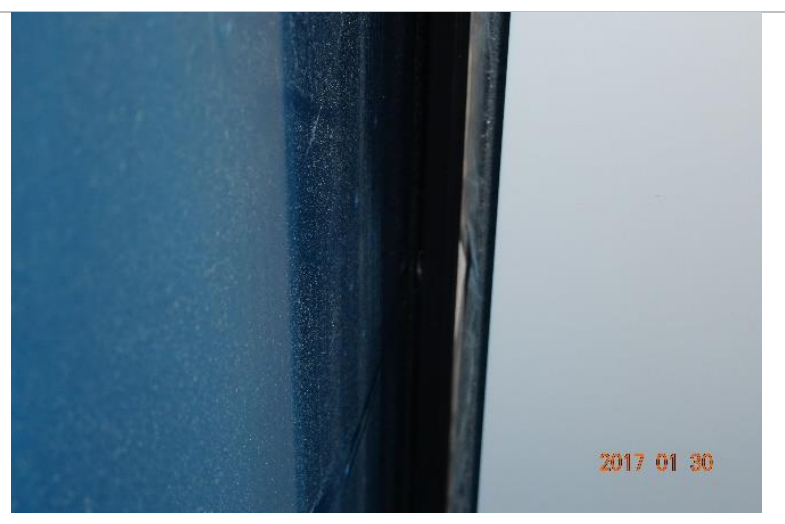

Glass to frame

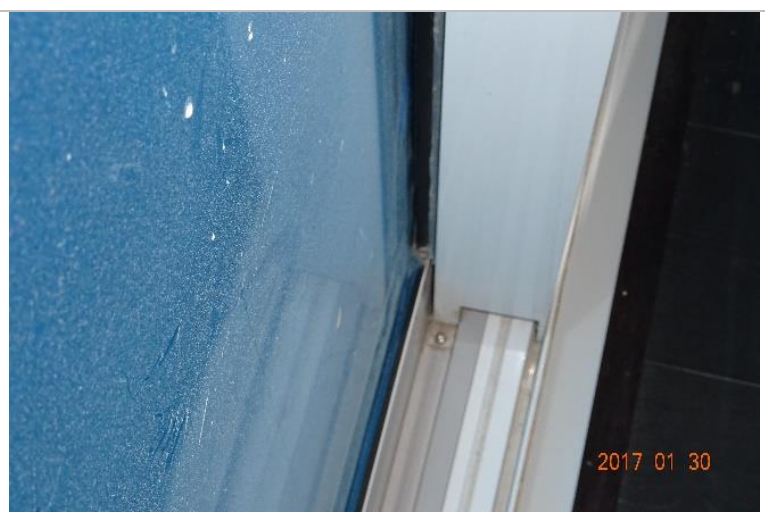

Door track

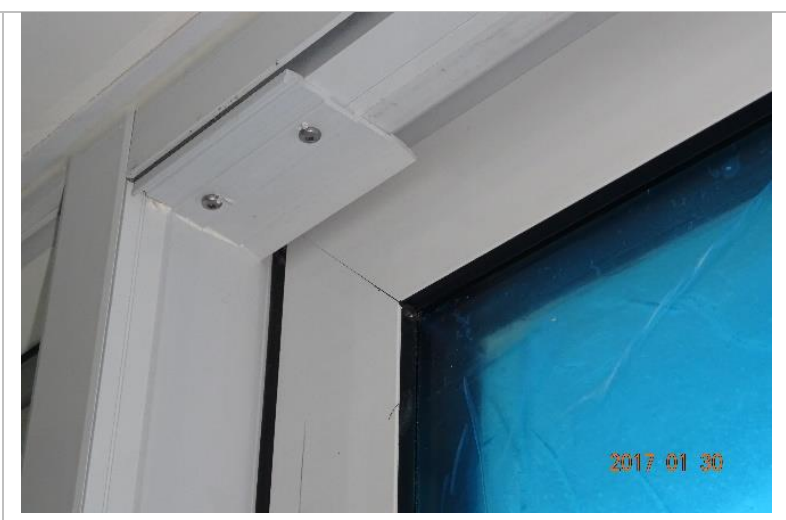

Frame joint

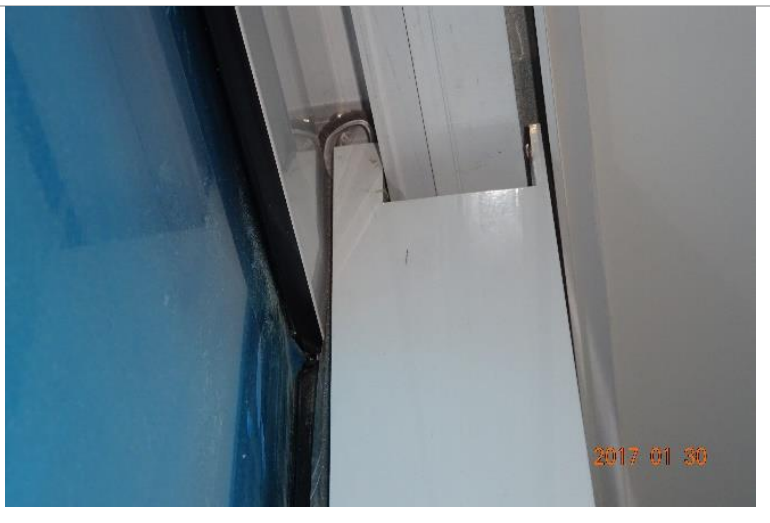

Door track

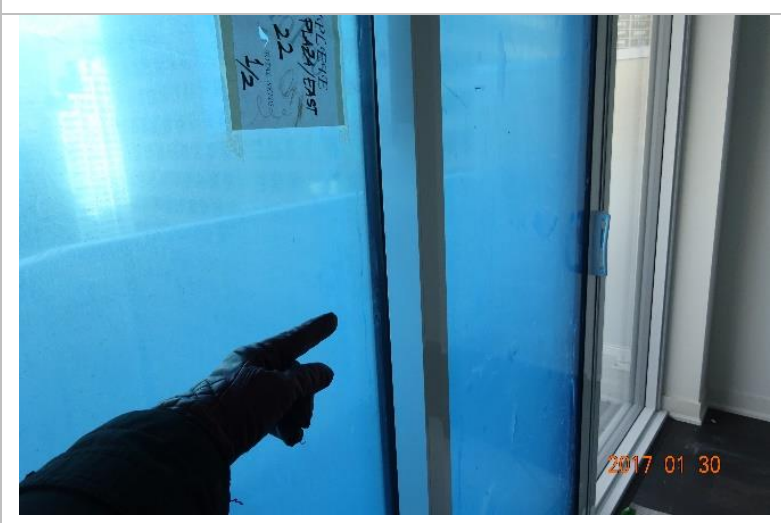

Meeting stile 


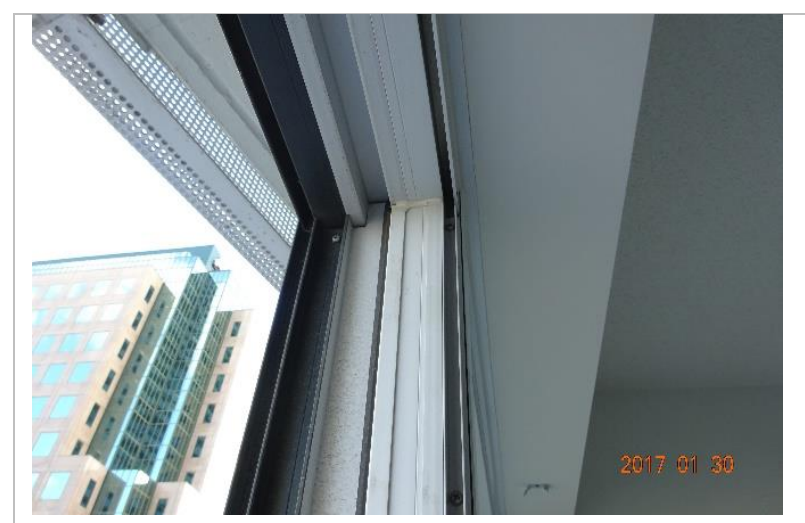

Frame and track joints

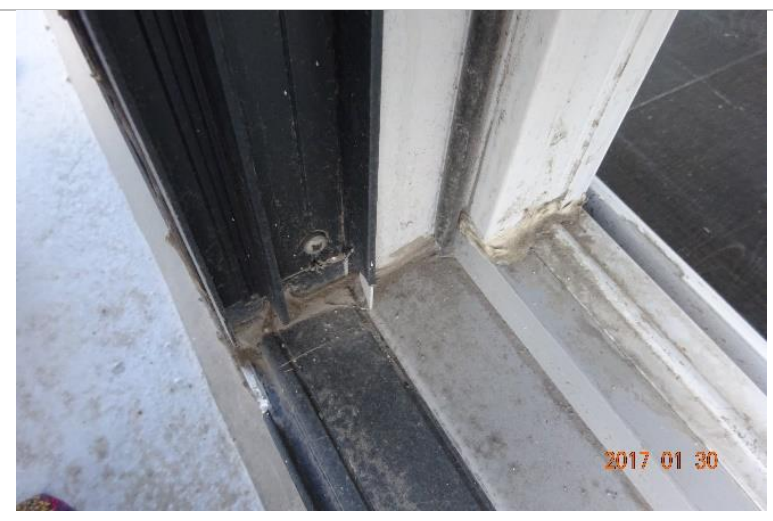

Frame and track joints

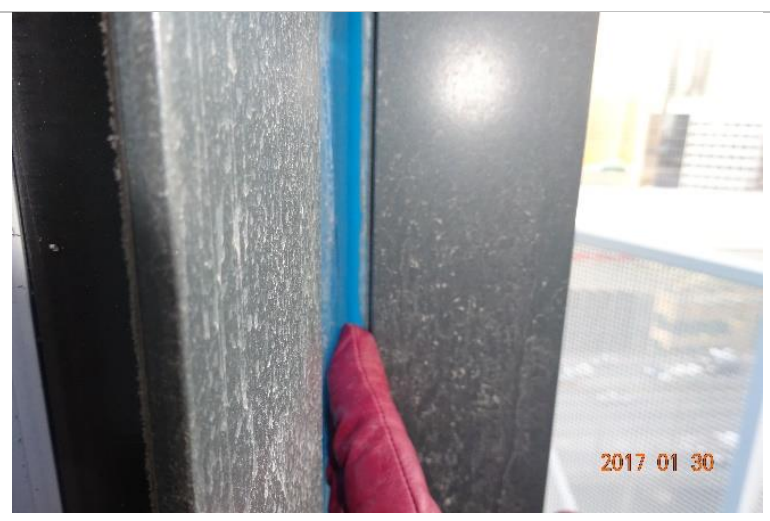

Door rubber sealant

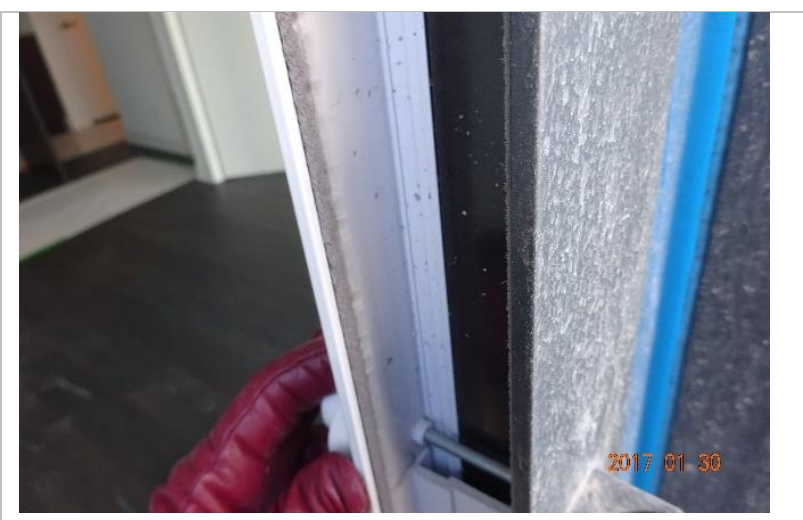

Weather stripping

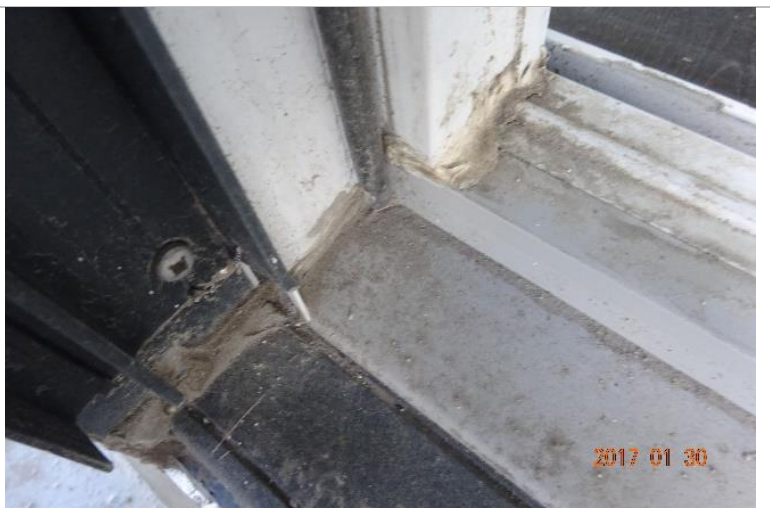

Frame and track joints

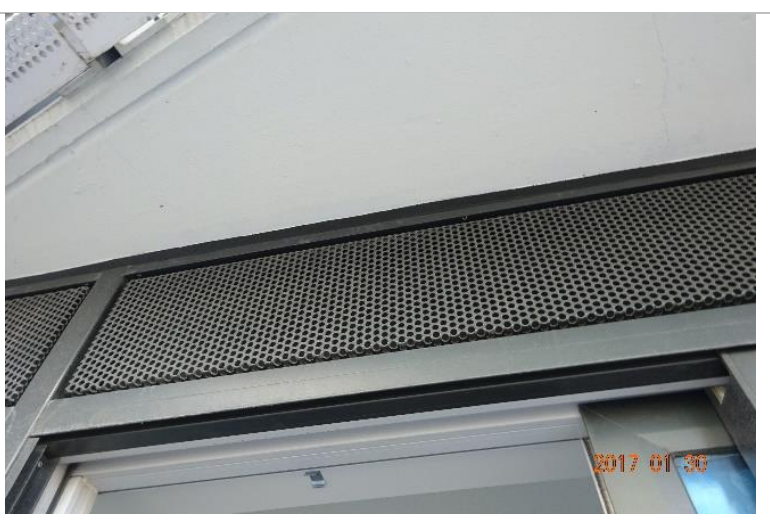

Door frame to concrete slab

\section{Discussion}

Test sample air leakage result is above laboratory air leakage result at 75 pascal pressure difference.

This test is excluded from test results analysis due to out-performance. 


\section{Test No.14}

\begin{tabular}{|l|l|}
\hline Date & $12 / 03 / 2016$ \\
\hline Time & $8: 54 \mathrm{AM}$ \\
\hline Suite & E09 \\
\hline Level & 53 construction/58 marketing \\
\hline
\end{tabular}

\section{Sample Description}

\begin{tabular}{|l|l|}
\hline Model & Double glazed, Argon gas filled \\
\hline Door type & $6 \mathrm{~mm}$ ESR42 Temp (PURCH) / 1" Black spacer /6 mm CLR Temp (PURCH) \\
\hline Assembly Type & $4 \mathrm{a}$ \\
\hline Size & $2260 \mathrm{~mm} \times 1830 \mathrm{~mm}$ \\
\hline Operation type & Sliding door \\
\hline
\end{tabular}

\section{Ambient Test Condition}

\begin{tabular}{|l|l|}
\hline Temperature inside & $5 \circ \mathrm{C}$ \\
\hline Temperature outside & $2 \circ \mathrm{C}$ \\
\hline Density of air at test site & $1.28 \mathrm{Kg} / \mathrm{m} 3$ \\
\hline Relative humidity & $50 \%$ \\
\hline Wind speed & $\mathrm{NW} 11 \mathrm{KPH}$
\end{tabular}

\section{Visual Observation}

No deficiency observed at the time of review.

\section{Readings}

Air flow rate at nonstandard condition

\begin{tabular}{|l|l|l|l|l|}
\hline Pressure difference & $\mathbf{0 . 1}(\mathbf{2 5}$ pa) & $\mathbf{0 . 2}(\mathbf{5 0}$ pa) & $\mathbf{0 . 3}(\mathbf{7 5}$ pa) & $\mathbf{0 . 4}(\mathbf{1 0 0}$ pa) \\
\hline Air flow Q (scfm) & 10.9 & 11 & 12.3 & 13.8
\end{tabular}

Extraneous air flow rate at nonstandard condition

\begin{tabular}{|l|l|l|l|l|}
\hline Pressure difference & $\mathbf{0 . 1}(\mathbf{2 5}$ pa) & $\mathbf{0 . 2}(\mathbf{5 0}$ pa) & $\mathbf{0 . 3}(\mathbf{7 5}$ pa) & $\mathbf{0 . 4}(\mathbf{1 0 0}$ pa) \\
\hline Air flow EQ (scfm) & 11.4 & 14.6 & 16.3 & 18.4 \\
\hline
\end{tabular}

Air leakage rate

\begin{tabular}{|c|c|c|c|c|}
\hline Pressure difference & 0.1 (25 pa) & 0.2 (50 pa) & 0.3 (75 pa) & $0.4(100$ pa) \\
\hline$Q d=E Q-Q(S c f m)$ & 0.7 & 5.3 & 4.9 & 6.7 \\
\hline $\begin{array}{l}\text { Temperature corrected Flow Rate } \\
\text { (Scfm) }\end{array}$ & 0.53 & 3.82 & 4.25 & 4.89 \\
\hline $\begin{array}{l}\text { Temperature corrected Flow Rate } \\
(\mathrm{L} / \mathrm{s})\end{array}$ & 0.25 & 1.79 & 1.99 & 2.29 \\
\hline Standard air leakage $\left(\mathrm{L} / \mathrm{s} / \mathrm{m}^{2}\right)$ & 0.06 & 0.43 & 0.48 & 0.55 \\
\hline Standardized air leakage $\left(\mathrm{Scfm} / \mathrm{ft}^{2}\right)$ & 0.01 & 0.10 & 0.11 & 0.13 \\
\hline
\end{tabular}




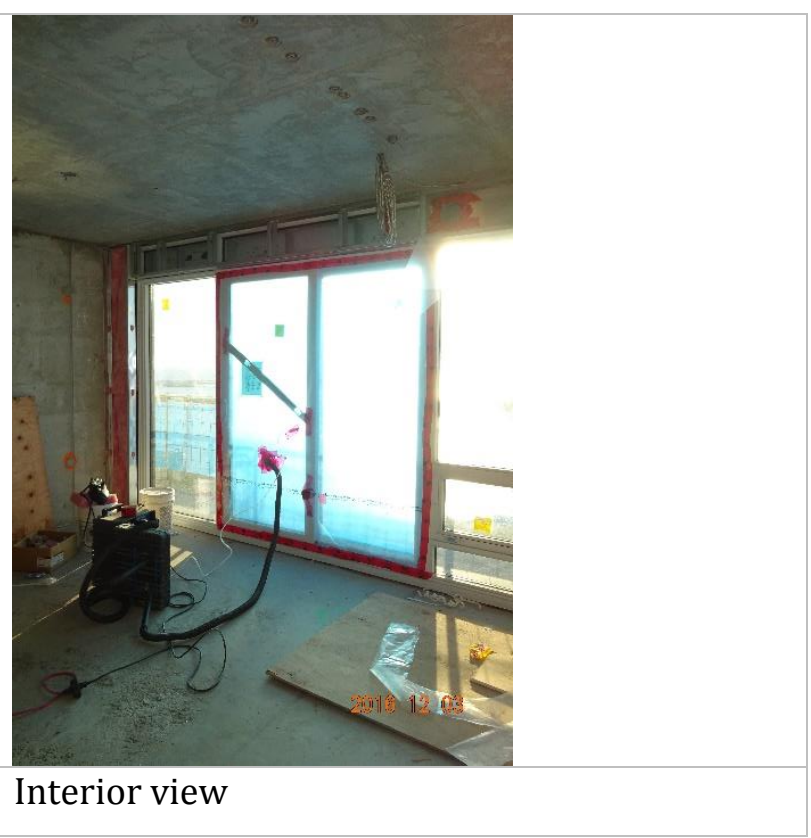

\section{Discussion}

Test sample air leakage result is below laboratory air leakage result at 75 pascal pressure difference. 


\section{Test No.15}

\begin{tabular}{|l|l|}
\hline Date & $12 / 03 / 2016$ \\
\hline Time & $9: 30 \mathrm{AM}$ \\
\hline Suite & E07 \\
\hline Level & 53 construction/58 marketing \\
\hline
\end{tabular}

\section{Sample Description}

\begin{tabular}{|l|l|}
\hline Model & Double glazed, Argon gas filled \\
\hline Door type & $6 \mathrm{~mm}$ ESR42 Temp (PURCH) / 1" Black spacer /6 mm CLR Temp (PURCH) \\
\hline Assembly Type & \\
\hline Size & $2260 \mathrm{~mm} \times 1830 \mathrm{~mm}$ \\
\hline Operation type & Sliding door \\
\hline
\end{tabular}

\section{Ambient Test Condition}

\begin{tabular}{|l|l|}
\hline Temperature inside & $5 \circ \mathrm{C}$ \\
\hline Temperature outside & $2 \circ \mathrm{C}$ \\
\hline Density of air at test site & $1.28 \mathrm{Kg} / \mathrm{m} 3$ \\
\hline Relative humidity & $50 \%$ \\
\hline Wind speed & $\mathrm{NW} 11 \mathrm{KPH}$
\end{tabular}

\section{Visual Observation}

No deficiency observed in the sample.

\section{Readings}

Air flow rate at nonstandard condition

\begin{tabular}{|l|l|l|l|l|}
\hline Pressure difference & $\mathbf{0 . 1}(\mathbf{2 5}$ pa) & $\mathbf{0 . 2}(\mathbf{5 0}$ pa) & $\mathbf{0 . 3}(\mathbf{7 5}$ pa) & $\mathbf{0 . 4}(\mathbf{1 0 0}$ pa) \\
\hline Air flow Q (scfm) & 8.3 & 9.2 & 12.8 & 13.2
\end{tabular}

Extraneous air flow rate at nonstandard condition

\begin{tabular}{|l|l|l|l|l|}
\hline Pressure difference & $\mathbf{0 . 1}(\mathbf{2 5}$ pa) & $0.2(50$ pa) & $0.3(75$ pa) & $0.4(100$ pa) \\
\hline Air flow EQ (scfm) & 11.8 & 16.9 & 20.2 & 24.1 \\
\hline
\end{tabular}

Air leakage rate

\begin{tabular}{|c|c|c|c|c|}
\hline Pressure difference & 0.1 (25 pa) & 0.2 (50 pa) & 0.3 (75 pa) & $0.4(100$ pa) \\
\hline$Q d=E Q-Q(S c f m)$ & 0.7 & 5.3 & 4.9 & 6.7 \\
\hline $\begin{array}{l}\text { Temperature corrected Flow Rate } \\
\text { (Scfm) }\end{array}$ & 3.72 & 8.18 & 7.86 & 11.58 \\
\hline $\begin{array}{l}\text { Temperature corrected Flow Rate } \\
(\mathrm{L} / \mathrm{s})\end{array}$ & 1.74 & 3.84 & 3.69 & 5.44 \\
\hline Standard air leakage $\left(\mathrm{L} / \mathrm{s} / \mathrm{m}^{2}\right)$ & 0.42 & 0.93 & 0.89 & 1.31 \\
\hline Standardized air leakage $\left(\mathrm{Scfm} / \mathrm{ft}^{2}\right)$ & 0.10 & 0.22 & 0.21 & 0.31 \\
\hline
\end{tabular}




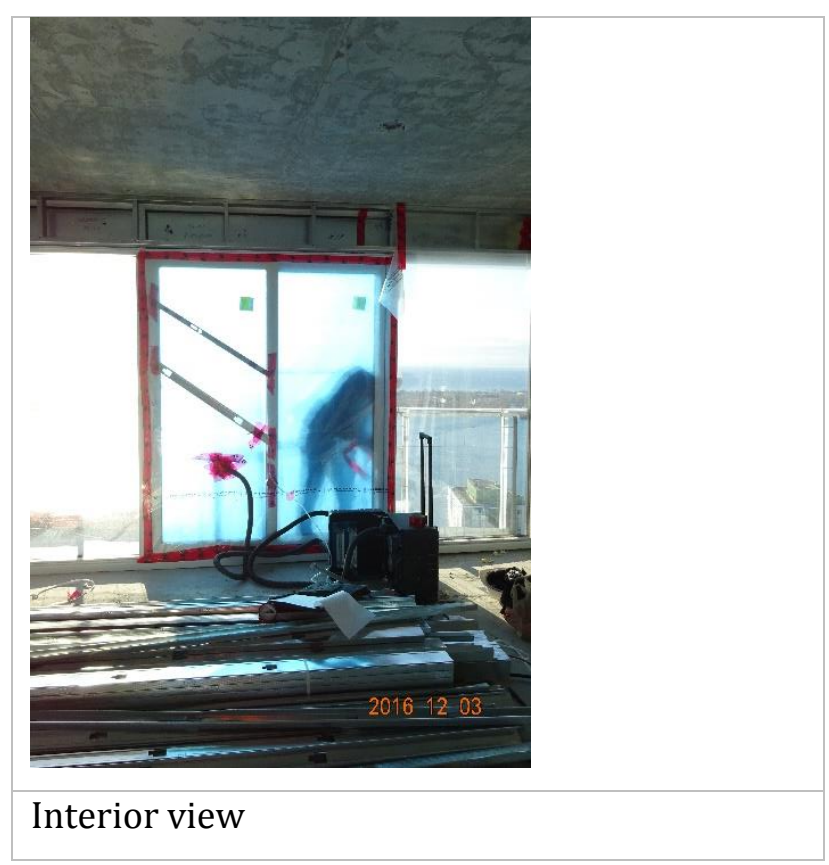

\section{Discussion}

Test sample air leakage result is above laboratory air leakage result at 75 pascal pressure difference. 


\section{Test No.16}

\begin{tabular}{|l|l|}
\hline Date & $12 / 03 / 2016$ \\
\hline Time & $10: 10 \mathrm{AM}$ \\
\hline Suite & E06 \\
\hline Level & 53 construction/58 marketing \\
\hline
\end{tabular}

\section{Sample Description}

\begin{tabular}{|l|l|}
\hline Model & Double glazed, Argon gas filled \\
\hline Door type & $6 \mathrm{~mm}$ ESR42 Temp (PURCH) / 1" Black spacer /6 mm CLR Temp (PURCH) \\
\hline Assembly Type & \\
\hline Size & $2260 \mathrm{~mm} \times 1830 \mathrm{~mm}$ \\
\hline Operation type & Sliding door \\
\hline
\end{tabular}

\section{Ambient Test Condition}

\begin{tabular}{|l|l|}
\hline Temperature inside & $5 \circ \mathrm{C}$ \\
\hline Temperature outside & $4 \circ \mathrm{C}$ \\
\hline Density of air at test site & $1.27 \mathrm{Kg} / \mathrm{m} 3$ \\
\hline Relative humidity & $50 \%$ \\
\hline Wind speed & WNW 25KPH
\end{tabular}

\section{Visual Observation}

No deficiency observed at the time of review.

\section{Readings}

Air flow rate at nonstandard condition

\begin{tabular}{|l|l|l|l|l|}
\hline Pressure difference & $\mathbf{0 . 1}(\mathbf{2 5}$ pa) & $0.2(50$ pa) & $0.3(75$ pa) & $0.4(100$ pa) \\
\hline Air flow Q (scfm) & 6.2 & 6.9 & 1.15 & 9
\end{tabular}

Extraneous air flow rate at nonstandard condition

\begin{tabular}{|l|l|l|l|l|}
\hline Pressure difference & $\mathbf{0 . 1}(\mathbf{2 5}$ pa) & $\mathbf{0 . 2}(\mathbf{5 0}$ pa) & $\mathbf{0 . 3}(\mathbf{7 5}$ pa) & $\mathbf{0 . 4}(\mathbf{1 0 0}$ pa) \\
\hline Air flow EQ (scfm) & 10.1 & 14.05 & 17.5 & 21.3 \\
\hline
\end{tabular}

Air leakage rate

\begin{tabular}{|c|c|c|c|c|}
\hline Pressure difference & 0.1 (25 pa) & 0.2 (50 pa) & 0.3 (75 pa) & $0.4(100$ pa) \\
\hline$Q d=E Q-Q(S c f m)$ & 0.7 & 5.3 & 4.9 & 6.7 \\
\hline $\begin{array}{l}\text { Temperature corrected Flow Rate } \\
\text { (Scfm) }\end{array}$ & 4.146 & 7.601 & 17.382 & 13.076 \\
\hline $\begin{array}{l}\text { Temperature corrected Flow Rate } \\
(\mathrm{L} / \mathrm{s})\end{array}$ & 1.949 & 3.573 & 8.170 & 6.146 \\
\hline Standard air leakage $\left(\mathrm{L} / \mathrm{s} / \mathrm{m}^{2}\right)$ & 0.471 & 0.864 & 1.975 & 1.486 \\
\hline Standardized air leakage $\left(\mathrm{Scfm} / \mathrm{ft}^{2}\right)$ & 0.114 & 0.209 & 0.478 & 0.359 \\
\hline
\end{tabular}



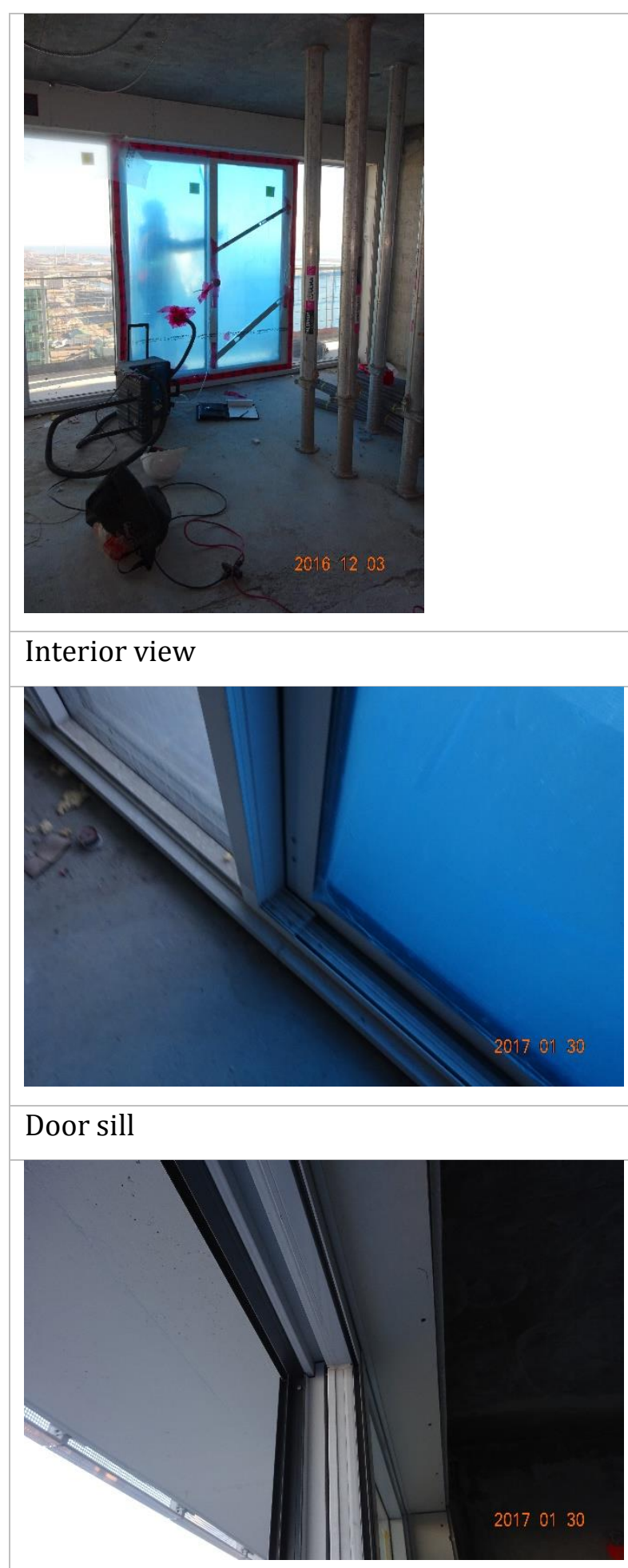

Door head frames

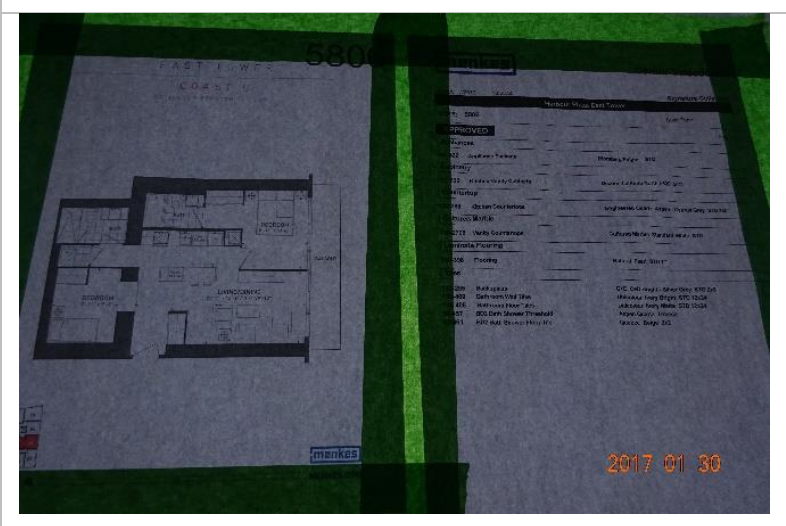

\section{Unit plan}

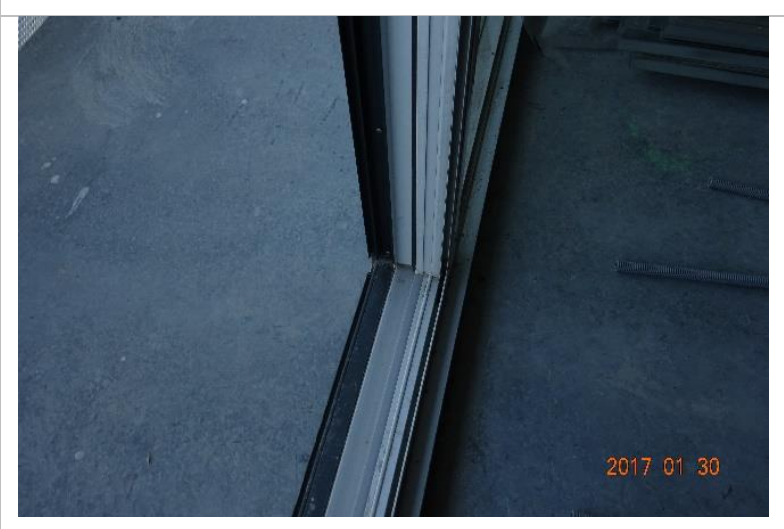

Door sill frames 


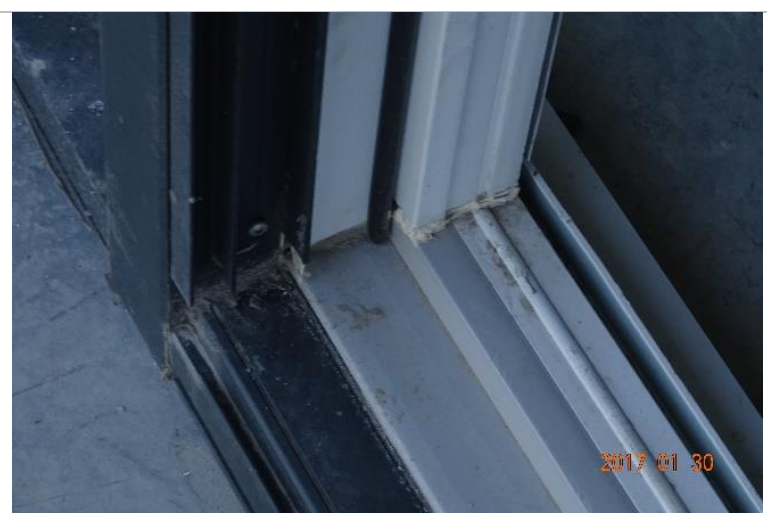

Door track and frame

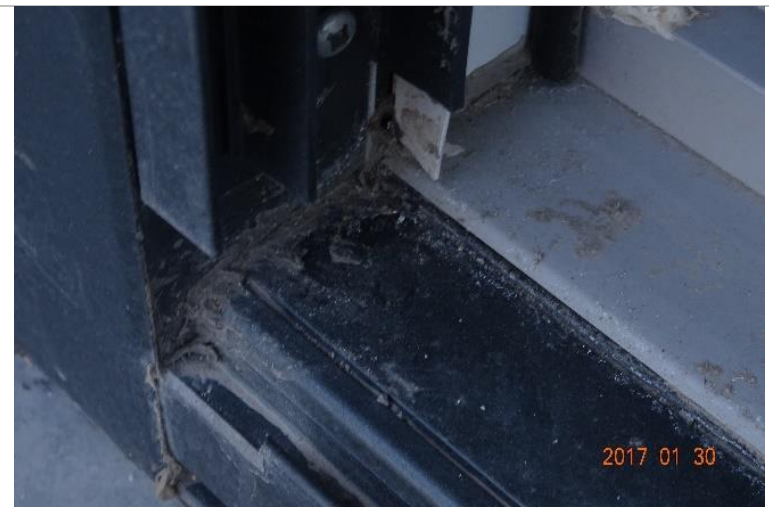

Track joint

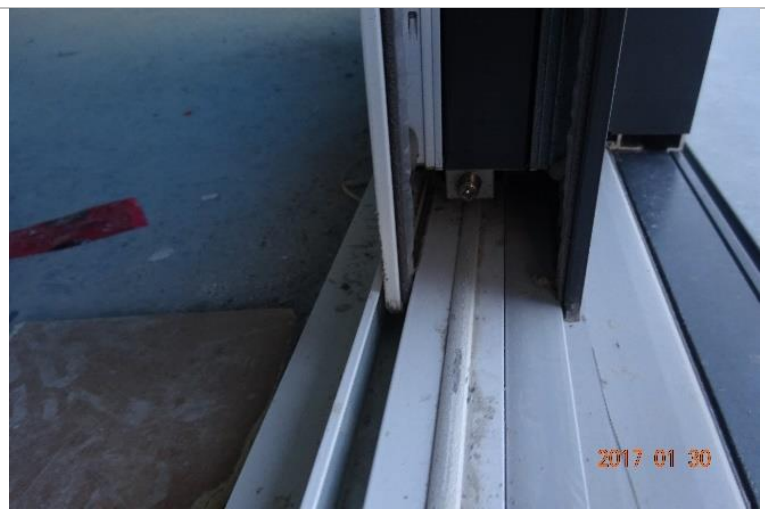

Door sill

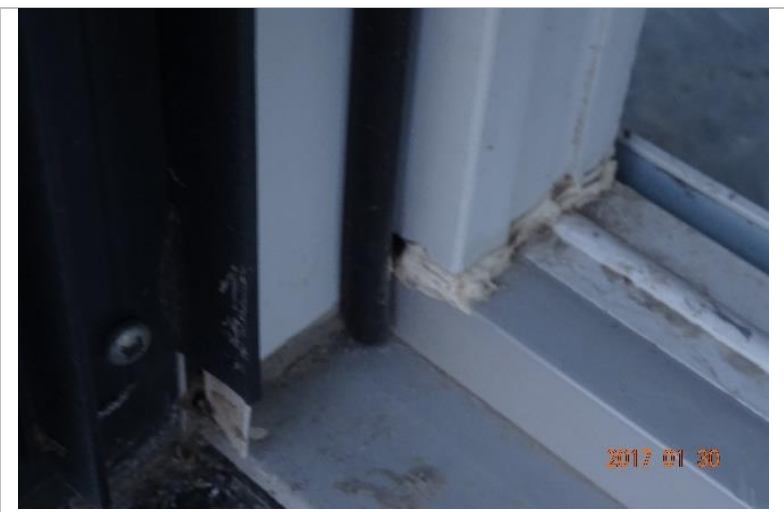

Frame and track joints

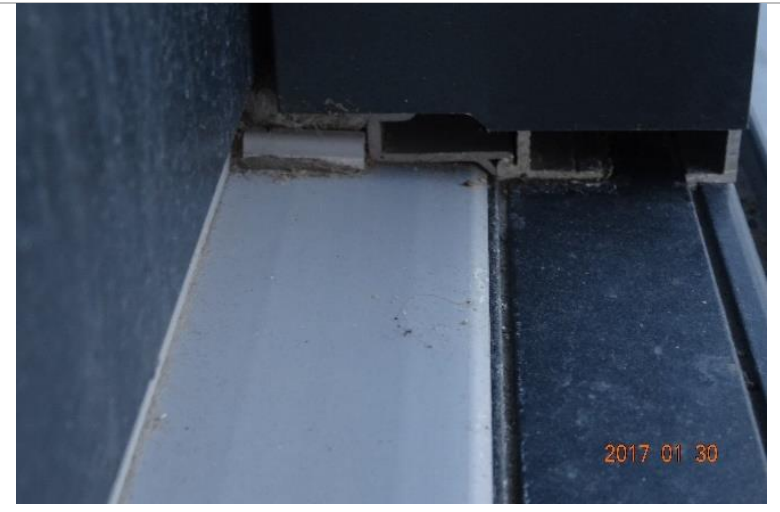

Dust plug and door track
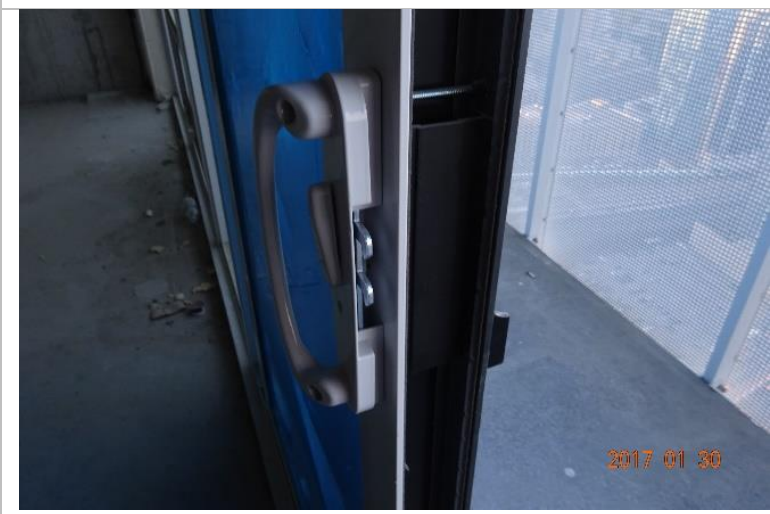

Door hardware 


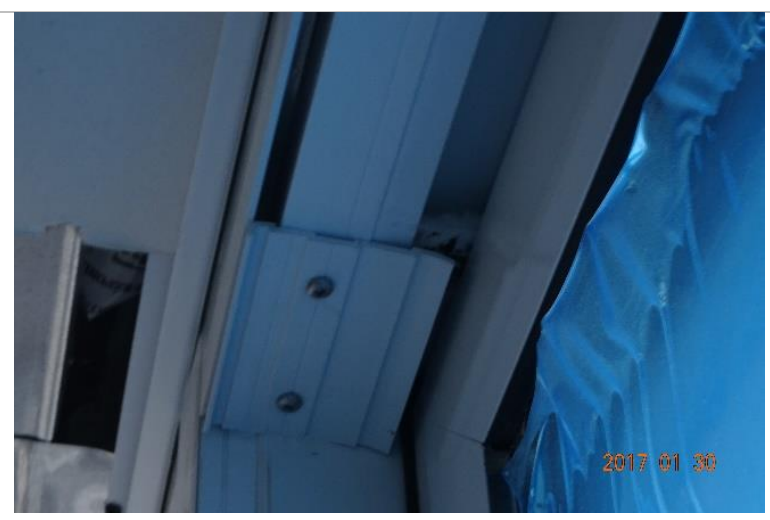

Door head frame joint

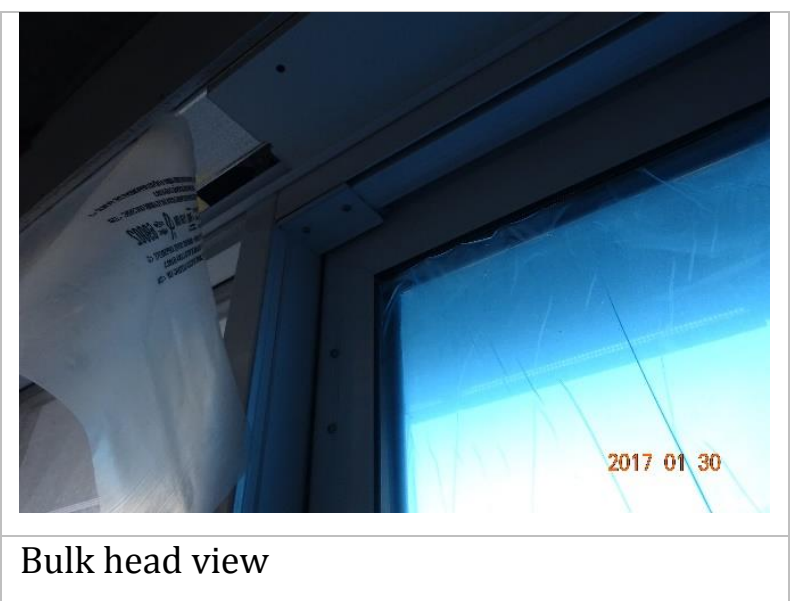

\section{Discussion}

Test sample air leakage result is above laboratory air leakage result at 75 pascal pressure difference.

This test is excluded from test results analysis due to out-performance. 


\section{Test No.17}

\begin{tabular}{|l|l|}
\hline Date & $12 / 03 / 2016$ \\
\hline Time & $10: 30 \mathrm{AM}$ \\
\hline Suite & E04 \\
\hline Level & 50 construction/55 marketing \\
\hline
\end{tabular}

\section{Sample Description}

\begin{tabular}{|l|l|}
\hline Model & Double glazed, Argon gas filled \\
\hline Door type & $6 \mathrm{~mm}$ ESR42 Temp (PURCH) / 1" Black spacer /6 mm CLR Temp (PURCH) \\
\hline Assembly Type & $1 \mathrm{a}$ \\
\hline Size & $2260 \mathrm{~mm} \times 1830 \mathrm{~mm}$ \\
\hline Operation type & Sliding door \\
\hline
\end{tabular}

\section{Ambient Test Condition}

\begin{tabular}{|l|l|}
\hline Temperature inside & $7 \circ \mathrm{C}$ \\
\hline Temperature outside & $4 \circ \mathrm{C}$ \\
\hline Density of air at test site & $1.27 \mathrm{Kg} / \mathrm{m} 3$ \\
\hline Relative humidity & $50 \%$ \\
\hline Wind speed & WNW 25KPH \\
\hline
\end{tabular}

\section{Visual Observation}

No deficiency observed at the time of review.

\section{Readings}

Air flow rate at nonstandard condition

\begin{tabular}{|l|l|l|l|l|}
\hline Pressure difference & $\mathbf{0 . 1}(\mathbf{2 5}$ pa) & $\mathbf{0 . 2}(\mathbf{5 0}$ pa) & $\mathbf{0 . 3}$ (75 pa) & $\mathbf{0 . 4}(\mathbf{1 0 0}$ pa) \\
\hline Air flow Q (scfm) & 8.4 & 9.1 & 10.1 & 12.2 \\
\hline
\end{tabular}

Extraneous air flow rate at nonstandard condition

\begin{tabular}{|l|l|l|l|l|}
\hline Pressure difference & $0.1(25$ pa) & $0.2(50$ pa) & $0.3(75$ pa) & $0.4(100$ pa) \\
\hline Air flow EQ (scfm) & 15.1 & 18 & 19.3 & 22.4 \\
\hline
\end{tabular}

Air leakage rate

\begin{tabular}{|c|c|c|c|c|}
\hline Pressure difference & 0.1 (25 pa) & $0.2(50 \mathrm{pa})$ & 0.3 (75 pa) & $0.4(100 \mathrm{pa})$ \\
\hline$Q d=E Q-Q(S c f m)$ & 0.7 & 5.3 & 4.9 & 6.7 \\
\hline $\begin{array}{l}\text { Temperature corrected Flow Rate } \\
\text { (Scfm) }\end{array}$ & 7.12 & 9.46 & 9.78 & 10.84 \\
\hline $\begin{array}{l}\text { Temperature corrected Flow Rate } \\
(\mathrm{L} / \mathrm{s})\end{array}$ & 3.34 & 4.44 & 4.59 & 5.09 \\
\hline Standard air leakage $\left(\mathrm{L} / \mathrm{s} / \mathrm{m}^{2}\right)$ & 0.80 & 1.07 & 1.11 & 1.23 \\
\hline Standardized air leakage $\left(\mathrm{Scfm} / \mathrm{ft}^{2}\right)$ & 0.19 & 0.26 & 0.26 & 0.29 \\
\hline
\end{tabular}



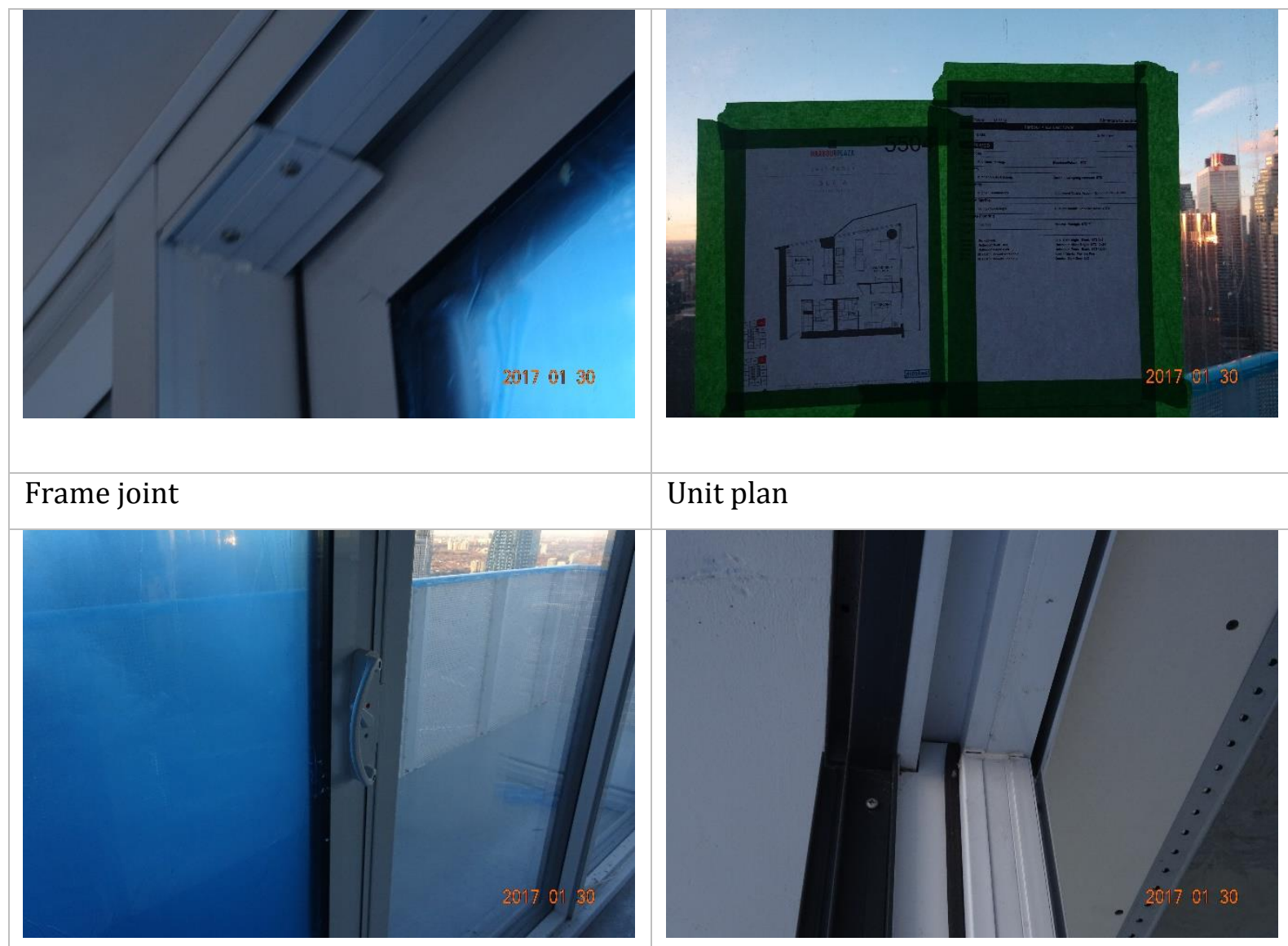

\section{Unit plan}

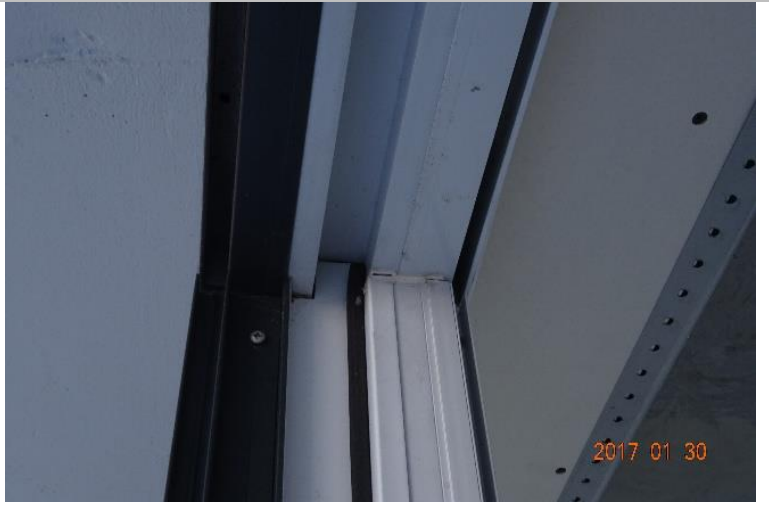

Interior view

Door head joint

\section{Discussion}

Test sample air leakage result is above laboratory air leakage result at 75 pascal pressure difference. 


\section{Test No.18}

\begin{tabular}{|l|l|}
\hline Date & $12 / 03 / 2016$ \\
\hline Time & $11: 00 \mathrm{AM}$ \\
\hline Suite & E10 \\
\hline Level & 50 construction/55 marketing \\
\hline
\end{tabular}

\section{Sample Description}

\begin{tabular}{|l|l|}
\hline Model & Double glazed, Argon gas filled \\
\hline Door type & $6 \mathrm{~mm}$ ESR42 Temp (PURCH) / 1" Black spacer/6 mm CLR Temp (PURCH) \\
\hline Assembly Type & $1 \mathrm{a}$ \\
\hline Size & $2260 \mathrm{~mm}$ x1830 $\mathrm{mm}$ \\
\hline Operation type & Sliding door \\
\hline
\end{tabular}

\section{Ambient Test Condition}

\begin{tabular}{|l|l|}
\hline Temperature inside & $8^{\circ} \mathrm{C}$ \\
\hline Temperature outside & $5^{\circ} \mathrm{C}$ \\
\hline Density of air at test site & $1.269 \mathrm{Kg} / \mathrm{m} 3$ \\
\hline Relative humidity & $50 \%$ \\
\hline Wind speed & WNW $25 \mathrm{KPH}$ \\
\hline
\end{tabular}

\section{Visual Observation}

No deficiency observed at the time of review.

\section{Readings}

Air flow rate at nonstandard condition

\begin{tabular}{|l|l|l|l|l|}
\hline Pressure difference & $0.1(25$ pa) & $0.2(50$ pa) & $0.3(75$ pa) & $0.4(100$ pa) \\
\hline Air flow Q (scfm) & 7.6 & 8.9 & 10.5 & 12 \\
\hline
\end{tabular}

Extraneous air flow rate at nonstandard condition

\begin{tabular}{|l|l|l|l|l|}
\hline Pressure difference & $0.1(25$ pa) & $0.2(50$ pa) & $0.3(75$ pa) & $0.4(100$ pa) \\
\hline Air flow EQ (scfm) & 8.9 & 12.5 & 15.4 & 17.1 \\
\hline
\end{tabular}

Air leakage rate

\begin{tabular}{|c|c|c|c|c|}
\hline Pressure difference & 0.1 (25 pa) & 0.2 (50 pa) & 0.3 (75 pa) & $0.4(100$ pa $)$ \\
\hline$Q d=E Q-Q(S c f m)$ & 1.3 & 5.3 & 4.9 & 5.1 \\
\hline $\begin{array}{l}\text { Temperature corrected Flow Rate } \\
\text { (Scfm) }\end{array}$ & 1.382 & 3.827 & 5.209 & 5.422 \\
\hline $\begin{array}{l}\text { Temperature corrected Flow Rate } \\
(\mathrm{L} / \mathrm{s})\end{array}$ & 0.650 & 1.799 & 2.448 & 2.548 \\
\hline Standard air leakage $\left(\mathrm{L} / \mathrm{s} / \mathrm{m}^{2}\right)$ & 0.157 & 0.435 & 0.592 & 0.616 \\
\hline Standardized air leakage $\left(\mathrm{Scfm} / \mathrm{ft}^{2}\right)$ & 0.038 & 0.105 & 0.143 & 0.149 \\
\hline
\end{tabular}




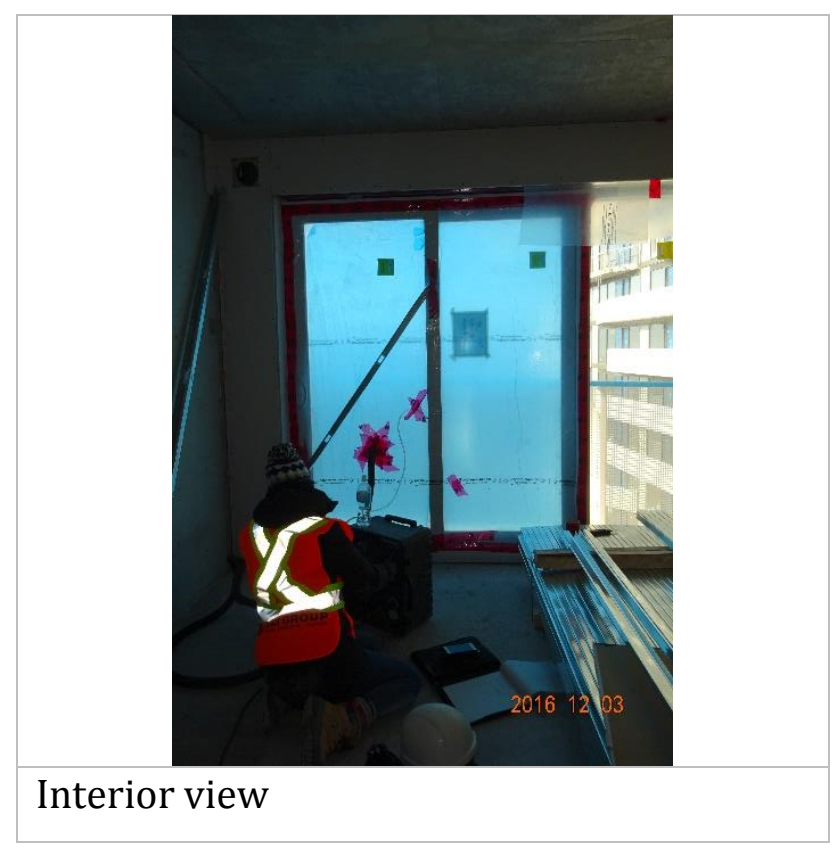

\section{Discussion}

Test sample air leakage result is above laboratory air leakage result at 75 pascal pressure difference. 


\section{Test No.19}

\begin{tabular}{|l|l|}
\hline Date & $12 / 03 / 2016$ \\
\hline Time & $11: 30 \mathrm{AM}$ \\
\hline Suite & E10 \\
\hline Level & 38 construction/43 marketing \\
\hline
\end{tabular}

\section{Sample Description}

\begin{tabular}{|l|l|}
\hline Model & Double glazed, Argon gas filled \\
\hline Door type & $6 \mathrm{~mm}$ ESR42 Temp (PURCH) / 1" Black spacer/6 mm CLR Temp (PURCH) \\
\hline Assembly Type & 1a or 1b \\
\hline Size & $2260 \mathrm{~mm}$ x1830 $\mathrm{mm}$ \\
\hline Operation type & Sliding door \\
\hline
\end{tabular}

\section{Ambient Test Condition}

\begin{tabular}{|l|l|}
\hline Temperature inside & $8^{\circ} \mathrm{C}$ \\
\hline Temperature outside & $5^{\circ} \mathrm{C}$ \\
\hline Density of air at test site & $1.269 \mathrm{Kg} / \mathrm{m} 3$ \\
\hline Relative humidity & $50 \%$ \\
\hline Wind speed & NW $22 \mathrm{Kph}$ \\
\hline
\end{tabular}

\section{Visual Observation}

No deficiency observed at the time of review.

\section{Readings}

Air flow rate at nonstandard condition

\begin{tabular}{|l|l|l|l|l|}
\hline Pressure difference & $\mathbf{0 . 1}(\mathbf{2 5}$ pa) & $\mathbf{0 . 2}$ (50 pa) & $\mathbf{0 . 3}$ (75 pa) & $\mathbf{0 . 4}(100$ pa) \\
\hline Air flow Q (scfm) & 8.9 & 12.2 & 14.05 & 16.2 \\
\hline
\end{tabular}

Extraneous air flow rate at nonstandard condition

\begin{tabular}{|l|l|l|l|l|}
\hline Pressure difference & $0.1(25$ pa) & $0.2(50$ pa) & 0.3 (75 pa) & $0.4(100$ pa) \\
\hline Air flow EQ (scfm) & 9 & 12.5 & 14.4 & 16.4 \\
\hline
\end{tabular}

Air leakage rate

\begin{tabular}{|c|c|c|c|c|}
\hline Pressure difference & 0.1 (25 pa) & $0.2(50$ pa $)$ & 0.3 (75 pa) & $0.4(100 \mathrm{pa})$ \\
\hline$Q d=E Q-Q(S c f m)$ & 0.1 & 0.3 & 0.35 & 0.2 \\
\hline $\begin{array}{l}\text { Temperature corrected Flow Rate } \\
\text { (Scfm) }\end{array}$ & 0.10 & 0.31 & 0.37 & 0.21 \\
\hline $\begin{array}{l}\text { Temperature corrected Flow Rate } \\
(\mathrm{L} / \mathrm{s})\end{array}$ & 0.05 & 0.15 & 0.17 & 0.10 \\
\hline Standard air leakage $\left(\mathrm{L} / \mathrm{s} / \mathrm{m}^{2}\right)$ & 0.01 & 0.03 & 0.04 & 0.024 \\
\hline Standardized air leakage $\left(\mathrm{Scfm} / \mathrm{ft}^{2}\right)$ & 0.003 & 0.009 & 0.01 & 0.006 \\
\hline
\end{tabular}




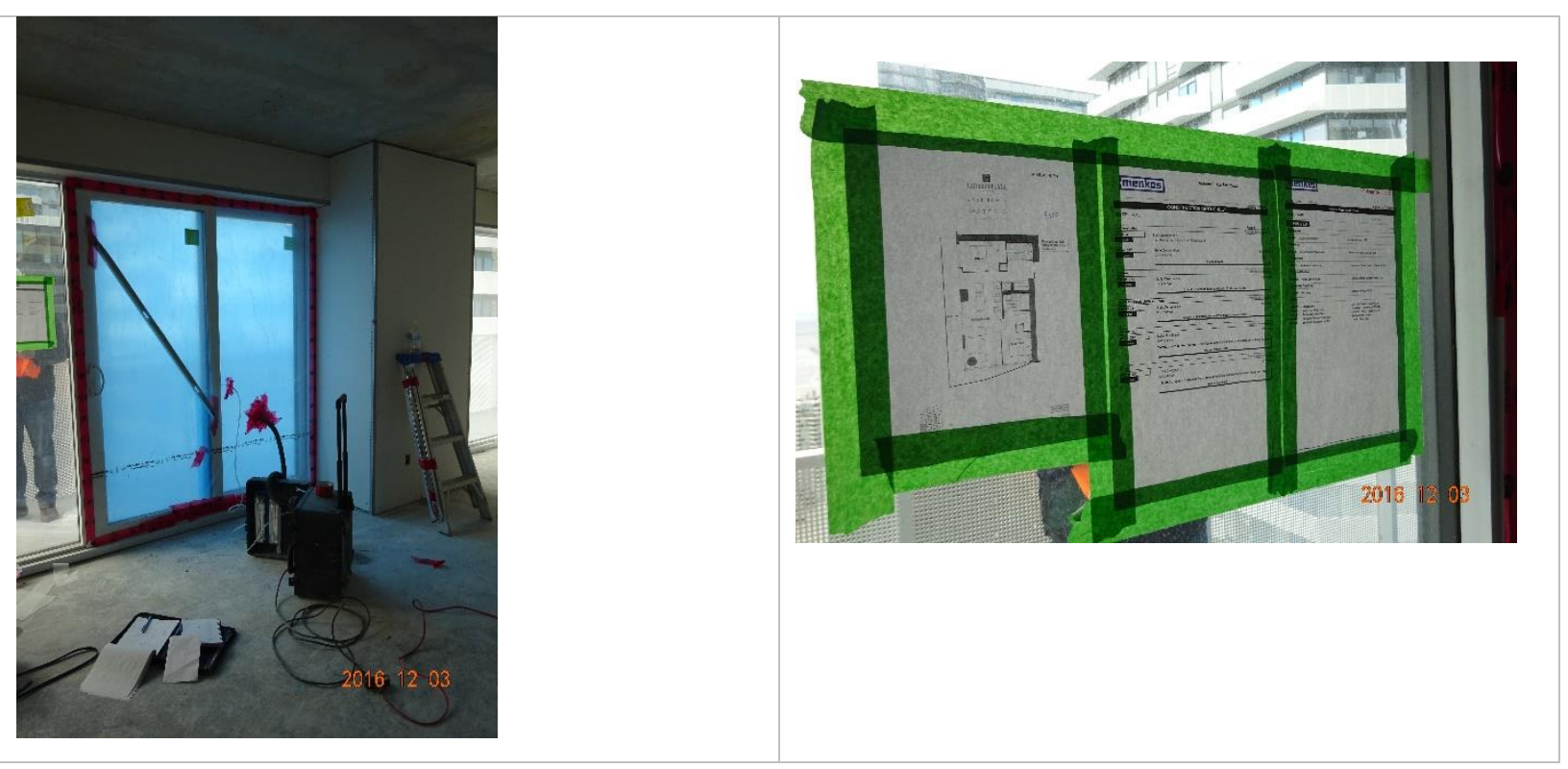

\section{Discussion}

Test sample air leakage result is way below laboratory air leakage result at 75 pascal pressure difference. This test is excluded from test results analysis due to out-performance. 


\section{Test No.20}

\begin{tabular}{|l|l|}
\hline Date & $12 / 03 / 2016$ \\
\hline Time & $01: 00 \mathrm{PM}$ \\
\hline Suite & E4 \\
\hline Level & 35 construction/40 marketing \\
\hline
\end{tabular}

\section{Sample Description}

\begin{tabular}{|l|l|}
\hline Model & Double glazed, Argon gas filled \\
\hline Door type & $6 \mathrm{~mm}$ ESR42 Temp (PURCH) / 1" Black spacer/6 mm CLR Temp (PURCH) \\
\hline Assembly Type & $1 \mathrm{a}$ \\
\hline Size & $2260 \mathrm{~mm} \times 1830 \mathrm{~mm}$ \\
\hline Operation type & Sliding door \\
\hline
\end{tabular}

\section{Ambient Test Condition}

\begin{tabular}{|l|l|}
\hline Temperature inside & $10^{\circ} \mathrm{C}$ \\
\hline Temperature outside & $7 \circ \mathrm{C}$ \\
\hline Density of air at test site & $1.269 \mathrm{Kg} / \mathrm{m} 3$ \\
\hline Relative humidity & $50 \%$ \\
\hline Wind speed & NW $22 \mathrm{Kph}$ \\
\hline
\end{tabular}

\section{Visual Observation}

No deficiency observed at the time of review.

\section{Readings}

Air flow rate at nonstandard condition

\begin{tabular}{|l|l|l|l|l|}
\hline Pressure difference & $\mathbf{0 . 1}(\mathbf{2 5}$ pa) & $\mathbf{0 . 2}(\mathbf{5 0}$ pa) & $\mathbf{0 . 3}(\mathbf{7 5}$ pa) & $\mathbf{0 . 4}(100 \mathrm{pa})$ \\
\hline Air flow Q (scfm) & 6.8 & 8.5 & 10.5 & 11.9
\end{tabular}

Extraneous air flow rate at nonstandard condition

\begin{tabular}{|l|l|l|l|l|}
\hline Pressure difference & $\mathbf{0 . 1}(\mathbf{2 5}$ pa) & $0.2(50$ pa) & 0.3 (75 pa) & $0.4(100$ pa) \\
\hline Air flow EQ (scfm) & 8.2 & 11.2 & 14 & 16.2 \\
\hline
\end{tabular}

Air leakage rate

\begin{tabular}{|c|c|c|c|c|}
\hline Pressure difference & 0.1 (25 pa) & 0.2 (50 pa) & $0.3(75 \mathrm{pa})$ & $0.4(100 \mathrm{pa})$ \\
\hline$Q d=E Q-Q(S c f m)$ & 1.4 & 2.7 & 3.5 & 4.1 \\
\hline $\begin{array}{l}\text { Temperature corrected Flow Rate } \\
\text { (Scfm) }\end{array}$ & 1.488 & 2.870 & 3.721 & 4.571 \\
\hline $\begin{array}{l}\text { Temperature corrected Flow Rate } \\
(\mathrm{L} / \mathrm{s})\end{array}$ & 0.700 & 1.349 & 1.749 & 2.149 \\
\hline Standard air leakage $\left(\mathrm{L} / \mathrm{s} / \mathrm{m}^{2}\right)$ & 0.169 & 0.326 & 0.423 & 0.520 \\
\hline Standardized air leakage $\left(\mathrm{Scfm} / \mathrm{ft}^{2}\right)$ & 0.041 & 0.079 & 0.102 & 0.126 \\
\hline
\end{tabular}




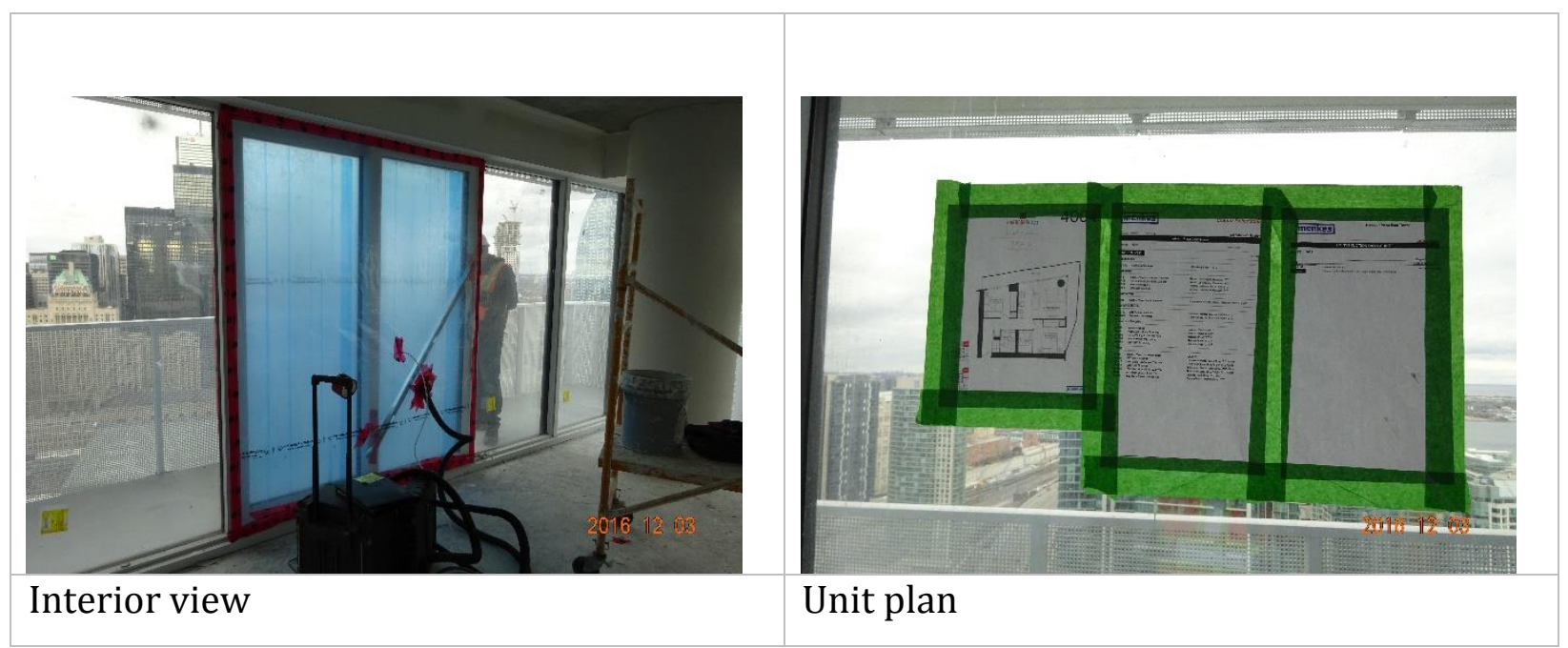

\section{Discussion}

Test sample air leakage result is below laboratory air leakage result at 75 pascal pressure difference. 


\section{Test No.21}

\begin{tabular}{|l|l|}
\hline Date & $12 / 03 / 2016$ \\
\hline Time & $01: 00 \mathrm{PM}$ \\
\hline Suite & E05 \\
\hline Level & 35 construction/40 marketing \\
\hline
\end{tabular}

\section{Sample Description}

\begin{tabular}{|l|l|}
\hline Model & Double glazed, Argon gas filled \\
\hline Door type & $6 \mathrm{~mm}$ ESR42 Temp (PURCH) / 1" Black spacer /6 mm CLR Temp (PURCH) \\
\hline Assembly Type & $5 \mathrm{~b}$ \\
\hline Size & $2260 \mathrm{~mm} \times 1830 \mathrm{~mm}$ \\
\hline Operation type & Sliding door \\
\hline
\end{tabular}

\section{Ambient Test Condition}

\begin{tabular}{|l|l|}
\hline Temperature inside & $10^{\circ} \mathrm{C}$ \\
\hline Temperature outside & $7 \circ \mathrm{C}$ \\
\hline Density of air at test site & $1.269 \mathrm{Kg} / \mathrm{m} 3$ \\
\hline Relative humidity & $50 \%$ \\
\hline Wind speed & WNW $20 \mathrm{KPH}$ \\
\hline
\end{tabular}

\section{Visual Observation}

No deficiency observed in the sample.

\section{Readings}

Air flow rate at nonstandard condition

\begin{tabular}{|l|l|l|l|l|}
\hline Pressure difference & $\mathbf{0 . 1}(\mathbf{2 5}$ pa) & $\mathbf{0 . 2}(\mathbf{5 0}$ pa) & $\mathbf{0 . 3}$ (75 pa) & $\mathbf{0 . 4}(\mathbf{1 0 0}$ pa) \\
\hline Air flow Q (scfm) & 8.5 & 11.2 & 11.4 & 13.2
\end{tabular}

Extraneous air flow rate at nonstandard condition

\begin{tabular}{|l|l|l|l|l|}
\hline Pressure difference & $\mathbf{0 . 1}(\mathbf{2 5}$ pa) & $\mathbf{0 . 2}(\mathbf{5 0}$ pa) & $\mathbf{0 . 3}(\mathbf{7 5}$ pa) & $\mathbf{0 . 4}(\mathbf{1 0 0}$ pa) \\
\hline Air flow EQ (scfm) & 7.9 & 13.3 & 16.4 & 19.9 \\
\hline
\end{tabular}

Air leakage rate

\begin{tabular}{|c|c|c|c|c|}
\hline Pressure difference & 0.1 (25 pa) & 0.2 (50 pa) & 0.3 (75 pa) & $0.4(100$ pa $)$ \\
\hline$Q d=E Q-Q(S c f m)$ & 0.7 & 5.3 & 4.9 & 6.7 \\
\hline $\begin{array}{l}\text { Temperature corrected Flow Rate } \\
\text { (Scfm) }\end{array}$ & -0.638 & 2.233 & 5.316 & 7.123 \\
\hline $\begin{array}{l}\text { Temperature corrected Flow Rate } \\
(\mathrm{L} / \mathrm{s})\end{array}$ & -0.300 & 1.049 & 2.498 & 3.348 \\
\hline Standard air leakage $\left(\mathrm{L} / \mathrm{s} / \mathrm{m}^{2}\right)$ & -0.072 & 0.254 & 0.604 & 0.809 \\
\hline Standardized air leakage $\left(\mathrm{Scfm} / \mathrm{ft}^{2}\right)$ & -0.018 & 0.061 & 0.146 & 0.196 \\
\hline
\end{tabular}




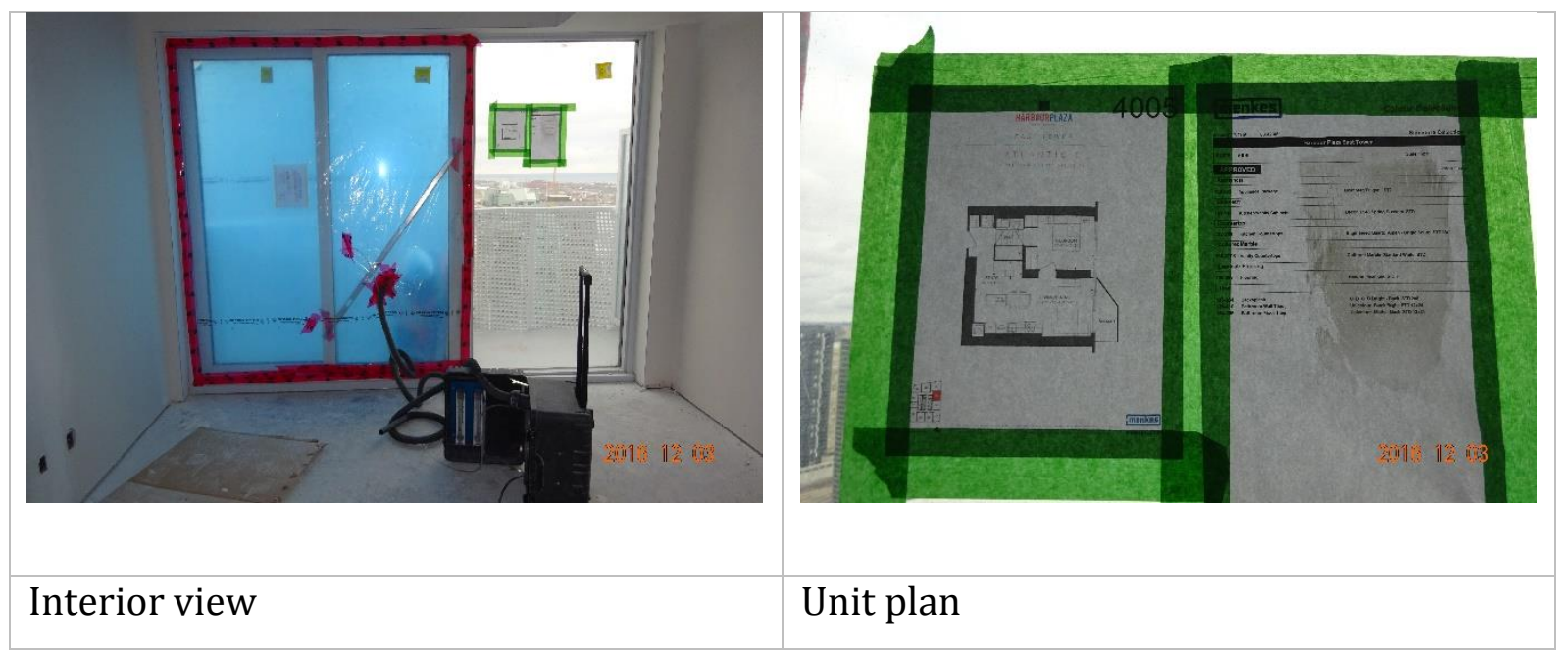

\section{Discussion}

Test sample air leakage result is above laboratory air leakage result at 75 pascal pressure difference. 


\section{Test No.22}

\begin{tabular}{|l|l|}
\hline Date & $12 / 03 / 2016$ \\
\hline Time & $02: 14 \mathrm{PM}$ \\
\hline Suite & E07 \\
\hline Level & 26 construction/31 marketing \\
\hline
\end{tabular}

\section{Sample Description}

\begin{tabular}{|l|l|}
\hline Model & Double glazed, Argon gas filled \\
\hline Door type & $6 \mathrm{~mm}$ ESR42 Temp (PURCH) / 1" Black spacer /6 mm CLR Temp (PURCH) \\
\hline Assembly Type & $5 \mathrm{~b}$ \\
\hline Size & $2260 \mathrm{~mm} \times 1830 \mathrm{~mm}$ \\
\hline Operation type & Sliding door \\
\hline
\end{tabular}

\section{Ambient Test Condition}

\begin{tabular}{|l|l|}
\hline Temperature inside & $10^{\circ} \mathrm{C}$ \\
\hline Temperature outside & $7 \circ \mathrm{C}$ \\
\hline Density of air at test site & $1.269 \mathrm{Kg} / \mathrm{m} 3$ \\
\hline Relative humidity & $50 \%$ \\
\hline Wind speed & NW $24 \mathrm{KHP}$ \\
\hline
\end{tabular}

\section{Visual Observation}

No deficiency observed at the time of review.

\section{Readings}

Air flow rate at nonstandard condition

\begin{tabular}{|l|l|l|l|l|}
\hline Pressure difference & $\mathbf{0 . 1}(\mathbf{2 5}$ pa) & $\mathbf{0 . 2}(\mathbf{5 0}$ pa) & $\mathbf{0 . 3}(\mathbf{7 5}$ pa) & $\mathbf{0 . 4}(100 \mathrm{pa})$ \\
\hline Air flow Q (scfm) & 7.8 & 8.7 & 8.9 & 11.3
\end{tabular}

Extraneous air flow rate at nonstandard condition

\begin{tabular}{|l|l|l|l|l|}
\hline Pressure difference & $0.1(25$ pa) & $0.2(50$ pa) & $0.3(75$ pa) & $0.4(100$ pa) \\
\hline Air flow EQ (scfm) & 11.3 & 14 & 15.4 & 17.5 \\
\hline
\end{tabular}

Air leakage rate

\begin{tabular}{|c|c|c|c|c|}
\hline Pressure difference & 0.1 (25 pa) & 0.2 (50 pa) & $0.3(75 \mathrm{pa})$ & $0.4(100 \mathrm{pa})$ \\
\hline$Q d=E Q-Q(S c f m)$ & 3.5 & 5.3 & 6.3 & 6.2 \\
\hline $\begin{array}{l}\text { Temperature corrected Flow Rate } \\
\text { (Scfm) }\end{array}$ & 3.721 & 5.635 & 6.910 & 6.591 \\
\hline $\begin{array}{l}\text { Temperature corrected Flow Rate } \\
(\mathrm{L} / \mathrm{s})\end{array}$ & 1.749 & 2.648 & 3.248 & 3.098 \\
\hline Standard air leakage $\left(\mathrm{L} / \mathrm{s} / \mathrm{m}^{2}\right)$ & 0.423 & 0.640 & 0.785 & 0.749 \\
\hline Standardized air leakage $\left(\mathrm{Scfm} / \mathrm{ft}^{2}\right)$ & 0.102 & 0.155 & 0.190 & 0.181 \\
\hline
\end{tabular}




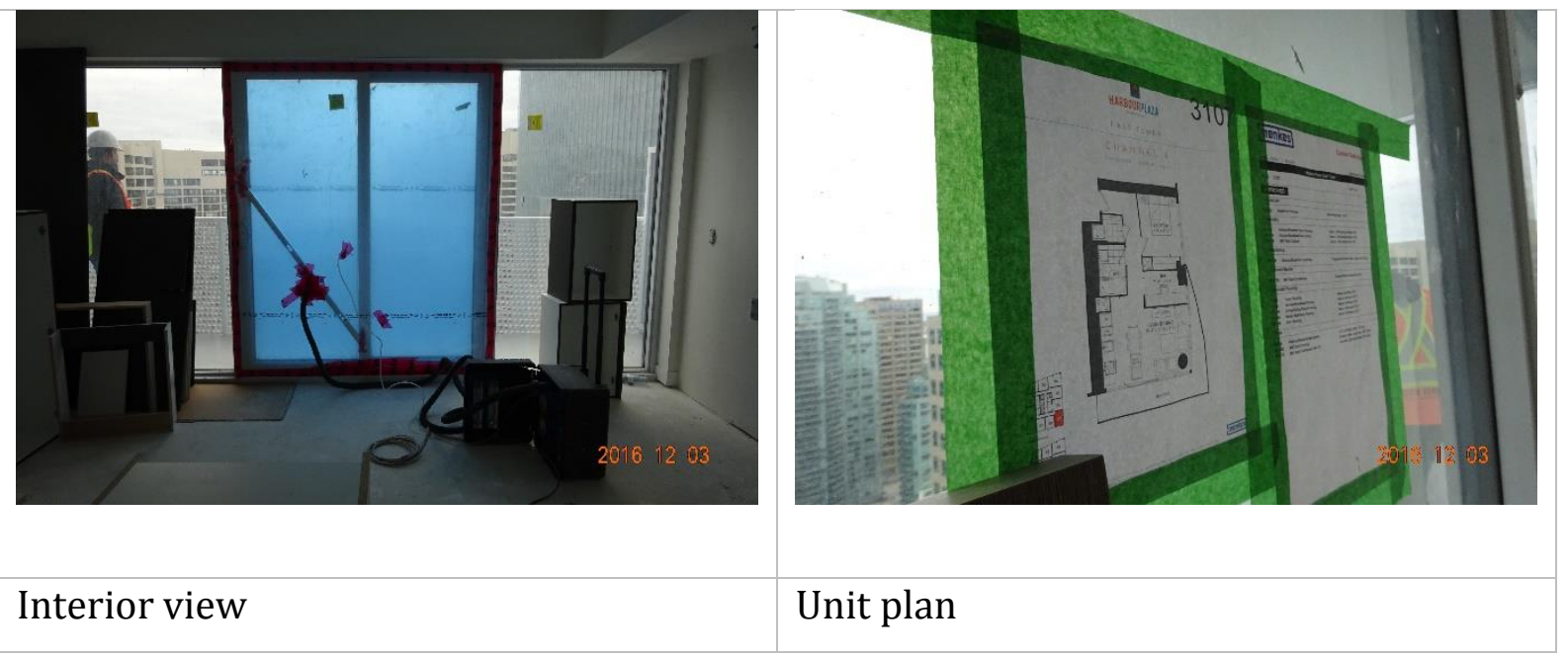

\section{Discussion}

Test sample air leakage result is above laboratory air leakage result at 75 pascal pressure difference. 


\section{Test No.23}

\begin{tabular}{|l|l|}
\hline Date & $12 / 03 / 2016$ \\
\hline Time & $02: 46 \mathrm{PM}$ \\
\hline Suite & E05 \\
\hline Level & 26 construction/31 marketing \\
\hline
\end{tabular}

\section{Sample Description}

\begin{tabular}{|l|l|}
\hline Model & Double glazed, Argon gas filled \\
\hline Door type & $6 \mathrm{~mm}$ ESR42 Temp (PURCH) / 1" Black spacer /6 mm CLR Temp (PURCH) \\
\hline Assembly Type & $5 \mathrm{~b}$ \\
\hline Size & $2260 \mathrm{~mm} \times 1830 \mathrm{~mm}$ \\
\hline Operation type & Sliding door \\
\hline
\end{tabular}

\section{Ambient Test Condition}

\begin{tabular}{|l|l|}
\hline Temperature inside & $8{ }^{\circ} \mathrm{C}$ \\
\hline Temperature outside & $7 \circ \mathrm{C}$ \\
\hline Density of air at test site & $1.269 \mathrm{Kg} / \mathrm{m} 3$ \\
\hline Relative humidity & $50 \%$ \\
\hline Wind speed & NW $18 \mathrm{KPH}$ \\
\hline
\end{tabular}

\section{Visual Observation}

No deficiency observed at the time of review.

\section{Readings}

Air flow rate at nonstandard condition

\begin{tabular}{|l|l|l|l|l|}
\hline Pressure difference & $\mathbf{0 . 1}(\mathbf{2 5}$ pa) & $\mathbf{0 . 2}$ (50 pa) & $\mathbf{0 . 3}$ (75 pa) & $\mathbf{0 . 4}(100$ pa) \\
\hline Air flow Q (scfm) & 8.5 & 12.2 & 15.3 & 20.4 \\
\hline
\end{tabular}

Extraneous air flow rate at nonstandard condition

\begin{tabular}{|l|l|l|l|l|}
\hline Pressure difference & $\mathbf{0 . 1}(\mathbf{2 5}$ pa) & $0.2(50$ pa) & $0.3(75$ pa) & $0.4(100$ pa) \\
\hline Air flow EQ (scfm) & 13.2 & 18.3 & 22.3 & 24.9 \\
\hline
\end{tabular}

Air leakage rate

\begin{tabular}{|c|c|c|c|c|}
\hline Pressure difference & 0.1 (25 pa) & 0.2 (50 pa) & 0.3 (75 pa) & $0.4(100$ pa $)$ \\
\hline$Q d=E Q-Q(S c f m)$ & 4.7 & 6.1 & 7 & 4.5 \\
\hline $\begin{array}{l}\text { Temperature corrected Flow Rate } \\
\text { (Scfm) }\end{array}$ & 4.997 & 6.485 & 7.442 & 4.784 \\
\hline $\begin{array}{l}\text { Temperature corrected Flow Rate } \\
(\mathrm{L} / \mathrm{s})\end{array}$ & 2.348 & 3.048 & 3.498 & 2.249 \\
\hline Standard air leakage $\left(\mathrm{L} / \mathrm{s} / \mathrm{m}^{2}\right)$ & 0.568 & 0.737 & 0.846 & 0.544 \\
\hline Standardized air leakage $\left(\mathrm{Scfm} / \mathrm{ft}^{2}\right)$ & 0.137 & 0.178 & 0.204 & 0.131 \\
\hline
\end{tabular}




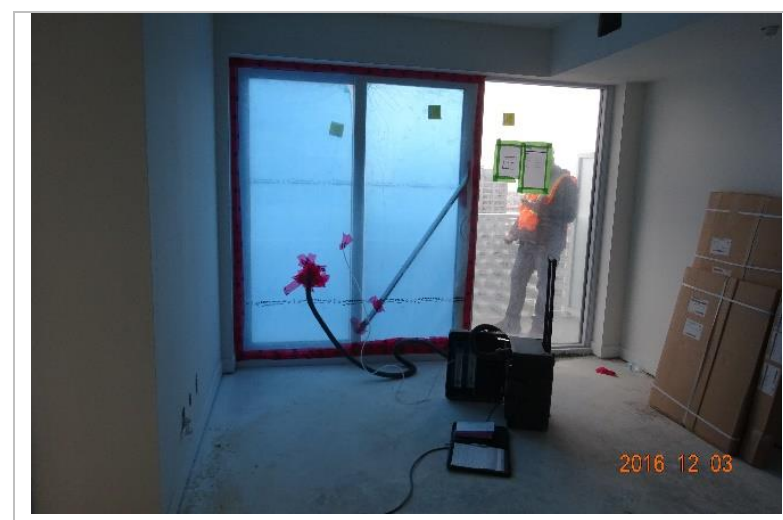

Interior view

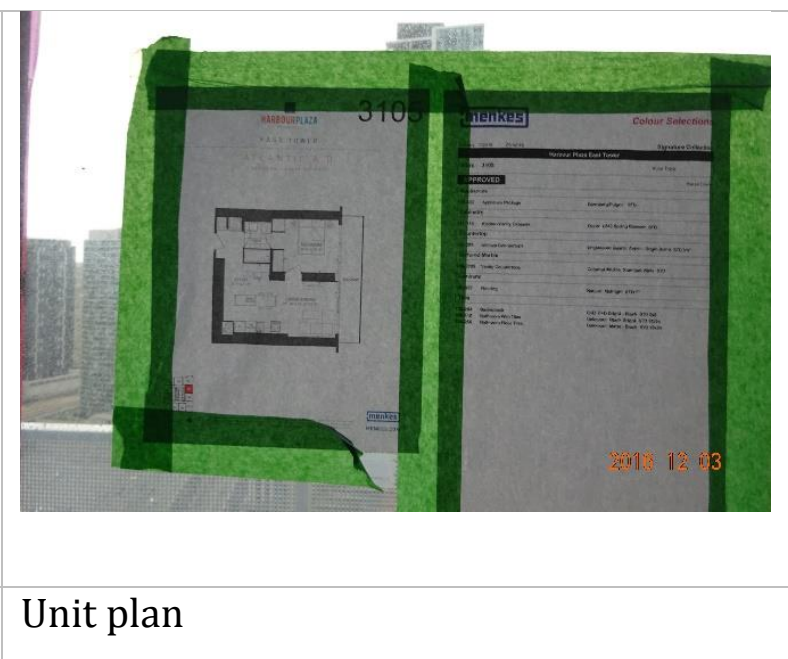

\section{Discussion}

Test sample air leakage result is above laboratory air leakage result at 75 pascal pressure difference. 


\section{Test No.24}

\begin{tabular}{|l|l|}
\hline Date & $12 / 16 / 2016$ \\
\hline Time & $08: 30 \mathrm{AM}$ \\
\hline Suite & E07 \\
\hline Level & 36 construction/41 marketing \\
\hline
\end{tabular}

\section{Sample Description}

\begin{tabular}{|l|l|}
\hline Model & Double glazed, Argon gas filled \\
\hline Door type & $6 \mathrm{~mm}$ ESR42 Temp (PURCH) / 1" Black spacer /6 mm CLR Temp (PURCH) \\
\hline Assembly Type & \\
\hline Size & $2260 \mathrm{~mm} \times 1830 \mathrm{~mm}$ \\
\hline Operation type & Sliding door \\
\hline
\end{tabular}

\section{Ambient Test Condition}

\begin{tabular}{|l|l|}
\hline Temperature inside & \\
\hline Temperature outside & $(-7) \circ \mathrm{C}-$ Feels $(-17) \circ \mathrm{C}$ \\
\hline Density of air at test site & $1.379 \mathrm{Kg} / \mathrm{m} 3$ \\
\hline Relative humidity & $50 \%$ \\
\hline Wind speed & W31KPH \\
\hline
\end{tabular}

\section{Visual Observation}

No deficiency observed at the time of review.

\section{Readings}

Air flow rate at nonstandard condition

\begin{tabular}{|l|l|l|l|l|}
\hline Pressure difference & $\mathbf{0 . 1}(\mathbf{2 5}$ pa) & 0.2 (50 pa) & 0.3 (75 pa) & $0.4(100$ pa) \\
\hline Air flow Q (scfm) & 7.8 & 11 & 14.1 & 15.8 \\
\hline
\end{tabular}

Extraneous air flow rate at nonstandard condition

\begin{tabular}{|l|l|l|l|l|}
\hline Pressure difference & $\mathbf{0 . 1}(\mathbf{2 5}$ pa) & $0.2(50$ pa) & 0.3 (75 pa) & $0.4(100$ pa) \\
\hline Air flow EQ (scfm) & 8.9 & 12.4 & 14.9 & 16.9 \\
\hline
\end{tabular}

Air leakage rate

\begin{tabular}{|c|c|c|c|c|}
\hline Pressure difference & 0.1 (25 pa) & 0.2 (50 pa) & 0.3 (75 pa) & $0.4(100$ pa $)$ \\
\hline$Q d=E Q-Q(S c f m)$ & 1.1 & 1.4 & 0.8 & 1.1 \\
\hline $\begin{array}{l}\text { Temperature corrected Flow Rate } \\
\text { (Scfm) }\end{array}$ & 1.260 & 1.603 & 0.916 & 1.260 \\
\hline $\begin{array}{l}\text { Temperature corrected Flow Rate } \\
(\mathrm{L} / \mathrm{s})\end{array}$ & 0.592 & 0.754 & 0.431 & 0.592 \\
\hline Standard air leakage $\left(\mathrm{L} / \mathrm{s} / \mathrm{m}^{2}\right)$ & 0.143 & 0.182 & 0.104 & 0.143 \\
\hline Standardized air leakage $\left(\mathrm{Scfm} / \mathrm{ft}^{2}\right)$ & 0.035 & 0.044 & 0.025 & 0.035 \\
\hline
\end{tabular}



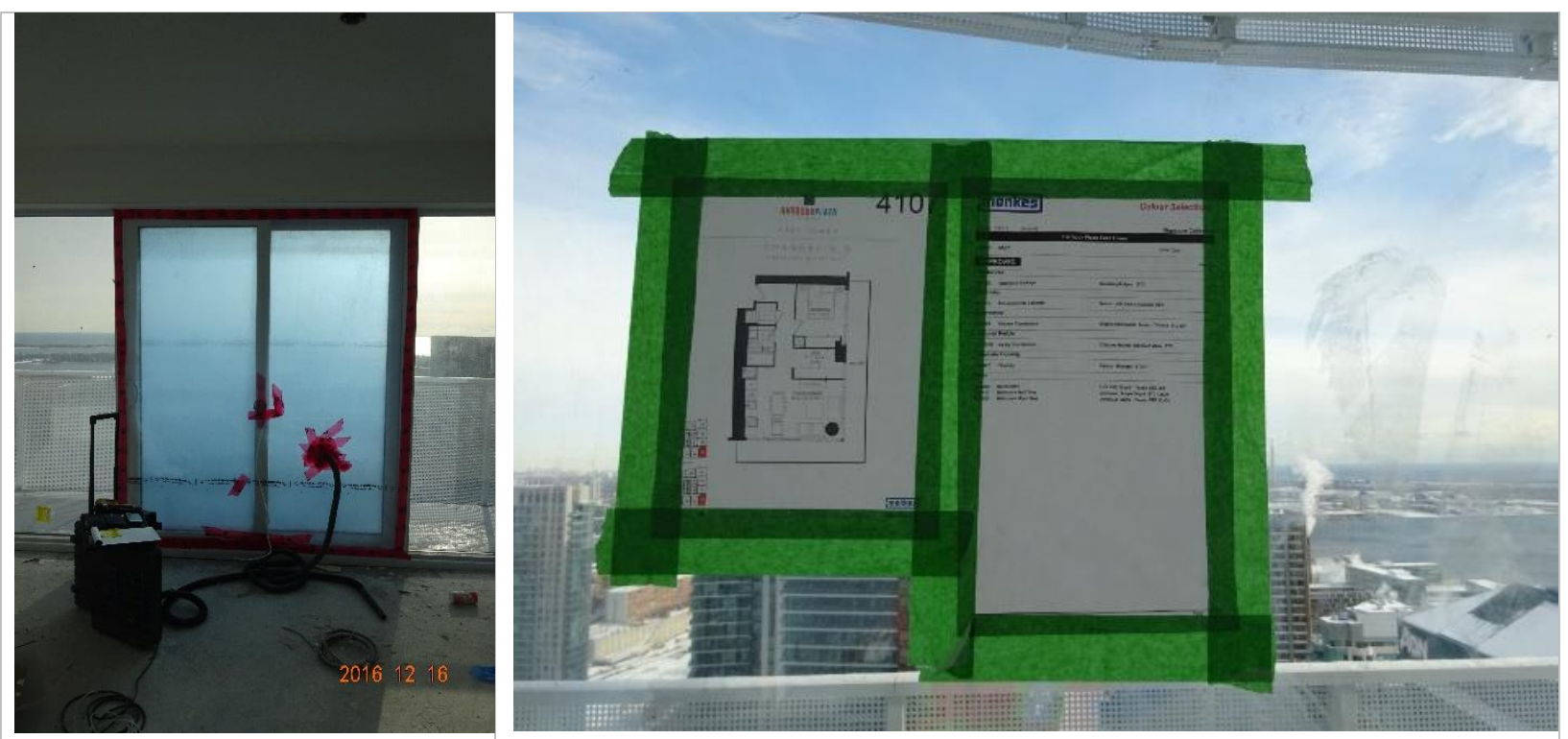

Interior view

\section{Unit plan}

\section{Discussion}

Test sample air leakage result is way below laboratory air leakage result at 75 pascal pressure difference.

This test is excluded from test results analysis due to out-performance. 


\section{Test No.25}

\begin{tabular}{|l|l|}
\hline Date & $12 / 16 / 2016$ \\
\hline Time & $10: 00 \mathrm{AM}$ \\
\hline Suite & E05 \\
\hline Level & 36 construction/41 marketing \\
\hline
\end{tabular}

\section{Sample Description}

\begin{tabular}{|l|l|}
\hline Model & Double glazed, Argon gas filled \\
\hline Door type & $6 \mathrm{~mm}$ ESR42 Temp (PURCH) / 1" Black spacer /6 mm CLR Temp (PURCH) \\
\hline Assembly Type & \\
\hline Size & $2260 \mathrm{~mm} \times 1830 \mathrm{~mm}$ \\
\hline Operation type & Sliding door \\
\hline
\end{tabular}

\section{Ambient Test Condition}

\begin{tabular}{|l|l|}
\hline Temperature inside & \\
\hline Temperature outside & $(-7) \circ \mathrm{C}-$ Feels $(-17) \circ \mathrm{C}$ \\
\hline Density of air at test site & $1.379 \mathrm{Kg} / \mathrm{m} 3$ \\
\hline Relative humidity & $50 \%$ \\
\hline Wind speed & W31KPH \\
\hline
\end{tabular}

\section{Visual Observation}

No deficiency observed in the sample.

\section{Readings}

Air flow rate at nonstandard condition

\begin{tabular}{|l|l|l|l|l|}
\hline Pressure difference & $\mathbf{0 . 1}(\mathbf{2 5}$ pa) & $\mathbf{0 . 2}(\mathbf{5 0}$ pa) & $\mathbf{0 . 3}$ (75 pa) & $\mathbf{0 . 4}(\mathbf{1 0 0}$ pa) \\
\hline Air flow Q (scfm) & 7.8 & 8.9 & 10.1 & 12.7
\end{tabular}

Extraneous air flow rate at nonstandard condition

\begin{tabular}{|l|l|l|l|l|}
\hline Pressure difference & $\mathbf{0 . 1}(\mathbf{2 5}$ pa) & $\mathbf{0 . 2}(\mathbf{5 0}$ pa) & $\mathbf{0 . 3}(\mathbf{7 5}$ pa) & $\mathbf{0 . 4}(\mathbf{1 0 0}$ pa) \\
\hline Air flow EQ (scfm) & 8.1 & 9.2 & 11.1 & 12.2 \\
\hline
\end{tabular}

Air leakage rate

\begin{tabular}{|c|c|c|c|c|}
\hline Pressure difference & 0.1 (25 pa) & $0.2(50$ pa) & 0.3 (75 pa) & $0.4(100$ pa $)$ \\
\hline$Q d=E Q-Q(S c f m)$ & 0.3 & 0.3 & 1.1 & 0.5 \\
\hline $\begin{array}{l}\text { Temperature corrected Flow Rate } \\
\text { (Scfm) }\end{array}$ & 0.344 & 0.344 & 1.145 & -0.573 \\
\hline $\begin{array}{l}\text { Temperature corrected Flow Rate } \\
(\mathrm{L} / \mathrm{s})\end{array}$ & 0.161 & 0.161 & 0.538 & -0.269 \\
\hline Standard air leakage $\left(\mathrm{L} / \mathrm{s} / \mathrm{m}^{2}\right)$ & 0.039 & 0.039 & 0.130 & -0.065 \\
\hline Standardized air leakage $\left(\mathrm{Scfm} / \mathrm{ft}^{2}\right)$ & 0.009 & 0.009 & 0.031 & -0.016 \\
\hline
\end{tabular}




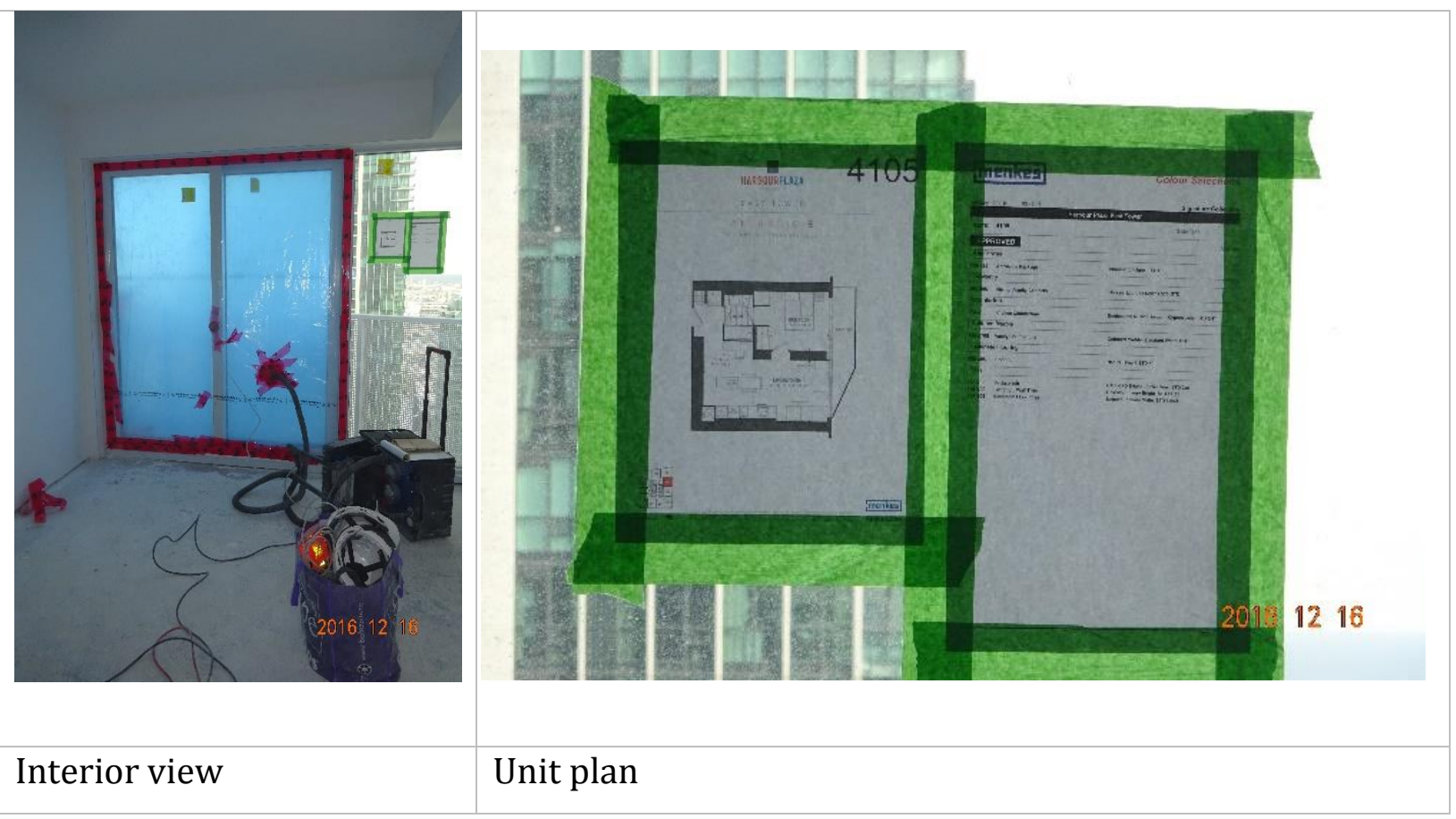

\section{Discussion}

Test sample air leakage result is below laboratory air leakage result at 75 pascal pressure difference.

This test is excluded from test results analysis due to out-performance. 


\section{Test No.26}

\begin{tabular}{|l|l|}
\hline Date & $12 / 16 / 2016$ \\
\hline Time & $12: 17 \mathrm{PM}$ \\
\hline Suite & E06 \\
\hline Level & 23 construction/27 marketing \\
\hline
\end{tabular}

\section{Sample Description}

\begin{tabular}{|l|l|}
\hline Model & Double glazed, Argon gas filled \\
\hline Door type & $6 \mathrm{~mm}$ ESR42 Temp (PURCH) / 1" Black spacer/6 mm CLR Temp (PURCH) \\
\hline Assembly Type & \\
\hline Size & $2260 \mathrm{~mm}$ x1830 $\mathrm{mm}$ \\
\hline Operation type & Sliding door \\
\hline
\end{tabular}

\section{Ambient Test Condition}

\begin{tabular}{|l|l|}
\hline Temperature inside & \\
\hline Temperature outside & $(-5) \circ \mathrm{C}-$ Feels $(-14) \circ \mathrm{C}$ \\
\hline Density of air at test site & $1.36 \mathrm{Kg} / \mathrm{m} 3$ \\
\hline Relative humidity & $50 \%$ \\
\hline Wind speed & WSW29KPH \\
\hline
\end{tabular}

\section{Visual Observation}

No deficiency observed at the time of review.

\section{Readings}

Air flow rate at nonstandard condition

\begin{tabular}{|l|l|l|l|l|}
\hline Pressure difference & $\mathbf{0 . 1}(\mathbf{2 5}$ pa) & $\mathbf{0 . 2}$ (50 pa) & $\mathbf{0 . 3}$ (75 pa) & $0.4(100$ pa) \\
\hline Air flow q (scfm) & 11.2 & 15.3 & 17.8 & 19.9 \\
\hline
\end{tabular}

Extraneous air flow rate at nonstandard condition

\begin{tabular}{|l|l|l|l|l|}
\hline Pressure difference & $\mathbf{0 . 1}(\mathbf{2 5}$ pa) & $\mathbf{0 . 2}(\mathbf{5 0}$ pa) & $\mathbf{0 . 3}(\mathbf{7 5}$ pa) & $\mathbf{0 . 4}(\mathbf{1 0 0}$ pa) \\
\hline Air flow eq (scfm) & 14.2 & 19.4 & 21.9 & 26.1 \\
\hline
\end{tabular}

Air leakage rate

\begin{tabular}{|c|c|c|c|c|}
\hline Pressure difference & 0.1 (25 pa) & $0.2(50$ pa) & 0.3 (75 pa) & $0.4(100$ pa $)$ \\
\hline$Q d=E Q-Q(S c f m)$ & 0.7 & 5.3 & 4.9 & 6.7 \\
\hline $\begin{array}{l}\text { Temperature corrected Flow Rate } \\
\text { (Scfm) }\end{array}$ & 3.389 & 4.631 & 4.631 & 7.003 \\
\hline $\begin{array}{l}\text { Temperature corrected Flow Rate } \\
(\mathrm{L} / \mathrm{s})\end{array}$ & 1.593 & 2.177 & 2.177 & 3.292 \\
\hline Standard air leakage $\left(\mathrm{L} / \mathrm{s} / \mathrm{m}^{2}\right)$ & 0.385 & 0.526 & 0.526 & 0.796 \\
\hline Standardized air leakage $\left(\mathrm{Scfm} / \mathrm{ft}^{2}\right)$ & 0.093 & 0.127 & 0.127 & 0.192 \\
\hline
\end{tabular}




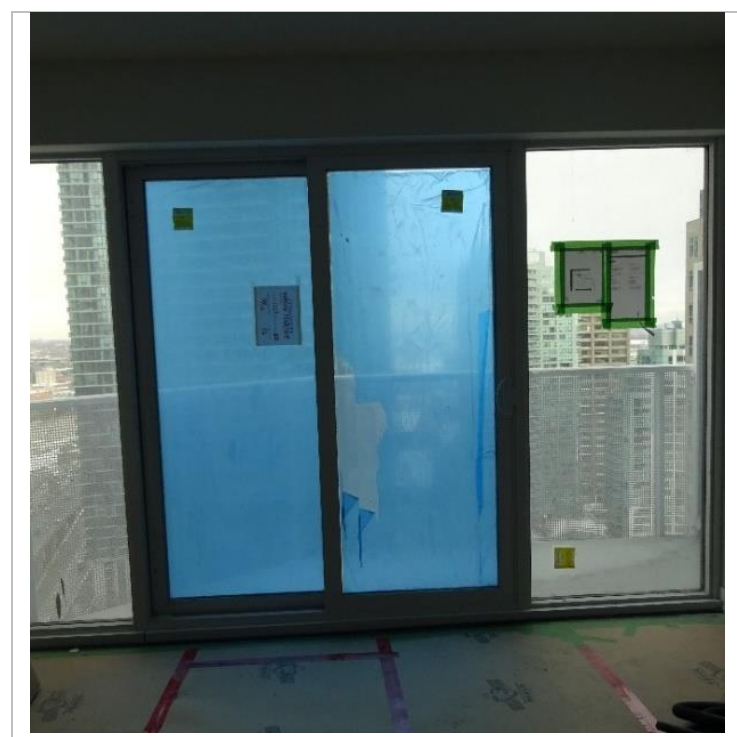

Interior view before test

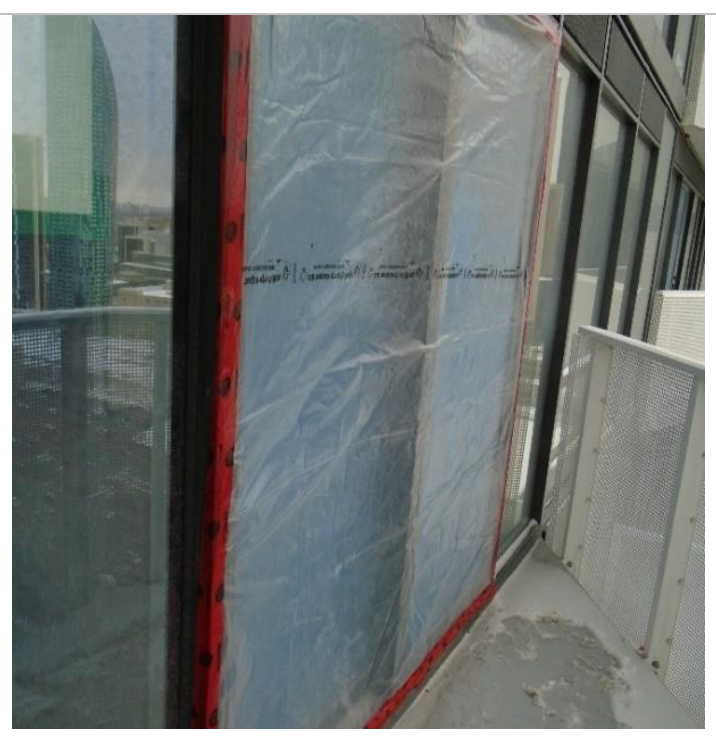

Exterior view

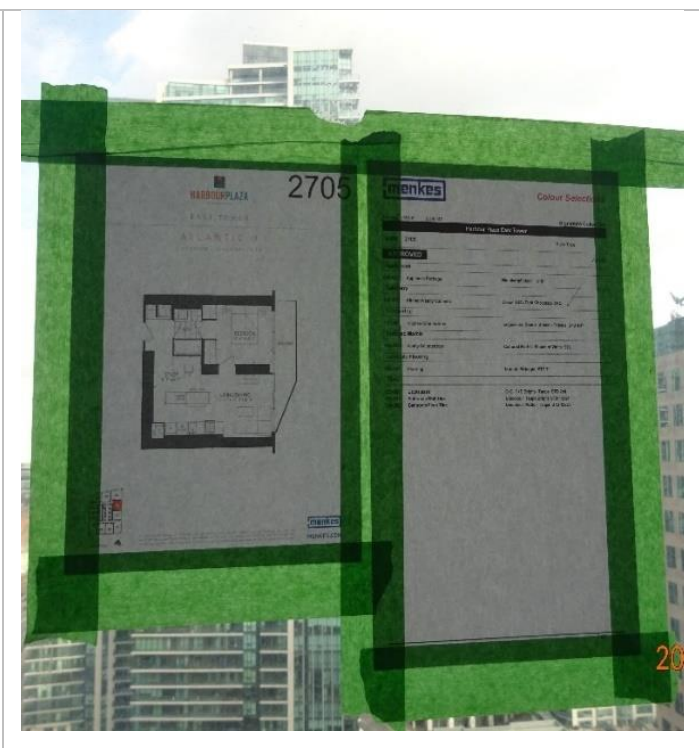

Unit plan

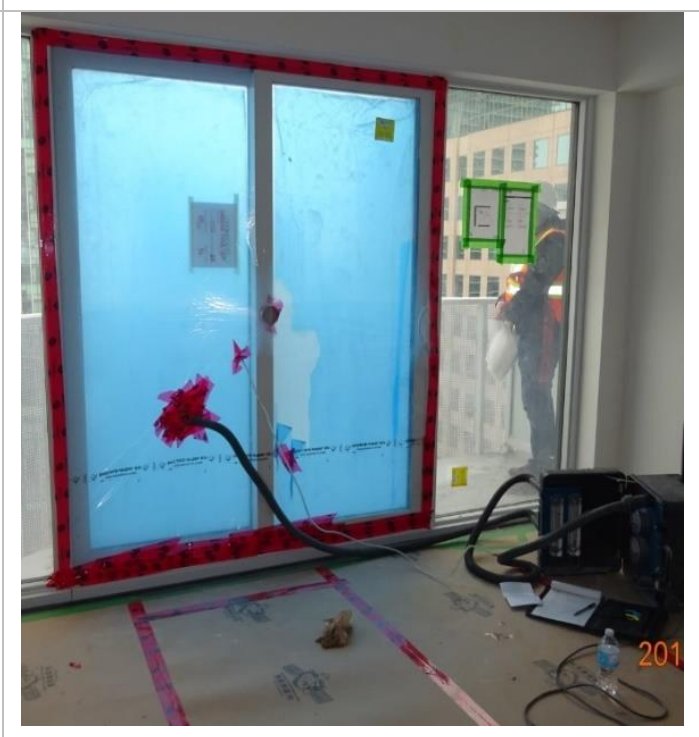

Interior view 


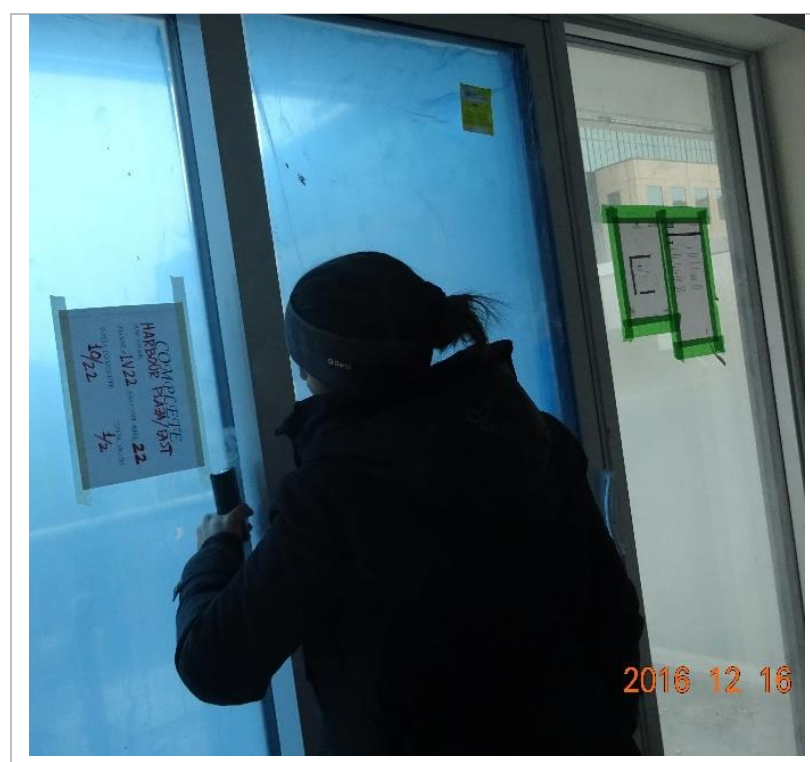

Smoke pencil test

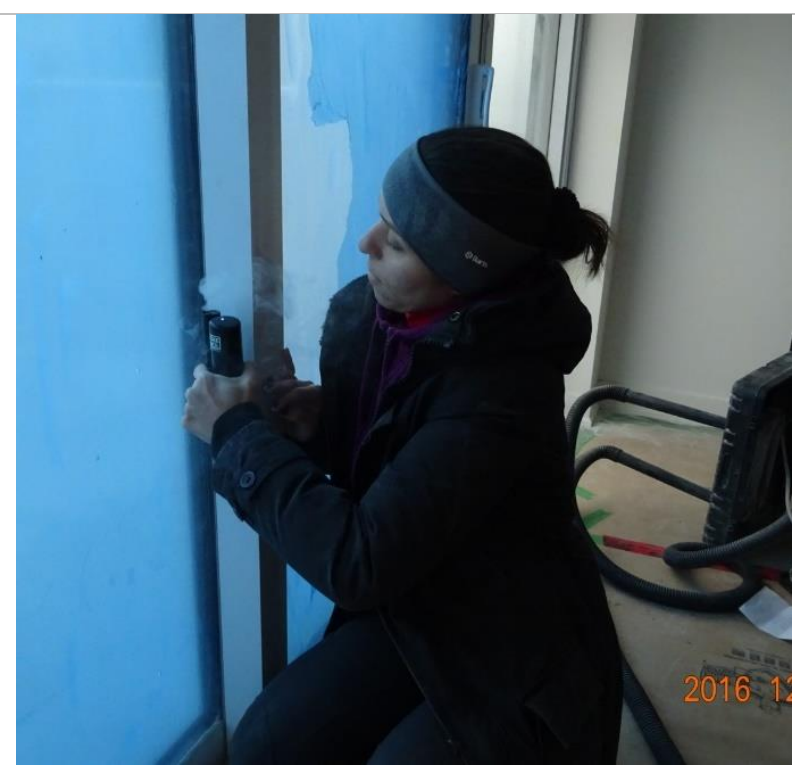

Smoke pencil test

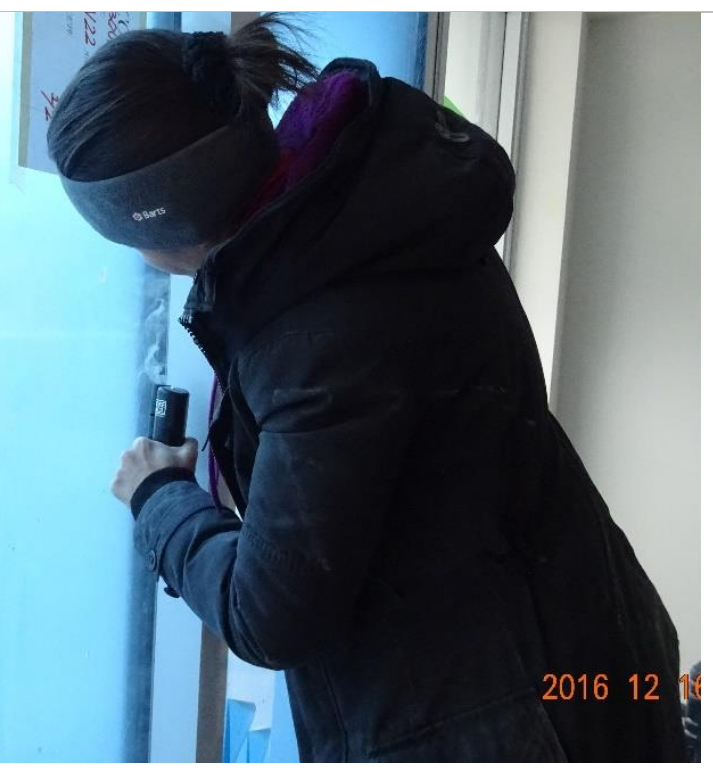

Smoke pencil test

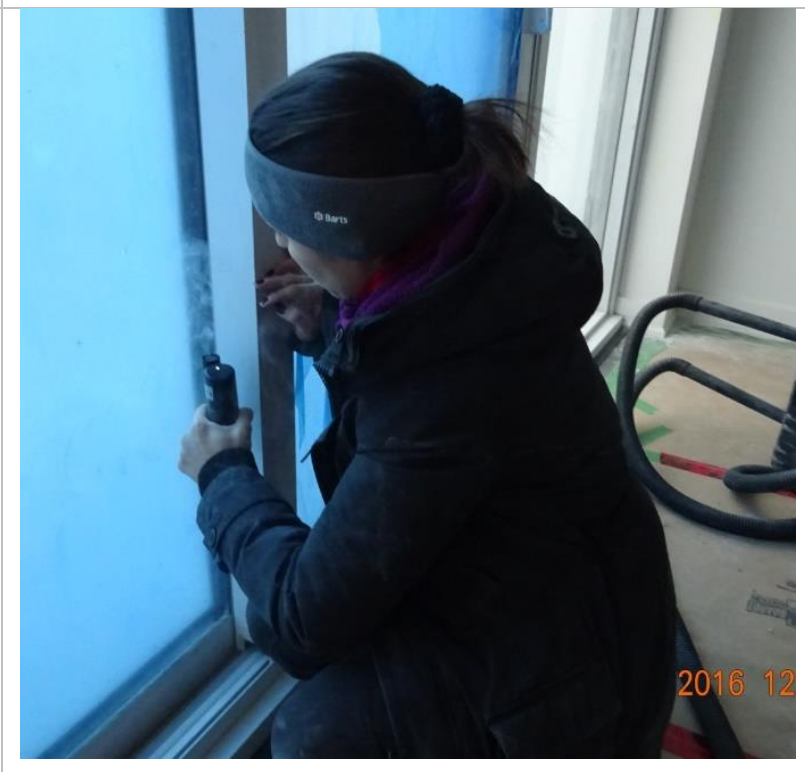

Smoke pencil test 

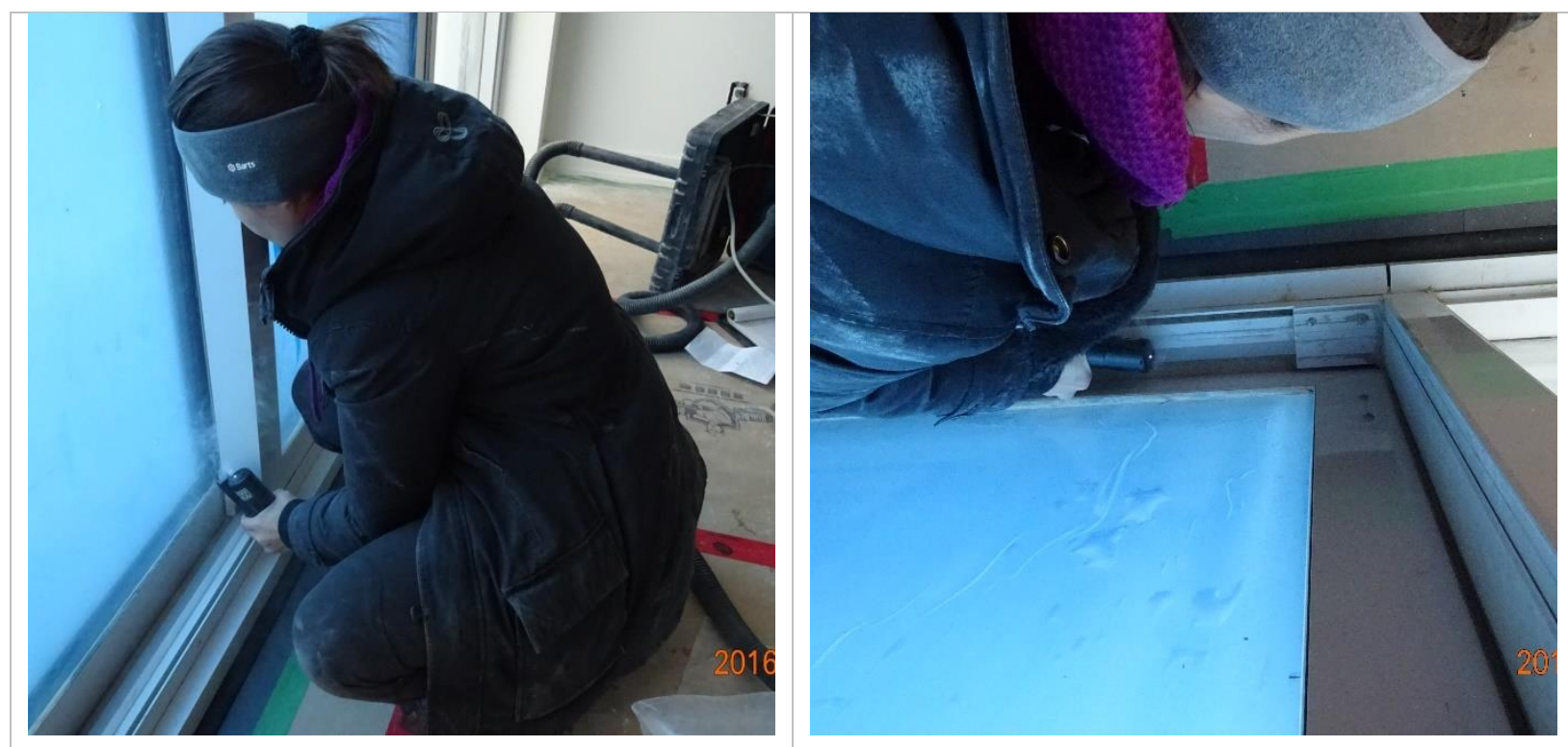

Smoke pencil test

Smoke pencil test
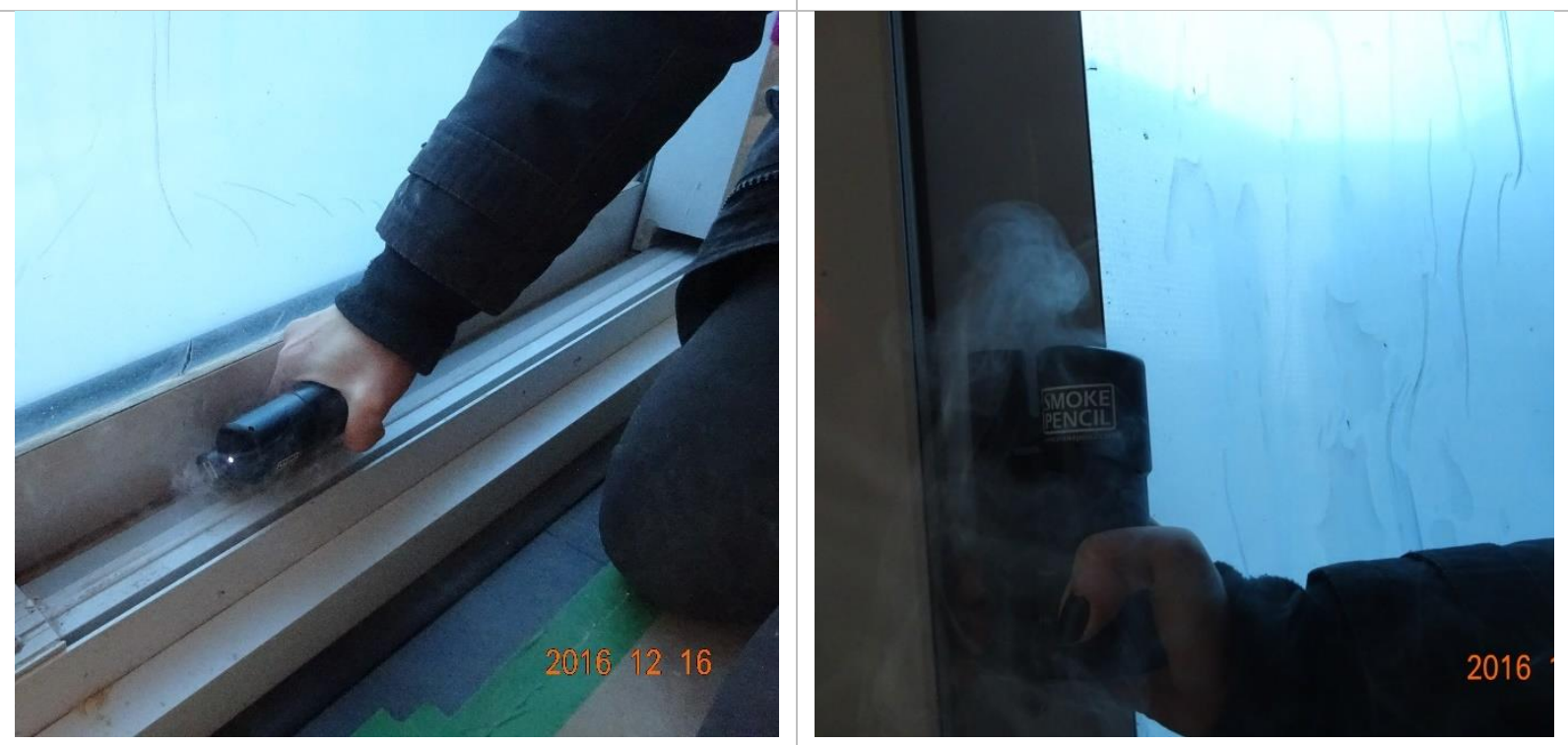

Smoke pencil test

Smoke pencil test 


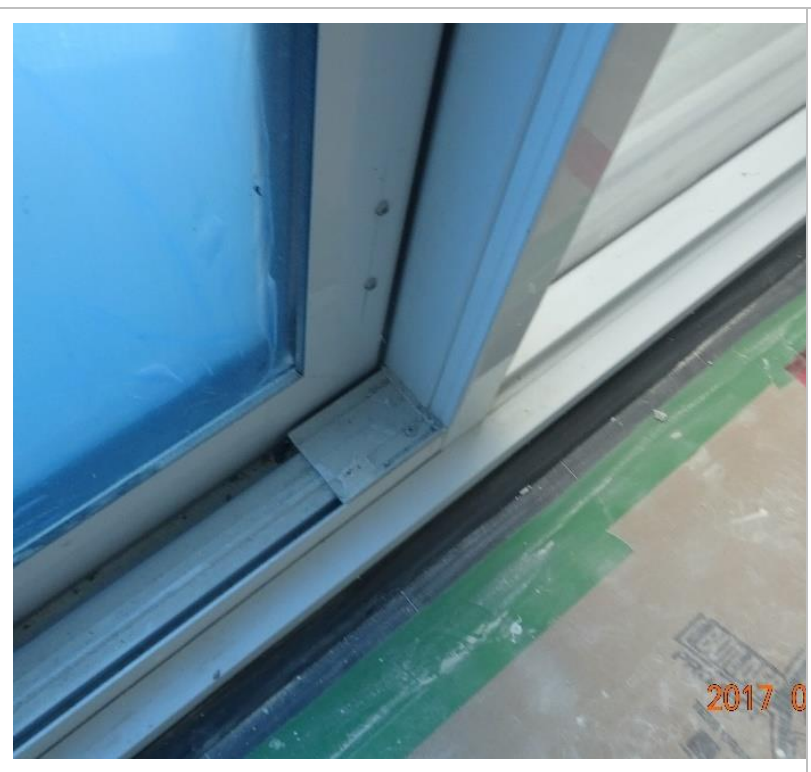

Frame joit

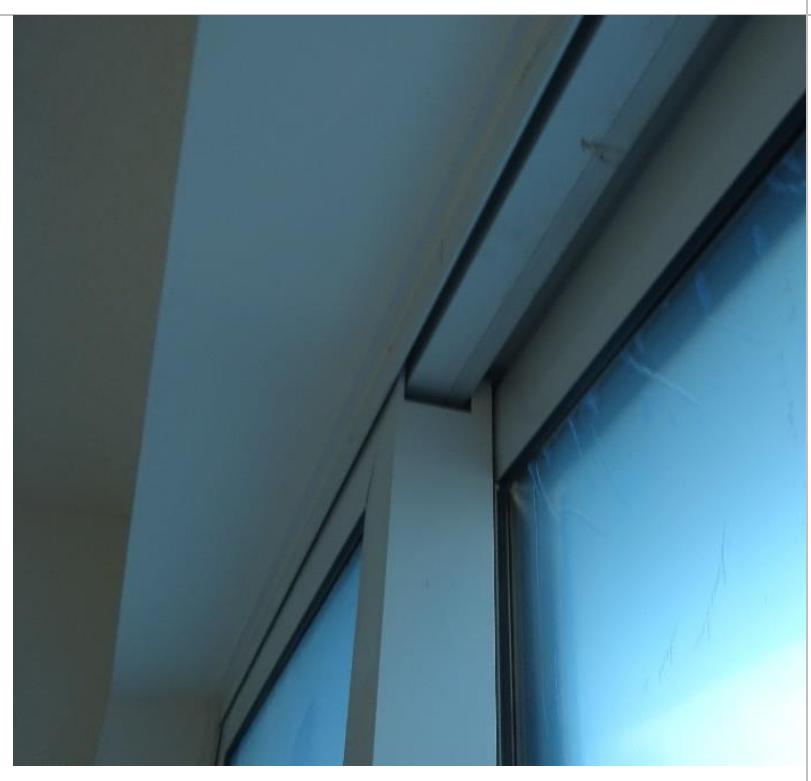

Door head frame and track

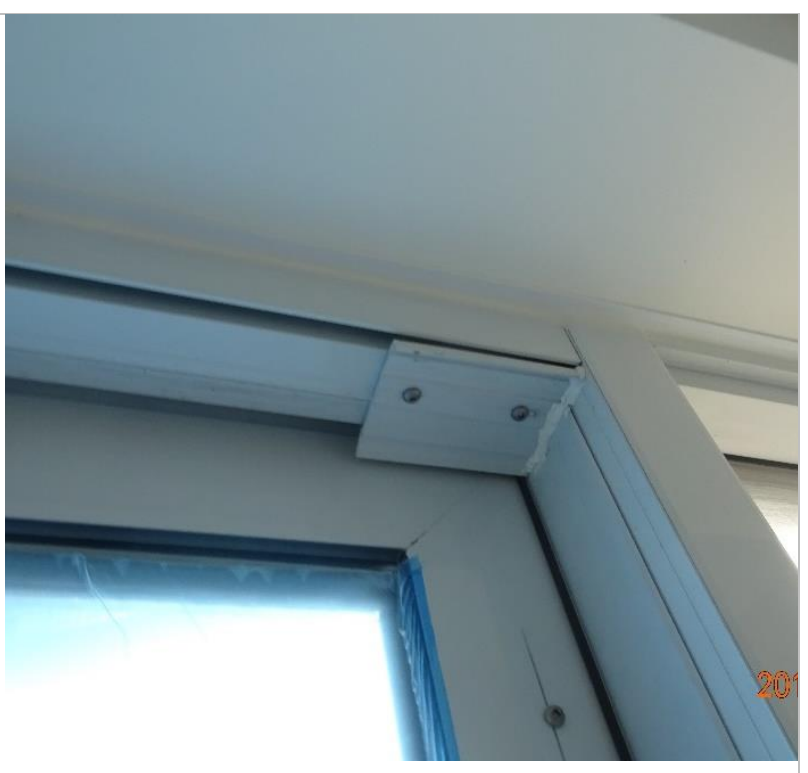

Frame joint

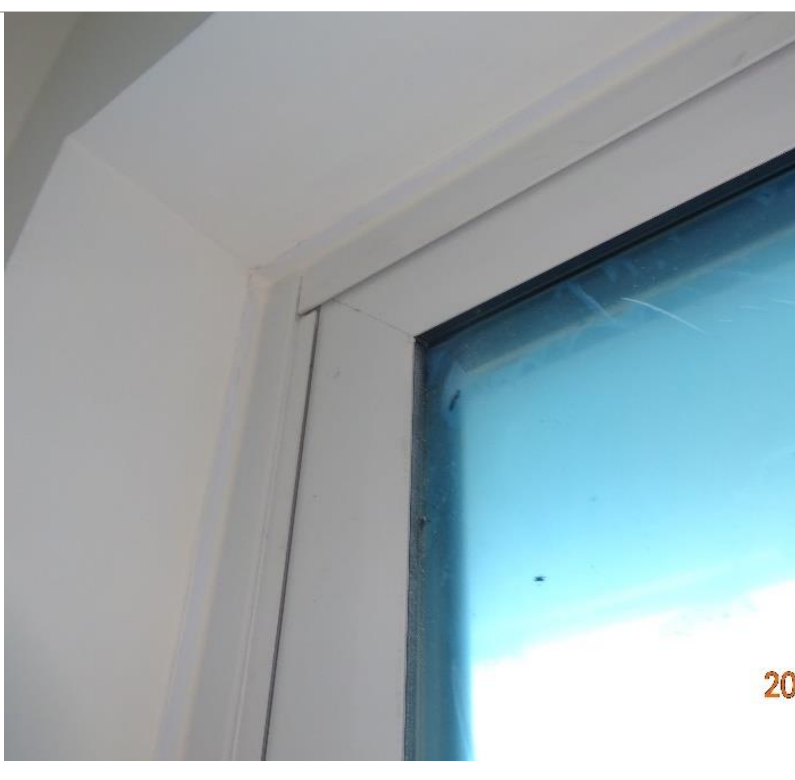

Frame joint 


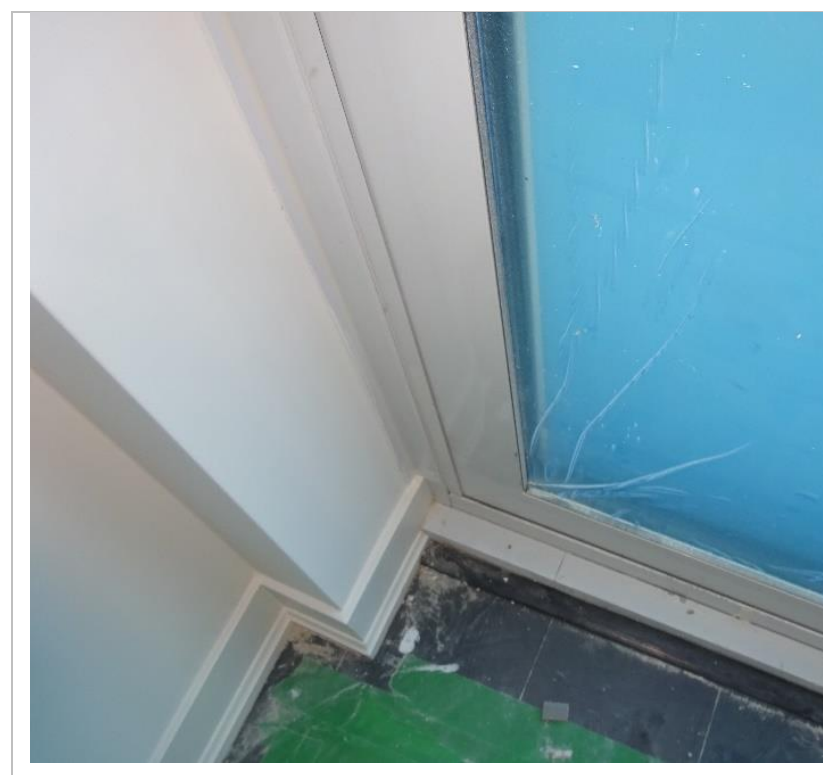

\section{Door corner}

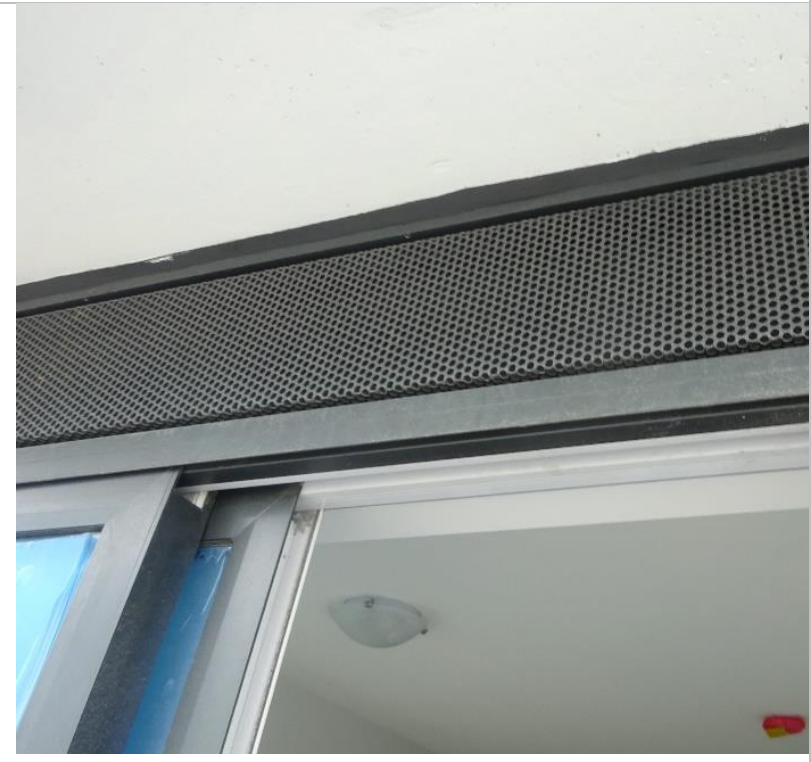

Window frame to soffit

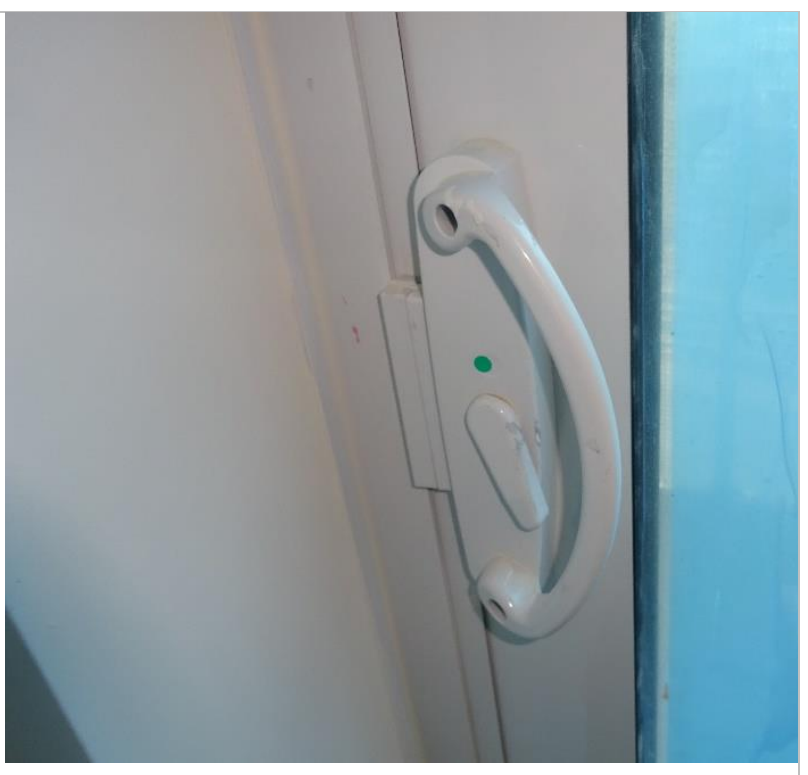

Door hardware

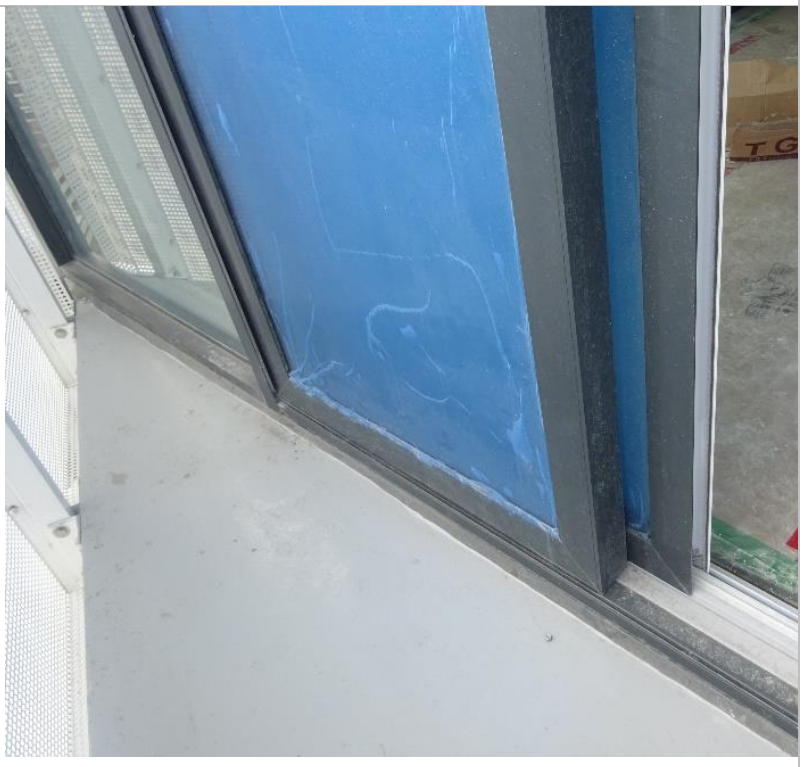

Exterior view 

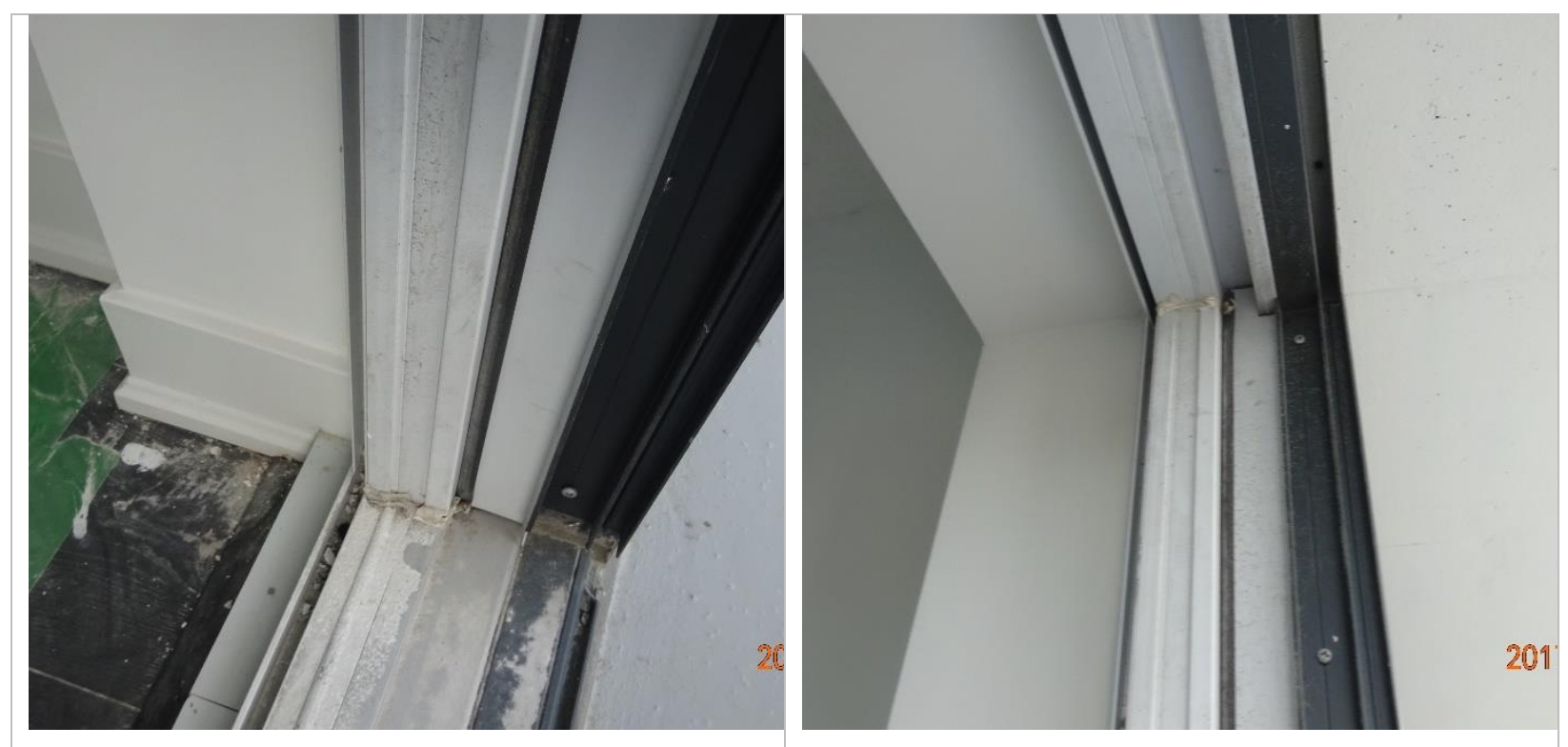

Door sill track

Door head track

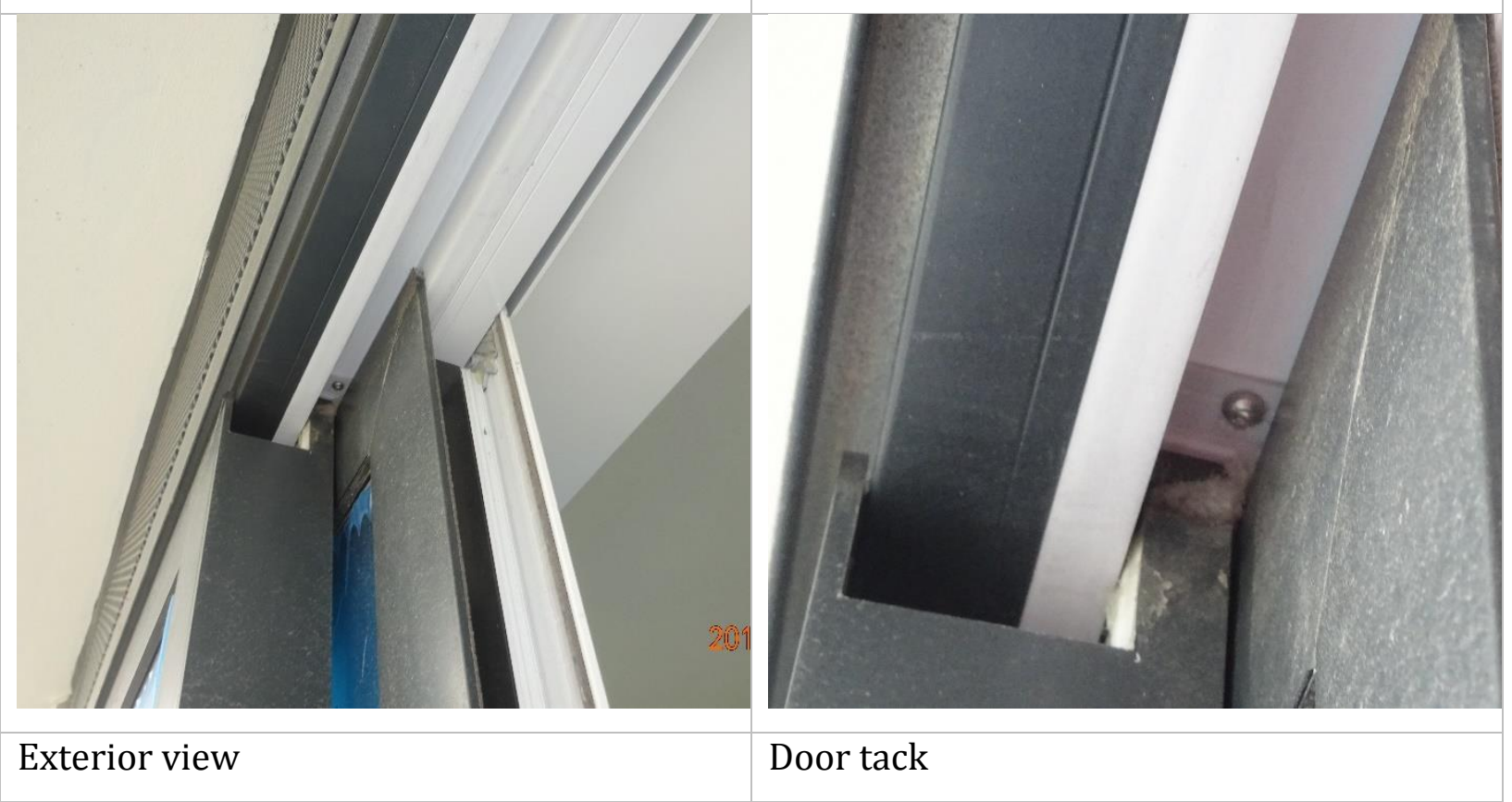



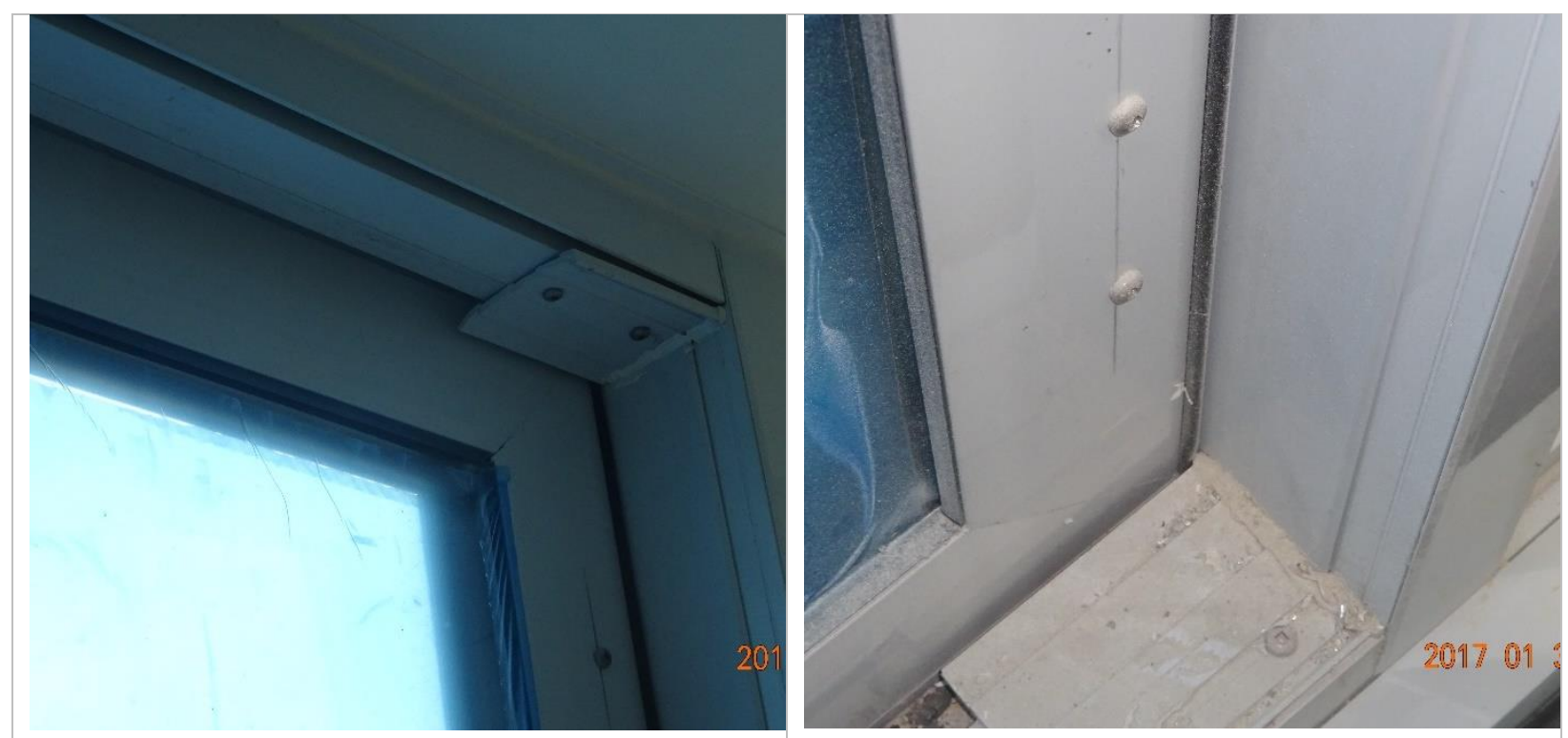

\section{Frame joint}

\section{Sash joint}

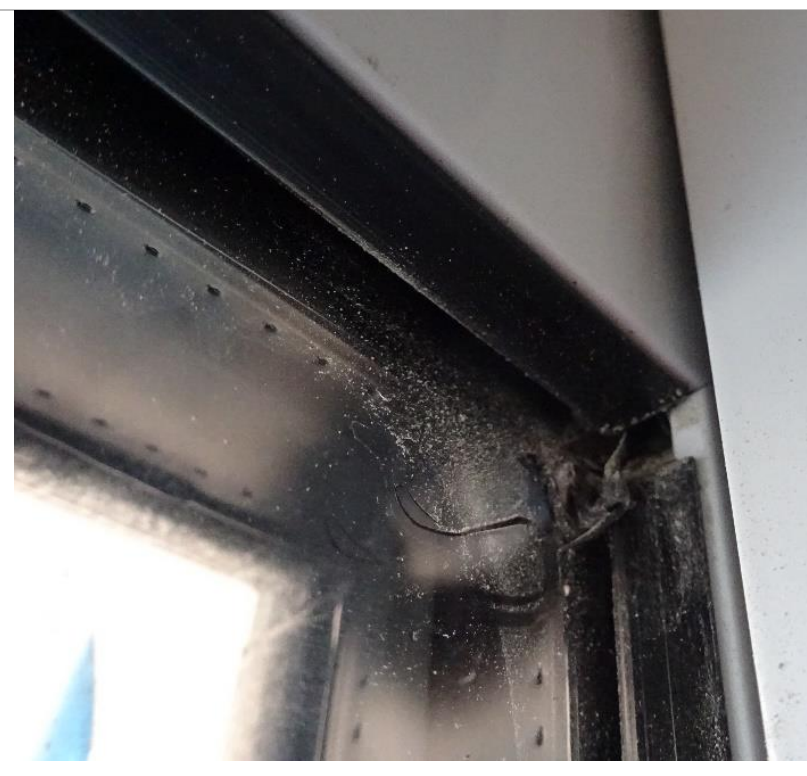

Sash corner joint

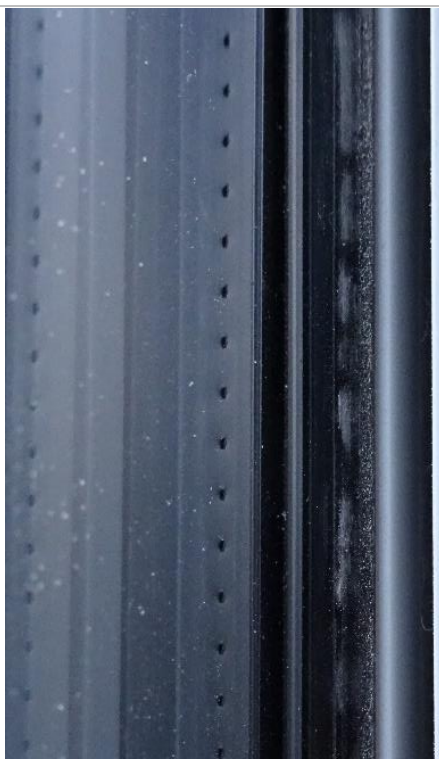

Glass to sash joint 

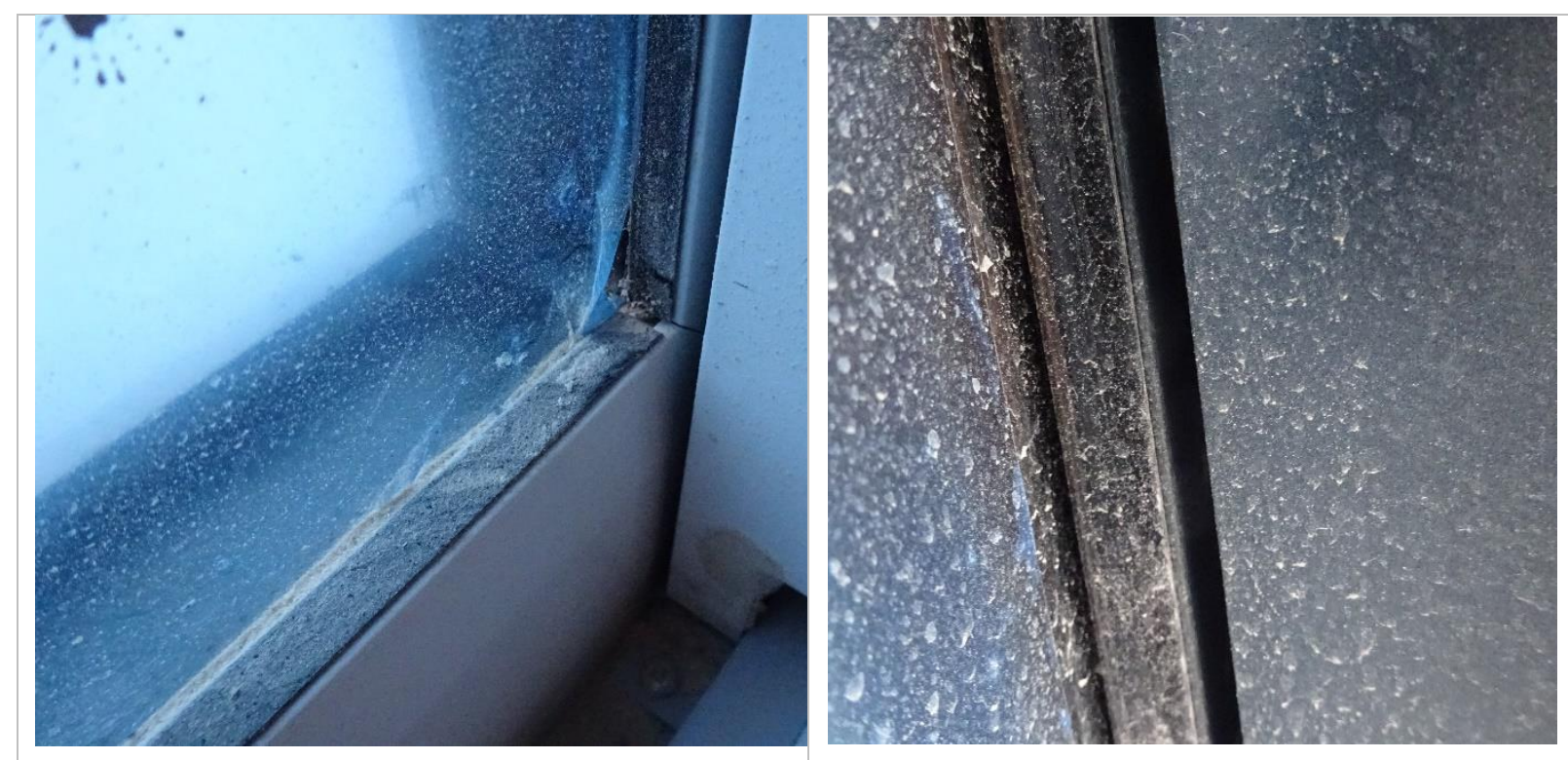

\section{Sash corner}

Glass to sash joint

\section{Termography capturing}
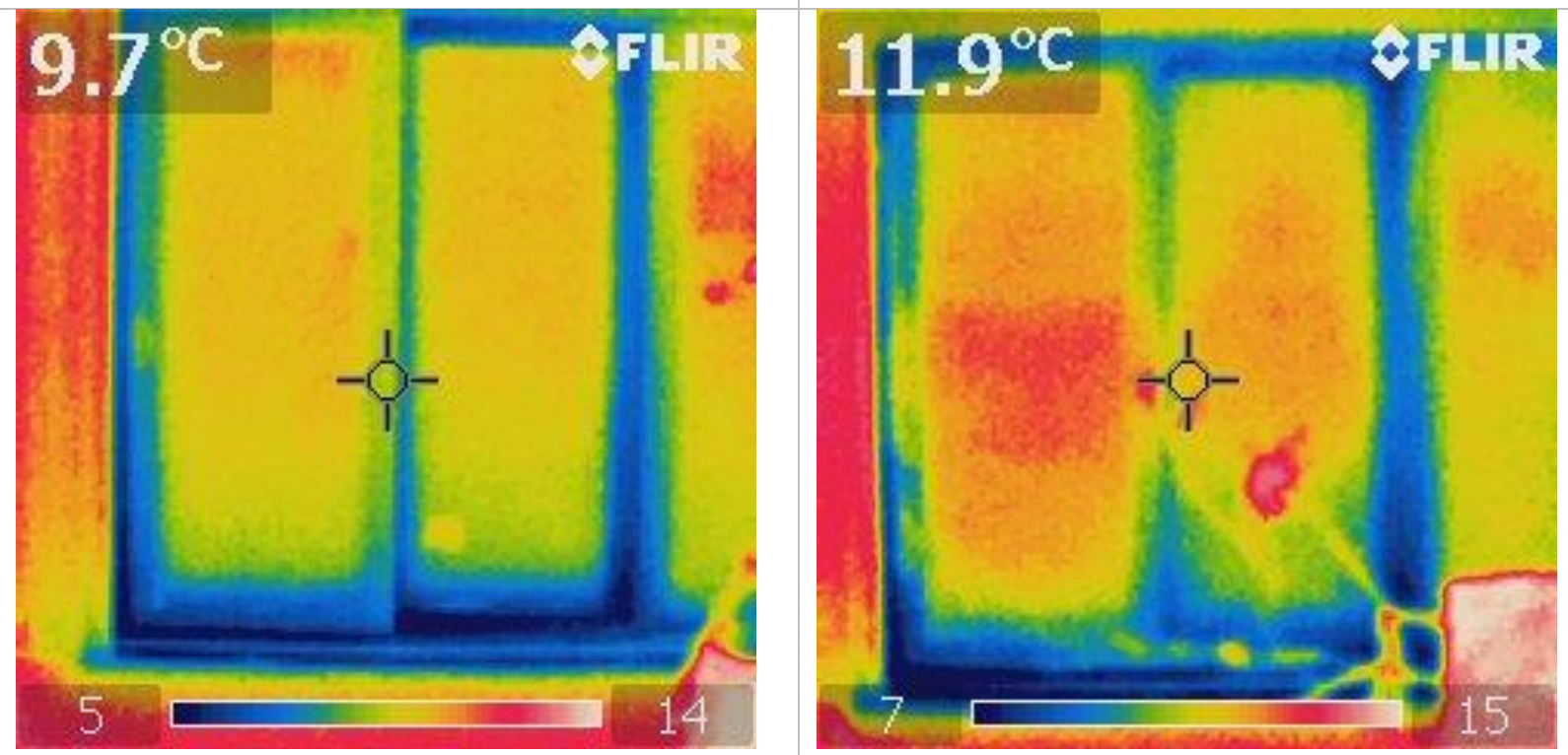

Before test

After starting the test 


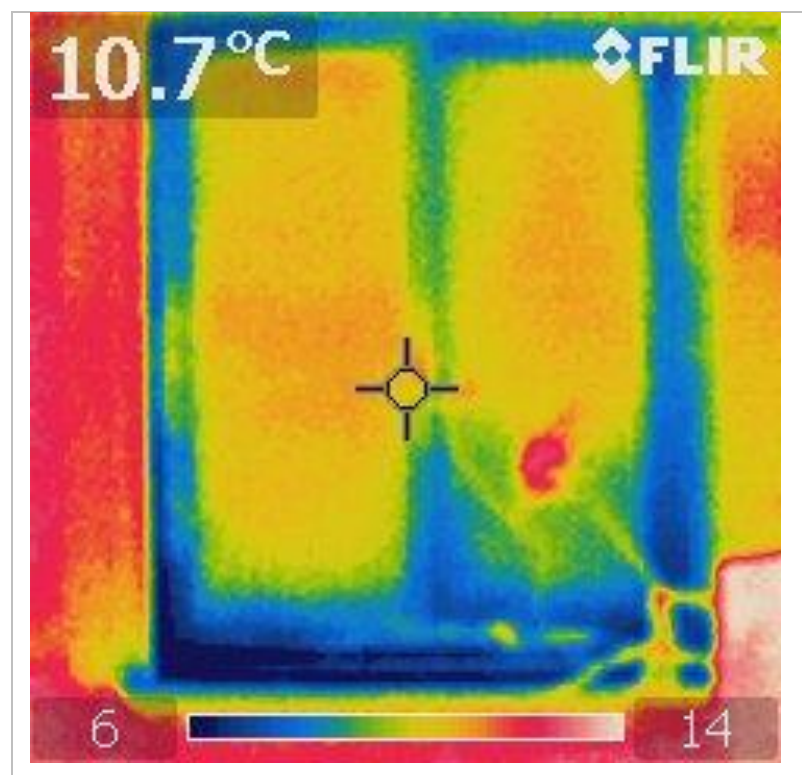

After starting the test

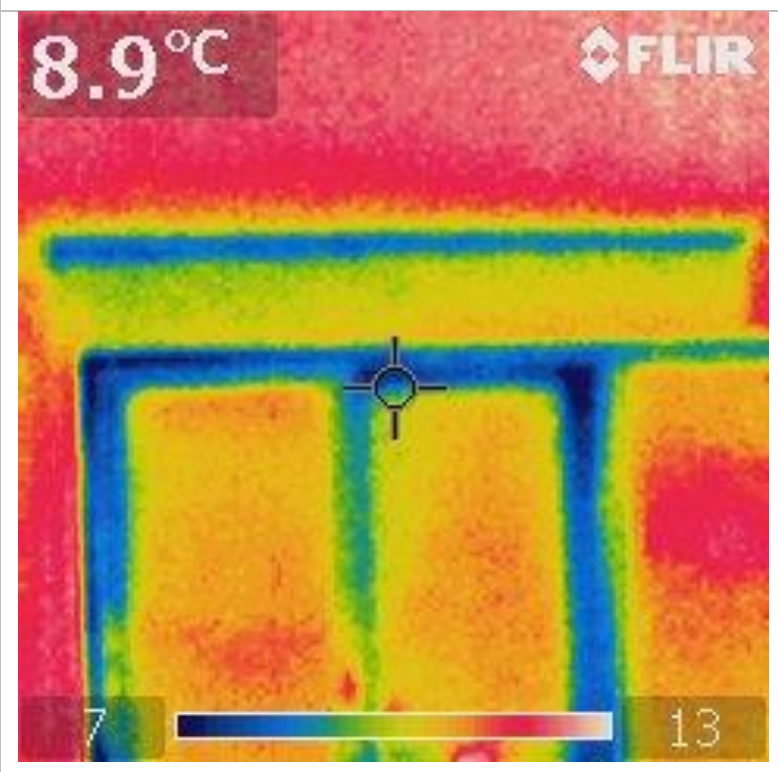

After starting the test

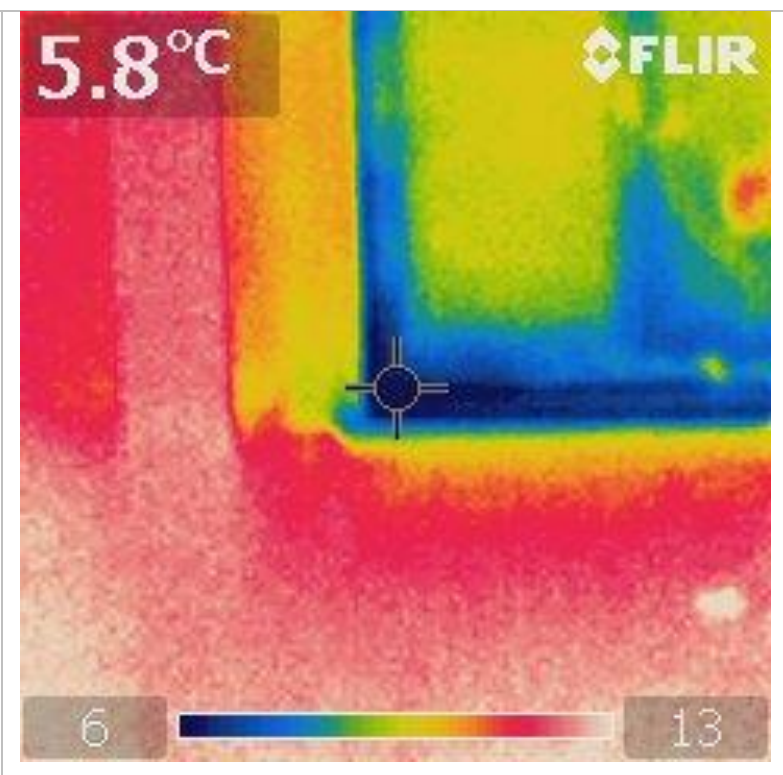

After starting the test

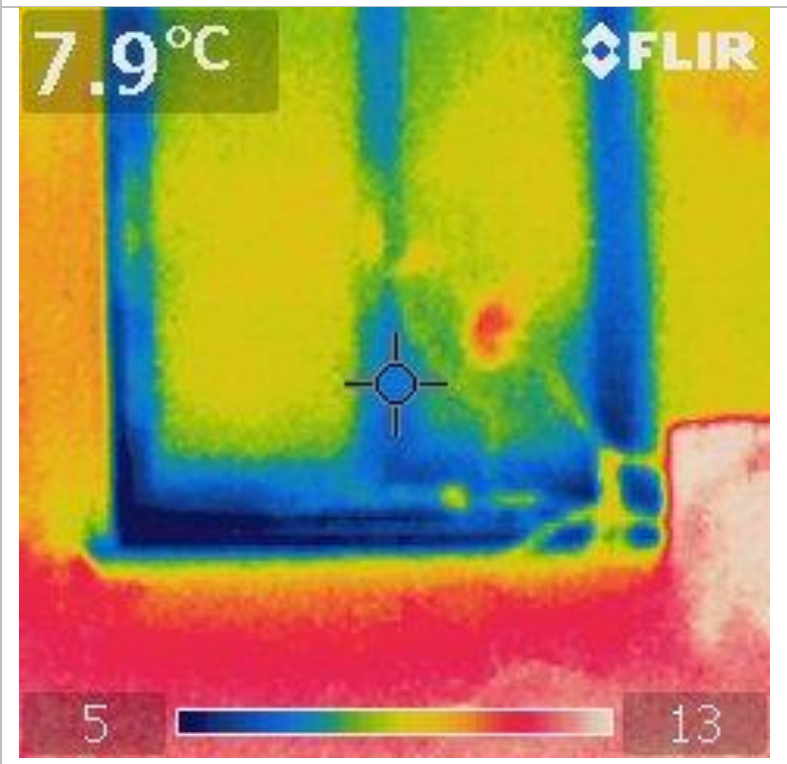

After starting the test 


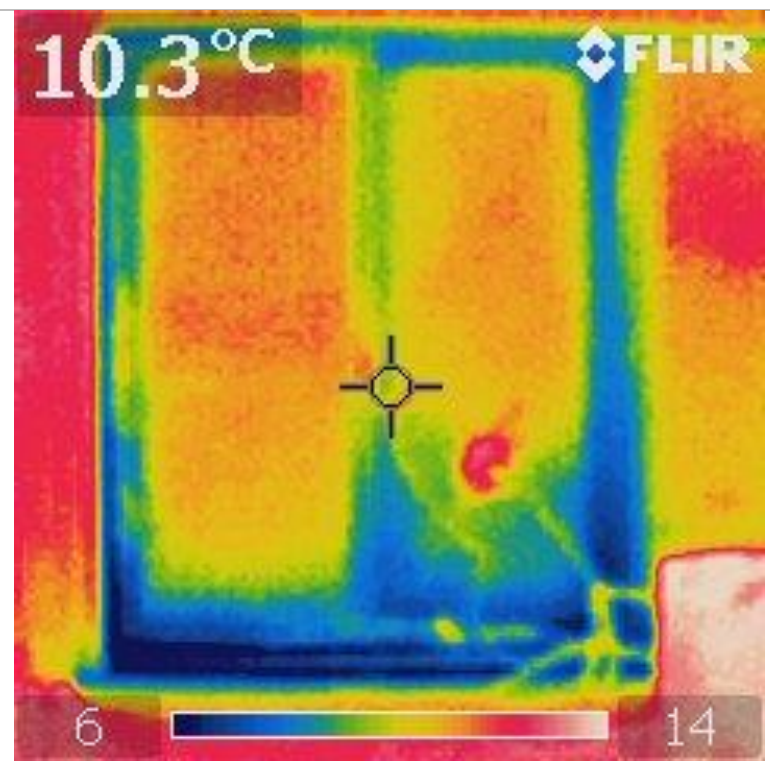

After taking of the exterior poly

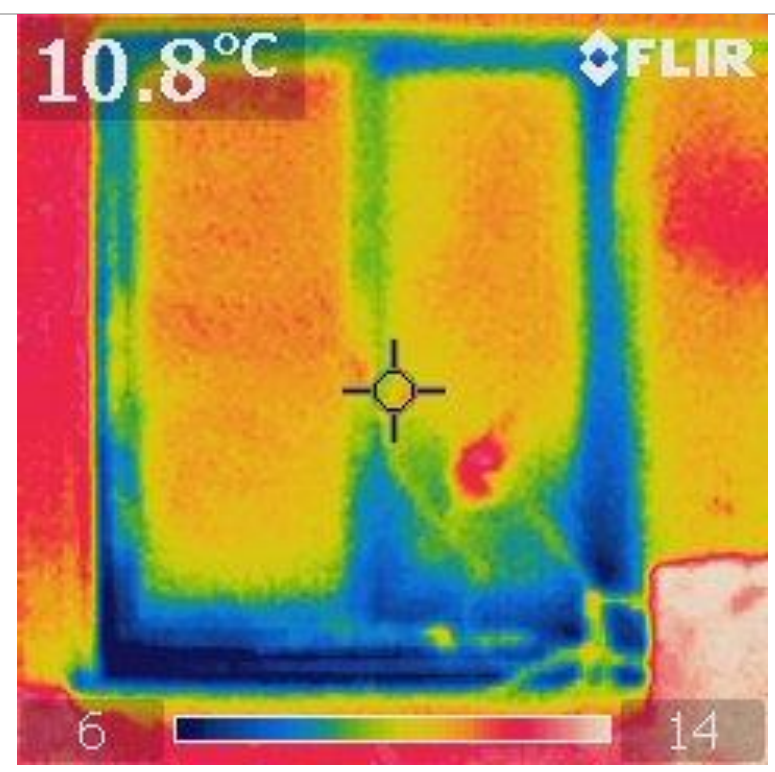

After taking of the exterior poly

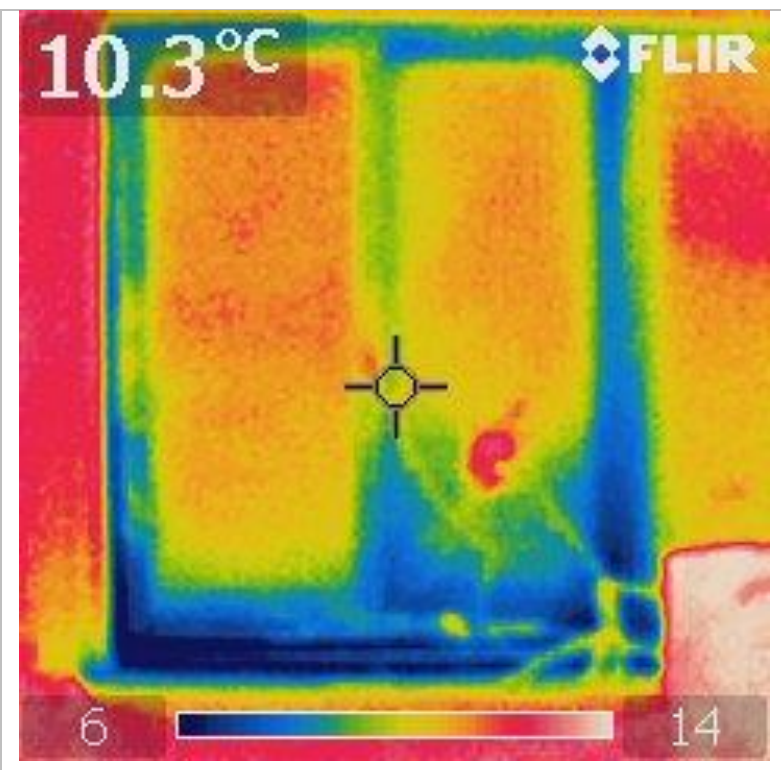

After taking of the exterior poly
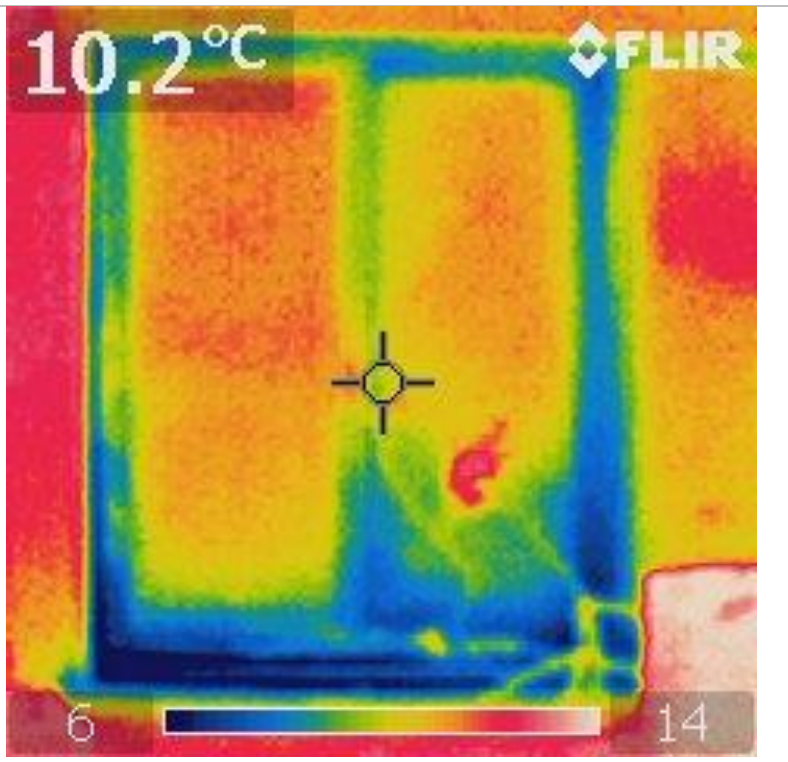

After taking of the exterior poly 


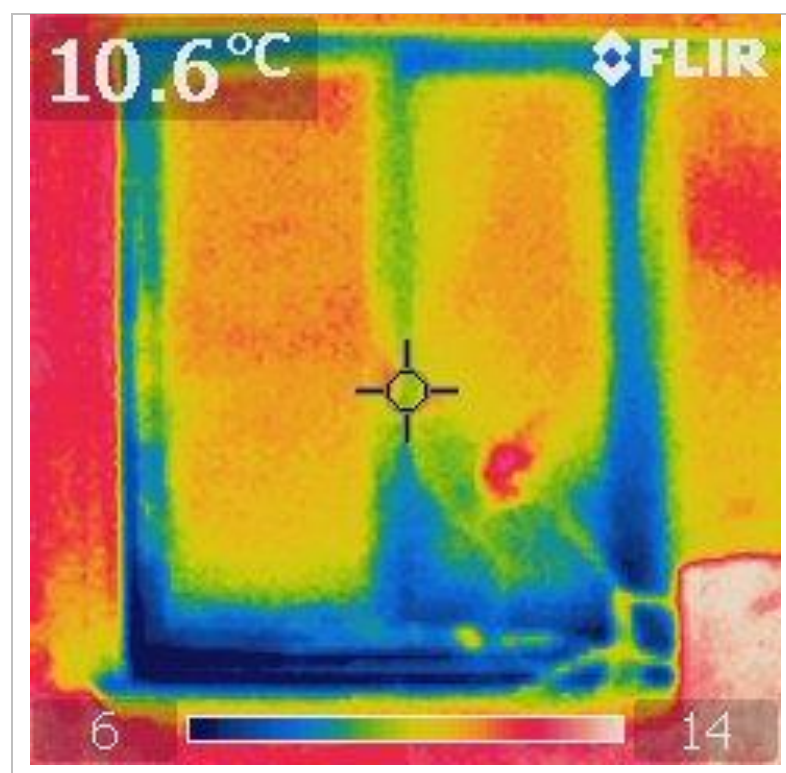

After taking of the exterior poly

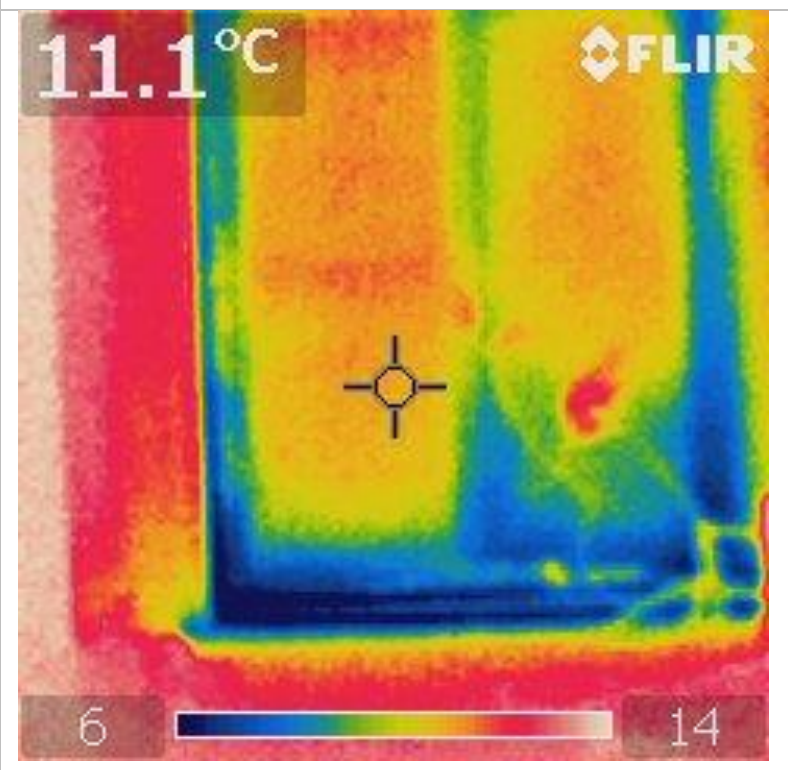

After taking of the exterior poly

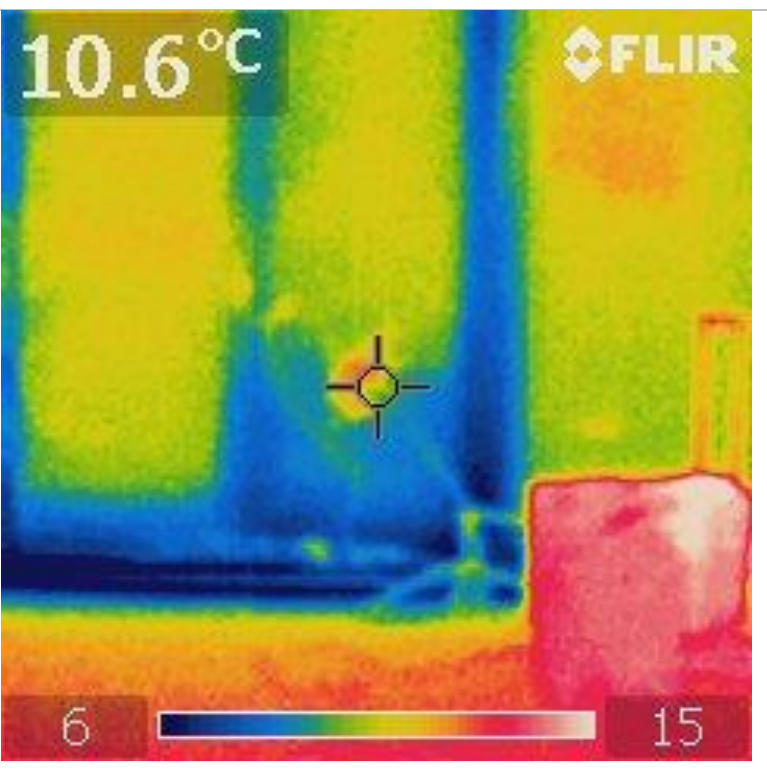

After taking of the exterior poly

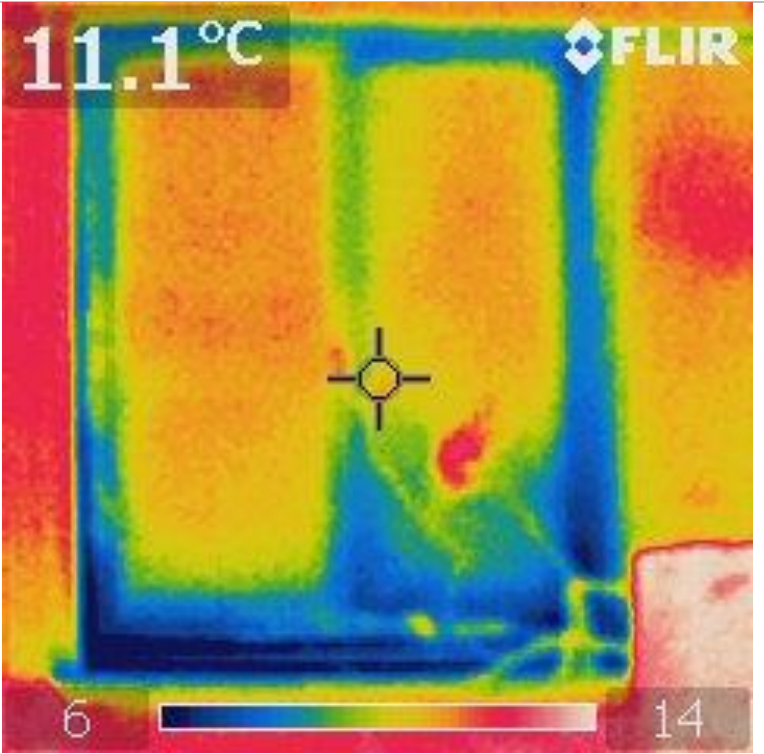

After taking of the exterior poly

\section{Discussion}

Test sample air leakage result is slightly above laboratory air leakage result at 75 pascal pressure difference. This test is excluded from test results analysis due to out-performance. 


\section{Test No.27}

\begin{tabular}{|l|l|}
\hline Date & $12 / 16 / 2016$ \\
\hline Time & $01: 40 \mathrm{PM}$ \\
\hline Suite & E07 \\
\hline Level & 23 construction/27 marketing \\
\hline
\end{tabular}

\section{Sample Description}

\begin{tabular}{|l|l|}
\hline Model & Double glazed, Argon gas filled \\
\hline Door type & $6 \mathrm{~mm}$ ESR42 Temp (PURCH) / 1" Black spacer /6 mm CLR Temp (PURCH) \\
\hline Assembly Type & \\
\hline Size & $2260 \mathrm{~mm} \times 1830 \mathrm{~mm}$ \\
\hline Operation type & Sliding door \\
\hline
\end{tabular}

\section{Ambient Test Condition}

\begin{tabular}{|l|l|}
\hline Temperature inside & \\
\hline Temperature outside & $(-5) \circ \mathrm{C}-$ Feels $(-14) \circ \mathrm{C}$ \\
\hline Density of air at test site & $1.35 \mathrm{Kg} / \mathrm{m} 3$ \\
\hline Relative humidity & $50 \%$ \\
\hline Wind speed & WSW24KPH \\
\hline
\end{tabular}

\section{Visual Observation}

No deficiency observed at the time of review.

\section{Readings}

Air flow rate at nonstandard condition

\begin{tabular}{|l|l|l|l|l|}
\hline Pressure difference & $\mathbf{0 . 1}(\mathbf{2 5}$ pa) & $\mathbf{0 . 2}$ (50 pa) & $\mathbf{0 . 3}$ (75 pa) & $\mathbf{0 . 4}(100$ pa) \\
\hline Air flow Q (scfm) & 9.9 & 11.2 & 12.9 & 14.8 \\
\hline
\end{tabular}

Extraneous air flow rate at nonstandard condition

\begin{tabular}{|l|l|l|l|l|}
\hline Pressure difference & $\mathbf{0 . 1}(\mathbf{2 5}$ pa) & $0.2(50$ pa) & $0.3(75$ pa) & $0.4(100$ pa) \\
\hline Air flow EQ (scfm) & 10.2 & 15.1 & 19.8 & 22.1 \\
\hline
\end{tabular}

Air leakage rate

\begin{tabular}{|c|c|c|c|c|}
\hline Pressure difference & 0.1 (25 pa) & 0.2 (50 pa) & 0.3 (75 pa) & $0.4(100$ pa $)$ \\
\hline$Q d=E Q-Q(S c f m)$ & 0.3 & 3.9 & 6.9 & 7.3 \\
\hline $\begin{array}{l}\text { Temperature corrected Flow Rate } \\
\text { (Scfm) }\end{array}$ & 0.339 & 4.405 & 7.794 & 8.246 \\
\hline $\begin{array}{l}\text { Temperature corrected Flow Rate } \\
(\mathrm{L} / \mathrm{s})\end{array}$ & 0.159 & 2.070 & 3.663 & 3.876 \\
\hline Standard air leakage $\left(\mathrm{L} / \mathrm{s} / \mathrm{m}^{2}\right)$ & 0.039 & 0.501 & 0.886 & 0.937 \\
\hline Standardized air leakage $\left(\mathrm{Scfm} / \mathrm{ft}^{2}\right)$ & 0.009 & 0.121 & 0.214 & 0.227 \\
\hline
\end{tabular}




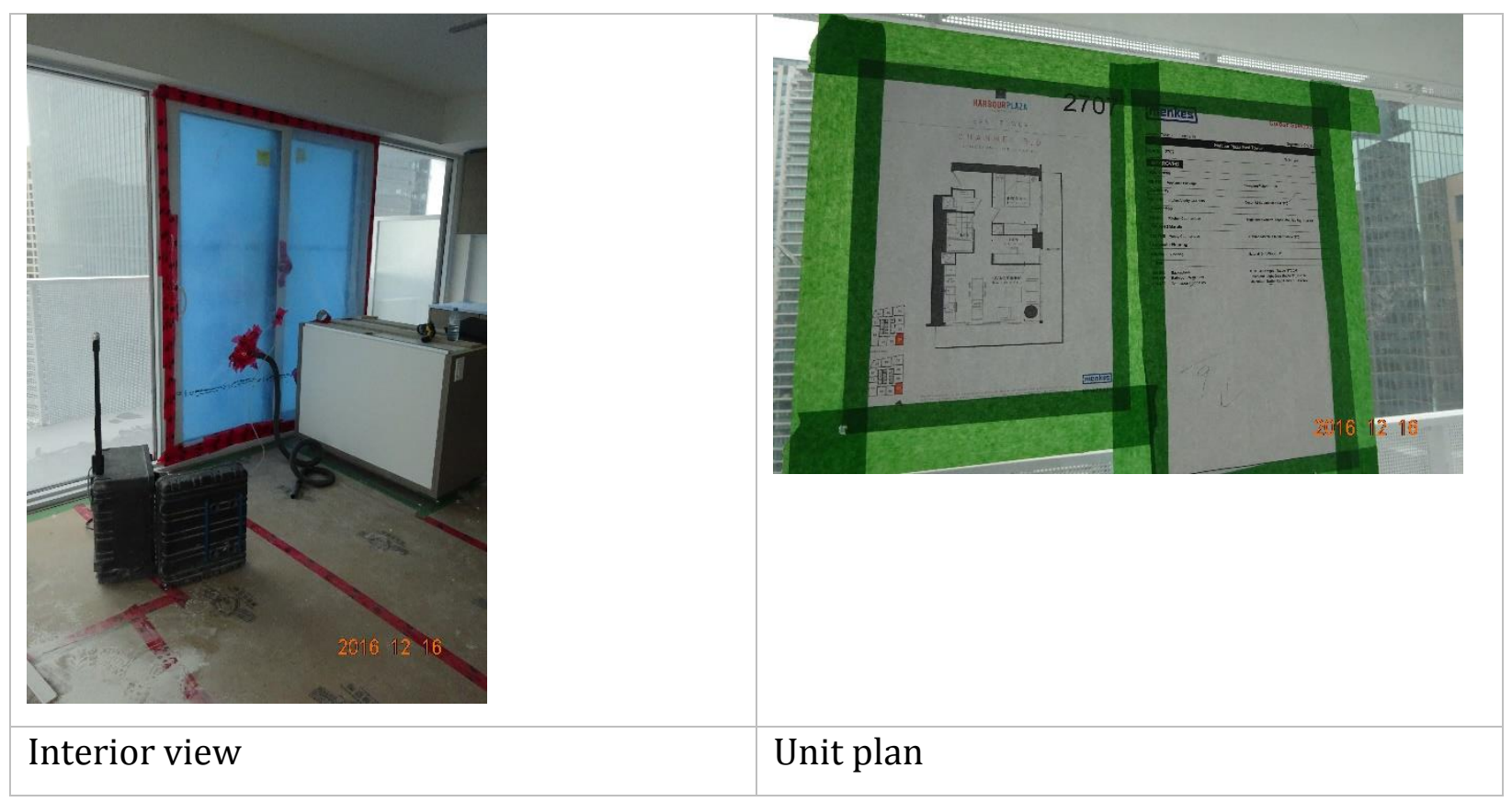

\section{Discussion}

Test sample air leakage result is above laboratory air leakage result at 75 pascal pressure difference. 


\section{Test No.28}

\begin{tabular}{|l|l|}
\hline Date & $12 / 16 / 2016$ \\
\hline Time & $02: 50 \mathrm{PM}$ \\
\hline Suite & E05 \\
\hline Level & 23 construction/27 marketing \\
\hline
\end{tabular}

\section{Sample Description}

\begin{tabular}{|l|l|}
\hline Model & Double glazed, Argon gas filled \\
\hline Door type & $6 \mathrm{~mm}$ ESR42 Temp (PURCH) / 1" Black spacer /6 mm CLR Temp (PURCH) \\
\hline Assembly Type & \\
\hline Size & $2260 \mathrm{~mm} \times 1830 \mathrm{~mm}$ \\
\hline Operation type & Sliding door \\
\hline
\end{tabular}

\section{Ambient Test Condition}

\begin{tabular}{|l|l|}
\hline Temperature inside & \\
\hline Temperature outside & $(-5) \circ \mathrm{C}-$ Feels $(-14) \circ \mathrm{C}$ \\
\hline Density of air at test site & $1.35 \mathrm{Kg} / \mathrm{m} 3$ \\
\hline Relative humidity & \\
\hline Wind speed & WSW24KPH
\end{tabular}

\section{Visual Observation}

No deficiency observed in the sample.

\section{Readings}

Air flow rate at nonstandard condition

\begin{tabular}{|l|l|l|l|l|}
\hline Pressure difference & $\mathbf{0 . 1}(25$ pa) & 0.2 (50 pa) & 0.3 (75 pa) & $0.4(100$ pa) \\
\hline Air flow Q (scfm) & 11.8 & 13.5 & 15.4 & 16.8 \\
\hline
\end{tabular}

Extraneous air flow rate at nonstandard condition

\begin{tabular}{|l|l|l|l|l|}
\hline Pressure difference & $\mathbf{0 . 1}(\mathbf{2 5}$ pa) & $0.2(50$ pa) & $0.3(75$ pa) & $0.4(100$ pa) \\
\hline Air flow EQ (scfm) & 15.2 & 21.1 & 24.4 & 25 \\
\hline
\end{tabular}

Air leakage rate

\begin{tabular}{|c|c|c|c|c|}
\hline Pressure difference & 0.1 (25 pa) & $0.2(50$ pa) & 0.3 (75 pa) & $0.4(100$ pa $)$ \\
\hline$Q d=E Q-Q(S c f m)$ & 3.4 & 7.6 & 9 & 9 \\
\hline $\begin{array}{l}\text { Temperature corrected Flow Rate } \\
\text { (Scfm) }\end{array}$ & 3.841 & 8.585 & 10.166 & 9.262 \\
\hline $\begin{array}{l}\text { Temperature corrected Flow Rate } \\
(\mathrm{L} / \mathrm{s})\end{array}$ & 1.805 & 4.035 & 4.778 & 4.353 \\
\hline Standard air leakage $\left(\mathrm{L} / \mathrm{s} / \mathrm{m}^{2}\right)$ & 0.436 & 0.976 & 1.155 & 1.053 \\
\hline Standardized air leakage $\left(\mathrm{Scfm} / \mathrm{ft}^{2}\right)$ & 0.106 & 0.236 & 0.279 & 0.255 \\
\hline
\end{tabular}




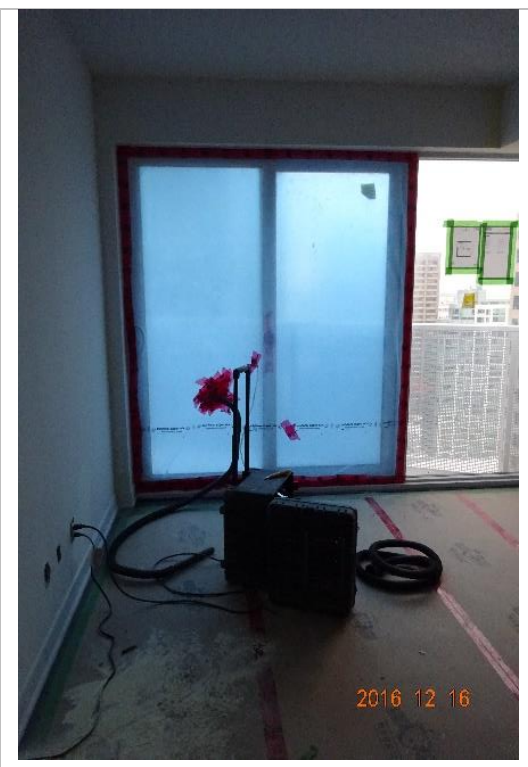

\section{Interior view}

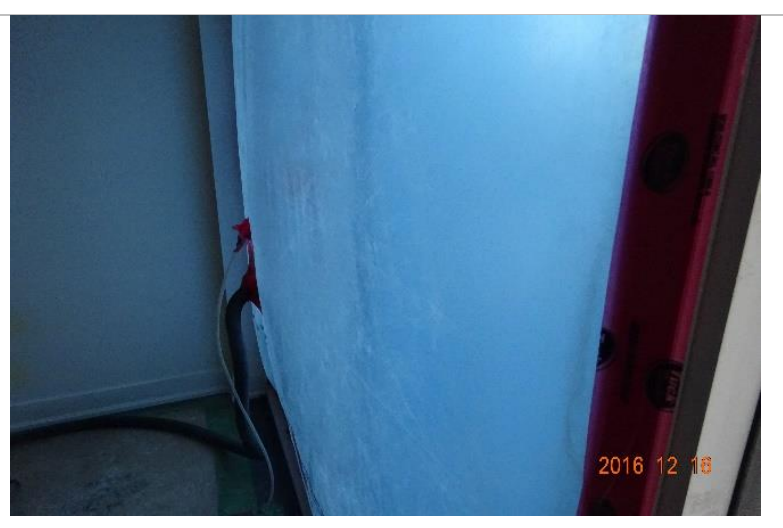

Interior view

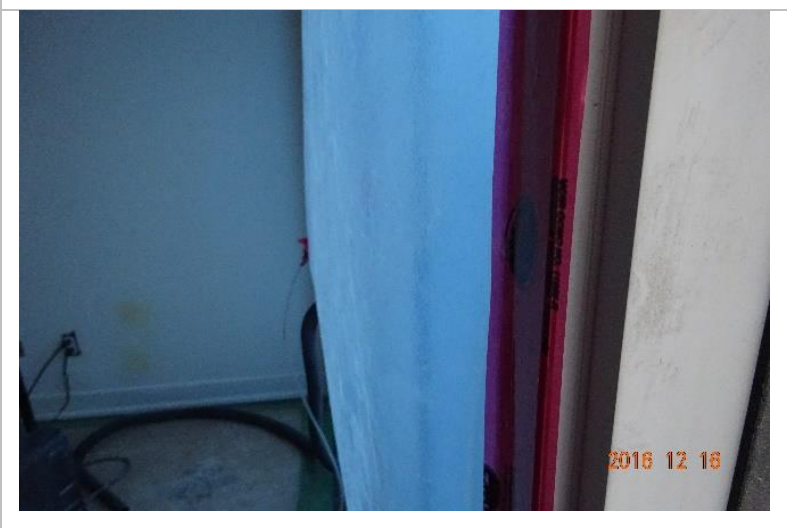

Interior view
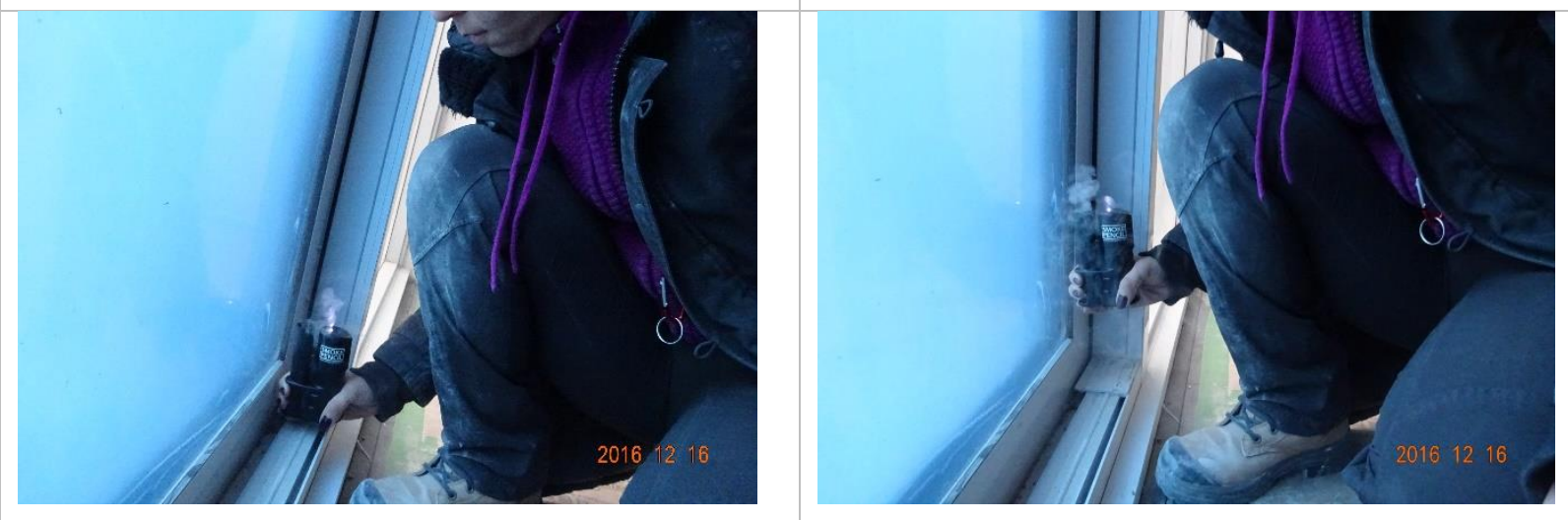

Smoke pencil test 


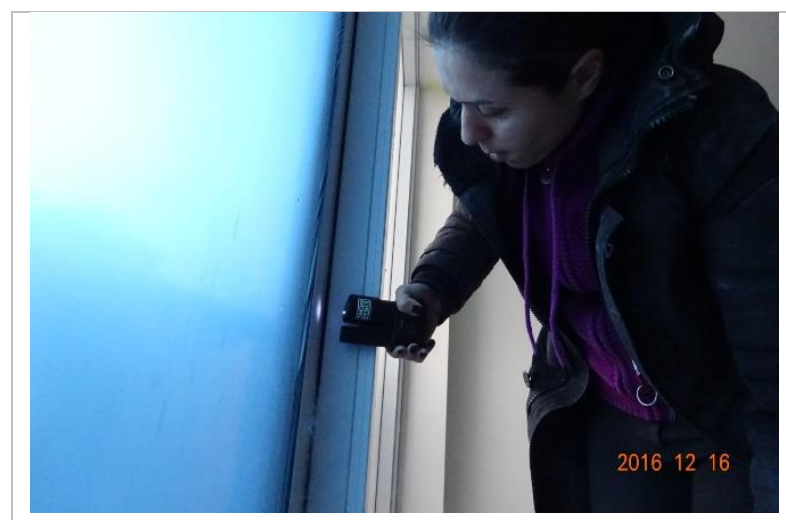

Smoke pencil test

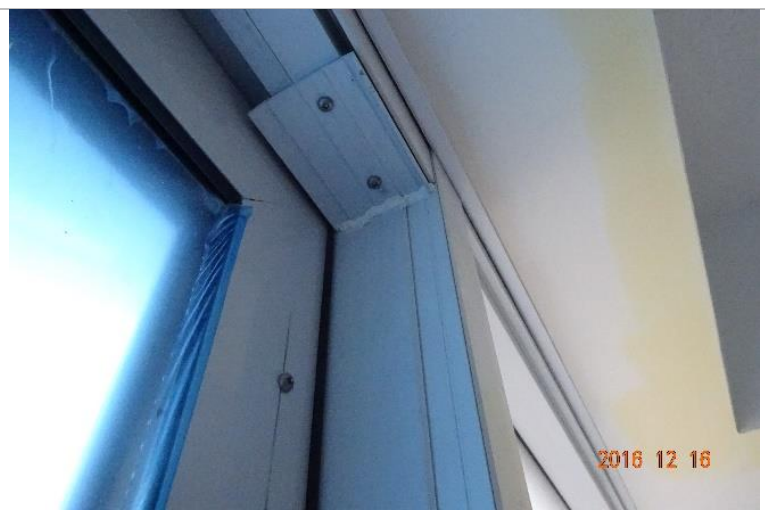

Sash joint

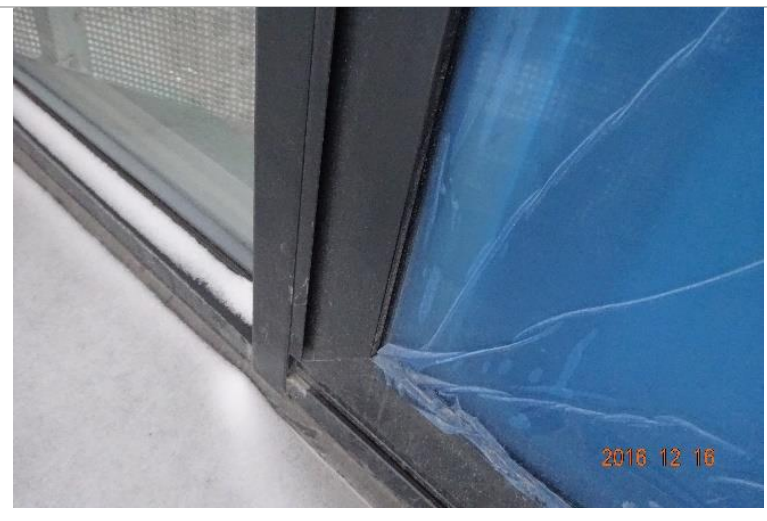

Interior view

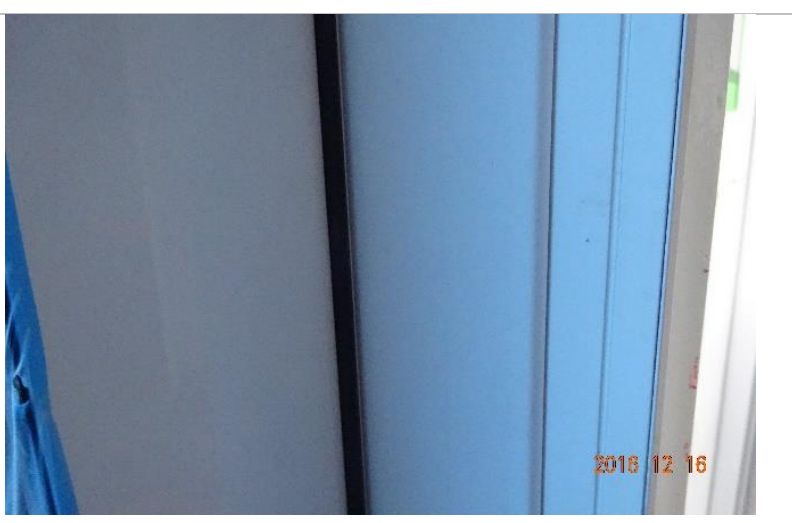

Meeting stile

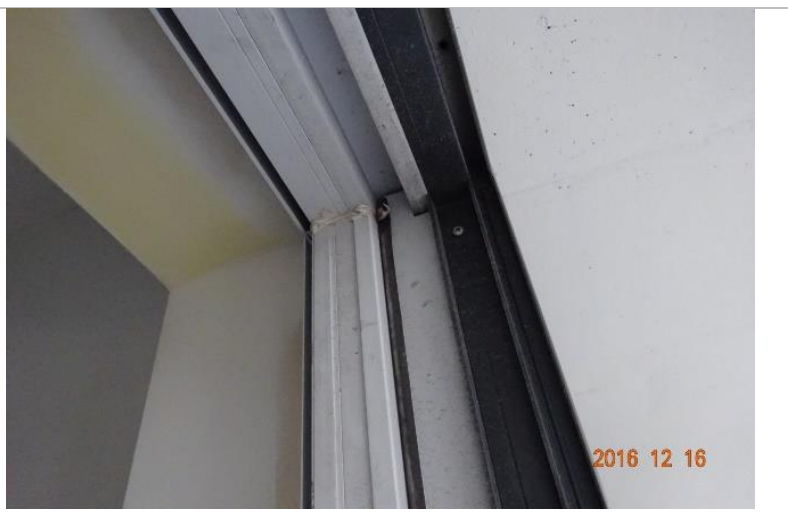

Sash joint

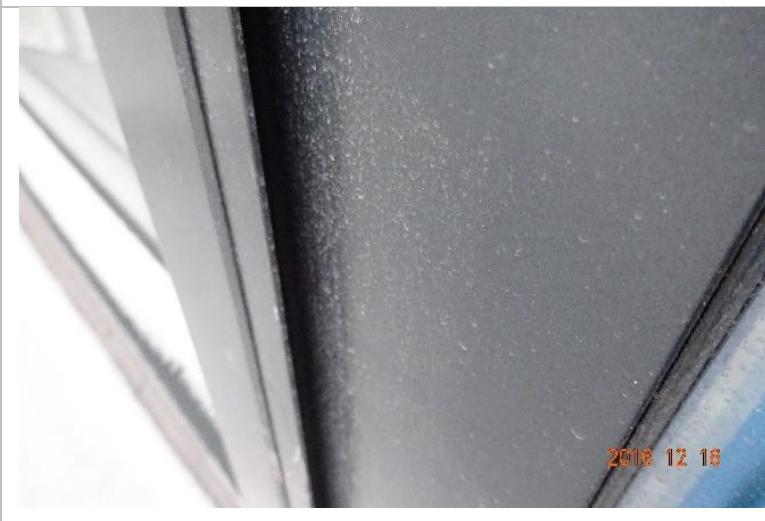

Interior view 

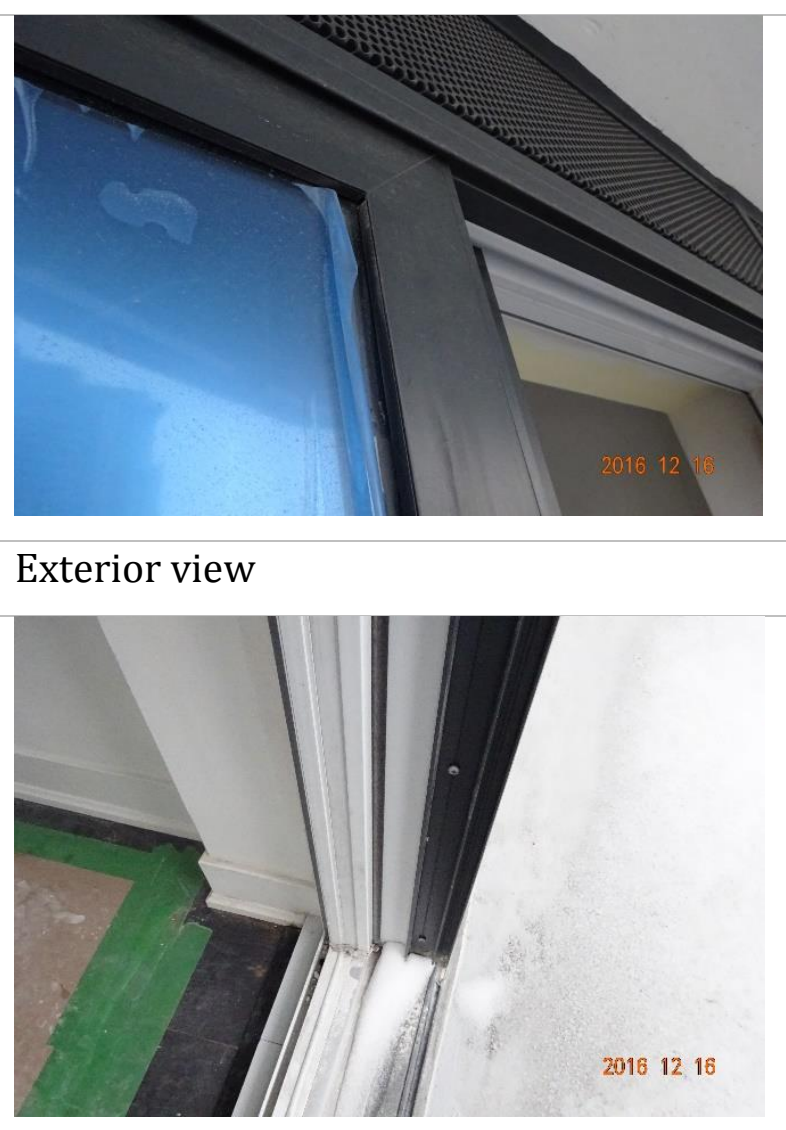

\section{Door sill}

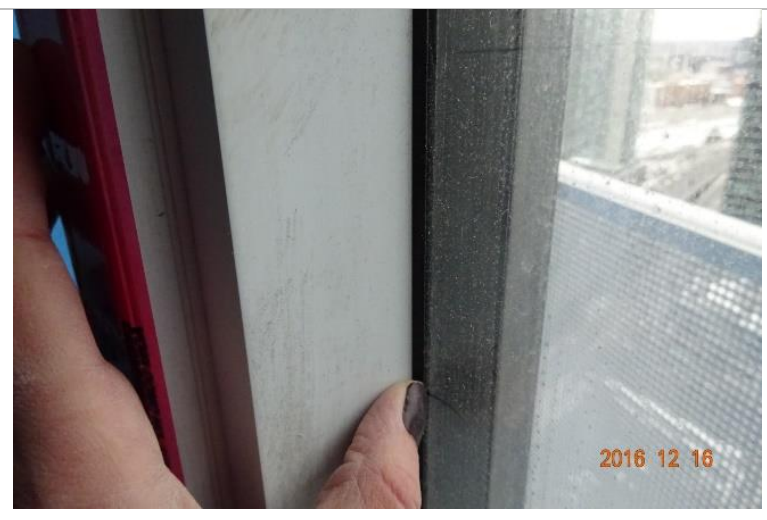

Glass to frame joints

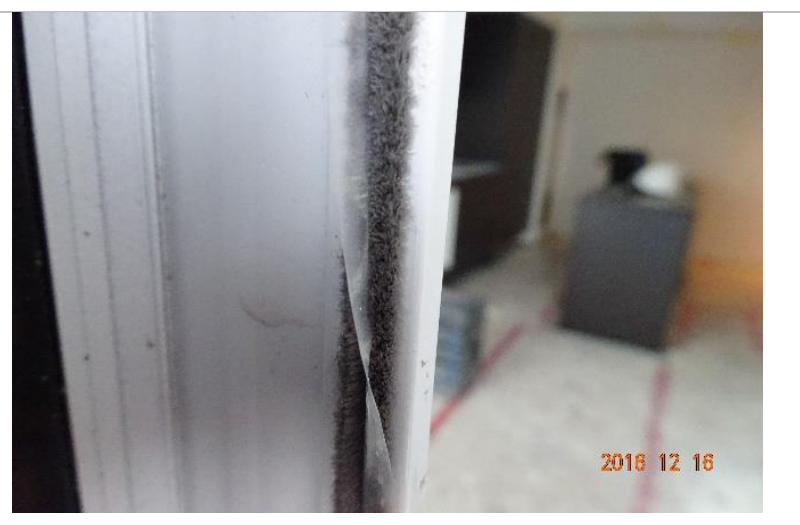

Weather stripping

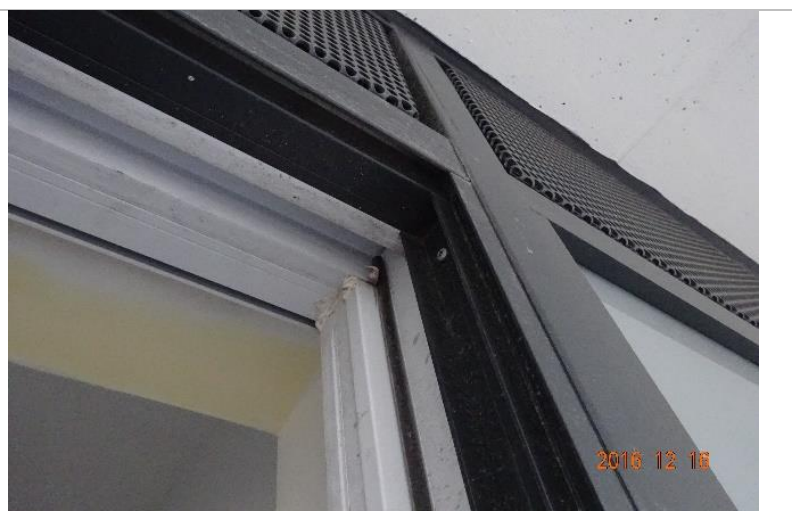

Door head

\section{Discussion}

Test sample air leakage result is above laboratory air leakage result at 75 pascal pressure difference. 


\section{Test No.29}

\begin{tabular}{|l|l|}
\hline Date & $12 / 28 / 2016$ \\
\hline Time & $10: 00 \mathrm{AM}$ \\
\hline Suite & E07 \\
\hline Level & 49 construction/54 marketing \\
\hline
\end{tabular}

\section{Sample Description}

\begin{tabular}{|l|l|}
\hline Model & Double glazed, Argon gas filled \\
\hline Door type & $6 \mathrm{~mm}$ ESR42 Temp (PURCH) / 1" Black spacer /6 mm CLR Temp (PURCH) \\
\hline Assembly Type & \\
\hline Size & $2260 \mathrm{~mm} \times 1830 \mathrm{~mm}$ \\
\hline Operation type & Sliding door \\
\hline
\end{tabular}

\section{Ambient Test Condition}

\begin{tabular}{|l|l|}
\hline Temperature inside & Very Hot \\
\hline Temperature outside & $(0) \circ \mathrm{C}-$ Feels $(-8)$ \\
\hline Density of air at test site & $1.33 \mathrm{Kg} / \mathrm{m} 3$ \\
\hline Relative humidity & \\
\hline Wind speed & W25KPH
\end{tabular}

\section{Visual Observation}

No deficiency observed in the sample.

\section{Readings}

Air flow rate at nonstandard condition

\begin{tabular}{|l|l|l|l|l|}
\hline Pressure difference & $\mathbf{0 . 1}(\mathbf{2 5}$ pa) & $\mathbf{0 . 2}(\mathbf{5 0}$ pa) & $\mathbf{0 . 3}(\mathbf{7 5}$ pa) & $\mathbf{0 . 4}(100 \mathrm{pa})$ \\
\hline Air flow Q (scfm) & 3.8 & 7.9 & 9.8 & 12.1
\end{tabular}

Extraneous air flow rate at nonstandard condition

\begin{tabular}{|l|l|l|l|l|}
\hline Pressure difference & $0.1(25$ pa) & $0.2(50$ pa) & 0.3 (75 pa) & $0.4(100$ pa) \\
\hline Air flow EQ (scfm) & 3.8 & 7.2 & 10.5 & 13.1 \\
\hline
\end{tabular}

Air leakage rate

\begin{tabular}{|c|c|c|c|c|}
\hline Pressure difference & 0.1 (25 pa) & 0.2 (50 pa) & 0.3 (75 pa) & $0.4(100 \mathrm{pa})$ \\
\hline$Q d=E Q-Q(S c f m)$ & 0 & 0.6 & 0.7 & 1.0 \\
\hline $\begin{array}{l}\text { Temperature corrected Flow Rate } \\
(\mathrm{Scfm})\end{array}$ & 0.000 & -0.773 & 0.773 & 1.105 \\
\hline $\begin{array}{l}\text { Temperature corrected Flow Rate } \\
(\mathrm{L} / \mathrm{s})\end{array}$ & 0.000 & -0.363 & 0.363 & 0.519 \\
\hline Standard air leakage $\left(\mathrm{L} / \mathrm{s} / \mathrm{m}^{2}\right)$ & 0.000 & -0.088 & 0.088 & 0.126 \\
\hline Standardized air leakage $\left(\mathrm{Scfm} / \mathrm{ft}^{2}\right)$ & 0.000 & -0.021 & 0.021 & 0.030 \\
\hline
\end{tabular}




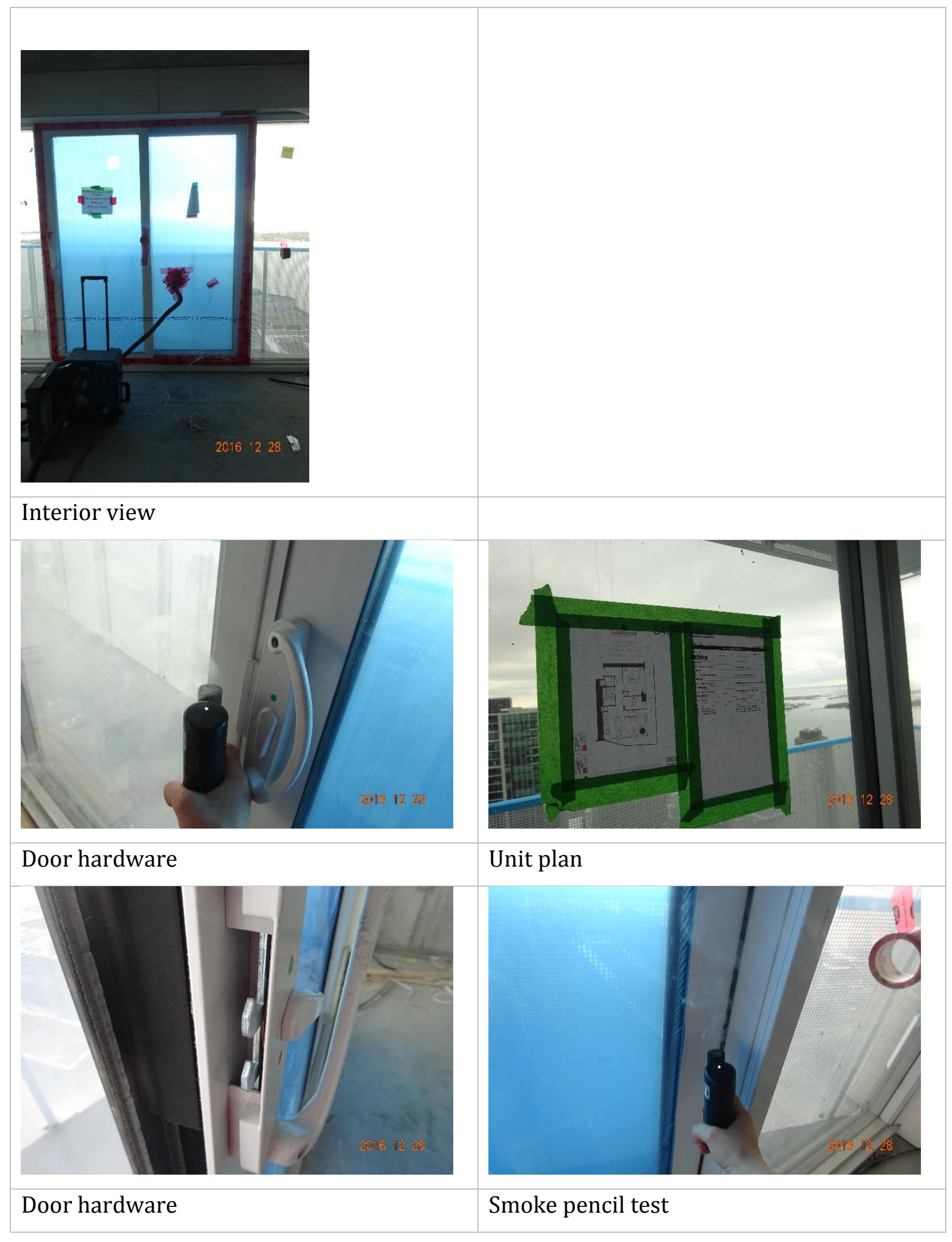




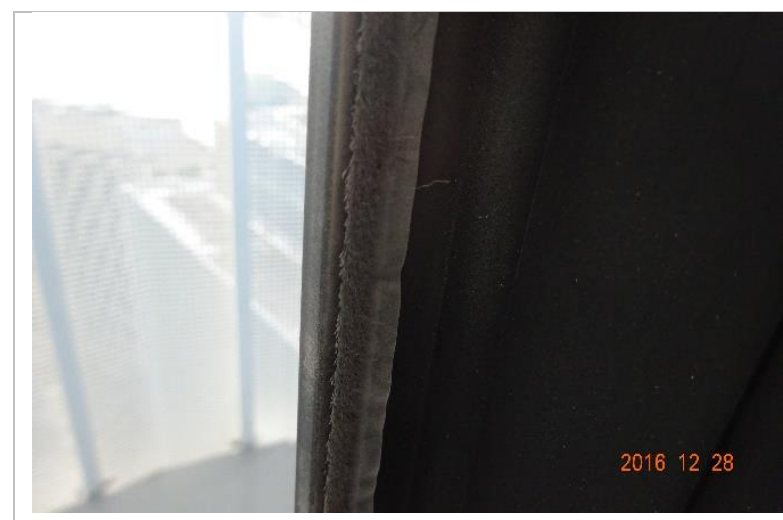

Weather stripping

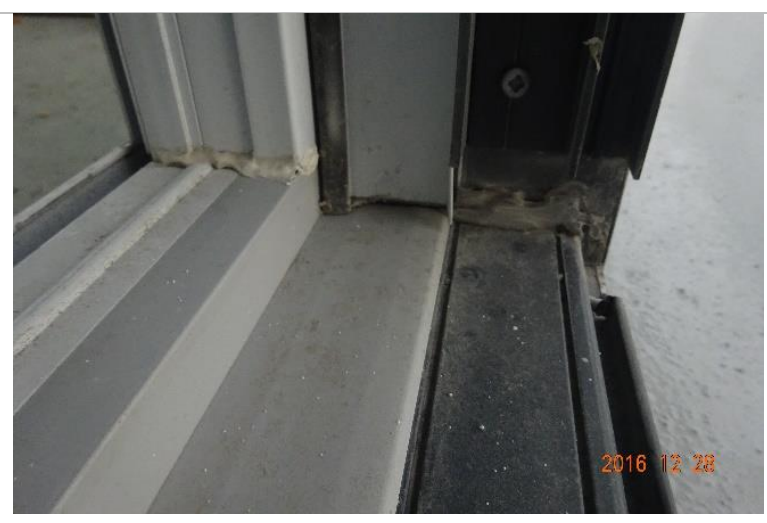

Door sill

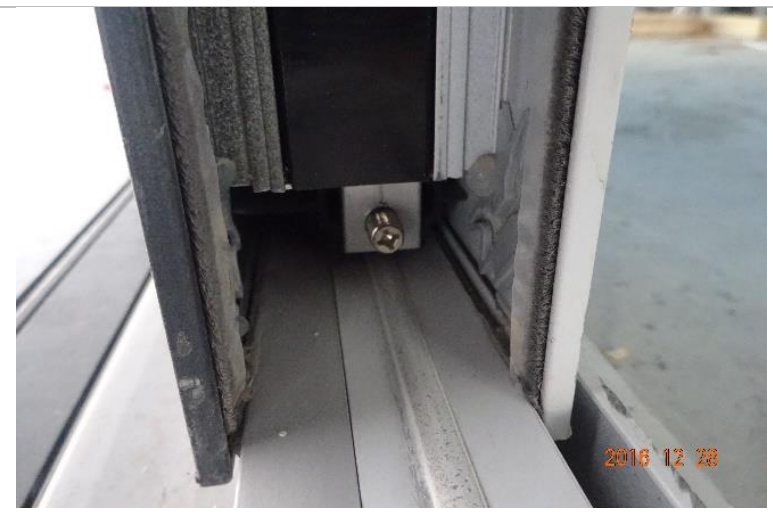

Dust plug

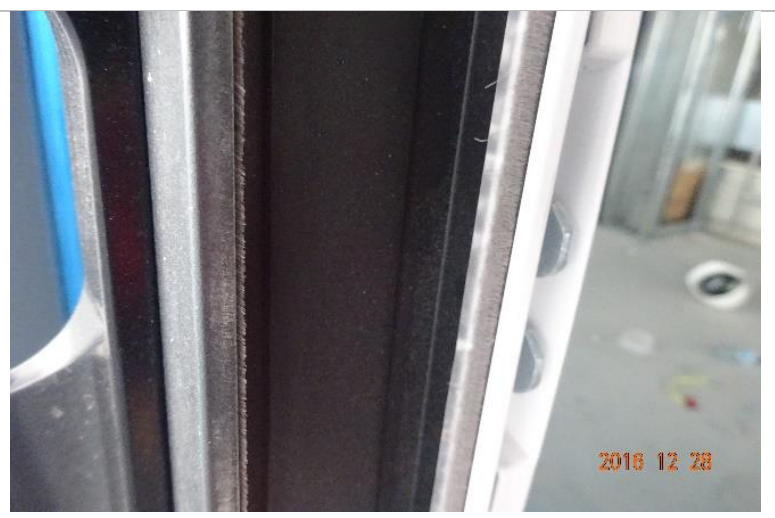

Weather stripping

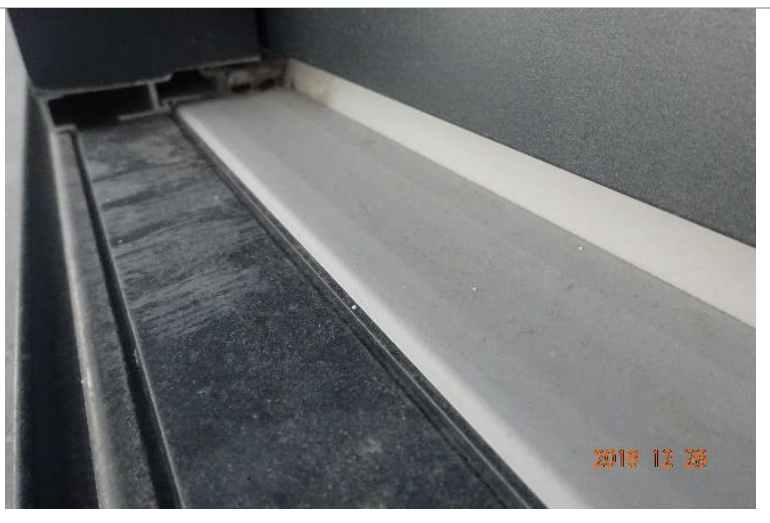

Door sill

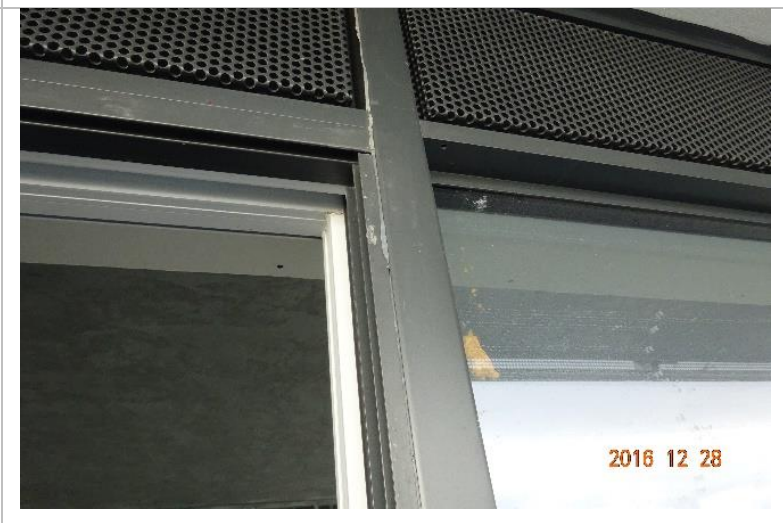

Exterior view 


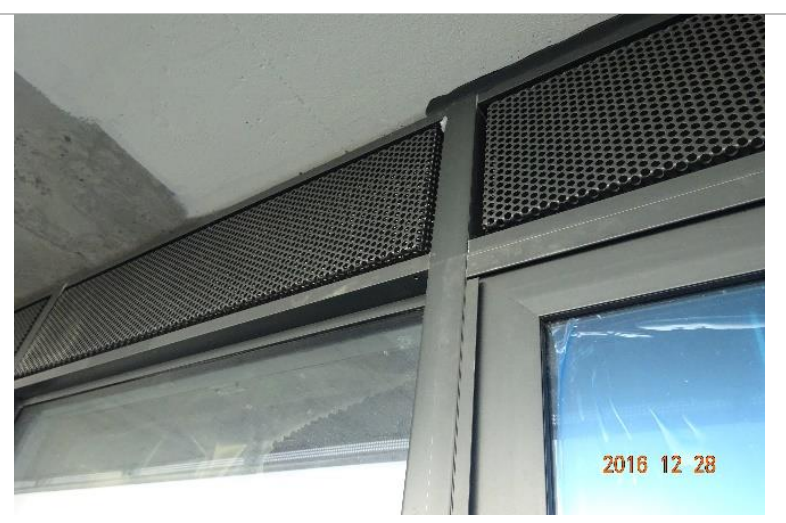

Door frame to concrete soffit

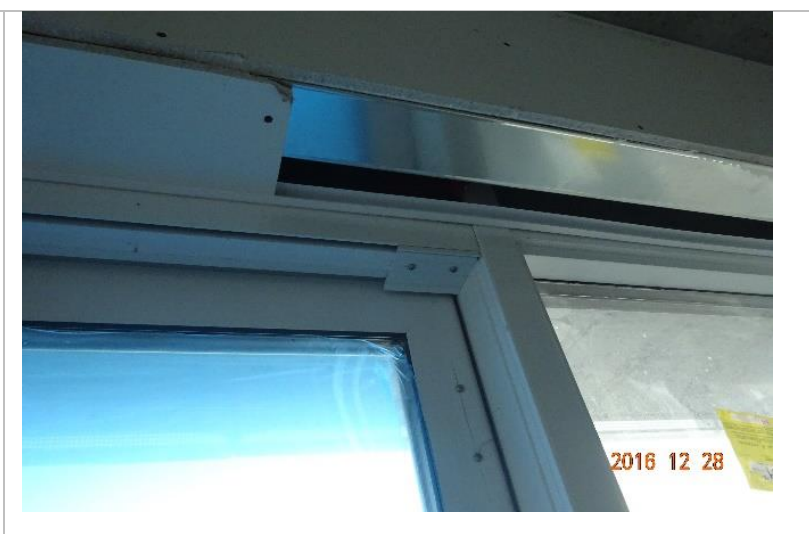

Bulk head

\section{Discussion}

Interior view Test sample air leakage result is above laboratory air leakage result at 75 pascal pressure difference. This test is excluded from test results analysis due to out-performance. 


\section{Test No.30}

\begin{tabular}{|l|l|}
\hline Date & $12 / 28 / 2016$ \\
\hline Time & $12: 10 \mathrm{PM}$ \\
\hline Suite & E04 \\
\hline Level & 49 construction/54 marketing \\
\hline
\end{tabular}

\section{Sample Descriptions}

\begin{tabular}{|l|l|}
\hline Model & Double glazed, Argon gas filled \\
\hline Door type & $6 \mathrm{~mm}$ ESR42 Temp (PURCH) / 1" Black spacer /6 mm CLR Temp (PURCH) \\
\hline Assembly Type & \\
\hline Size & $2260 \mathrm{~mm} \times 1830 \mathrm{~mm}$ \\
\hline Operation type & Sliding door \\
\hline
\end{tabular}

\section{Ambient Test Condition}

\begin{tabular}{|l|l|}
\hline Temperature inside & Very Hot \\
\hline Temperature outside & $(0) \circ \mathrm{C}-$ Feels $(-8)$ \\
\hline Density of air at test site & $1.33 \mathrm{Kg} / \mathrm{m} 3$ \\
\hline Relative humidity & \\
\hline Wind speed & W25KPH
\end{tabular}

\section{Visual Observation}

No deficiency observed in the sample.

\section{Readings}

Air flow rate at nonstandard condition

\begin{tabular}{|l|l|l|l|l|}
\hline Pressure difference & $\mathbf{0 . 1}(\mathbf{2 5}$ pa) & $\mathbf{0 . 2}(\mathbf{5 0}$ pa) & $\mathbf{0 . 3}(\mathbf{7 5}$ pa) & $\mathbf{0 . 4}(\mathbf{1 0 0}$ pa) \\
\hline Air flow q (scfm) & 7.1 & 12.2 & 17.2 & 19.7
\end{tabular}

Extraneous air flow rate at nonstandard condition

\begin{tabular}{|l|l|l|l|l|}
\hline Pressure difference & $0.1(25$ pa) & $0.2(50$ pa) & $0.3(75$ pa) & $0.4(100$ pa) \\
\hline Air flow eq (scfm) & 4 & 12.7 & 15.2 & 19.8 \\
\hline
\end{tabular}

Air leakage rate

\begin{tabular}{|c|c|c|c|c|}
\hline Pressure difference & 0.1 (25 pa) & 0.2 (50 pa) & 0.3 (75 pa) & 0.4 (100 pa) \\
\hline Qd= EQ - Q (SCFM) & 0.7 & 5.3 & 4.9 & 6.7 \\
\hline Temperature corrected qdst (scfm) & 0.543 & 4.668 & 3.582 & 6.730 \\
\hline Temperature corrected qdst (1/s) & 0.255 & 2.194 & 1.684 & 3.163 \\
\hline Standard air leakage $\left(1 / \mathrm{s} / \mathrm{m}^{2}\right)$ & 0.058 & 0.497 & 0.382 & 0.717 \\
\hline Standardized air leakage $\left(\mathrm{scfm} / \mathrm{ft}^{2}\right)$ & 0.013 & 0.113 & 0.087 & 0.163 \\
\hline
\end{tabular}




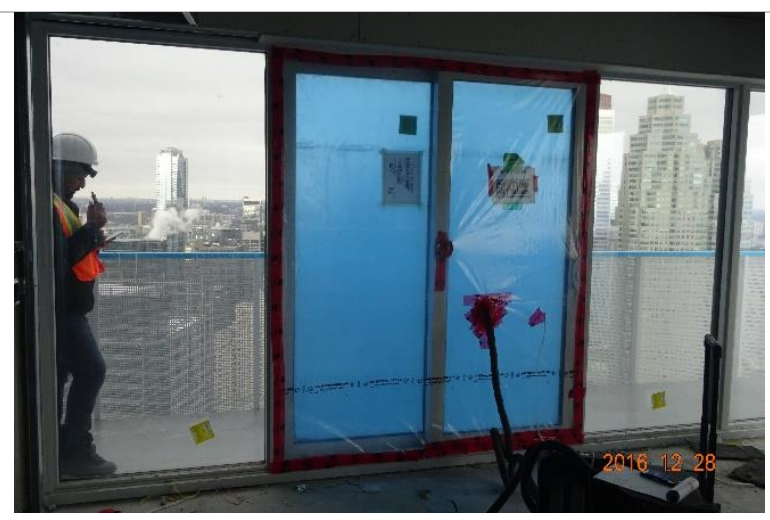

Interior view

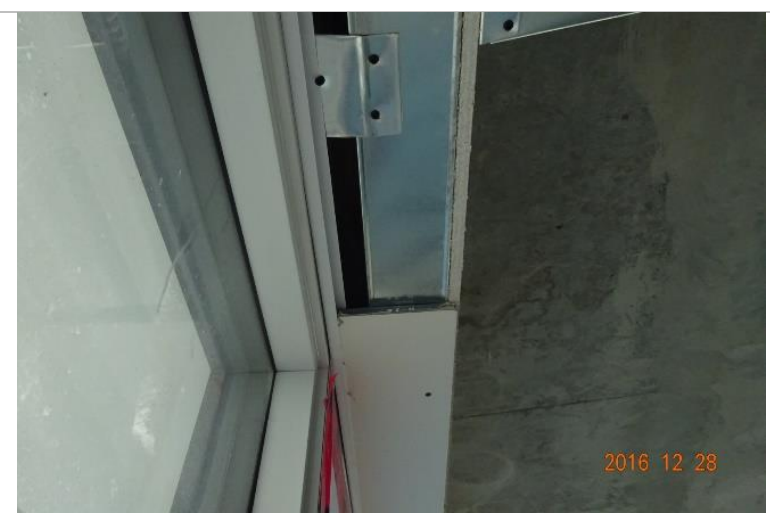

Door head

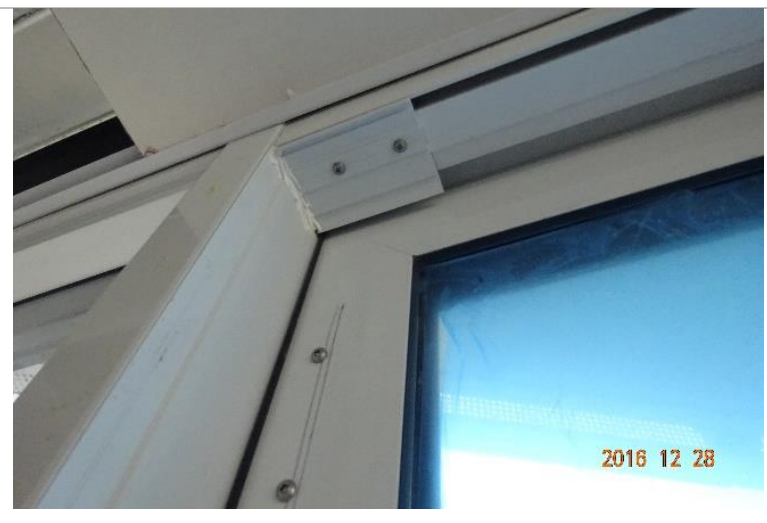

Frame joint

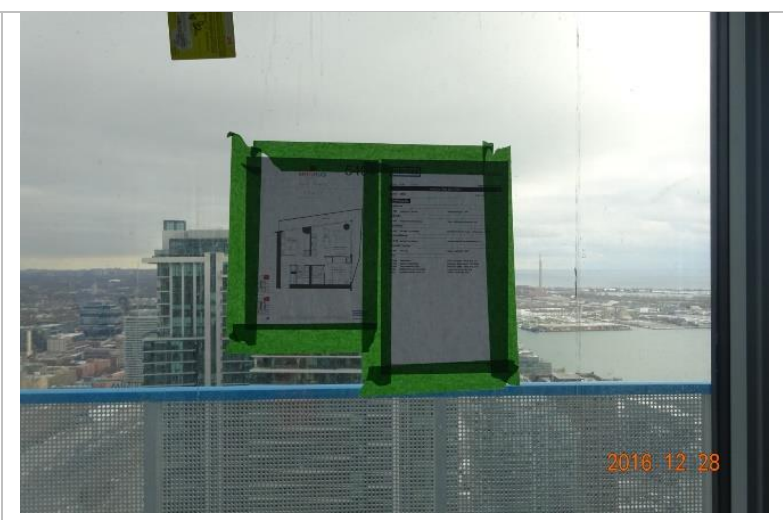

Unit plan

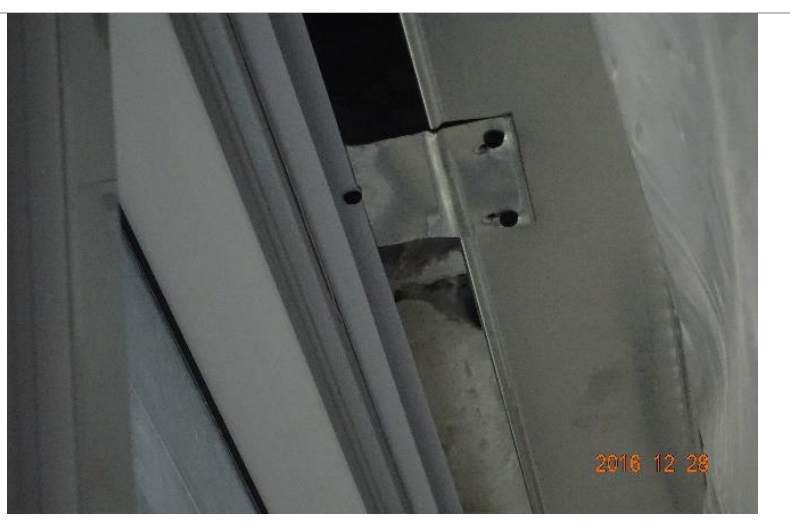

Door head

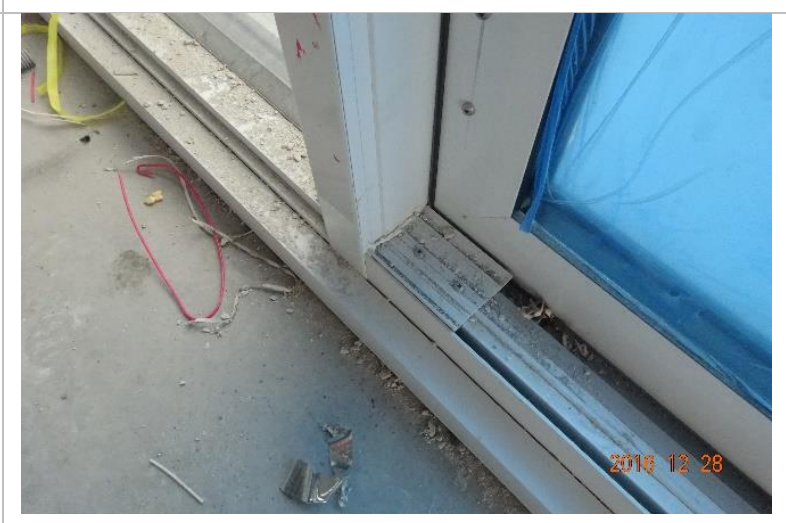

Door sill sash joint 


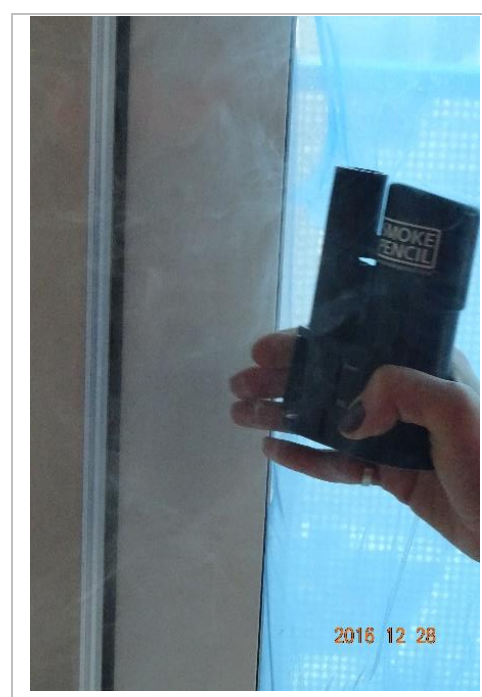

Smoke pencil test

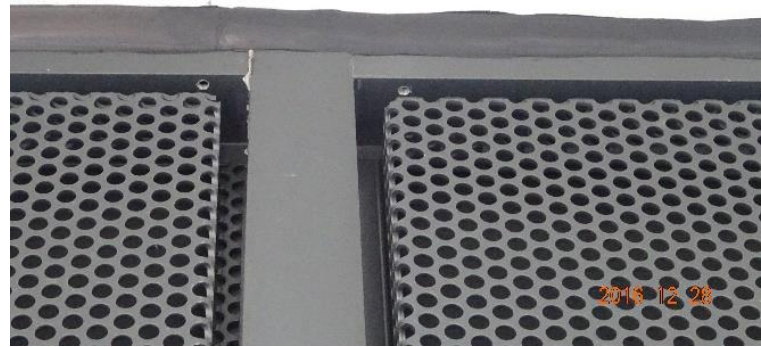

Door frame to soffit joit

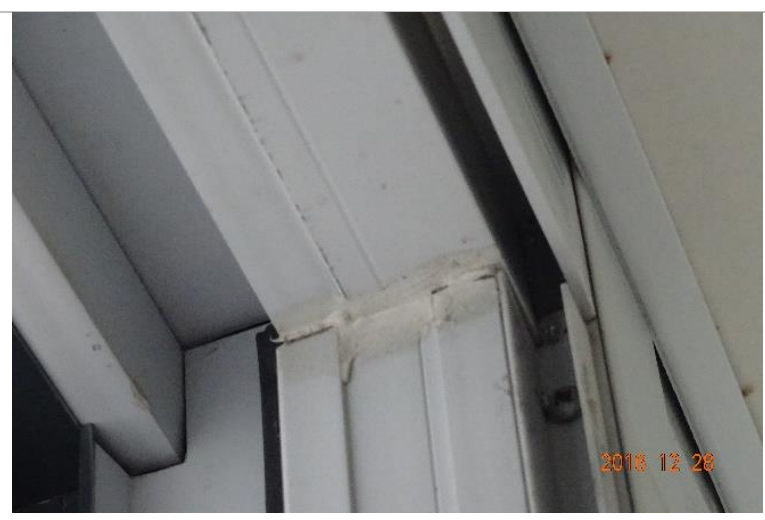

Frame joint

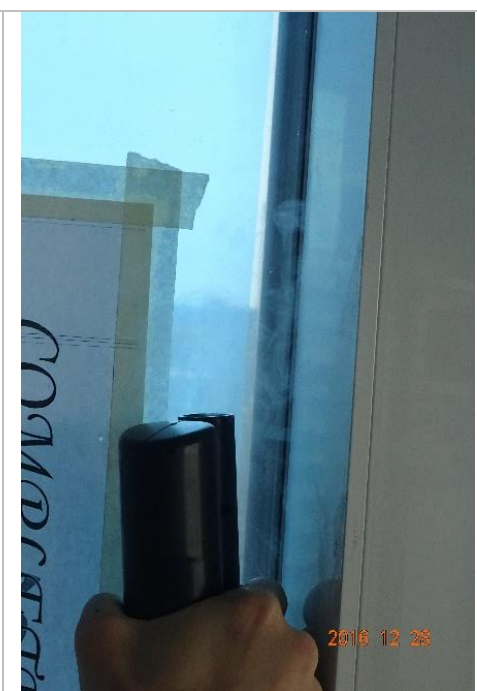

Smoke pencil test

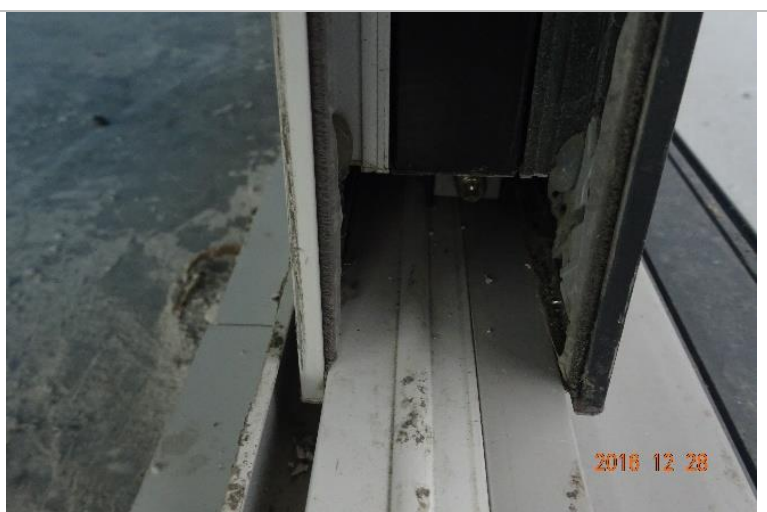

Door sill

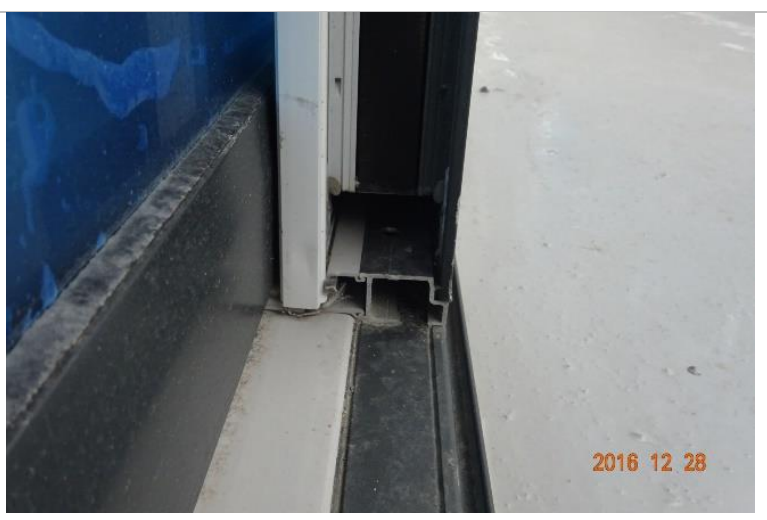

Dust plug

\section{Discussion}

Interior view Test sample air leakage result is below laboratory air leakage result at 75 pascal pressure difference. This test is excluded from test results analysis due to out-performance. 


\section{Test No.31}

\begin{tabular}{|l|l|}
\hline Date & $12 / 28 / 2016$ \\
\hline Time & $02: 00 \mathrm{PM}$ \\
\hline Suite & E04 \\
\hline Level & 48 construction/53 marketing \\
\hline
\end{tabular}

\section{Sample Description}

\begin{tabular}{|l|l|}
\hline Model & Double glazed, Argon gas filled \\
\hline Door type & $6 \mathrm{~mm}$ ESR42 Temp (PURCH) / 1" Black spacer /6 mm CLR Temp (PURCH) \\
\hline Assembly Type & \\
\hline Size & $2260 \mathrm{~mm} \times 1830 \mathrm{~mm}$ \\
\hline Operation type & Sliding door \\
\hline
\end{tabular}

\section{Ambient Test Condition}

\begin{tabular}{|l|l|}
\hline Temperature inside & Very Hot \\
\hline Temperature outside & $(0) \circ \mathrm{C}-$ Feels $(-8)$ \\
\hline Density of air at test site & $1.33 \mathrm{Kg} / \mathrm{m} 3$ \\
\hline Relative humidity & \\
\hline Wind speed & W25KPH
\end{tabular}

\section{Visual Observation}

No deficiency observed in the sample.

\section{Readings}

Air flow rate at nonstandard condition

\begin{tabular}{|l|l|l|l|l|}
\hline Pressure difference & 0.1 (25 pa) & 0.2 (50 pa) & 0.3 (75 pa) & $0.4(100$ pa) \\
\hline Air flow Q (scfm) & & 7.2 & 7.5 & 8.7 \\
\hline
\end{tabular}

Extraneous air flow rate at nonstandard condition

\begin{tabular}{|l|l|l|l|l|}
\hline Pressure difference & $\mathbf{0 . 1}(\mathbf{2 5}$ pa) & $0.2(50$ pa) & $0.3(75$ pa) & $0.4(100$ pa) \\
\hline Air flow EQ (scfm) & 8.1 & 11.8 & 14.7 & 15.9 \\
\hline
\end{tabular}

Air leakage rate

\begin{tabular}{|c|c|c|c|c|}
\hline Pressure difference & 0.1 (25 pa) & 0.2 (50 pa) & $0.3(75 \mathrm{pa})$ & $0.4(100 \mathrm{pa})$ \\
\hline$Q d=E Q-Q(S c f m)$ & & 4.6 & 7.2 & 7.2 \\
\hline $\begin{array}{l}\text { Temperature corrected Flow Rate } \\
\text { (Scfm) }\end{array}$ & & 5.081 & 7.953 & 7.953 \\
\hline $\begin{array}{l}\text { Temperature corrected Flow Rate } \\
(\mathrm{L} / \mathrm{s})\end{array}$ & & 2.388 & 3.738 & 3.738 \\
\hline Standard air leakage $\left(\mathrm{L} / \mathrm{s} / \mathrm{m}^{2}\right)$ & & 0.577 & 0.904 & 0.904 \\
\hline Standardized air leakage $\left(\mathrm{Scfm} / \mathrm{ft}^{2}\right)$ & & 0.140 & 0.219 & 0.219 \\
\hline
\end{tabular}




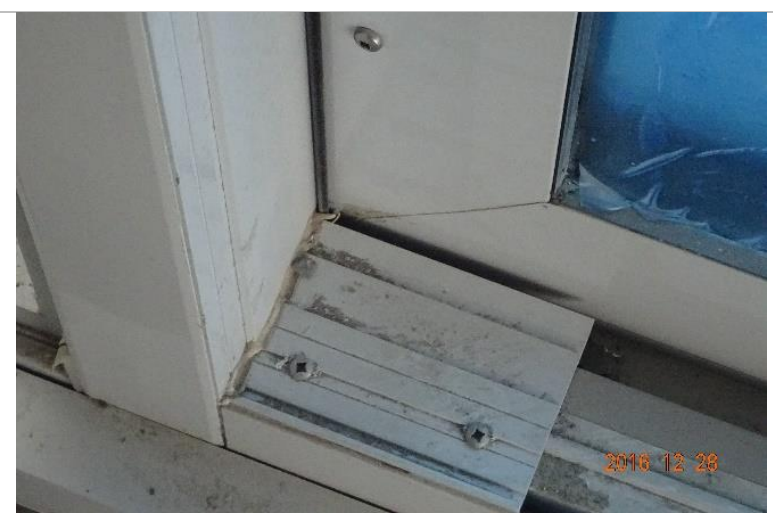

Door frame joint

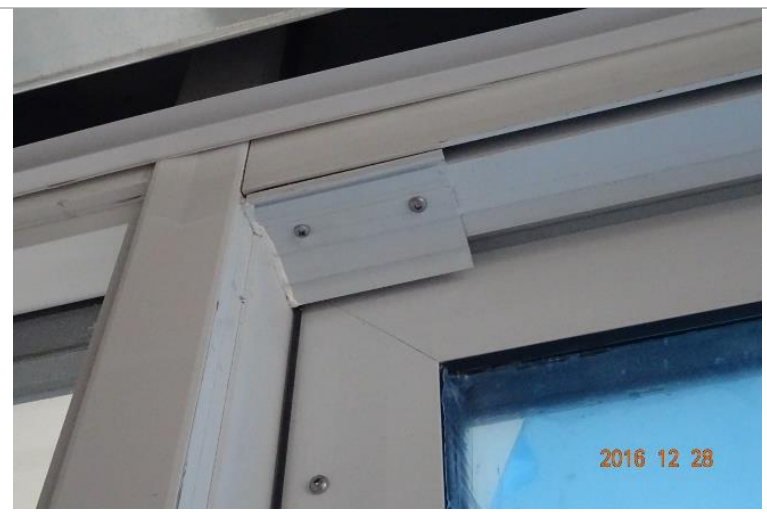

Frame joint

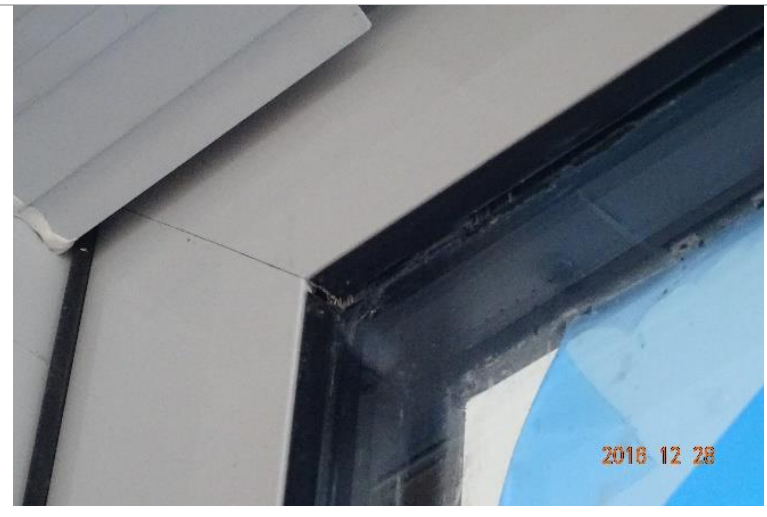

Frame joint

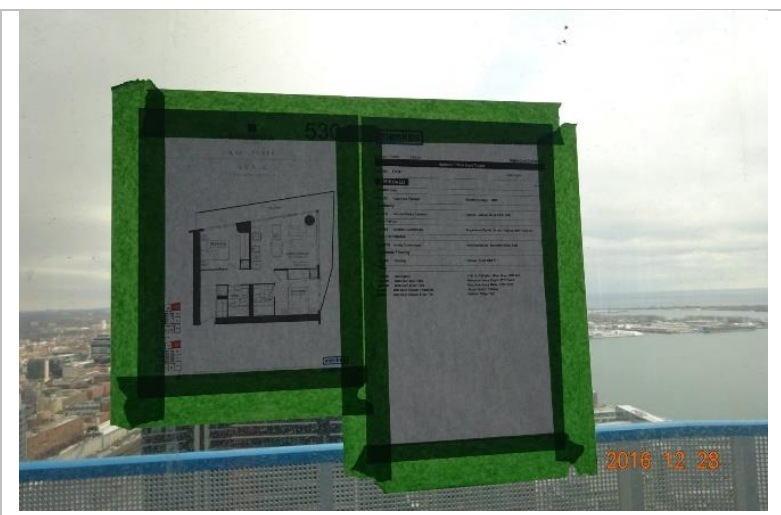

Unit plan

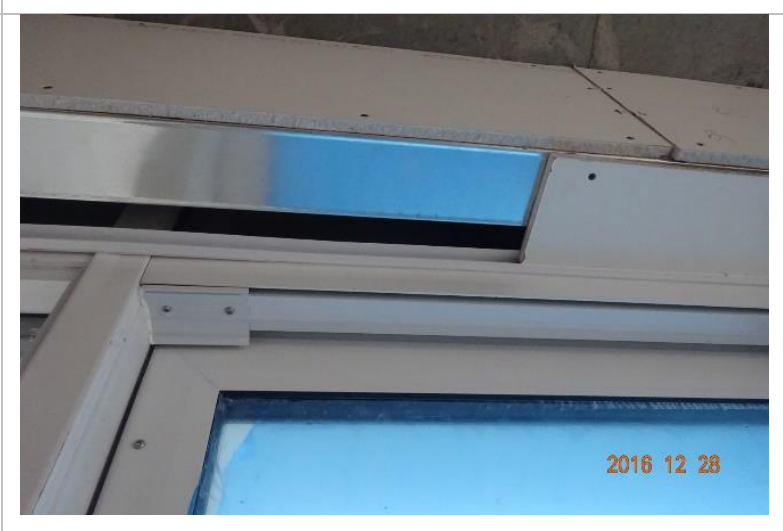

Door head

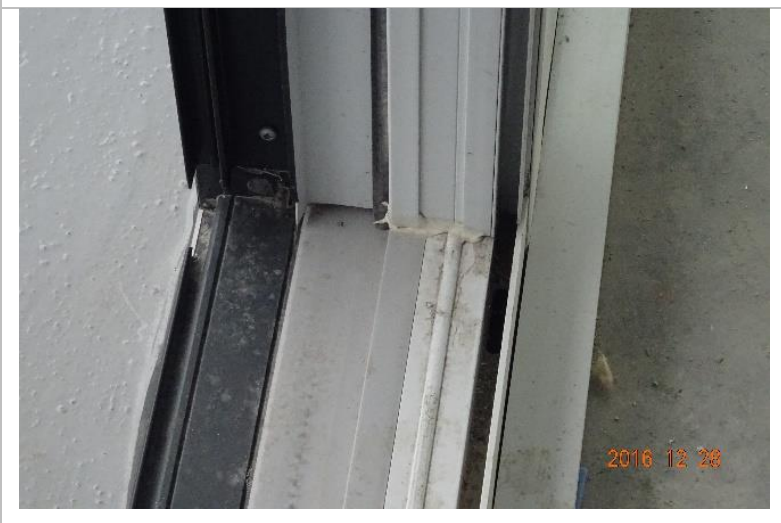

Door sill 

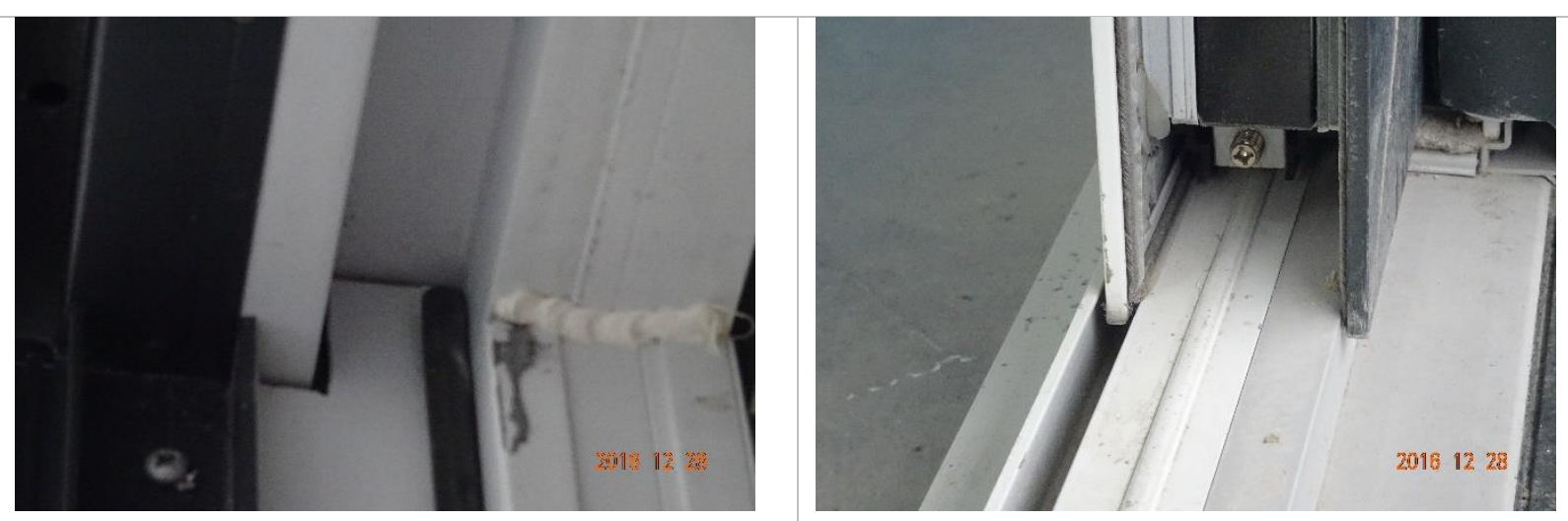

Frame joint selant

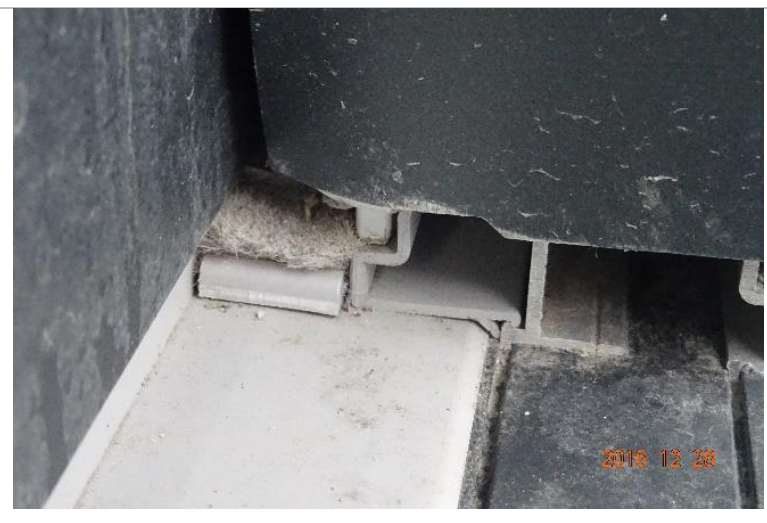

Dust plug

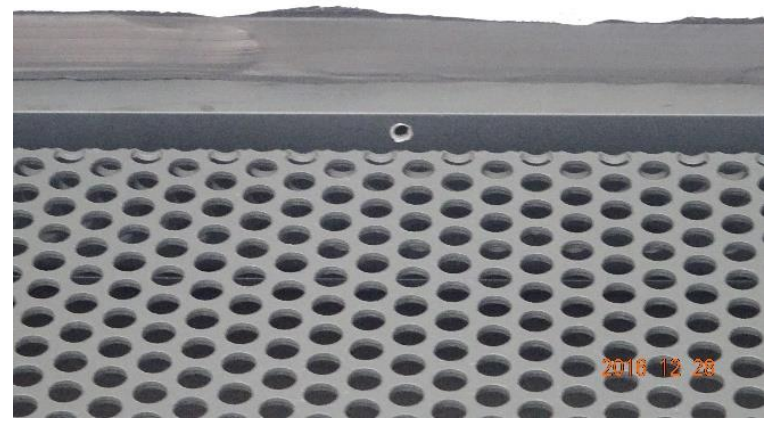

Exterior door frame to soffit

\section{Door track}

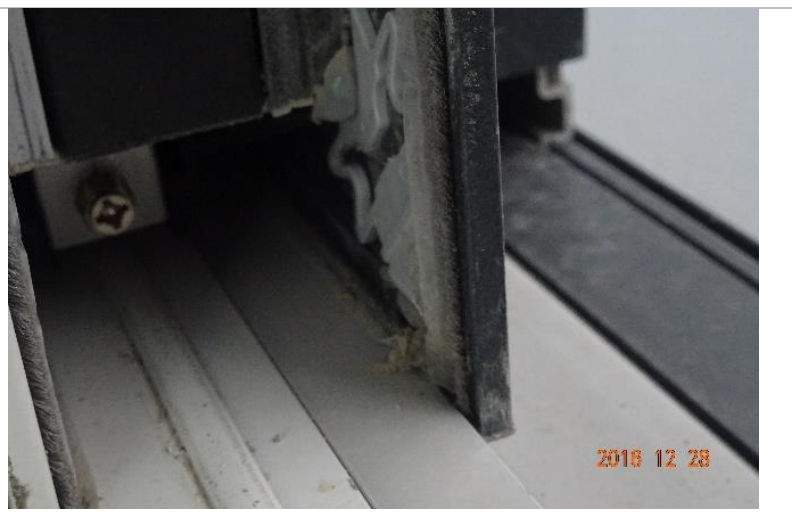

Dust plug and weather stripping

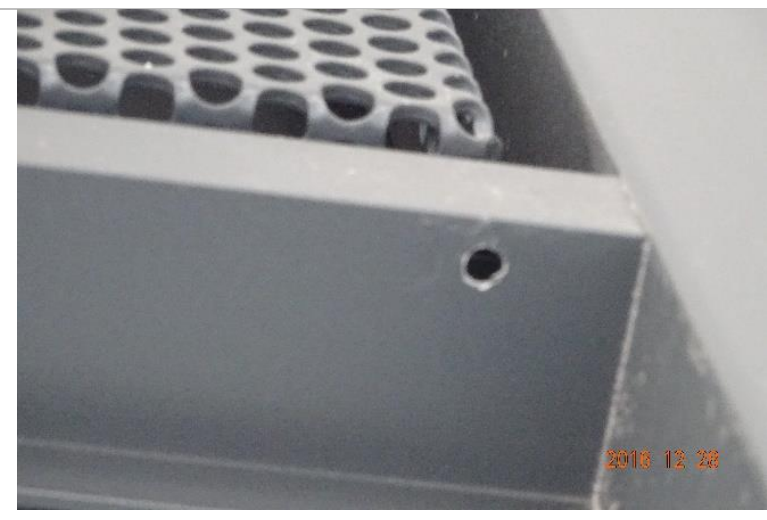

Abandoned screw holes

\section{Discussion}

Interior view Test sample air leakage result is above laboratory air leakage result at 75 pascal 


\section{Test No.32}

\begin{tabular}{|l|l|}
\hline Date & $12 / 28 / 2016$ \\
\hline Time & $03: 30 \mathrm{PM}$ \\
\hline Suite & E04 \\
\hline Level & 54 construction/59 marketing \\
\hline
\end{tabular}

\section{Sample Description}

\begin{tabular}{|l|l|}
\hline Model & Double glazed, Argon gas filled \\
\hline Door type & $6 \mathrm{~mm}$ ESR42 Temp (PURCH) / 1" Black spacer /6 mm CLR Temp (PURCH) \\
\hline Assembly Type & \\
\hline Size & $2260 \mathrm{~mm} \times 1830 \mathrm{~mm}$ \\
\hline Operation type & Sliding door \\
\hline
\end{tabular}

\section{Ambient Test Condition}

\begin{tabular}{|l|l|}
\hline Temperature inside & $-1{ }^{\circ} \mathrm{C}$ \\
\hline Temperature outside & $(-1)^{\circ} \mathrm{C}-$ Feels $(-8) \circ \mathrm{C}$ \\
\hline Density of air at test site & $1.33 \mathrm{Kg} / \mathrm{m} 3$ \\
\hline Relative humidity & \\
\hline Wind speed & W25KPH \\
\hline
\end{tabular}

\section{Visual Observation}

No deficiency observed in the sample.

\section{Readings}

Air flow rate at nonstandard condition

\begin{tabular}{|l|l|l|l|l|}
\hline Pressure difference & $\mathbf{0 . 1}(\mathbf{2 5}$ pa) & $\mathbf{0 . 2}(\mathbf{5 0}$ pa) & $\mathbf{0 . 3}$ (75 pa) & $\mathbf{0 . 4}(\mathbf{1 0 0}$ pa) \\
\hline Air flow Q (scfm) & 8.2 & 12.3 & 14.8 & 16.2 \\
\hline
\end{tabular}

Extraneous air flow rate at nonstandard condition

\begin{tabular}{|l|l|l|l|l|}
\hline Pressure difference & $0.1(25$ pa) & $0.2(50$ pa) & $0.3(75$ pa) & $0.4(100$ pa) \\
\hline Air flow EQ (scfm) & 11.8 & 16.8 & 19.8 & 23.9 \\
\hline
\end{tabular}

Air leakage rate

\begin{tabular}{|c|c|c|c|c|}
\hline Pressure difference & 0.1 (25 pa) & 0.2 (50 pa) & 0.3 (75 pa) & $0.4(100$ pa $)$ \\
\hline$Q d=E Q-Q(S c f m)$ & 0.7 & 5.3 & 4.9 & 6.7 \\
\hline $\begin{array}{l}\text { Temperature corrected Flow Rate } \\
\text { (Scfm) }\end{array}$ & 3.977 & 4.971 & 5.523 & 8.506 \\
\hline $\begin{array}{l}\text { Temperature corrected Flow Rate } \\
(\mathrm{L} / \mathrm{s})\end{array}$ & 1.869 & 2.336 & 2.596 & 3.998 \\
\hline Standard air leakage $\left(\mathrm{L} / \mathrm{s} / \mathrm{m}^{2}\right)$ & 0.452 & 0.565 & 0.628 & 0.967 \\
\hline Standardized air leakage $\left(\mathrm{Scfm} / \mathrm{ft}^{2}\right)$ & 0.109 & 0.137 & 0.152 & 0.234 \\
\hline
\end{tabular}



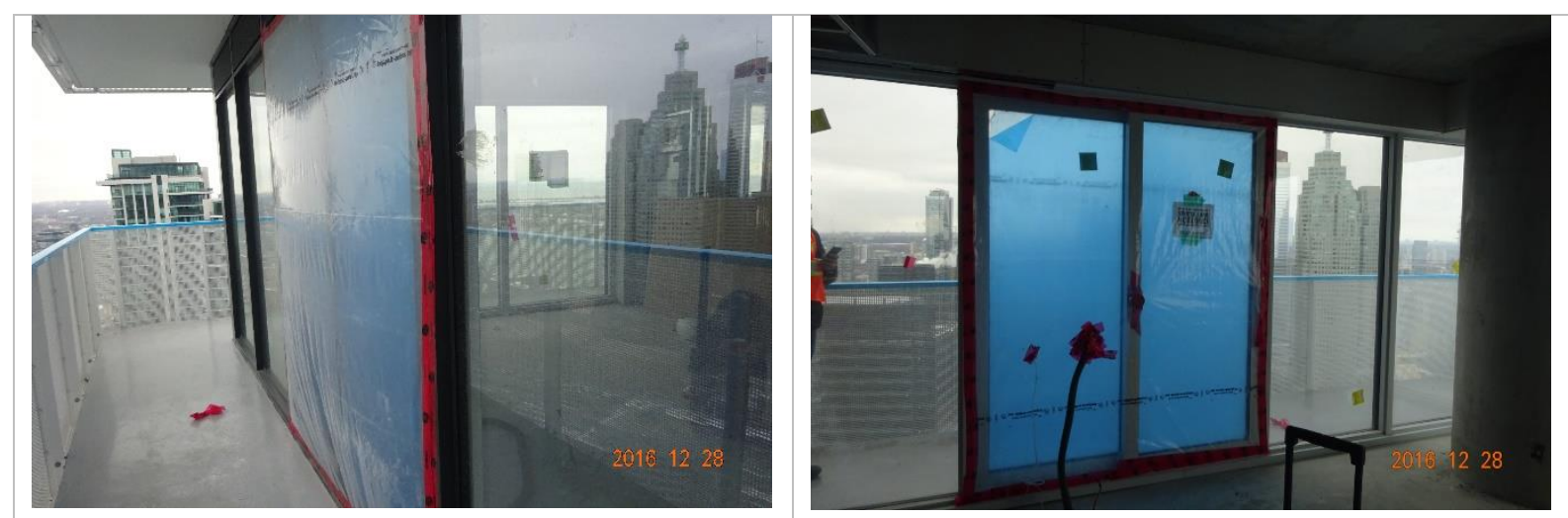

\section{Exterior view}
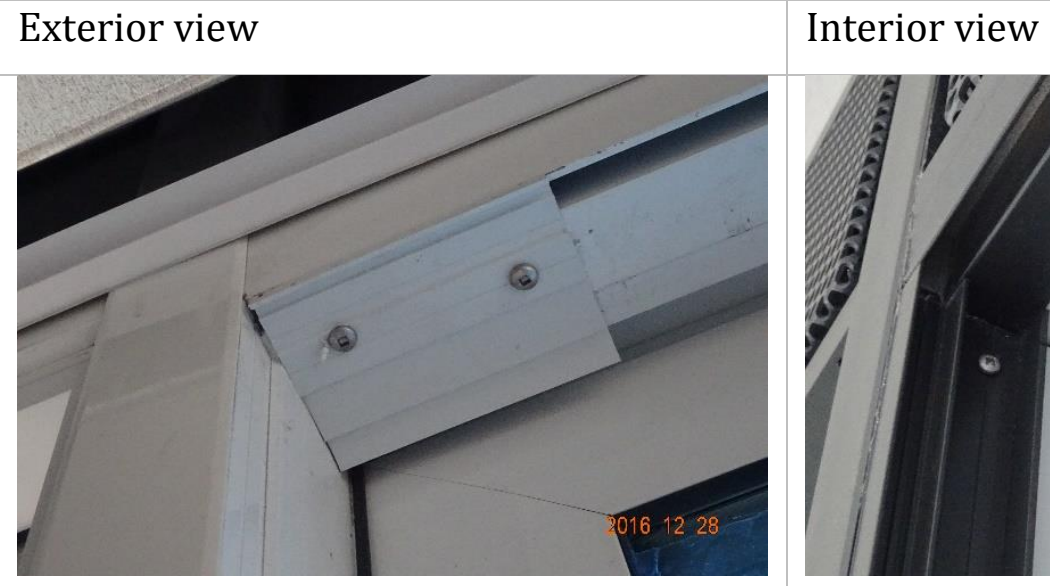

\section{Frame joint}

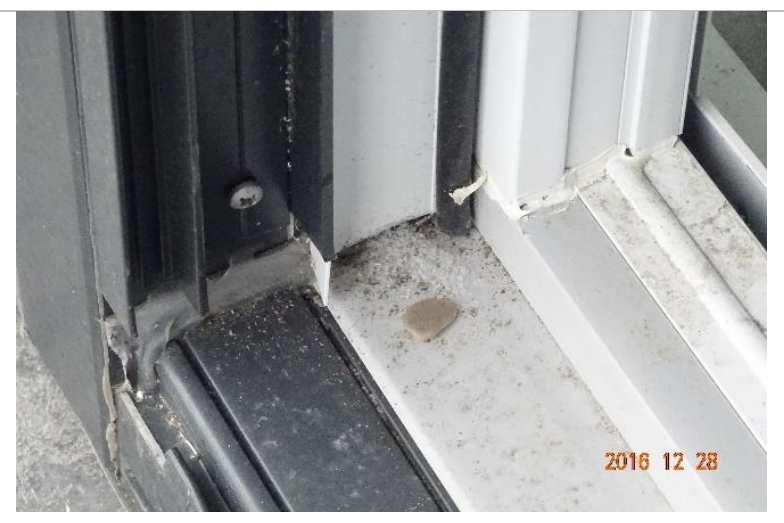

Sash joint

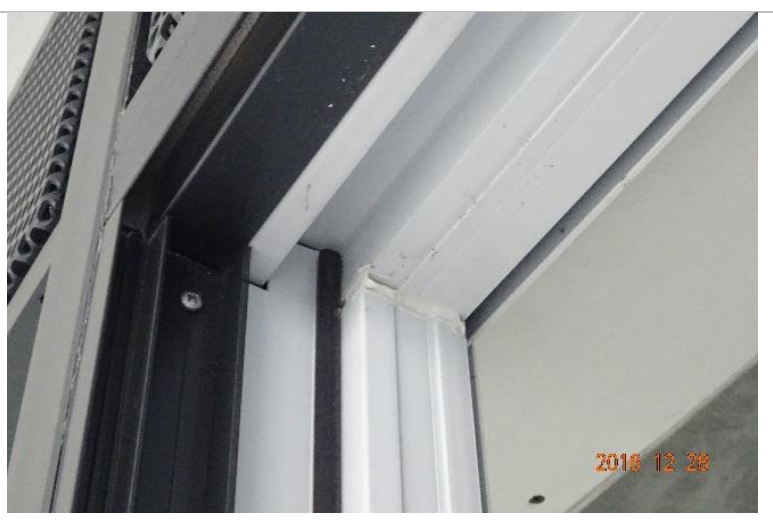

Sash joint

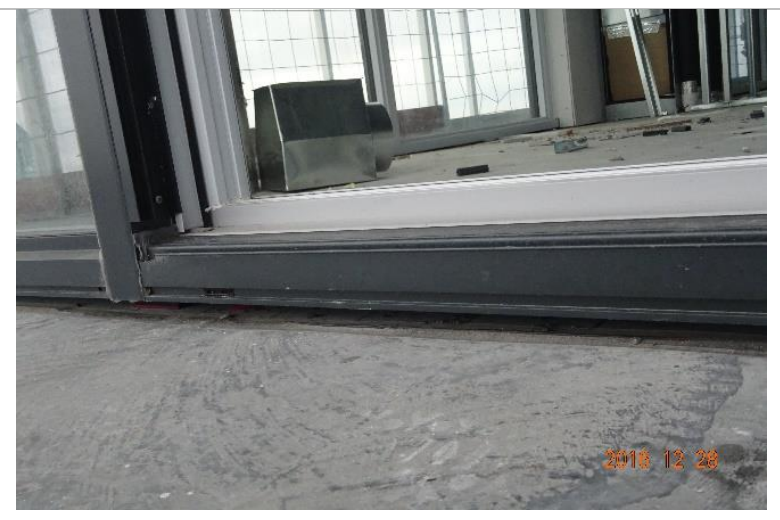

Door sill 


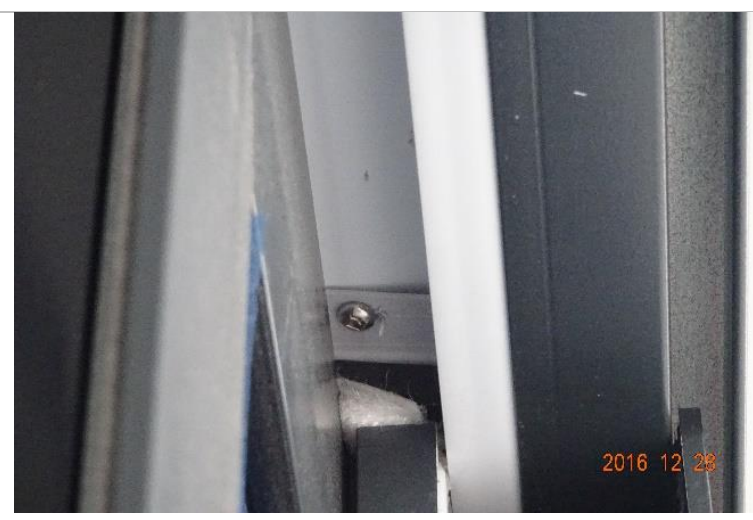

Interior view

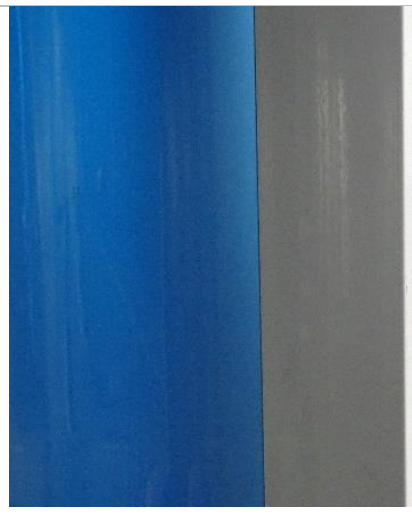

Door meeting stile

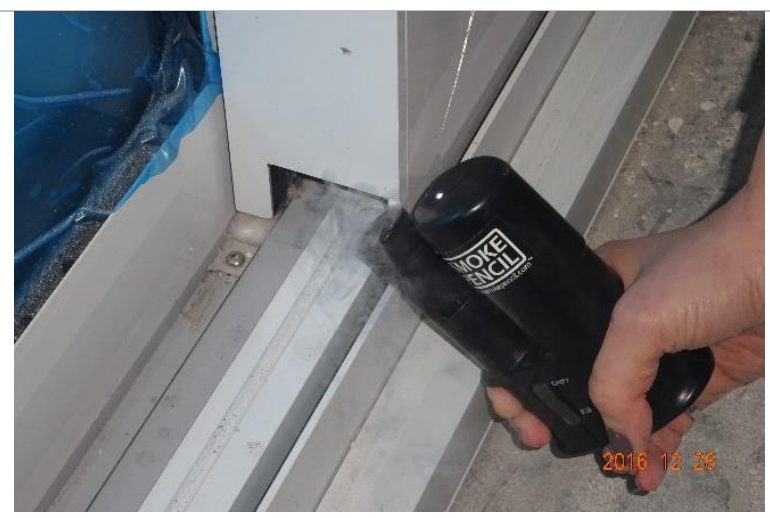

Smoke pencil test

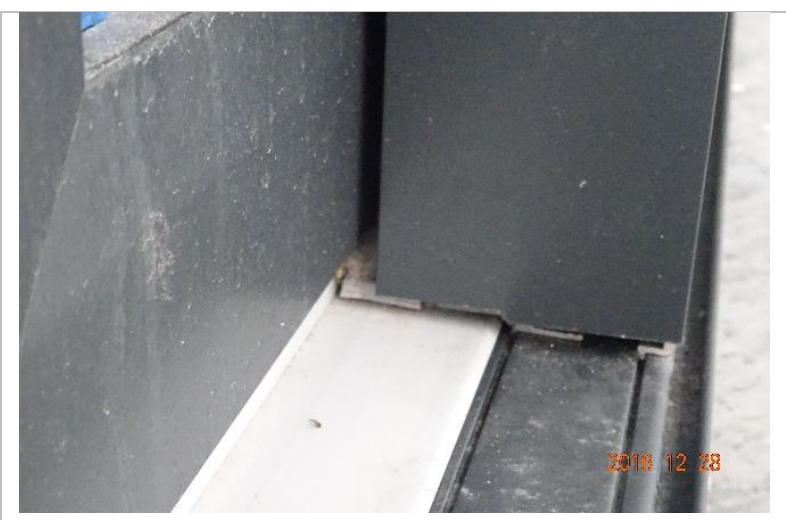

Door meeting stile

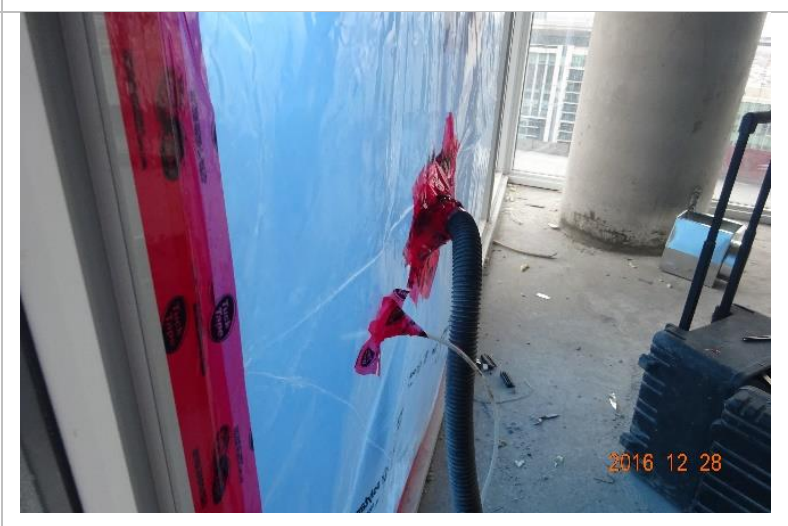

Interior view

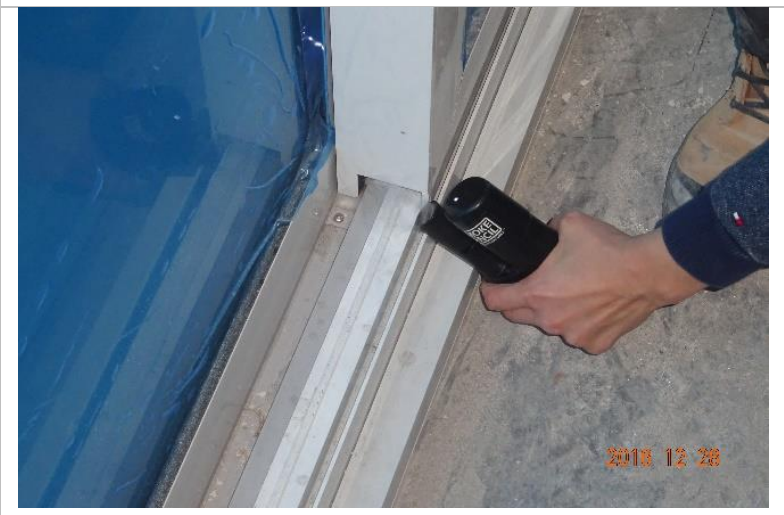

Smoke pencil test

\section{Discussion}

Interior view Test sample air leakage result is above laboratory air leakage result at 75 pascal pressure difference. 